UNIVERSIDADE DE SÃO PAULO

ESCOLA DE ENGENHARIA DE SÃO CARLOS

ANDREY ALEXSANDRO ROSA

PRÉ-CLORAÇÃO ASSOCIADA À ADSORÇÃO EM CARVÃO ATIVADO EM PÓ E FLOTAÇÃO POR AR DISSOLVIDO NA REMOÇÃO DE MICROCISTINA PRESENTE EM TRÊS DIFERENTES CONCENTRAÇÕES EM ÁGUAS PROVENIENTES DE RESERVATÓRIO EUTROFIZADO 


\section{PRÉ-CLORAÇÃO ASSOCIADA À ADSORÇÃO EM CARVÃO ATIVADO EM PÓ E FLOTAÇÃO POR AR DISSOLVIDO NA REMOÇÃO DE MICROCISTINA PRESENTE EM TRÊS DIFERENTES CONCENTRAÇÕES EM ÁGUAS PROVENIENTES DE RESERVATÓRIO EUTROFIZADO}

Dissertação apresentada à Escola de Engenharia de São Carlos, da Universidade de São Paulo, como parte dos requisitos necessários à obtenção do titulo de Mestre em Engenharia Civil: Hidráulica e Saneamento.

Orientador: Prof. Dr. Marco Antônio Penalva Reali 
Dedico este trabalho a toda minha família, em especial a minha mãe, Lucia Roseli Rosa, que sempre se preocupou e apoiou minhas decisões. Também dedico ao meu pai, Adilson João Rosa, a quem devo toda honestidade, respeito e coragem com que encarei mais este desafio. 


\section{Agradecimentos}

Agradeço ao prof ${ }^{\circ}$ Marco Antônio Penalva Reali pela oportunidade de realizar este mestrado, sobretudo pela confiança e paciência durante estes anos que compartilhamos discussões e intenso aprendizado.

À equipe de trabalho, Eng. Maurício Perez que me ajudou em toda pesquisa e a Eng. Jaque e o futuro Eng. Eduardo Migliati com quem dividi o laboratório.

Aos técnicos Luci, Beth, Julio, Wagner que sempre estiveram à disposição para ajudar e ensinar.

Ao José Luiz, grande amigo e responsável pelo laboratório de psicultura do reservatório de Barra Bonita, que sempre se colocou à disposição para me receber e ajudar durante as coletas e com quem aprendi muito.

Agradeço especialmente, à técnica do LATAR, Glauce Guimarães Pereira uma das pessoas mais importantes que contribuíram neste trabalho. Desde o início foi quem me ensinou toda parte laboratorial e que se mostrou extremamente competente e dedicada. Sem esquecer o apoio nos momentos mais difíceis e agradáveis que pudemos compartilhar. Uma grande amiga que levo daqui e tenho certeza que posso contar.

Aos grandes amigos, Gabriel Souto e Daniele Vich, com quem compartilhei ótimos momentos regados a “canapezis” (preparados pela Glauce), e outros eventos memoráveis.

À Lissa Maria Nocko pela companhia e lições aprendidas.

Aos amigos de turma Eduardo (Curió), Camila (Camilinha), Jorge Pantoja, Diego (Dibeatles) pela ajuda e diversão nestes anos de pós-graduação.

Aos funcionários do departamento de Hidráulica e Saneamento: André, Rosi, Sá e Pavi. 
Ao CNPq pela bolsa de estudo, à FAPESP pelo financiamento da pesquisa e à Escola de Engenharia de São Carlos pela estrutura oferecida.

A toda minha família que mesmo longe me deu forças para continuar e seguir em frente. 


\section{RESUMO}

ROSA, A. A. Pré-cloração associada à adsorção com carvão ativado em pó e flotação por ar dissolvido na remoção de microcistina presente em três concentrações em águas provenientes de reservatório eutrofizado. Dissertação (Mestrado) - Escola de Engenharia de São Carlos, Departamento de Hidráulica e Saneamento, Universidade de São Paulo, São Carlos, 2008.

O crescimento desordenado das cidades, a utilização de áreas para plantio próximas aos mananciais e o lançamento de águas residuárias domésticas e industriais sem tratamento são consideradas as principais fontes de poluição dos corpos d'água. Tal poluição contribui para o enriquecimento dos corpos hídricos em relação aos nutrientes. Isto, combinado com fatores climáticos proporciona condições para a ocorrência de florações de algas que podem apresentar espécies potencialmente tóxicas. Desta forma, aumenta a preocupação com desenvolvimento de técnicas de tratamento que forneçam água de qualidade garantindo a saúde da população consumidora. Nesta pesquisa, foram preparadas águas de estudo com diferentes concentrações de microcistina, com as quais foram testados alguns processos de tratamento, em escala de bancada, que consistiram na pré-cloração, adsorção em carvão ativado em pó, coagulação/floculação, flotação por ar dissolvido e centrifugação. O fluxograma de tratamento com aplicação de carvão ativado logo após a mistura rápida foi o que apresentou melhores resultados em termos de cor aparente, turbidez e concentração residual de microcistina. Foi avaliada a influência da concentração de microcistina nos tratamentos simulados. Constatou-se que para 104,92 $\mu \mathrm{g} / \mathrm{L}$ de microcistina a aplicação de 3,0 $\mathrm{mgCl}_{2} / \mathrm{L}$ (10 segundos antes da mistura rápida) e $30 \mathrm{mg} / \mathrm{L}$ de CAP (logo após a mistura rápida) não foram capazes de reduzir a concentração de microcistina para menos de $1 \mu \mathrm{g} / \mathrm{L}$, conforme o limite estabelecido pela Portaria 518 / 04 do Ministério da Saúde. Assim, optou-se pela estimativa da dosagem mínima de carvão ativado em pó (CAP) em função da concentração inicial de microcistina das três águas preparadas. O residual de microcistina em cada água preparada, após a aplicação da dosagem estimada de CAP, foi: Água de Estudo $1=$ 0,80 $\mu \mathrm{g} / \mathrm{L}$, Água de Estudo 2 = 0,82 $\mu \mathrm{g} / \mathrm{L}$ e Água de Estudo $3=0,23 \mu \mathrm{g} / \mathrm{L}$.

Palavras-chaves: Microcistina, Adsorção, Carvão Ativado em Pó, Flotação por Ar Dissolvido, Pré-cloração, Tratamento de água. 


\begin{abstract}
ROSA, A. A. Prechlorination associated to adsorption with powdered activated carbon and dissolved air flotation in the removal of three concentrations of microcystin present in eutroficated reservoir water. Msc Dissertation - Hidraulics and Sanitation Department, Universidade de São Paulo, São Carlos, 2008.
\end{abstract}

The disordered growth of cities, the use of planting areas near the water sources and the launch of domestic and industrial wastewater without treatment are the main sources of water bodies' pollution. Such pollution contributes to increase the nutrient loading in the water bodies. In association with climatic factors, this enrichment of nutrient provides suitable conditions for the bloom of potentially toxic algae. Thus, increases the concern over to develop treatment techniques that provide water quality able to ensure the health of the consumer population. In this research, waters were prepared with different concentrations of microcystin and some treatments were tested in bench scale. These tests consisted in prechlorination, adsorption on powdered activated carbon, coagulation / flocculation, dissolved air flotation and centrifugation. The diagram of treatment with activated carbon application after the rapid mix showed better results of apparent color, turbidity and residual concentration of microcystin. The influence of the concentration of microcystin in the simulated treatments was evaluated. It was found that for $104.92 \mu \mathrm{g} / \mathrm{L}$ of microcystin the application of $3.0 \mathrm{mgCl} 2$ / L (10 seconds before rapid mix) and $30 \mathrm{mg} / \mathrm{L}$ of PAC (after a quick mixture) were not able to reduce the concentration of microcystin to less than $1 \mu \mathrm{g} / \mathrm{L}$, as the limit established by Order 518 / 04 of the Health Ministry. Thus, it was decided to estimate the minimum dosage of powdered activated carbon (PAC) according to the initial concentration of microcystin found in the three prepared waters. The residual concentration of microcystin in each water, after the estimated dosage application of PAC was: Water $1=0.80$ $\mu \mathrm{g} / \mathrm{L}$; Water $2=0.82 \mu \mathrm{g} / \mathrm{L}$; Water $3=0,23 \mu \mathrm{g} / \mathrm{L}$.

Key words: microcystin, adsorption, powdered activated carbon, dissolved air flotation, prechlorination, water treatment. 


\section{LISTA DE FIGURAS}

Figura 3.1: A) Estrutura química das microcistinas; B) Estrutura química das nodularinas; C)

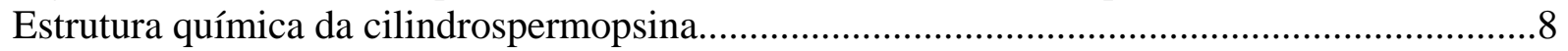

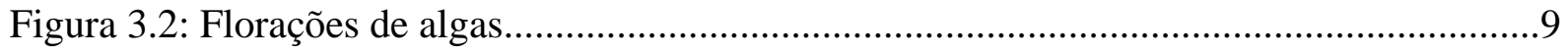

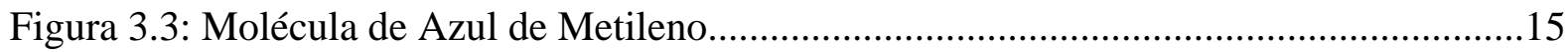

Figura 3.4: A) Estrutura molecular da microcistina - LR; B) Dimensões da molécula de

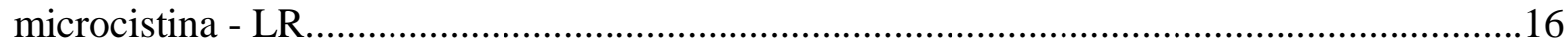

Figura 4.1: A) Placa para determinação de microcistina; B) Lavadora de placas; C) Leitora de

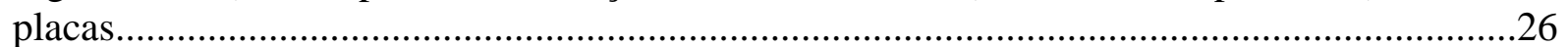

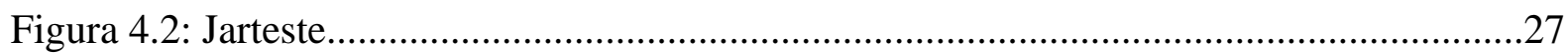

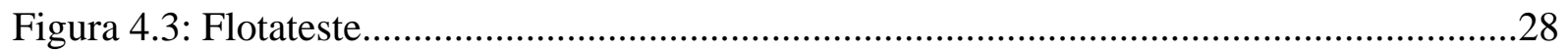

Figura 4.4: Curva de centrifugação - Tempo de centrifugação de 15 min................................29

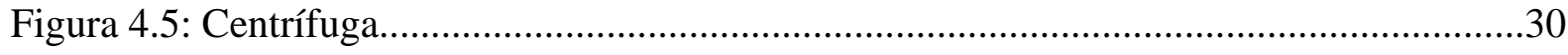

Figura 4.6: Floração de algas no Reservatório de Barra Bonita................................................31

Figura 4.7: A) Bombeamento do Reservatório; B) Tanque de Armazenamento; C) Canaletas de Distribuição; D) Local de Coleta..................................................................................33

Figura 4.8: A) Temporizador para controle de iluminação; B) Lâmpadas fluorescentes; C)

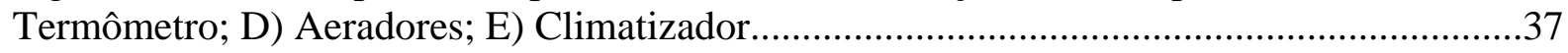

Figura 4.9: Pipeta Pasteur preparada para a aeração da cultura de algas.................................40

Figura 4.10: A) Recipientes para tratamento da vidraria; B) Frascos esterilizados; C)

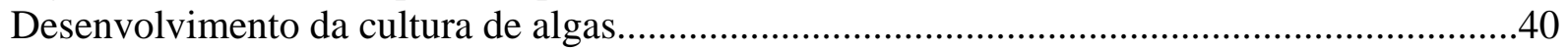

Figura 4.11: A) Placas para secagem dos CAPs; B) Balança de precisão................................43

Figura 4.12: Agitador de amostras em temperatura constante..............................................44

Figura 4.13: A) Frascos com as massas de CAP; B) Separação do CAP; C) Titulação até coloração amarelo palha; D) Aplicação solução indicadora de amido; E) Titulação até a eliminação da coloração azulada.................................................................................4

Figura 4.14: A) Frascos com as massas de CAP; B) Agitação em temperatura constante; C)

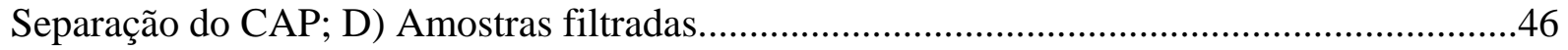

Figura 4.15: A) Membranas para filtração; B) Equipamento para microfiltração do extrato de

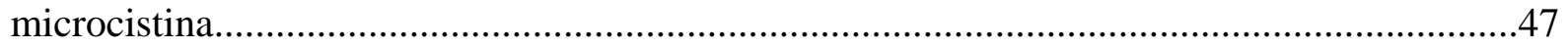

Figura 4.16: A) Frasco após a agitação em temperatura constante; B) Filtração a vácuo para separação do CAP; C) Membranas utilizadas na filtração das amostras...................................48

Figura 4.17: Fluxograma dos ensaios da FASE - A da ETAPA - I........................................56

Figura 4.18: Fluxograma dos ensaios da FASE - B da ETAPA - I......................................59 
Figura 4.19: Fluxograma dos ensaios da FASE - C da ETAPA - I.......................................62

Figura 4.20: Fluxograma dos ensaios da FASE - A da ETAPA - II......................................69

Figura 4.21: Fluxograma dos ensaios da FASE - B da ETAPA - II.....................................71

Figura 5.1: Isoterma de Freundlich (NI) - CAP 1................................................................

Figura 5.2: Isoterma de Langmuir (NI) - CAP 1 …........................................................... 74

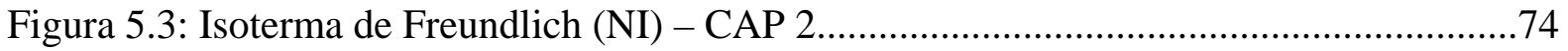

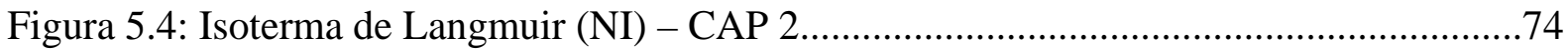

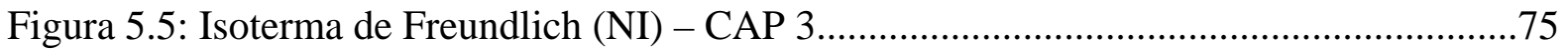

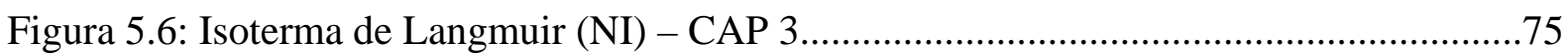

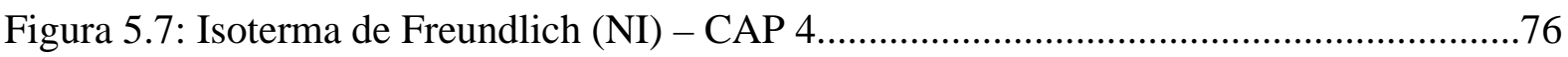

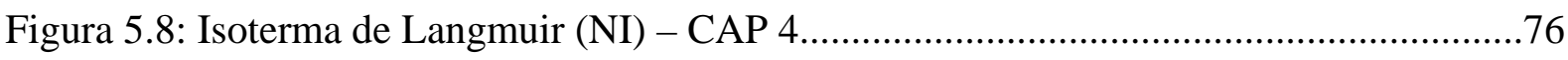

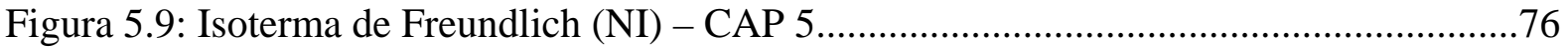

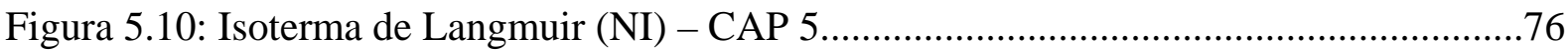

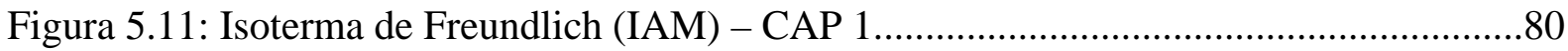

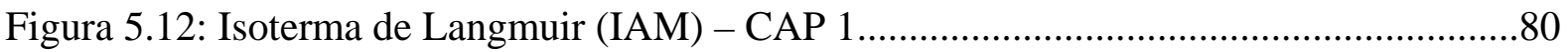

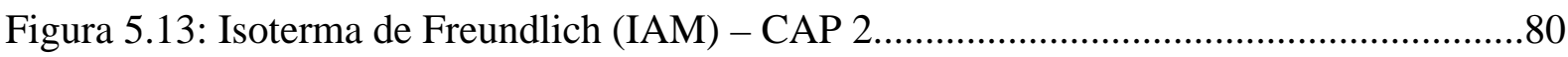

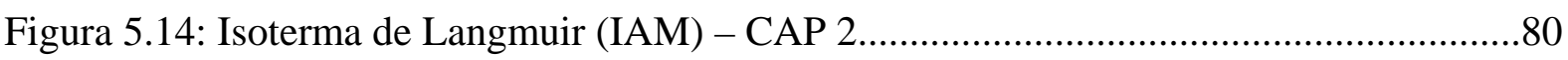

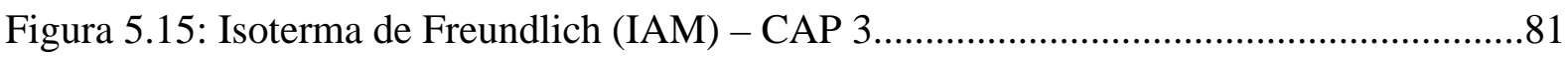

Figura 5.16: Isoterma de Langmuir (IAM) - CAP 3..........................................................81

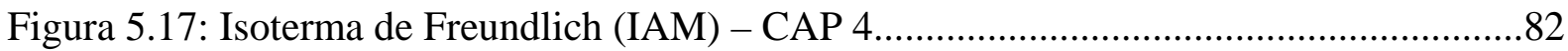

Figura 5.18: Isoterma de Langmuir (IAM) - CAP 4..........................................................82

Figura 5.19: Isoterma de Freundlich (IAM) - CAP 5.........................................................82

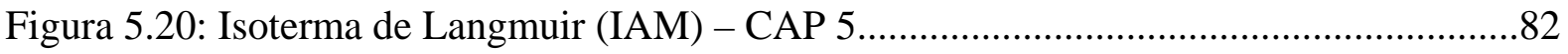

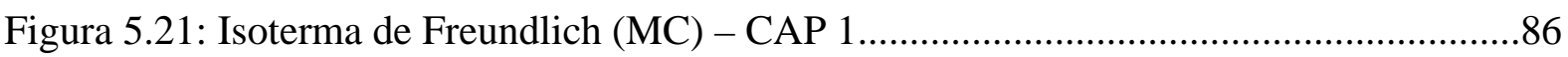

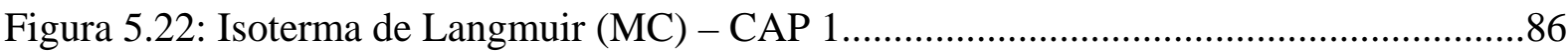

Figura 5.23: Isoterma de Freundlich (MC) - CAP 2 2...........................................................87

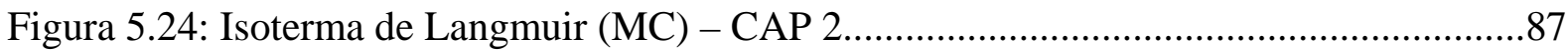

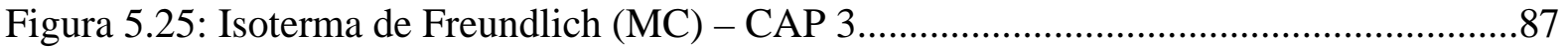

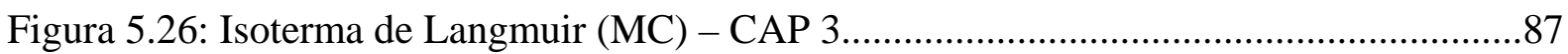

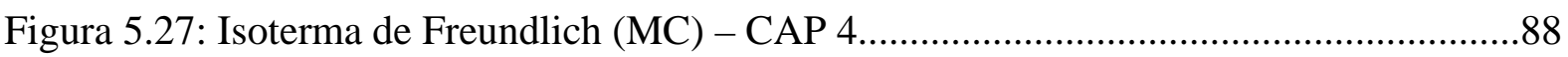

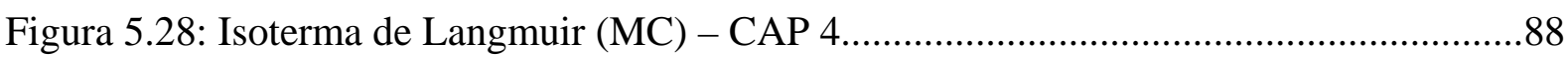

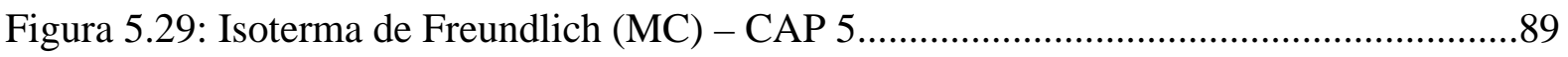

Figura 5.30: Isoterma de Langmuir (MC) - CAP 5..............................................................89 
Figura 5.31: № de Iodo, Índice de Azul de Metileno e Adsorção Máxima de Microcistina dos carvões ativados amostrados......

Figura 5.32: Valores de Índice de Azul de Metileno e Adsorção Máxime de Microcistina.....93

Figura 5.33: Turbidez residual das amostras flotadas e pH de coagulação..............................96

Figura 5.34: Turbidez residual das amostras centrifugadas e pH de coagulação......................96

Figura 5.35: Cor aparente residual das amostras flotadas e pH de coagulação.......................97

Figura 5.36: Cor aparente residual das amostras centrifugadas e pH de coagulação................97

Figura 5.37: Turbidez residual das amostras flotadas e pH de coagulação.............................99

Figura 5.38: Turbidez residual das amostras centrifugadas e pH de coagulação.....................99

Figura 5.39: Cor aparente residual das amostras flotadas e pH de coagulação......................100

Figura 5.40: Cor aparente residual das amostras centrifugadas e pH de coagulação..............100

Figura 5.41: Turbidez residual das amostras flotadas e pH de coagulação............................102

Figura 5.42: Turbidez residual das amostras centrifugadas e pH de coagulação...................102

Figura 5.43: Cor aparente residual das amostras flotadas e pH de coagulação......................103

Figura 5.44: Cor aparente residual das amostras centrifugadas e pH de coagulação.............103

Figura 5.45: Valores de turbidez e pH de coagulação - amostras centrifugadas - Água de

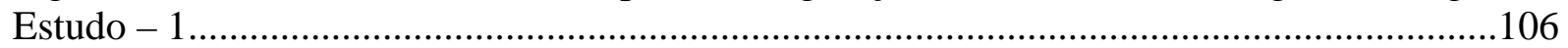

Figura 5.46: Valores de cor aparente e pH de coagulação - amostras centrifugadas - Água de

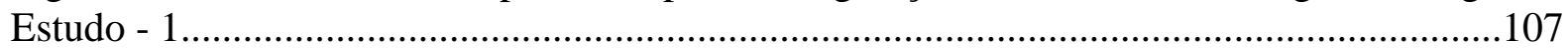

Figura 5.47: Valores de ABS 254 nm e pH de coagulação - amostras centrifugadas - Água de

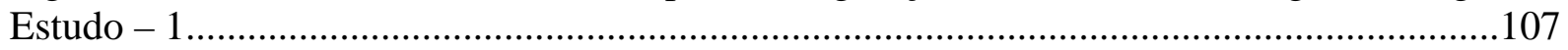

Figura 5.48: Valores de concentração de microcistina (MC) - amostras centrifugadas - Água

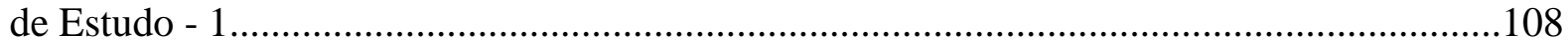

Figura 5.49: Valores de turbidez e pH de coagulação - amostras centrifugadas - Água de

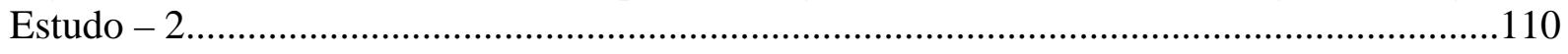

Figura 5.50: Valores de cor aparente e pH de coagulação - amostras centrifugadas - Água de

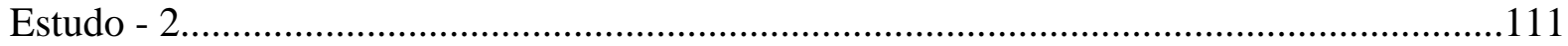

Figura 5.51: Valores de ABS 254 nm e pH de coagulação - amostras centrifugadas - Água de

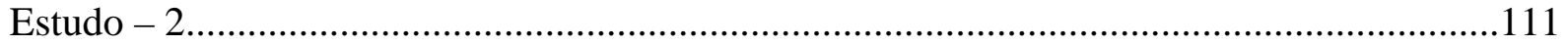

Figura 5.52: Valores de concentração de microcistina (MC) - amostras centrifugadas - Água

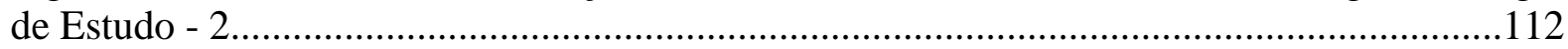

Figura 5.53: Valores de turbidez e pH de coagulação - amostras centrifugadas - Água de

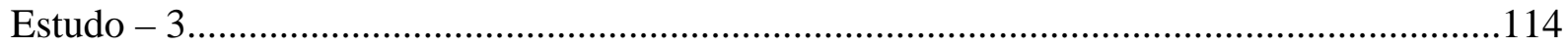

Figura 5.54: Valores de cor aparente e pH de coagulação - amostras centrifugadas - Água de

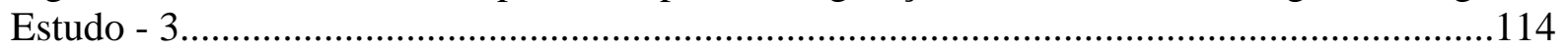

Figura 5.55: Valores de ABS 254 nm e pH de coagulação - amostras centrifugadas - Água de

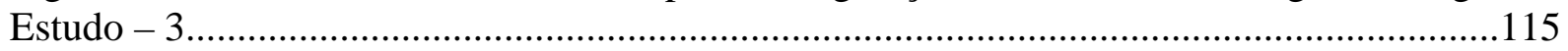

Figura 5.56: Valores de concentração de microcistina (MC) - amostras centrifugadas - Água de Estudo - 3. 
Figura 5.57: Valores de turbidez e pH de coagulação - amostras centrifugadas - Água de Estudo - 1

Figura 5.58: Valores de cor aparente e pH de coagulação - amostras centrifugadas - Água de Estudo - 1.

Figura 5.59: Valores de ABS 254 nm e pH de coagulação - amostras centrifugadas - Água de Estudo - 1

Figura 5.60: Valores de concentração de microcistina (MC) - amostras centrifugadas - Água de Estudo - 1.

Figura 5.61: Valores de turbidez e pH de coagulação - amostras centrifugadas - Água de Estudo - 2 .

Figura 5.62: Valores de cor aparente e pH de coagulação - amostras centrifugadas - Água de Estudo - 2.

Figura 5.63: Valores de ABS 254 nm e pH de coagulação - amostras centrifugadas - Água de Estudo - 2 .

Figura 5.64: Valores de microcistina (MC) - amostras centrifugadas - Água de Estudo 2.

Figura 5.65: Valores de turbidez e pH de coagulação - amostras centrifugadas - Água de Estudo - 3 .

Figura 5.66: Valores de cor aparente e pH de coagulação - amostras centrifugadas - Água de Estudo - 3.

Figura 5.67: Valores de ABS 254 nm e pH de coagulação - amostras centrifugadas - Água de Estudo - 3.

Figura 5.68: Valores de concentração de microcistina (MC) - amostras centrifugadas - Água de Estudo - 3.

Figura 5.69: Turbidez residual das amostras flotadas e centrifugadas e pH de

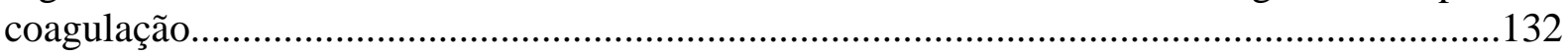

Figura 5.70: Cor aparente residual das amostras flotadas e centrifugadas e pH de

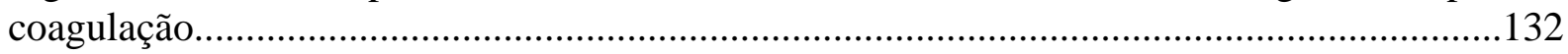

Figura 5.71: Turbidez residual das amostras flotadas e centrifugadas e pH de

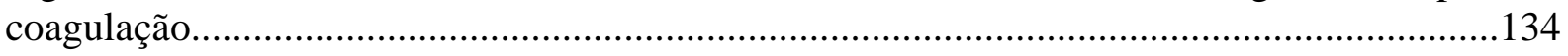

Figura 5.72: Cor aparente residual das amostras flotadas e centrifugadas e $\mathrm{pH}$ de

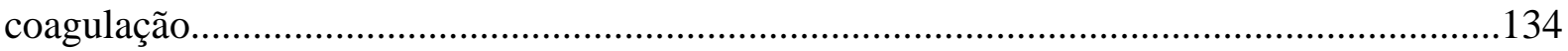

Figura 5.73: Turbidez residual das amostras flotadas e centrifugadas e pH de

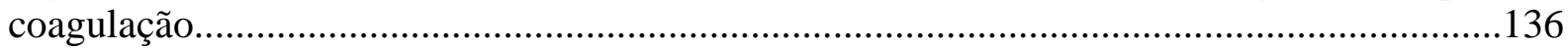

Figura 5.74: Cor aparente residual das amostras flotadas e centrifugadas e $\mathrm{pH}$ de

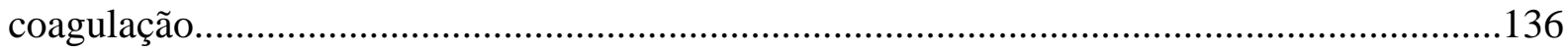

Figura 5.75: Concentração de trialometanos das amostras centrifugadas - Água de Estudo 1 .

Figura 5.76: Carbono orgânico total das amostras flotadas e centrifugadas - Água de Estudo 1.

Figura 5.77: ABS 254 nm e COT das amostras flotadas - Água de Estudo - 1 
Figura 5.78: ABS 254 nm e COT das amostras centrifugadas - Água de Estudo - 1.

Figura 5.79: Concentração de microcistina (MC) das amostras flotadas e centrifugadas - Água de Estudo - 1.

Figura 5.80: Carbono orgânico total das amostras flotadas e centrifugadas - Água de Estudo -

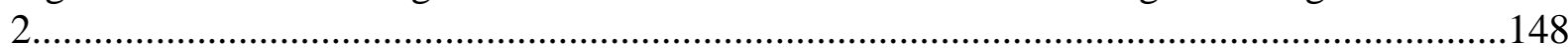

Figura 5.81: ABS 254 nm e COT das amostras flotadas - Água de Estudo - 2....................150

Figura 5.82: ABS 254 nm e COT das amostras centrifugadas - Água de Estudo - 2............150

Figura 5.83: Concentração de trialometanos das amostras centrifugadas - Água de Estudo -

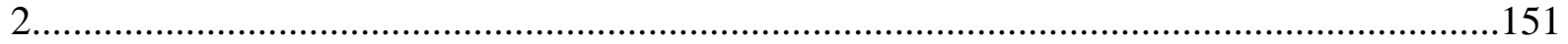

Figura 5.84: Concentração de microcistina (MC) das amostras flotadas e centrifugadas - Água de Estudo - 2 .

Figura 5.85: Carbono orgânico total das amostras flotadas e centrifugadas - Água de Estudo 3. 155

Figura 5.86: ABS 254 nm e COT das amostras flotadas - Água de Estudo - 3. 157

Figura 5.87: ABS 254 nm e COT das amostras centrifugadas - Água de Estudo - 3. .157

Figura 5.88: Concentração de trialometanos das amostras centrifugadas - Água de Estudo -

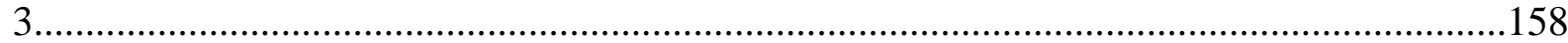

Figura 5.89: Concentração de microcistina (MC) das amostras flotadas e centrifugadas - Água de Estudo - 3. 


\section{LISTA DE TABELAS}

Tabela 4.1: Caracterização das águas coletadas no Reservatório de Barra Bonita - SP...........34

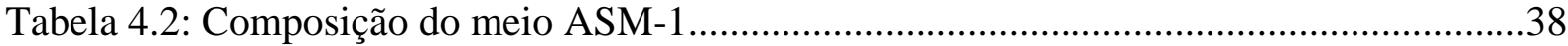

Tabela 4.3: Características das amostras de CAP avaliadas de acordo com dados dos

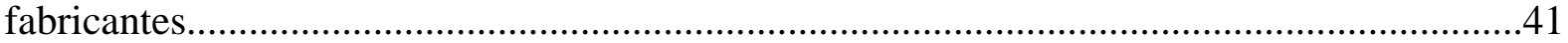

Tabela 4.4: Caracterização das Águas de Estudo - ETAPA - I...............................................54

Tabela 4.5:Caracterização das Águas de Estudo - ETAPA - II..............................................65

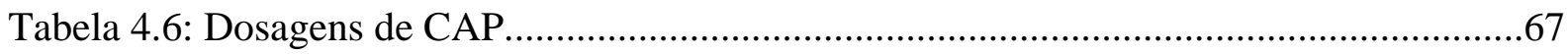

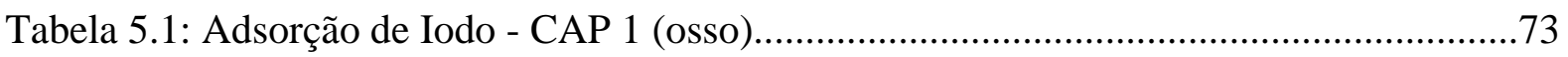

Tabela 5.2: Adsorção de Iodo - CAP 2 (madeira)...................................................................74

Tabela 5.3: Adsorção de Iodo - CAP 3 (madeira)...................................................................75

Tabela 5.4: Adsorção de Iodo - CAP 4 (casca de coco)..........................................................75

Tabela 5.5: Adsorção de Iodo - CAP 5 (madeira)..................................................................76

Tabela 5.6: Parâmetros da Equação de Freundlich e Número de Iodo (NI)............................77

Tabela 5.7: Parâmetros da Equação de Langmuir para adsorção de iodo.................................78

Tabela 5.8: Adsorção de Azul de Metileno - CAP 1 (osso).....................................................79

Tabela 5.9: Adsorção de Azul de Metileno - CAP 2 (madeira).................................................80

Tabela 5.10: Adsorção de Azul de Metileno - CAP 3 (madeira)...............................................81

Tabela 5.11: Adsorção de Azul de Metileno - CAP 4 (casca de coco).....................................81

Tabela 5.12: Adsorção de Azul de Metileno - CAP 5 (madeira).............................................82

Tabela 5.13: Parâmetros da Equação de Freundlich e Índice de Azul de Metileno (IAM)......83

Tabela 5.14: Parâmetros da Equação de Langmuir para adsorção de azul de metileno...........84

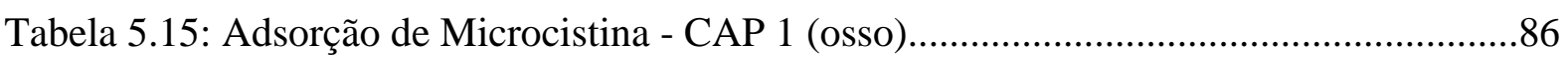

Tabela 5.16: Adsorção de Microcistina - CAP 2 (madeira).....................................................86

Tabela 5.17: Adsorção de Microcistina - CAP 3 (madeira).....................................................87

Tabela 5.18: Adsorção de Microcistina - CAP 4 (casca de coco).............................................88

Tabela 5.19: Adsorção de Microcistina - CAP 5 (madeira)....................................................88

Tabela 5.20: Parâmetros da Equação de Freundlich e Adsorção Máxima de Microcistina......89

Tabela 5.21: Parâmetros da Equação de Langmuir para adsorção de microcistina...................91

Tabela 5.22: Determinação da correlação entre IAM e MC....................................................92 
Tabela 5.23: Valores dos resultados da FASE - B da ETAPA - I para Água de Estudo - 1...106 Tabela 5.24: Valores dos resultados da FASE - B da ETAPA - I para Água de Estudo - 2...110 Tabela 5.25: Valores dos resultados da FASE - B da ETAPA - I para Água de Estudo - 3...113 Tabela 5.26: Valores dos resultados da FASE - C da ETAPA - I para Água de Estudo - 1...118 Tabela 5.27: Valores dos resultados da FASE - C da ETAPA - I para Água de Estudo - 2...122 Tabela 5.28: Valores dos resultados da FASE - C da ETAPA - I para Água de Estudo - 3...126 Tabela 5.29: Valores dos resultados da FASE - B da ETAPA - II para Água de Estudo 1 . 140

Tabela 5.30: Correlação entre ABS 254 nm e COT das amostras flotadas e centrifugadas Água de estudo 1.

Tabela 5.31: Valores dos resultados da FASE - B da ETAPA - II para Água de Estudo 2 .

Tabela 5.32: Correlação entre ABS 254 nm e COT das amostras flotadas e centrifugadas Água de estudo 2 149

Tabela 5.33: Valores dos resultados da FASE - B da ETAPA - II para Água de Estudo 3. .154

Tabela 5.34: Correlação entre ABS 254 nm e COT das amostras flotadas e centrifugadas Água de estudo 3. 


\section{LISTA DE ABREVIATURAS E SIGLAS}

$\mathrm{AE}$

AWWA

BIOTACE

CAG

CAP

COT

DQO

EESC

ELISA

EPA

FAD

GC

GF

IAM

IUPAC

JIS

LATAR

$\mathrm{MC}$

NI

NT

SST

TC

$\mathrm{TF}$

THM

WHO
Água de Estudo

American Water Works Association

Laboratório de Biotoxicologia em Águas Continentais e Efluentes

Carvão Ativado Granular

Carvão Ativado em Pó

Carbono Orgânico Total

Demanda Química de Oxigênio

Escola de Engenharia de São Carlos

Enzyme Linked Immuno Sorbent Assay

U.S. Environmental Protection Agency

Flotação por Ar Dissolvido

Gradiente de Coagulação

Gradiente de Floculação

Índice de Azul de Metileno

International Union of Pure and Applied Chemistry

Japanese Industrial Standards

Laboratório de Tratamento Avançado e Reuso de Águas

Microcistina

Número de Iodo

Nitrogênio Total

Sólidos Suspensos Totais

Tempo de Coagulação

Tempo de Floculação

Trialometanos

World Health Organization 


\section{LISTA DE SÍMBOLOS}

\begin{tabular}{|c|c|}
\hline$\%$ & Porcentagem \\
\hline${ }^{\circ} \mathrm{C}$ & Grau Celsius \\
\hline$\mu \mathrm{g} / \mathrm{L}$ & Micrograma por litro \\
\hline $\mathrm{CaOCl}$ & Hipoclorito de cálcio \\
\hline $\mathrm{Ce}$ & Concentração de equilíbrio do adsorvato \\
\hline $\mathrm{CHBr}_{2} \mathrm{Cl}$ & Dibromoclorometano \\
\hline $\mathrm{CHBr}_{3}$ & Bromofórmio \\
\hline $\mathrm{CHBrCl}_{2}$ & Bromodiclorometano \\
\hline $\mathrm{CHCl}_{3}$ & Clorofórmio \\
\hline $\mathrm{CHICl}_{2}$ & Dicloroiodometano \\
\hline $\mathrm{Cl}_{2}$ & Cloro \\
\hline $\mathrm{cm} / \mathrm{min}$ & Centímetro por minuto \\
\hline $\mathrm{cm}^{3} / \mathrm{g}$ & Centímetro cúbico por minuto \\
\hline D CAPmín & Dosagem mínima de carvão ativado em pó \\
\hline $\mathrm{FeCl}_{3} \times 6 \mathrm{H}_{2} \mathrm{O}$ & Cloreto férrico hexahidratado \\
\hline$g / L$ & Grama por litro \\
\hline $\mathrm{HCl}$ & Ácido clorídrico \\
\hline $\mathrm{kgf} / \mathrm{cm}^{2}$ & Kilogramaforça por centímetro quadrado \\
\hline $\mathrm{m} / \mathrm{h}$ & Metro por hora \\
\hline $\mathrm{m}^{2} / \mathrm{g}$ & Metro quadrado por grama \\
\hline $\mathrm{mg} \mathrm{Al}_{2} \mathrm{O}_{3} / \mathrm{L}$ & Miligrama de óxido de alumínio por litro \\
\hline $\mathrm{mg} / \mathrm{g}$ & Miligrama por grama \\
\hline $\mathrm{mg} / \mathrm{L}$ & Miligrama por litro \\
\hline $\mathrm{mg} \mathrm{C} / \mathrm{L}$ & Miligrama de carbono por litro \\
\hline $\mathrm{mg} \mathrm{CaCO}_{3} / \mathrm{L}$ & Miligrama de carbonato de cálcio por litro \\
\hline $\mathrm{mg} \mathrm{Cl} / \mathrm{L}$ & Miligrama de cloro livre por litro \\
\hline $\mathrm{mg} \mathrm{Fe}{ }^{3+} / \mathrm{L}$ & Miligrama de ferro por litro \\
\hline $\mathrm{mg} \mathrm{O}_{2} / \mathrm{L}$ & Miligrama de oxigênio por litro \\
\hline $\min$ & Minuto \\
\hline
\end{tabular}




\begin{tabular}{ll}
$\mathrm{mL}$ & Mililitro \\
$\mathrm{Na}_{2} \mathrm{~S}_{2} \mathrm{O}_{3}$ & Tiosulfato de sódio \\
$\mathrm{NaOCl}$ & Hipoclorito de sódio \\
$\mathrm{NaOH}$ & Hidróxido de sódio \\
$\mathrm{nm}$ & Nanometro \\
$\mathrm{nm}^{2}$ & Nanometro quadrado \\
$\mathrm{P}_{\mathrm{SAT}}$ & Pressão de saturação \\
$\mathrm{q}_{\mathrm{e}}$ & Quantidade de adsorvato por massa de carvão ativado \\
$\mathrm{q}_{\mathrm{e}}, \mathrm{máx}$ & Quantidade máxima de adsorvato por massa de carvão ativado \\
$\mathrm{R}$ & Recirculação de água saturada com ar dissolvido \\
$\mathrm{rpm}$ & Rotação por minuto \\
$\mathrm{T}_{\text {con }}$ & Tempo de contato \\
$\mathrm{T}_{\mathrm{FLO}}$ & Tempo de floculação \\
$\mathrm{T}_{\mathrm{MR}}$ & Tempo de mistura rápida \\
$\mathrm{T}_{\mathrm{SAT}}$ & Tempo de saturação \\
$\mathrm{uC}$ & Unidade de cor \\
$\mathrm{uT}$ & Unidade de turbidez \\
$\mathrm{V}_{1} \mathrm{e} \mathrm{V}_{2}$ & Velocidades de flotação \\
$\mathrm{Vr}$ & Velocidade de rotação na floculação \\
$\mathrm{Vr}$ & Velocidade de rotação na mistura rápida \\
$\mu \mathrm{Mg} / \mathrm{mg}$ & Micrograma por miligrama \\
\hline &
\end{tabular}




\section{SUMÁRIO}

1. INTRODUÇÃO E JUSTIFICATIVA 1

2. OBJETIVOS 4

2.1. Objetivo Geral 4

2.2. Objetivos Específicos 4

3. REVISÃO BIBLIOGRÁFICA 6

3.1. Cianobactérias e suas Toxinas 6

3.1.1. Florações de algas 9

3.2. Remoção de Algas por Flotação por Ar Dissolvido e Efeito dos Produtos Químicos sobre a Liberação de Toxinas 10

3.3. Carvão Ativado $\quad 12$

3.3.1. Caracterização de Carvão Ativado 14

3.3.2. Adsorção em Carvão Ativado 17

3.4. Oxidação 19

3.4.1. Formação de Trialometanos 21

4. MATERIAL E MÉTODOS 23

4.1. Monitoramento dos Ensaios 24

4.2. Equipamentos Utilizados 26

4.2.1. Jarteste 27

4.2.2. Flotateste 27

4.2.3. Centrífuga 29

4.3. Reservatório de Barra Bonita e Coletas 30

4.3.1. Coletas 32

4.3.2. Características da água do reservatório 34

4.3.3. Cultura de Cianobactérias 35

4.4. Desenvolvimento da pesquisa $\quad 40$

4.4.1. Escolha do Carvão Ativado em Pó (CAP) 41

4.4.1.1. $\quad$ Preparo das amostras de CAP 42

4.4.1.2. Número de Iodo $\quad 43$

4.4.1.3. Índice de Azul de Metileno $\quad 45$

4.4.1.4. $\quad$ Adsorção de Microcistina 46 
4.4.1.5. Isotermas de Adsorção

4.4.2. ETAPA - I

4.4.2.1. Preparo das Águas de Estudo - ETAPA - I 52

4.4.2.2. FASE - A 54

4.4.2.3. FASE-B 57

4.4.2.4. FASE-C 60

4.4.3. ETAPA - II 63

4.4.3.1. Preparo das Águas de Estudo - ETAPA - II 64

4.4.3.2. $\quad$ Estimativa da Dosagem de Carvão Ativado em Pó 66

$\begin{array}{lll}\text { 4.4.3.3. } & \text { FASE - A } & 67\end{array}$

$\begin{array}{lll}\text { 4.4.3.4. } & \text { FASE - B } & 70\end{array}$

5. RESULTADOS E DISCUSSÃO

5.1. Escolha do Carvão Ativado em Pó (CAP) 72

5.1.1. Adsorção de Iodo

5.1.2. Adsorção de Azul de Metileno $\quad 79$

5.1.3. Adsorção de Microcistina 85

5.2. RESULTADOS DA ETAPA - I 94

5.2.1. FASE - A $\quad 95$

5.2.1.1. Água de Estudo 1 (FASE - A) 95

5.2.1.2. $\quad$ Água de Estudo 2 (FASE - A) 98

5.2.1.3. $\quad$ Água de Estudo 3 (FASE - A) 101

5.2.1.4. $\quad$ Resumo dos Resultados da FASE - A / ETAPA - I 104

$\begin{array}{lll}\text { 5.2.2. } & \mathrm{FASE}-\mathrm{B} & 105\end{array}$

5.2.2.1. Água de Estudo 1 (FASE - B) 105

5.2.2.2. $\quad$ Água de Estudo 2 (FASE - B) 109

5.2.2.3. Água de Estudo 3 (FASE - B) 113

5.2.2.4. Resumo dos Resultados da FASE - B / ETAPA - I 116

$\begin{array}{lll}\text { 5.2.3. FASE - C } & 117\end{array}$

5.2.3.1. $\quad$ Água de Estudo 1 (FASE - C) 118

5.2.3.2. $\quad$ Água de Estudo 2 (FASE - C) 122

5.2.3.3. Água de Estudo 3 (FASE - C) 125

5.2.3.4. Resumo dos Resultados da FASE - C / ETAPA - I 129

5.3. RESULTADOS DA ETAPA - II 130

$\begin{array}{llr}\text { 5.3.1. } & \text { FASE - A } & 130\end{array}$ 
5.3.1.1. Água de Estudo 1 (FASE - A) 131

5.3.1.2. Água de Estudo 2 (FASE - A) 133

5.3.1.3. Água de Estudo 3 (FASE - A) 135

5.3.1.4. Resumo dos resultados da FASE - A / ETAPA - II 137

5.3.2. FASE - B 138

5.3.2.1. Água de Estudo 1 (FASE - B) 139

5.3.2.2. Água de Estudo 2 (FASE - B) 146

5.3.2.3. $\quad$ Água de Estudo 3 (FASE - B) 153

5.3.2.4. Resumo dos resultados da FASE - B / ETAPA - II 160

6. CONCLUSÕES 162

REFERÊNCIAS BIBLIOGRÁFICAS

$\begin{array}{ll}\text { ANEXO A } & 170\end{array}$

$\begin{array}{ll}\text { ANEXO B } & 172\end{array}$ 


\section{INTRODUÇÃO E JUSTIFICATIVA}

A demanda de água vem aumentando conforme seus diversos usos, dentre os quais se destacam: o abastecimento público, os processos industriais e a agricultura. O crescimento desordenado dos centros urbanos e a utilização de áreas para a agricultura próximas às margens de rios e reservatórios são consideradas algumas das principais causas da poluição dos corpos d'água. Isto decorre, por exemplo, pelo lançamento nos rios de águas residuárias domésticas sem tratamento adequado. A perda das matas ciliares também acelera o processo de eutrofização de tais corpos receptores, o que prejudica ou inviabiliza a utilização destes para o consumo humano. O problema da utilização dos corpos da água eutrofizados está relacionado aos problemas operacionais no tratamento por processos convencionais ou aos elevados custos associados às técnicas eficientes de tratamento para água de abastecimento.

A eutrofização artificial dos sistemas aquáticos (rios e reservatórios) é caracterizada pela elevada produtividade primária destes, ou seja, rápido crescimento do fitoplâncton provocado pelo excesso de nutrientes, principalmente fósforo e nitrogênio. Estes nutrientes são levados aos corpos d’água pelo escoamento superficial proveniente das precipitações em áreas de agricultura enriquecidas com adubos a base de NPK, além do lançamento de

resíduos domésticos e industriais sem tratamento adequado. Com a alta produtividade primária, podem ocorrer florações de algas (também conhecidos como blooms). Estas 
florações dependem de condições ambientais favoráveis, como: elevadas concentrações de nutrientes, temperatura adequada da água e elevada intensidade luminosa.

As florações também podem estar associadas à competição entre diferentes espécies fitoplanctônicas. Algumas espécies possuem a habilidade de regular a posição na coluna da água em busca de melhores condições de luz e temperatura. Outra habilidade é a capacidade de liberação de toxinas, que visa a defesa contra predadores ou como resultado da lise celular. Assim, determinadas espécies fitoplanctônicas como a Microcystis sp., têm vantagens na competição com outros organismos, o que colabora com sua predominância em uma eventual floração de algas.

Os problemas da predominância do grupo das cianobactérias nas florações de algas estão relacionados com a produção de compostos que conferem odor e gosto à água, e a liberação de toxinas com ação hepática, neurológica e dermatológica. Com a maior ocorrência de tais florações - devido ao alto grau de eutrofização dos reservatórios utilizados para abastecimento - aumenta a preocupação com o controle destes e o uso de técnicas de tratamento eficientes, que possibilitem o fornecimento de água que atenda aos padrões de potabilidade estabelecidos pela Portaria 518 de 25/03/2004 do Ministério da Saúde.

No caso de mananciais eutrofizados, a técnica de flotação por ar dissolvido para o tratamento de água tem vantagens quando comparada com os processos convencionais, pois apresenta maior eficiência na remoção de elevados teores de algas em suspensão e conseqüentemente eficiente remoção da porção de toxina intracelular. Contudo, devido à dificuldade de remoção da toxina dissolvida na água, torna-se necessária a aplicação de barreiras capazes de eliminar ou reduzir a concentração de toxina presente na água tratada.

Para esta finalidade a aplicação de carvão ativado em pó apresenta bons resultados devido à capacidade de adsorção de diversos compostos dissolvidos. Contudo, o emprego do carvão ativado em pó pode ser inviabilizado economicamente quando se trata de elevadas 
dosagens aplicadas na água a ser tratada. Por isso, pode-se efetuar a pré-cloração para promover a oxidação da matéria orgânica natural dissolvida e pode diminuir a competição por sítios de adsorção do carvão ativado para que as dosagens de carvão ativado sejam reduzidas.

Existem poucos relatos de intoxicação humana causada por cianotoxinas. Isto pode ocorrer, segundo Yuan et al. (2006), devido a diversos fatores, por exemplo: 1) muitas intoxicações são leves, portanto não diagnosticadas; 2) a falta de diagnósticos precisos; 3) casos não divulgados; ou 4) a ocorrência pode ser rara.

No entanto, um grave caso de intoxicação por cianotoxinas teve repercussão mundial, ocorrido em Fevereiro de 1996 num centro de hemodiálise da cidade de Caruaru - PE. Neste local foi utilizada água contaminada com cianotoxinas nas sessões de hemodiálise, o que alertou para o potencial toxicológico destas toxinas. Dos 136 pacientes submetidos ao tratamento, 117 sentiram distúrbios visuais, náusea, vômitos, dores musculares e fortes dores no fígado. 100 pacientes desenvolveram falência aguda do fígado e 50 destes morreram (CHORUS \& BARTRAM, 1999).

Diante deste fato e do grau de eutrofização em que se encontram os reservatórios utilizados para abastecimento público, comprova-se a importância da realização de estudos para o desenvolvimento de técnicas eficientes de tratamento de água que visem remoção de algas e suas toxinas em níveis seguros para o consumo humano. 


\section{OBJETIVOS}

\subsection{Objetivo Geral}

O objetivo geral deste trabalho foi a verificação da eficiência de um sistema constituído por pré-cloração, adsorção em carvão ativado em pó (CAP), coagulação/floculação e flotação por ar dissolvido (FAD) na remoção de diferentes concentrações de microcistina.

\subsection{Objetivos Específicos}

Dentro do contexto geral do estudo, tiveram-se os seguintes objetivos específicos:

a) Caracterizar e avaliar a capacidade de adsorção de 5 amostras de CAP, provenientes de diferentes matérias-primas, aplicados no tratamento de água para abastecimento; 
b) Avaliar dois pontos de aplicação de CAP e definir qual configuração de tratamento apresenta os melhores resultados segundo a remoção de microcistina;

c) Estimar a dosagem mínima de CAP que reduza a concentração inicial de microcistina para valores menores que $1 \mu \mathrm{g} / \mathrm{L}$ conforme o estabelecido pela Portaria 518 / 04 do Ministério da Saúde. 


\section{REVISÃO BIBLIOGRÁFICA}

\subsection{Cianobactérias e suas Toxinas}

Segundo Black (2002), conforme a classificação atual dos seres vivos, as cianobactérias pertencem ao reino Monera juntamente com as bactérias. São organismos procariontes, ou seja, não possuem núcleo verdadeiro e tampouco organelas envolvidas por membranas, reproduzem-se assexuadamente por divisão binária.

Registros datam estes organismos em 3 bilhões de anos, sendo possível encontrálos tanto em águas doces e salgadas, quanto em ambientes terrestres. Há cerca de 150 gêneros e 2000 espécies deste grupo, variando também na forma e tamanho, são unicelulares e se apresentam também na forma de colônias ou filamentos, que são tipicamente caracterizados por cobertura mucilaginosa de proteção. Algumas espécies possuem estruturas especializadas como o heterocito (fixação de nitrogênio), pigmentos acessórios da fotossíntese (ficobilinas) e vacúolos gasosos (regulagem da profundidade).

Somado a estas características, está a capacidade das cianobactérias liberarem potentes toxinas que afetam seus predadores naturais, além da probabilidade da intoxicação de pessoas que consomem ou têm contato primário com águas que 
apresentam elevadas concentrações de algas, pois neste caso, é possível a presença de elevadas concentrações de tais toxinas (AWWA, 1995).

Segundo Chorus \& Bartram (1999), as cianotoxinas podem ser classificadas em hepatotoxinas, neurotoxinas e dermotoxinas, e de acordo com suas características químicas estão divididas em peptídeos cíclicos, alcalóides e lipopolissacarídeos. A maior porção destas toxinas está armazenada dentro das células e são liberadas como estratégia de defesa, na fase de senescência ou morte e lise celular. A toxina livre é uma séria preocupação devido à sua persistência no meio que pode durar meses ou anos e pela sua difícil degradação por microrganismos.

Chorus \& Bartram (1999) relatam que os peptídeos cíclicos hepatotóxicos (microcistinas e nodularinas, ver Figura 3.1) são os mais encontrados em todo mundo e são produzidos pelas espécies: Anabaena, Microcystis, Oscillatoria (Planktothrix), Nostoc e Anabaenopsis, estas responsáveis pela microcistina; e a nodularina foi caracterizada na espécie Nodularia spumigena. A ocorrência de alcalóides neurotóxicos (anatoxinas e saxitoxinas) foi registrada na América do Norte, Europa e Austrália, sendo as principais espécies produtoras de anatoxinas a Anabaena, Oscillatoria e Aphanizomenon. As espécies Lyngbya, Cylindrospermopsis, Aphanizomenon e Anabaena as principais produtoras das saxitoxinas. 


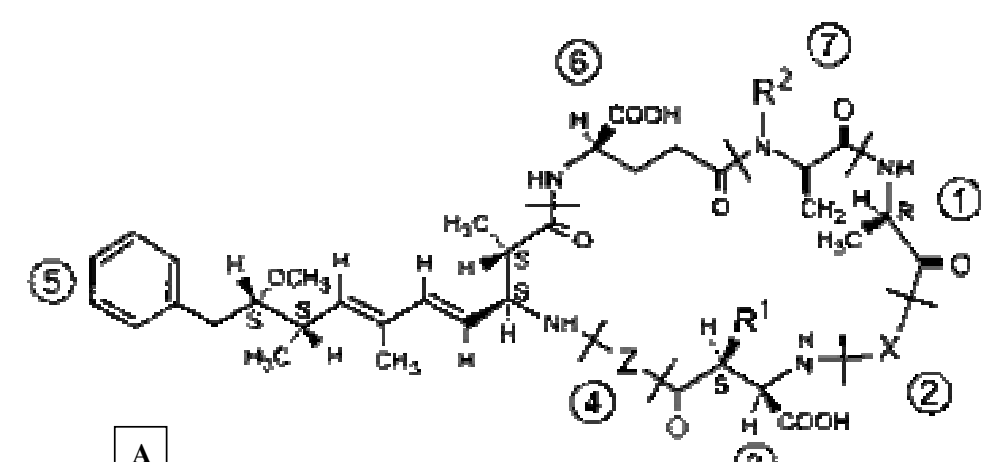

A

(3)
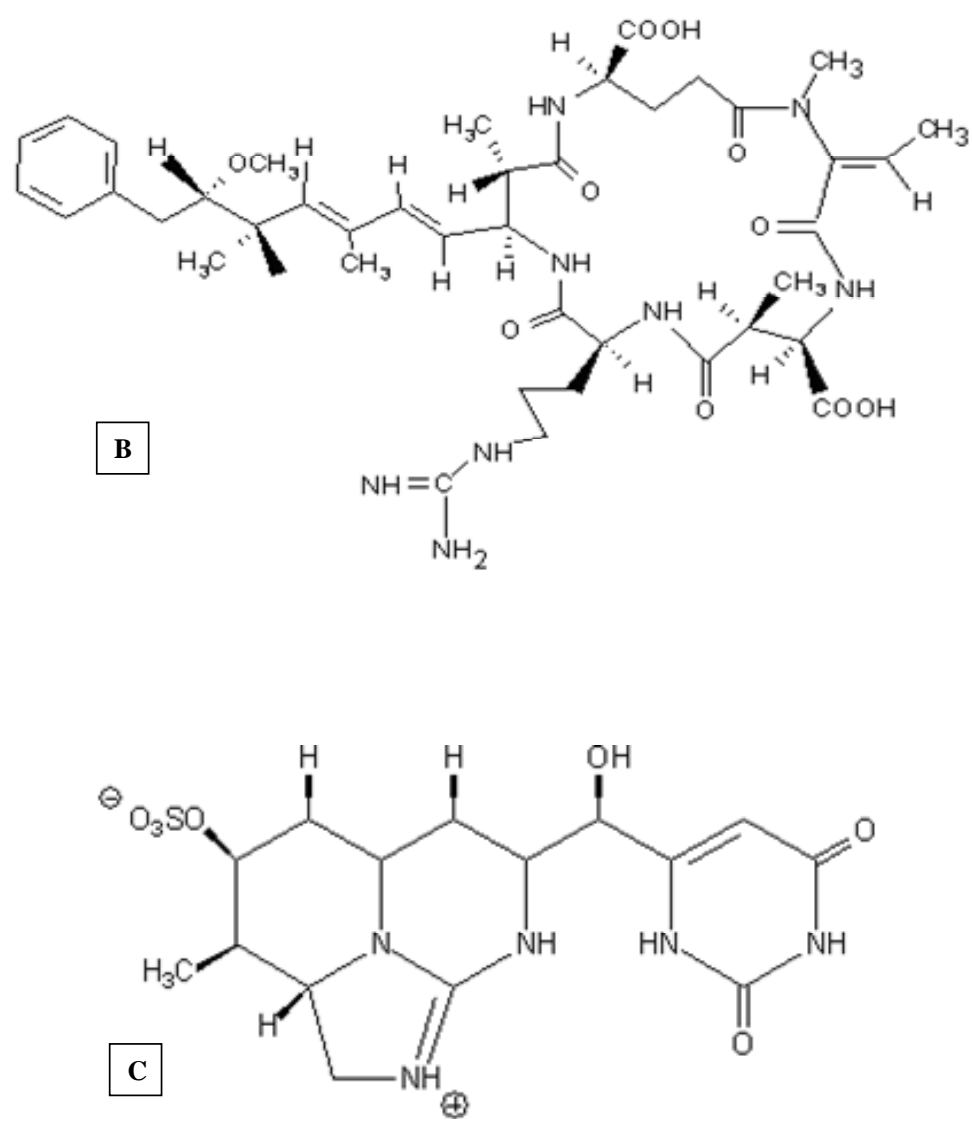

Figura 3.1: A) Estrutura química das microcistinas; B) Estrutura química das nodularinas; C) Estrutura química da cilindrospermopsina.

(Fonte: Chorus \& Bartram, 1999)

Em relação à remoção de tais toxinas, é de suma importância que durante as fases do tratamento d’água - tanto químico quanto físico - não haja a lise celular, pois, na 
ocorrência disto haverá um incremento na concentração de toxina dissolvida, dificultando o tratamento e comprometendo a qualidade da água produzida.

\subsubsection{Florações de algas}

Águas ricas em nutrientes, elevadas temperaturas e luz solar são condições propícias para a multiplicação acelerada das algas e cianobactérias, e conseqüente ocorrência das florações de algas (Figura 3.2). Estas florações se caracterizam pelo acúmulo excessivo dos microrganismos na superfície da água, e que muitas vezes podem ser dominadas por duas, três ou até mesmo uma única espécie (CHARMICHAEL, 1992; MATTHIENSEN, 1996).

Esse acúmulo na superfície da água se deve à capacidade das cianobactérias flutuarem buscando melhores condições de luz e temperatura, além da ausência de vento e chuva que também colaboram para a ocorrência das florações de algas.
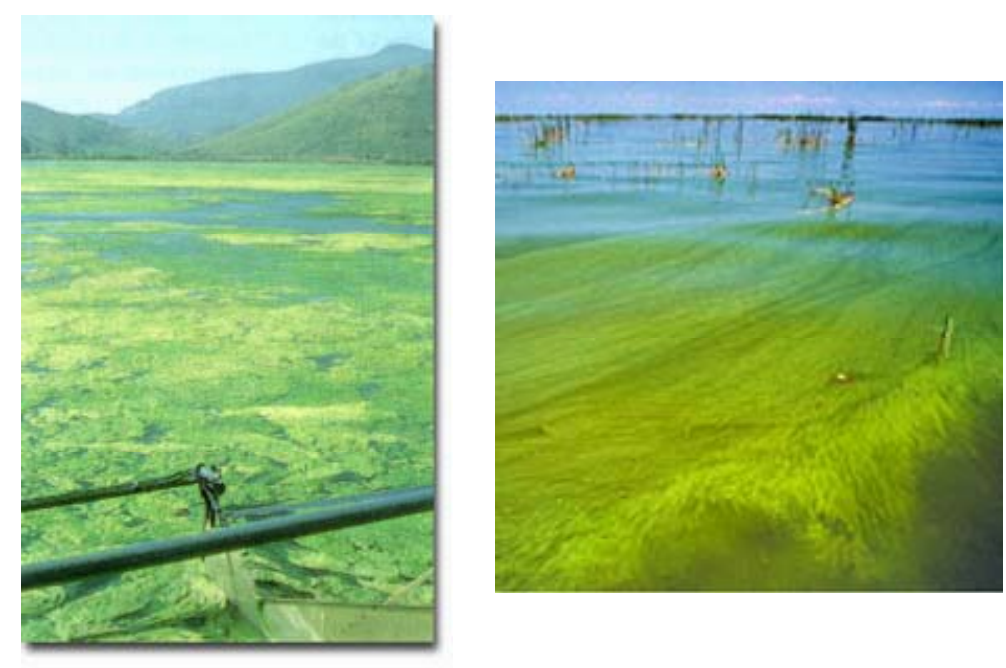

Figura 3.2: Florações de algas.

(Fonte: www.algae.info) 
Os ambientes de água doce são os mais propícios para o desenvolvimento das cianobactérias porque a maioria das espécies apresenta melhor crescimento em águas com pH entre 6 e 9, temperaturas entre $15{ }^{\circ} \mathrm{C}$ e $30{ }^{\circ} \mathrm{C}$ e elevadas concentrações de nutrientes.

\subsection{Remoção de Algas por Flotação por Ar Dissolvido e Efeito dos Produtos Químicos sobre a Liberação de Toxinas}

Reali (1991) descreveu o processo de flotação como a operação pela qual se pode separar sólidos ou líquidos de uma fase líquida pela introdução de pequenas bolhas de ar. Tais bolhas aderem à superfície dos flocos aumentando o seu empuxo. Isto favorece o deslocamento dos flocos em direção à superfície de onde o material pode ser devidamente removido.

O processo de flotação por ar dissolvido tem sido aplicado em estudos para o tratamento de águas com elevada concentração de algas, resultando em uma alternativa promissora quando comparada com os processos convencionais de tratamento (coagulação, floculação, sedimentação e filtração) conforme citado por Teixeira \& Rosa (2006 b), Edzwald (1995), Reali (1991). Além dos processos, investigações sobre os produtos químicos utilizados no tratamento de água também são realizadas. Estas têm o objetivo de verificar o efeito sobre as células das algas cuja importância está relacionada com a lise celular, e conseqüente liberação da toxina contida no interior das mesmas.

Chow et al. (1998), em estudo sobre o efeito da floculação com cloreto férrico, verificaram que não houve efeito negativo sobre as células de Microcystis, ou seja , não ocorreu liberação da toxina intracelular para as amostras ensaiadas. 
Chow et al. (1999) investigaram o efeito do tratamento convencional sobre células de Microcystis aeruginosa em escala de laboratório e estação piloto. Na avaliação de produtos químicos, compararam sulfato de cobre (algicida) e sulfato de alumínio (coagulante), e concluíram que o coagulante não causou danos às células ao contrário do algicida, que proporcionou um aumento na toxina dissolvida das amostras, alertando para o perigo do uso deste produto como controle de florações nos reservatórios. Os impactos mecânicos - provenientes das etapas de coagulação e floculação - em ambos os ensaios de bancada e estação piloto, não causaram danos às células. Sendo que neste último, no qual foram realizadas todas as etapas do processo de tratamento convencional (coagulação, floculação, sedimentação e filtração), as células de Microcystis aeruginosa foram removidas em boas condições e sem acréscimo da toxina dissolvida na água tratada. No entanto, os autores ressaltam que o tratamento convencional, realizado em escala piloto, não foi capaz de remover microcistina-LR extracelular a menos de $1 \mu \mathrm{g} / \mathrm{L}$, Sendo este o limite definido para concentração de microcistina em águas para o consumo humano pela Organização Mundial da Saúde (WHO, 2006).

Comparando a flotação por ar dissolvido e a sedimentação convencional, Teixeira \& Rosa (2006 a) afirmam que ambas as técnicas de tratamento são capazes de remover as células de Microcystis aeruginosa sem causar danos. Entretanto, mostraram que a flotação tem maior eficiência na remoção dos organismos utilizando: 1) baixas taxas de recirculação (8\%); 2) baixa dosagem de coagulante (3 mg $\mathrm{Al}_{2} \mathrm{O}_{3} / \mathrm{L}$ ); 3) flocos densos e pequenos nas condições de coagulação $\left(\mathrm{GC}=380 \mathrm{~s}^{-1}\right.$; $\left.\mathrm{TC}=2 \mathrm{~min}\right)$ e floculação (GF = $70 \mathrm{~s}^{-1}$; TF $\left.=8 \mathrm{~min}\right)$. Avaliando a influência da matéria orgânica natural dissolvida, Teixeira \& Rosa (2006 b) comentam sobre a importância da coagulação/floculação na remoção de células de algas pela flotação por ar dissolvido e da grande influência da 
matéria orgânica sobre a coagulação, pois esta adsorve sobre partículas naturais e age como um agente estabilizante em águas de superfície. O resultado deste estudo mostra que a flotação sofre menor influência da matéria orgânica quando comparada com a sedimentação, isto segundo as autoras, explicado pela necessidade de geração de flocos mais densos para que a sedimentação seja eficiente. Por outro lado, ambas as técnicas foram incapazes de reduzir a concentração da toxina dissolvida na água de estudo para o padrão estabelecido pela Organização Mundial da Saúde de $1 \mu \mathrm{g} / \mathrm{L}$.

Estudos realizados no Departamento de Hidráulica e Saneamento da Escola de Engenharia de São Carlos por Ferreira (2004), Bueno (2005) e Silva (2005) mostraram que nem o tratamento convencional (coagulação, floculação, sedimentação e filtração) e tampouco a coagulação/floculação, flotação por ar dissolvido e filtração, foram capazes de remover a parcela extracelular de microcistina presente nas águas de estudo. Este fato mostra a necessidade de associar outras técnicas (p.e. adsorção e/ou oxidação) que sejam eficazes na eliminação de tais compostos.

\subsection{Carvão ativado}

Segundo Marsh et al. (1997), carvão ativado é o nome dado ao grupo de carvões porosos, manufaturado pelo tratamento com queima de gases ou por carbonização de materiais carbonáceos com ativação química simultânea. Todos esses carvões são preparados para exibirem alto grau de porosidade.

O carvão ativado é obtido do porcesso de carbonização, com temperaturas abaixo de $800^{\circ} \mathrm{C}$, seguido pela ativação do material carbonáceo. O processo de carbonização, isto é, a pirólise do material, gera um produto livre de ar e outros elementos químicos e 
não possui propriedades favoráveis à adsorção com elevada área superficial medida em $\mathrm{m}^{2} / \mathrm{g}$.

A ativação é necessária para converter este produto em um adsorvente de alta porosidade com elevada área superficial, com isto, a área superficial ocupada pelos poros por unidade de massa de carvão aumenta significativamente. O processo de ativação também remove os carbonos som estrutura desorganizada e expõe os anéis aromáticos à ação dos agentes ativadores fato que favorece o desenvolvimento da estrutura dos microporos. O processo de ativação pode ser com ativação química e ativação física (BANSAL et al., 1988).

Na ativação química o material é impregnado com o agente ativador na forma de solução concentrada e o resultado é a degradação do material. O material químico impregnado é eliminado e pirolisado em temperaturas entre $400^{\circ} \mathrm{C}$ e $600^{\circ} \mathrm{C}$ na ausência de ar. O produto pirolisado é resfriado e lavado para remover o agente ativador (BANSAL et al., 1988).

A ativação física é o processo que o produto carbonizado desenvolve extensa área superficial e uma estrutura de poros de dimensão molecular. Esta etapa em temperaturas entre $800^{\circ} \mathrm{C}$ e $1100^{\circ} \mathrm{C}$ na presença de gases oxidantes como vapor, dióxido de carbono, ar ou qualquer mistura de gases. Em saneamento a ativação física é amplamente usada a ativação de carvões ativados (BANSAL et al., 1988).

Baçaoui et al. (2001) verificaram que a temperatura e o tempo de ativação têm grande impacto na capacidade de adsorção de carvões. Durante seus estudos, referentes à produção de carvão ativado a partir de caroço de azeitona, o aumento da temperatura e do tempo de ativação elevou a capacidade de adsorção de iodo, e conseqüentemente a quantidade de microporos do carvão produzido. 
O carvão ativado é uma família de substâncias carbonáceas manufaturadas por processo que desenvolve porosidade interna, desse modo criando propriedades de adsorção (AWWA, 1991).

De acordo com a união internacional de química pura e aplicada (IUPAC), os poros dos carvões ativados podem ser classificados em três grupos:

- Microporos: são poros menores que 2 nm. São os maiores responsáveis pela capacidade de adsorção de carvões ativados. Os microporos são classificados ainda por estreitos (acima de 0,7 nm) e largos (entre 0,7 e $2,0 \mathrm{~nm})$.

- Mesoporos ( ou poros de transição): Com abertura entre 2,0 nm e $50 \mathrm{~nm}$.

- Macroporos: com aberturas superiores a $50 \mathrm{~nm}$.

\subsubsection{Caracterização de Carvão Ativado}

Os índices mais utilizados para a caracterização de carvões ativados são: número de iodo e índice de azul de metileno.

Segundo Baçaoui et al. (2001), as moléculas de iodo possuem diâmetro médio próximo de 0,27 nm e são facilmente adsorvidas pelos microporos dos carvões ativados (poros menores que $2 \mathrm{~nm}$ ). Assim, a determinação do número de iodo é comumente utilizada como uma medida indireta da quantidade de microporos das amostras de CAP.

Conforme a norma japonesa (JIS 1474 / 91), o número de iodo é a quantidade de iodo adsorvido por unidade de carvão ativado em pó (mg/g) quando a concentração residual de iodo é igual a 2,5 g/L. 
Os ensaios de adsorção de azul de metileno são freqüentemente aplicados na avaliação indireta da mesoporosidade de carvões ativados, (BAÇAOUI et al., 2001). Isto se deve às características da molécula de azul de metileno $\left(\mathrm{C}_{16} \mathrm{H}_{18} \mathrm{ClN}_{3} \mathrm{~S} \times{ }_{3} \mathrm{H}_{2} \mathrm{O}\right)$ ilustrada pela Figura 3.3, que apresenta diâmetro médio de aproximadamente 0,8 nm, mas necessita de poros com abertura da ordem de 1,3 nm. Sobretudo, é preferencialmente adsorvida por poros com abertura próxima de 2 nm, (BARTON, 1987; WARHURST et al., 1997; YENISOY-KARAKAS et al., 2004).

Segundo a norma JIS 1474 / 91, o índice de azul de metileno (IAM) é a quantidade de azul de metileno adsorvida por unidade de carvão ativado em pó, em $\mathrm{mg} / \mathrm{g}$, quando a concentração residual é igual a 0,24 mg/L.

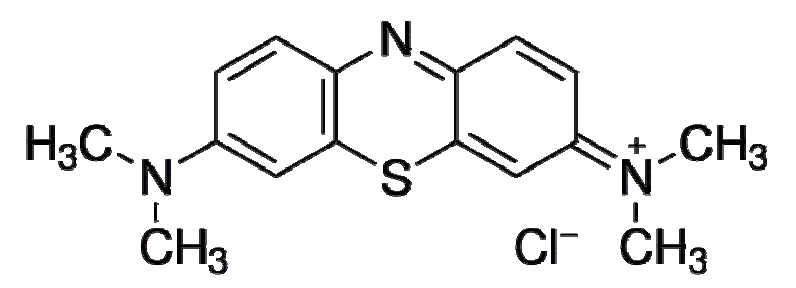

Figura 3.3: Molécula de Azul de Metileno.

No que se refere à adsorção de microcistina, a molécula apresenta área de aproximadamente 1,8 $\mathrm{nm}^{2}$ e largura máxima da ordem de 1,9 nm (Figura 3.4) (PENDLETON et al,. 2001). Estes autores avaliaram cinco carvões ativados de madeira e dois carvões de coco, e concluíram que os carvões que apresentaram maior volume de mesoporos, que no caso foram os provenientes de madeira, obtiveram melhor desempenho na adsorção de Microcistina - LR. A correlação encontrada entre a adsorção de microcistina e o volume de mesoporos foi $\mathrm{R}^{2}=0,93$ e para microporos $\mathrm{R}^{2}=$ 0,54 . 
Donati et al., (1994), após avaliarem carvões ativados de diferentes matériasprimas, verificaram que os dois CAP de madeira estudados apresentaram os maiores volumes de mesoporos $\left(0,49\right.$ e $\left.0,27 \mathrm{~cm}^{3} / \mathrm{g}\right)$, e diante do resultado de adsorção máxima de microcistina igual a 280 e $220 \mu \mathrm{g} / \mathrm{mg}$, comprovaram a hipótese de adsorção da toxina por poros acima de $2 \mathrm{~nm}$.
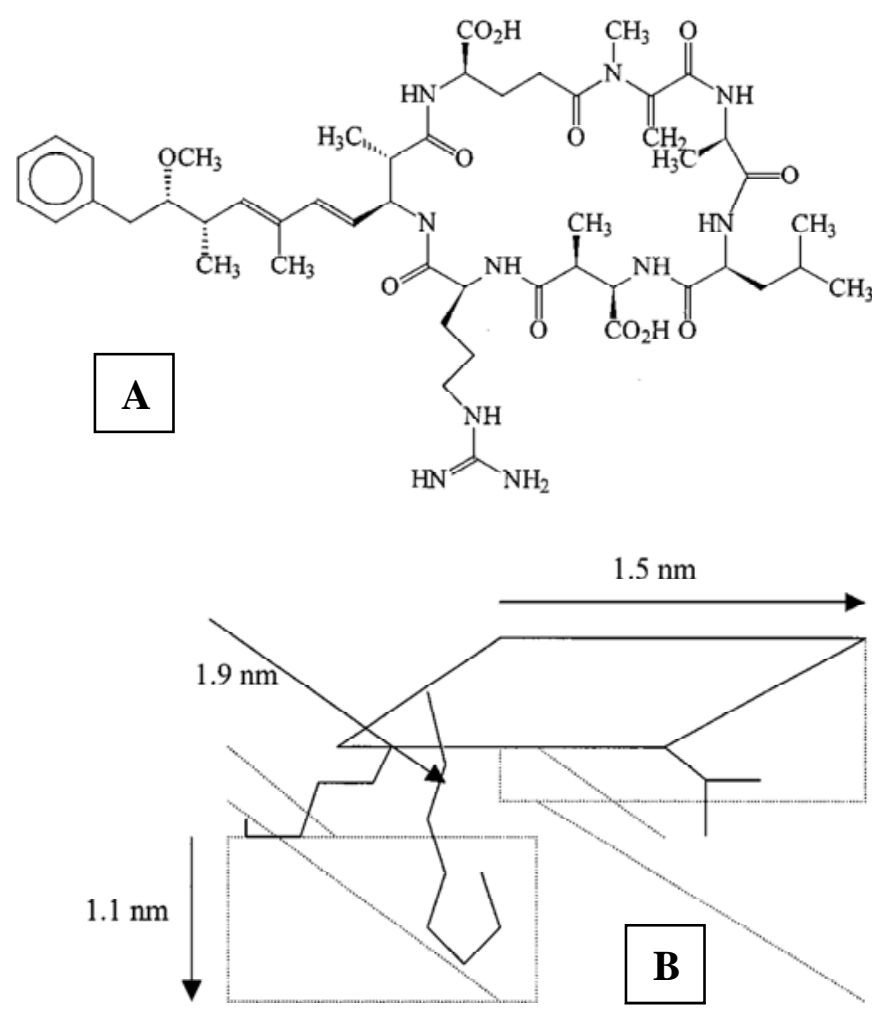

Figura 3.4: A) Estrutura molecular da microcistina - LR; B) Dimensões da molécula de microcistina - LR.

(Fonte: Pendleton et al,. 2001) 


\subsubsection{Adsorção em Carvão Ativado}

A adsorção consiste no uso da capacidade de um adsorvente para remover compostos de soluções. O carvão ativado é um produto amplamente utilizado como adsorvente em águas para abastecimento pela sua capacidade de remover compostos que conferem cor, gosto e odor. Vários materiais são empregados na sua fabricação, como: madeira, casca de coco, sementes, resíduos a base de petróleo entre outros (Reynolds \& Richards, 1995).

A adsorção se dá por interações dipolo-dipolo, pontes de hidrogênio e principalmente por forças de van der Waals entre os compostos e o adsorvente. O carvão ativado é utilizado na forma granular (em leitos fixos) ou em pó. Diversos autores investigaram a eficiência de diferentes tipos de carvão ativado na remoção de microcistina, e constataram a aplicabilidade deste produto para tal finalidade.

Falconer et al. (1989) testaram diversas amostras de carvão ativado em pó (CAP) e carvão ativado granular (CAG) em ensaios de bancada e estação piloto, obtendo resultados com pouca diferença entre os dois tipos de ensaios, e confirmando a eficiência do carvão ativado visando a remoção de hepatotoxinas e neurotoxinas. Vale ressaltar que elevadas dosagens de CAP foram requeridas para remoções acima de $90 \%$. Lambert et al. (1996) e Huang et al. (2006) avaliaram três tipos carvões ativados, investigando a interferência da matéria orgânica natural, presente na água, na capacidade de adsorção de microcistina. Os primeiros analisaram duas estações de tratamento, sendo que uma realizava filtração com CAG e a outra aplicava CAP antes da mistura rápida. Foi constatada boa eficiência na remoção de microcistina (> 80 \%), porém, com redução na capacidade de adsorção do carvão ativado, causada pela competição da matéria orgânica natural por sítios de adsorção. Ao estudar diferentes CAG, Huang et al. 
(2006) discorreram sobre o efeito do pH, verificando uma tendência de cargas positivas na superfície do carvão até valores de $\mathrm{pH}$ igual 3,0, fato que favorece a adsorção da microcistina.

Os autores Ferreira (2004), Silva (2005) e Bueno (2005) desenvolveram estudos sobre a eficiência do CAP associado tanto ao tratamento convencional (coagulação, floculação, sedimentação e filtração), quanto à técnica de flotação por ar dissolvido (FAD) anterior à filtração, ambos em escala de bancada. Ferreira (2004) avaliou a remoção de microcistina em processo convencional de tratamento d’água associada à adsorção por CAP, concluindo que o tratamento convencional não foi efetivo na remoção da toxina, concordando com AWWA (1995) e Teixeira \& Rosa (2006 a), e que foi necessária elevada dosagem de CAP (300 mg/L) para que se reduzisse a concentração de toxina dissolvida abaixo de $1 \mu \mathrm{g} / \mathrm{L}$, fato atribuído à baixa qualidade do carvão. Silva (2005) associou unidades de adsorção por carvão ativado em pó e flotação por ar dissolvido, e verificou que somente a FAD não foi capaz de reduzir a concentração de microcistina a níveis estabelecidos pela Portaria 518 de 25/03/2004 do Ministério da Saúde. Ao adicionar CAP concluiu que com dosagem igual a $50 \mathrm{mg} / \mathrm{L}$ de carvão aplicado 1,5 h antes da coagulação, e coagulante (Cloreto Férrico 45 mg/L), foi possível produzir amostras com concentrações abaixo do limite estabelecido pela Portaria 518. Bueno (2005) estudou sistema constituído por etapas de pré-cloração, coagulação/floculação, flotação por ar dissolvido e adsorção por CAP e verificou a eficiência da associação proposta quando: $20 \mathrm{mg} / \mathrm{L}$ de CAP com tempo de contato igual ao da floculação, $50 \mathrm{mg} / \mathrm{L}$ de cloreto férrico e 6,0 mg/L de hipoclorito de sódio aplicado 10 segundos antes da mistura rápida, foram eficientes na remoção da toxina. 


\subsection{Oxidação}

A oxidação é o processo no qual o estado de oxidação de uma substância é aumentado. Na reação de oxidação, que ocorre de forma simultânea com a de redução, as substâncias orgânicas doam elétrons, ganham oxigênio e perdem hidrogênio. De um modo geral a oxidação no tratamento de água tem como objetivo converter substâncias indesejáveis em substâncias não prejudiciais ou não objetáveis (Posselt \& Weber ${ }^{1} \mathrm{Jr}$. apud Ministério da Saúde, 2003.). Os principais oxidantes utilizados são: cloro, cloraminas, ozônio, dióxido de cloro e permanganato de potássio (CHORUS \& BARTRAM, 1999).

O grau de degradação de um composto orgânico pela ação de oxidantes depende de diversos fatores incluindo força e tipo de oxidante, tempo de contato, tipos dos organismos presente na água, $\mathrm{pH}$, temperatura, matéria orgânica dissolvida, entre outros. O Cloro é tipicamente utilizado na forma gasosa $\left(\mathrm{Cl}_{2}\right)$, hipoclorito de sódio $(\mathrm{NaOCl})$ ou hipoclorito de cálcio $(\mathrm{CaOCl})$. O hipoclorito de sódio é utilizado nas estações de tratamento de água devido a quatro fatores, 1) eficiente inativação de vários patogênicos encontrados na água; 2) fornece residuais, que são fundamentais na manutenção da qualidade da água durante a distribuição, e também de fácil medição e controle; 3) é econômico; 4) possui histórico de sucesso por melhorar os processos de tratamento de água, apesar da dificuldade de aplicação e manejo especificamente do cloro na forma gasosa (EPA, 1999).

\footnotetext{
${ }^{1}$ POSSELT, H. S. \& WEBER JR., W. J. (1972). Chemical Oxidation. In: WEBER JR., W. J. (editor). Physicochemical Processes for Water Quality Control. Wiley-Interscience.
} 
Segundo a Water Environment Federation (1996), o hipoclorito de sódio é a única forma de hipoclorito líquido, sendo que este tem aparência amarelada, é altamente alcalino e corrosivo e tem forte odor. É instável com degradação acelerada por calor, luz e longo tempo de estocagem. É destrutivo para madeira, corrosivo para a maioria dos metais e prejudicial aos olhos, pele e outros tecidos do corpo que estiverem em contato. Dadas tais características, é compreensível a influência deste oxidante no $\mathrm{pH}$ de coagulação por ser altamente alcalino, além do cuidado no manuseio e estocagem em estações de tratamento de água.

Os oxidantes são empregados no tratamento de água para controlar o gosto e o odor, manter os filtros mais limpos, remover ferro e manganês, diminuir a cor, controlar o crescimento bacteriano nas redes, desinfetar adutoras, aprimorar a floculação, oxidar amônica na proteção de membranas filtrantes e no controle de algas no pré-tratamento (DANIEL, 2001; CHORUS \& BARTRAM, 1999).

Acero et al. (2005) investigaram a cinética da reação entre cloro (solução de hipoclorito de sódio) e microcistina. Com relação à influência da concentração inicial presente na água, mostraram que concentrações de microcistina acima $10 \mu \mathrm{g} / \mathrm{L}$ demandaram valores de Ct (produto da concentração de cloro pelo tempo de detenção) acima de 30 min.mg/L, para que fossem atingidos valores residuais da toxina menores que $1 \mu \mathrm{g} / \mathrm{L}$. Dentre os valores de $\mathrm{pH}$ estudados $(8,0,7,0,6,0)$, o menor proporcionou melhor eficiência na oxidação da microcistina, concordando com o conceito de que o meio ácido contribui com o potencial de oxidação do cloro.

Xagoraraki et al. (2006) estudaram os valores de Ct requeridos para a degradação da microcistina-LR por cloro livre, em água preparada no laboratório (isenta de matéria orgânica dissolvida), e amostras coletadas de reservatórios destinada para o abastecimento público. Também constataram que quanto menor o valor do $\mathrm{pH}$, mais 
rápido era a degradação da toxina, entretanto, surpreenderam-se com os resultados que mostraram menores valores de Ct para as amostras coletadas nos reservatórios - obtevese $90 \%$ de remoção da toxina com Ct igual a 100 min.mg/L - ao contrário do que era esperado pela presença de matéria orgânica natural dissolvida, pois para atingir o mesmo grau de remoção da toxina na água de estudo preparada foi necessário Ct igual a 170 min.mg/L. Isto ocorreu, por hipótese dos autores, pela presença de algum composto que catalisou a reação entre o cloro e a microcistina-LR, no entanto não detectado.

Bueno (2005) avaliou oxidação com $\mathrm{NaOCl}$ da microcistina - sem tratamento posterior - com tempo de contato de 30 min. Os resultados mostraram que houve um acréscimo na concentração de microcistina, ao dosar 1,0 mg/L de hipoclorito de sódio, resultante da lise celular e conseqüente liberação da parcela intracelular de toxina. Por outro lado, este autor concluiu que dosagens entre 3,0 e 4,0 mg/L de hipoclorito de sódio foram capazes de oxidar ambas parcelas - extra e intracelular - resultando em residuais abaixo de $1 \mu \mathrm{g} / \mathrm{L}$.

\subsubsection{Formação de Trialometanos}

A pesar do cloro ser o agente desinfetante e oxidante mais utilizado em sistemas de tratamento de água no mundo, a aplicação deste oxidante em águas contendo substâncias húmicas leva à formação de compostos organoclorados indesejáveis e potencialmente carcinogênicos. Dentre os subprodutos formados pela oxidação com cloro se destacam os trialometanos, e citado por Di Bernardo \& Dantas (2005) os precursores da formação de trialometanos (THM) e de outros compostos organoclorados não voláteis são:

- Pigmentos (clorofila); 
- Produtos da decomposição de plantas (ácidos húmicos e fúlvicos);

- Biomassa de algas;

- Aminoácidos;

- Proteínas;

Os principais fatores que influenciam na formação dos subprodutos da oxidação com cloro são: $\mathrm{pH}$, tempo de contato, temperatura, natureza e concentração da matéria orgânica natural, dosagem de cloro aplicada e residual de cloro livre (EPA, 1999).

Os trialometanos incluem compostos de clorofórmio $\left(\mathrm{CHCl}_{3}\right)$; bromofórmio $\left(\mathrm{CHBr}_{3}\right)$; dois intermediários bromoclorofórmio: bromodiclorometano $\left(\mathrm{CHBrCl}_{2}\right)$ e o dibromoclorometano $\left(\mathrm{CHBr}_{2} \mathrm{Cl}\right)$; e dicloroiodometano $\left(\mathrm{CHICl}_{2}\right)$. O limite máximo estabelecido pela Portaria 518 de 25 de março de 2004 para trialometanos é de 0,1 mg/L. 


\section{MATERIAL E MÉTODOS}

Este capítulo apresenta a descrição de todas as etapas cumpridas durante a realização da presente pesquisa. Inicialmente, estão listadas as metodologias adotadas para a determinação dos parâmetros físico-químicos de monitoramento dos ensaios e caracterização das águas do reservatório, de estudo e tratada. Os equipamentos utilizados nos ensaios de tratabilidade também são apresentados neste capítulo, seguidos de algumas informações sobre o reservatório de Barra Bonita - SP e as características de sua água. Finalmente, detalham-se as diferentes fases do trabalho no que se referem às estratégias adotadas e métodos específicos a cada etapa de investigação.

A pesquisa foi dividida em três etapas, as quais estão brevemente descritas a seguir:

- ETAPA PRELIMINAR DE ESCOLHA DO CARVÃO ATIVADO EM PÓ (CAP): avaliação de diferentes tipos de CAP utilizados no tratamento de água para abastecimento;

- ETAPA - I: para investigar a eficiência na remoção de células e toxinas de algas Microcystis sp. esta etapa foi dividida em duas fases (A e B), que consistem em dois fluxogramas de tratamento de água. Tais fluxogramas envolvem a aplicação 
de hipoclorito de sódio e CAP em diferentes pontos no tratamento, ambos associados à técnica de Flotação por Ar Dissolvido (FAD);

- ETAPA - II: repetição do fluxograma que apresentou os melhores resultados em termos de cor aparente, turbidez e microcistina residual nos ensaios da ETAPA - I, no entanto, com diferentes estratégias no que diz respeito à pré-cloração e adsorção em CAP.

Para as ETAPAS I e II do trabalho, foram efetuadas coletas no reservatório de Barra Bonita. Em cada coleta, ou seja, em cada fase, foram preparadas três águas de estudo com diferentes concentrações de microcistina. Melhores detalhes sobre o preparo de tais águas, incluindo os equipamentos empregados em cada uma das ETAPAS - I e II, estão descritos posteriormente.

Os ensaios de adsorção e tratabilidade foram realizados em escala de bancada, nas dependências do Laboratório de Tratamento Avançado e Reuso de Águas - LATAR, sendo que as análises físico-químicas foram divididas entre o Laboratório de Saneamento e o LATAR. Durante a pesquisa também foi necessária a utilização de alguns equipamentos do Laboratório de Biotoxicologia de Águas Continentais e Efluentes - BIOTACE. Todos os três laboratórios são ligados ao Departamento de Hidráulica e Saneamento - SHS, da Escola de Engenharia de São Carlos da Universidade de São Paulo - EESC / USP.

\subsection{MONITORAMENTO DOS ENSAIOS}

Para a caracterização das águas - coletadas no reservatório e preparadas para os ensaios - foram determinados os seguintes parâmetros: temperatura, $\mathrm{pH}$, cor aparente, 
turbidez, absorbância 254 nm, SST, alcalinidade, DQO, nitrogênio total (soma dos nitrogênios orgânico e amoniacal, nitrito e nitrato), COT, clorofila-a e microcistina.

Para o monitoramento dos ensaios da ETAPA - I foram realizadas leituras de $\mathrm{pH}$ de coagulação, cor aparente, turbidez, ABS 254 nm e microcistina.

Para os ensaios da ETAPA - II foram realizadas leituras de $\mathrm{pH}$ de coagulação, cor aparente, turbidez, ABS $254 \mathrm{~nm}$, DQO, nitrogênio total, cloro residual, COT, clorofila- $a$, trialometanos e microcistina.

As metodologias adotadas para a determinação dos parâmetros físico-químicos são as definidas pelo Standards Methods for the Examination of Water and Wastewater $21^{a}$ edição (2005), com exceção da microcistina.

A concentração de microcistina foi determinada com o emprego de kits de detecção de microcistina. A determinação é baseada no método ELISA (Enzyme Linked ImmunoSorbent Assays). Para a lavagem das placas foi utilizada uma lavadora automática, e as leituras das placas foram feitas por espectofotometria no comprimento de onda $\lambda=455 \mathrm{~nm}$.

A vantagem no uso deste método está no pequeno volume de amostra necessária (50 $\mu \mathrm{L}$ ) e no tempo de obtenção dos resultados (aproximadamente $2 \mathrm{~h}$ ), além de este método atender à Portaria 518/04 do Ministério da Saúde que regulamenta o controle da microcistina presente em águas para o consumo humano. Na figura 4.1 se vê a placa para determinação da concentração de microcistina, bem como os equipamentos usados na lavagem e leitura das placas. É importante lembrar que a leitora de placas pertence ao BIOTACE e foi gentilmente cedido para a utilização neste trabalho. 


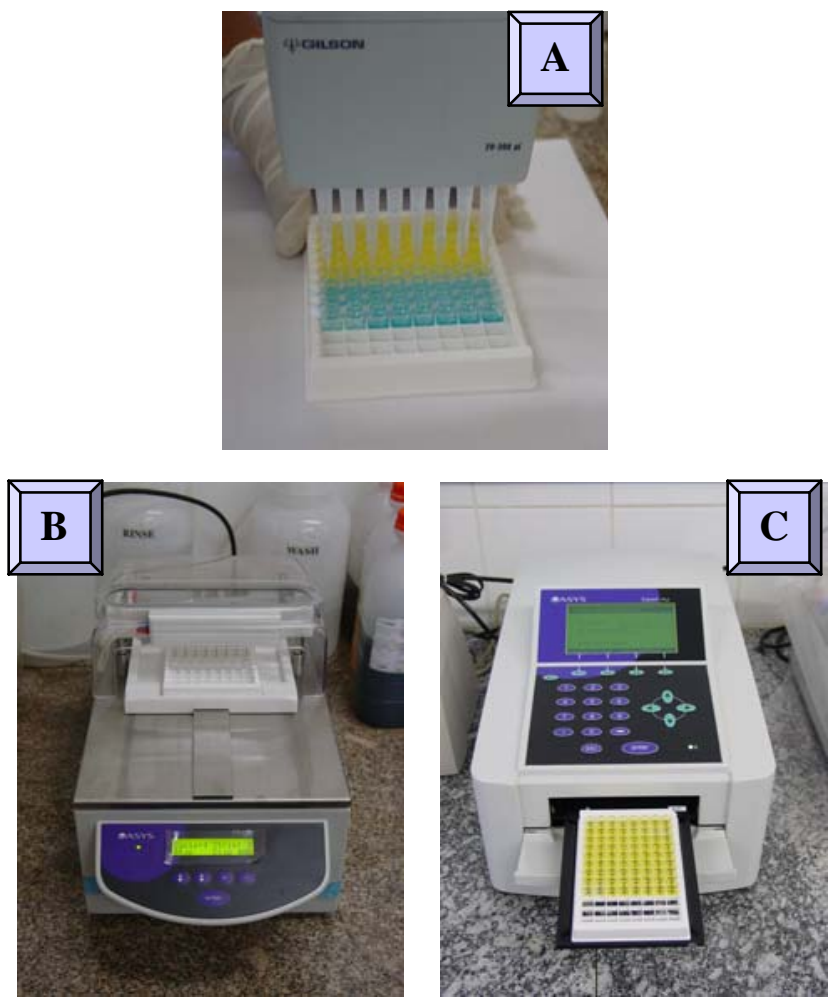

Figura 4.1: A) Placa para determinação de microcistina; B) Lavadora de placas; C) Leitora de placas.

A faixa de concentração detectável pelos kits de microcistina é de $0,15-2,5 \mu \mathrm{g} / \mathrm{L}$, desta forma, foi necessário diluir as amostras que continham valores de concentrações superiores a esta faixa.

\subsection{EQUIPAMENTOS UTILIZADOS}

Neste item estão apresentados os equipamentos utilizados durante a realização da presente pesquisa. 


\subsubsection{Jarteste}

O jarteste (Figura 4.2) foi utilizado na mistura rápida, pré-cloração e adsorção em CAP das águas de estudo preparadas em cada etapa desta pesquisa. O equipamento é composto por seis jarros de acrílico e palhetas metálicas nos quais se pode simular as condições de mistura rápida encontradas nas estações de tratamento de água. Os valores de rotação de mistura são controlados por botões de macro e micro ajuste. Os valores de velocidade de rotação foram fixados em rpm. A aplicação do coagulante é realizada com frascos de vidro que são fixados em um suporte metálico que possibilita a aplicação em diferentes jarros simultaneamente.

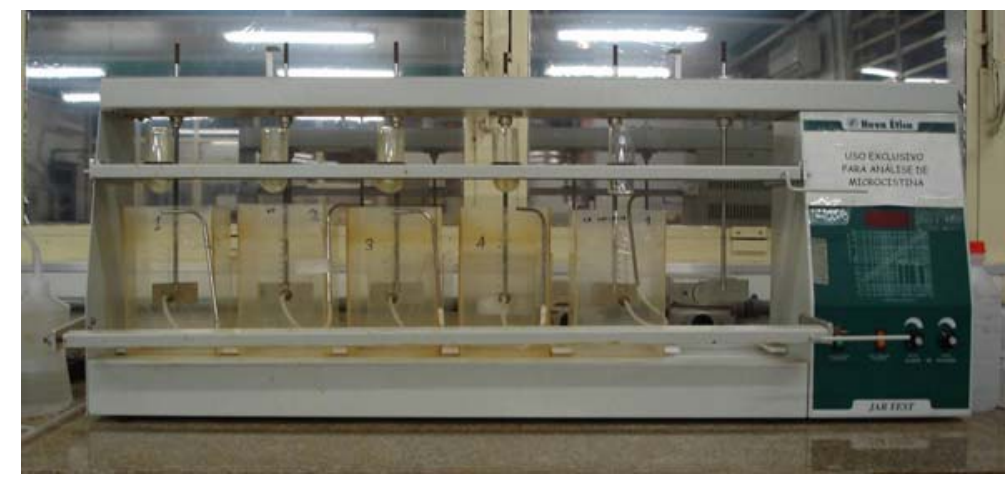

Figura 4.2: Jarteste.

\subsubsection{Flotateste}

O equipamento denominado flotateste, para ensaios em escala de bancada e alimentação por batelada, foi desenvolvido por Reali (1991). Este equipamento é composto por quatro jarros de acrílico e é calibrado para ensaios com 2 litros de amostra. Cada jarro possui palhetas metálicas que possibilitam a floculação das amostras coaguladas. Uma ampla faixa de velocidades de rotação pode ser avaliada, sendo que tais velocidades são controladas 
por inversores de freqüência e aplicadas por meio de motores elétricos que são controlados independentemente.

A saturação da água com ar é feita em uma câmara de saturação de acrílico que é interligada com os jarros. Esta câmara é equipada com válvula de segurança e manômetro que indica a pressão, alimentada por compressor de ar, conforme o especificado para o ensaio. A câmara de saturação também possui uma válvula que está interligada ao compressor de ar, esta válvula tem a função de manter constante a pressão do ar dentro da câmara durante a liberação da água com ar dissolvido nos jarros.

Cada jarro possui na parte inferior uma válvula do tipo agulha que possibilita a liberação da água com ar dissolvido para a realização da flotação das amostras estudadas.

As amostras flotadas são coletadas com o auxílio de mangueiras posicionadas em dois pontos ao longo de cada jarro. A Figura 4.3 ilustra o equipamento brevemente descrito.

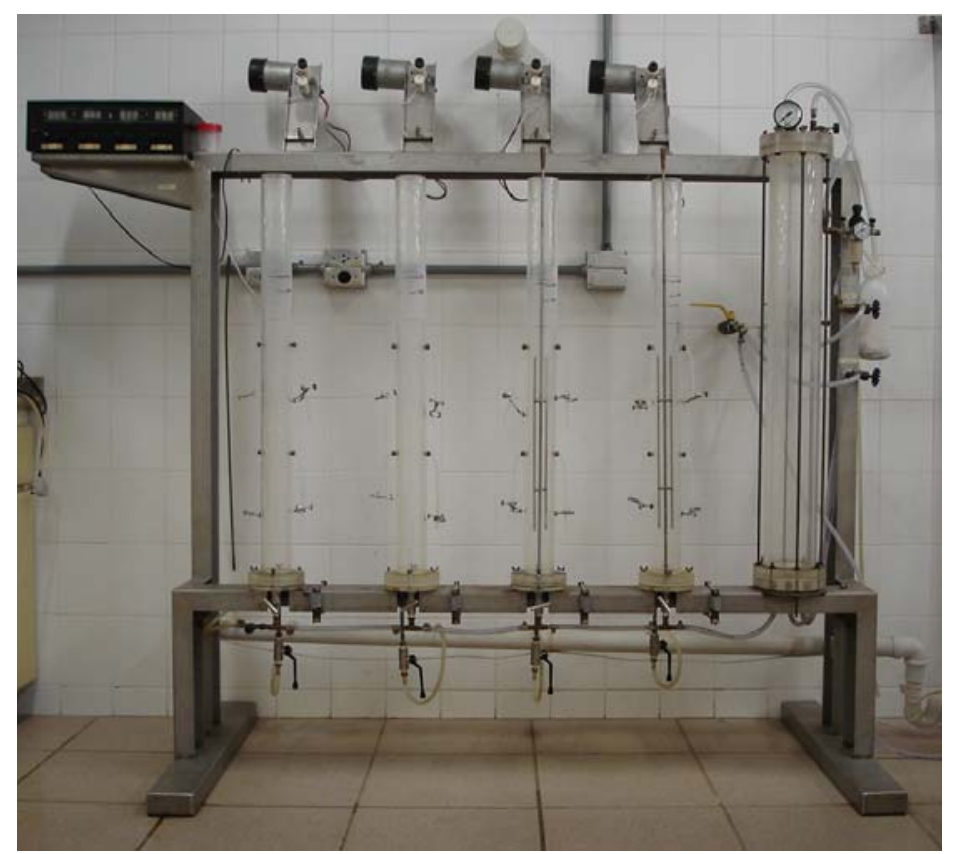

Figura 4.3: Flotateste. 


\subsubsection{Centrífuga}

Visto que foram realizados ensaios em escala de bancada, optou-se pela centrifugação das amostras floculadas/flotadas como etapa final de clarificação em lugar da filtração com papel filtro. Esta escolha é valida tendo em vista que esta etapa final de clarificação tem como papel principal a remoção da menor parte dos sólidos suspensos remanescentes da flotação, papel este que pode ser cumprido pela centrifugação em bancada. Utilizou-se a centrífuga (Figura 4.5) da marca FANEM, modelo 215. Este equipamento possui suporte para frascos com volume útil de 20; 40 e $100 \mathrm{~mL}$. A velocidade rotação máxima sugerida pelo fabricante é de $3500 \mathrm{rpm}$.

Foi determinada uma curva de centrifugação com diferentes velocidades ilustrada pela Figura 4.4.

Curva de Centrifugação

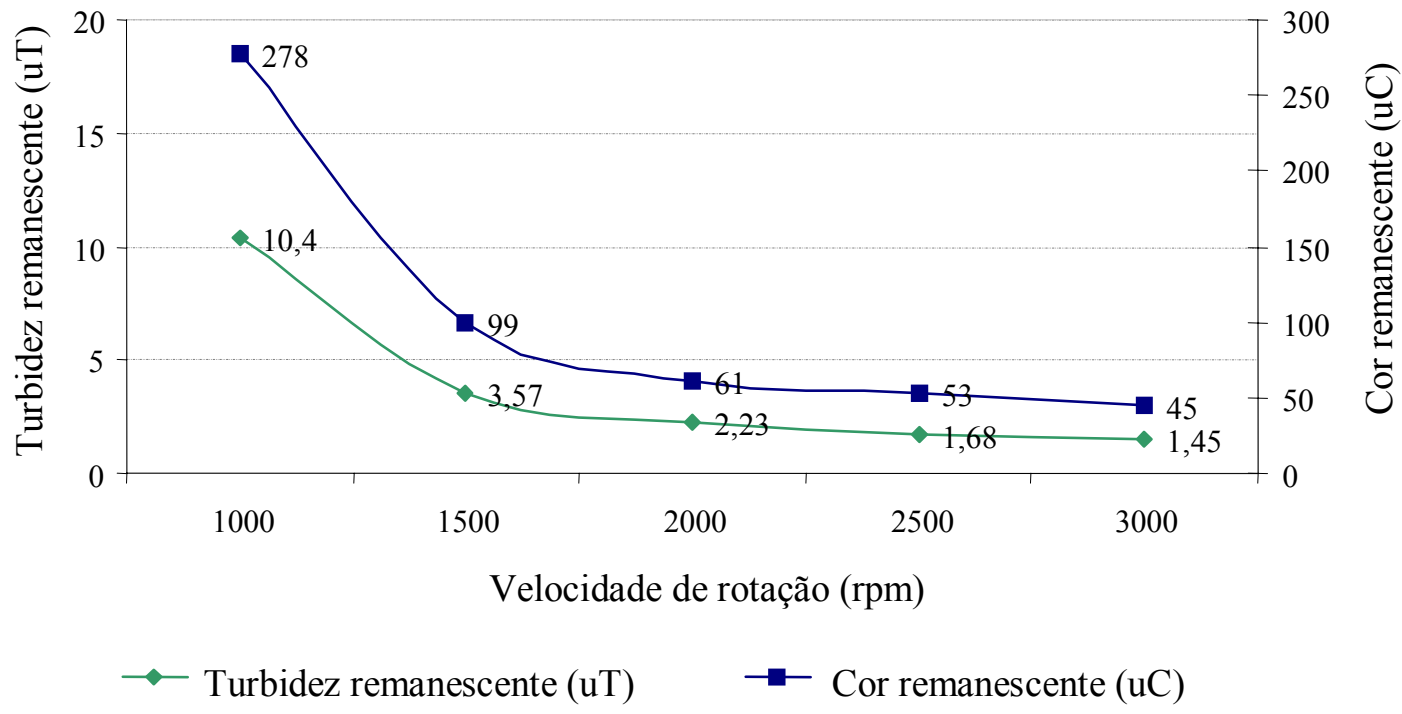

Figura 4.4: Curva de centrifugação - Tempo de centrifugação de 15 min. 
Pela Figura 4.4 se vê que a partir da velocidade de rotação igual a $2000 \mathrm{rpm}$ as amostras não apresentaram grande diferença nos valores remanescentes de cor e turbidez. Com isto, para todas as etapas da pesquisa, nas quais a centrifugação foi aplicada, fixaram-se os parâmetros de tempo de centrifugação (15 minutos) e velocidade de centrifugação (2000 r.pm). Esta velocidade de centrifugação foi selecionada para ser aplicada nos ensaios para minimizar a possibilidade de rompimento de células de algas, e consequentemente, evitar a liberação de toxina na amostra após a centrifugação.

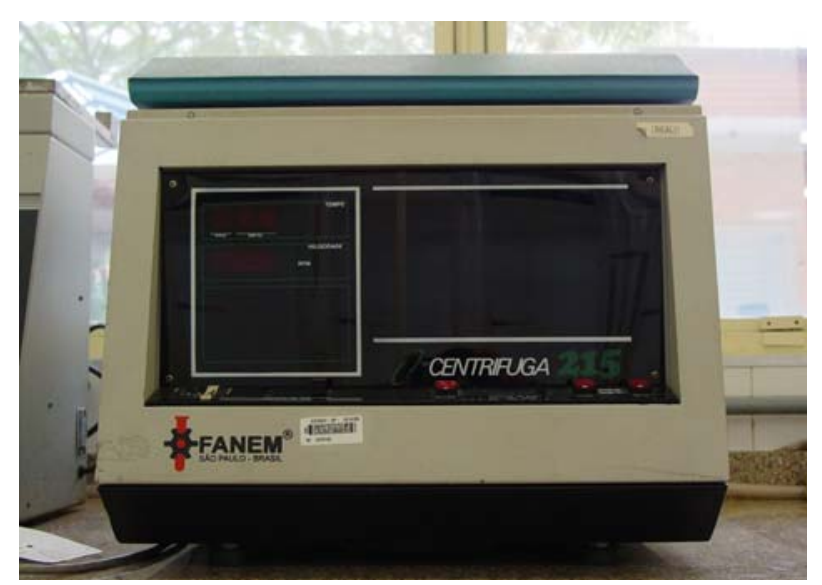

Figura 4.5: Centrífuga.

\subsection{RESERVATÓRIO DE BARRA BONITA E COLETAS}

A água utilizada na pesquisa foi proveniente do reservatório de Barra Bonita - SP que recebe as águas de seus principais contribuintes, os rios Tietê e Piracicaba, e está localizada na Bacia Hidrográfica do Médio Tietê.

As bacias hidrográficas dos rios Tietê e Piracicaba são caracterizadas pela elevada densidade populacional e a intensa atividade industrial e agropecuária. Esta ocupação causou uma progressiva degradação dos sistemas aquáticos pelo lançamento de despejos domésticos e efluentes industriais, além do aporte de nutrientes provenientes das áreas agricultadas. Tais 
fatores contribuem para a eutrofização dos mananciais, fato que foi constatado por Calijuri (1999) que definiu o reservatório como um ambiente adequado para o desenvolvimento do fitoplâncton, em especial as cianofíceas, que são as algas que predominam no reservatório na maior parte do ano.

$\mathrm{Na}$ linha de pesquisa sobre remoção de algas e toxinas, a água do reservatório de Barra Bonita vem sendo utilizada no preparo de águas de estudo, devido ao seu histórico de florações de algas. Além disto, sua água tem usos múltiplos como a geração de energia, transporte fluvial, irrigação, recreação além do abastecimento público, o que proporciona uma avaliação mais realista das pesquisas propostas, no que se refere à qualidade da água de parte dos reservatórios atualmente utilizados para o abastecimento público.

A figura 4.6 mostra o aspecto da água do reservatório próximo à barragem diante da floração de algas, evento este, que se intensifica em determinadas épocas do ano que têm como características a alta intensidade luminosa e ventos fracos.
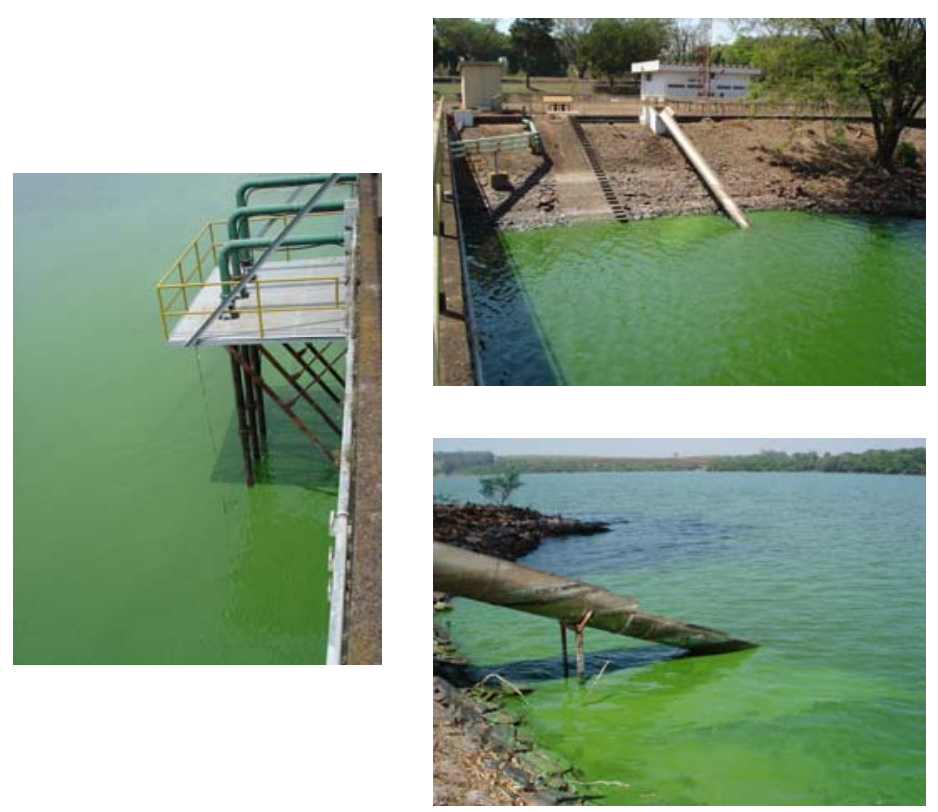

Figura 4.6: Floração de algas no reservatório de Barra Bonita. 


\subsubsection{Coletas}

Duas viagens foram programadas para as coletas de água do reservatório, a primeira em 10/09/2007 e a segunda em 01/11/2007. Em ambas as oportunidades foram coletados 290 litros de água, aproximadamente. Este volume foi armazenado em câmara fria com temperatura em torno de $4^{\circ} \mathrm{C}$. Vale ressaltar que a água coletada permaneceu armazenada durante o período máximo de uma semana. Procedeu-se desta forma para que não ocorresse alteração significativa das características da água coletada.

A água do reservatório é bombeada para um tanque que se localiza ao lado de um laboratório de piscicultura, na área mais alta do terreno. Esta captação é feita a poucos metros da superfície do reservatório. Assim, a água armazenada é distribuída por meio de canaletas para os tanques de piscicultura.

A Figura 4.7 ilustra o ponto de bombeamento da água do reservatório, as canaletas de distribuição, alguns dos tanques de piscicultura e o ponto de coleta. 

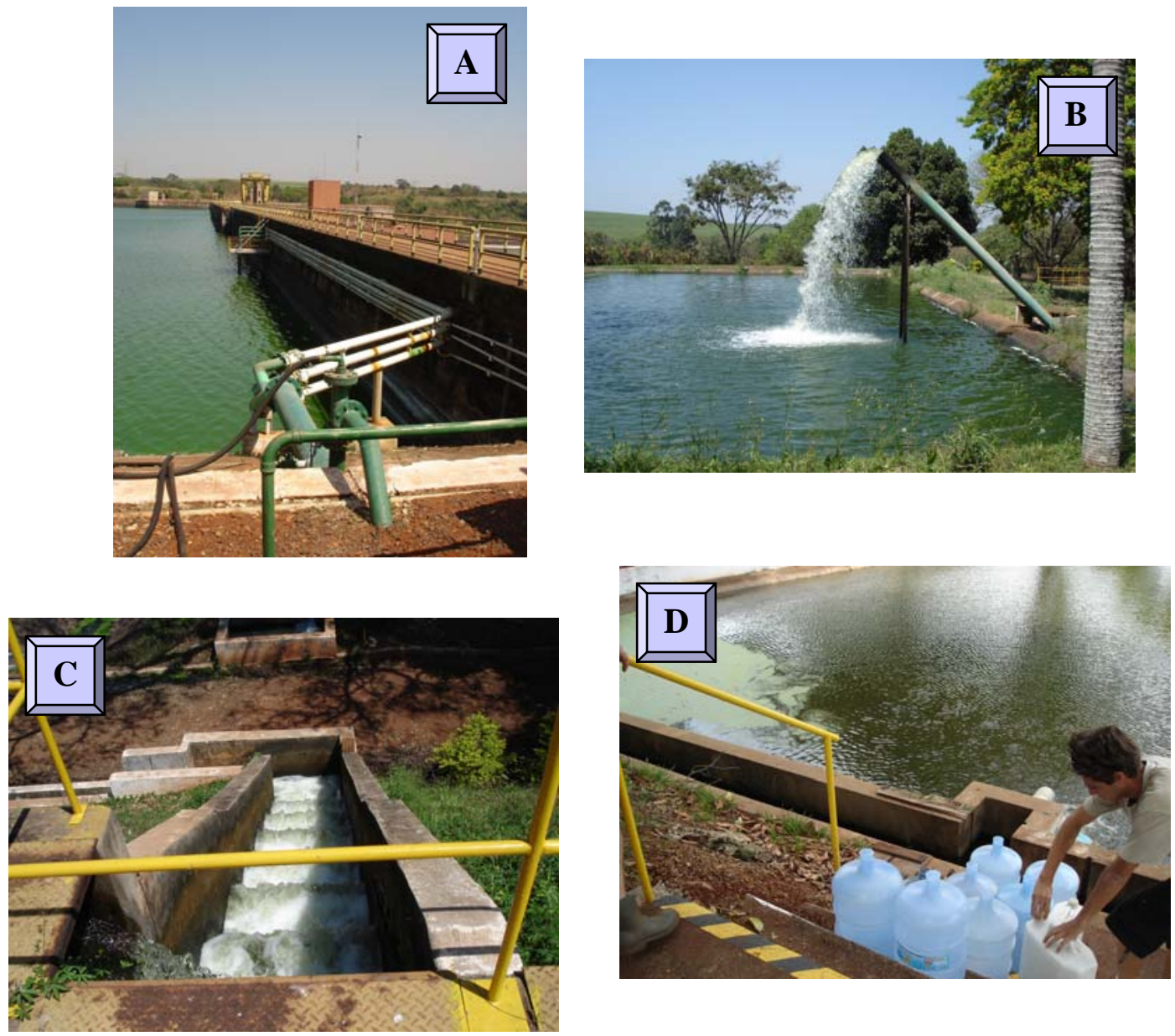

Figura 4.7: A) Bombeamento do Reservatório; B) Tanque de Armazenamento; C) Canaletas de Distribuição; D) Local de Coleta.

Na figura 4.6, é evidente o acúmulo de algas na margem do reservatório, entretanto, não houve a preocupação de coletar a "nata" suspensa (algas acumuladas na superfície) junto com a água. Isto porque durante o preparo das águas de estudo, foram adicionadas alíquotas da cultura de algas desenvolvida no LATAR. Garantindo-se assim, a presença de células de algas e suas toxinas em concentrações suficientes para a realização da pesquisa. Mais adiante, estão descritos melhores detalhes referentes ao desenvolvimento da cultura de algas no laboratório e do preparo das águas. 


\subsubsection{Características da água do reservatório}

Como dito anteriormente, duas coletas no Reservatório de Barra Bonita foram programadas: a primeira em 10/09/2007 que foi utilizada na realização da ETAPA - I, e a segunda coleta em 01/11/2007 para a ETAPA - II.

Ambas as amostras foram caracterizadas através dos seguintes parâmetros: $\mathrm{pH}$, cor aparente, turbidez, ABS $254 \mathrm{~nm}$, SST, alcalinidade, DQO, nitrogênio total, COT, clorofila-a e microcistina. Na Tabela 4.1 estão apresentados os valores encontrados para os parâmetros de caracterização da água coletada em ambas datas.

Tabela 4.1: Caracterização das águas coletadas no Reservatório de Barra Bonita - SP.

\begin{tabular}{|c|c|c|}
\hline Parâmetros & $\begin{array}{c}\text { Água Barra Bonita } \\
1^{\mathrm{a}} \text { coleta } \\
10 / 09 / 2007\end{array}$ & $\begin{array}{c}\text { Água Barra Bonita } \\
2^{\mathrm{a}} \text { coleta } \\
01 / 11 / 2007\end{array}$ \\
\hline $\mathrm{pH}$ & 6,89 & 6,72 \\
\hline Cor Aparente (uC) & 84 & 95 \\
\hline Turbidez (uT) & 7,02 & 6,12 \\
\hline Absorbância 254 nm & 0,160 & 0,173 \\
\hline Alcalinidade $\left(\mathrm{mgCaCO}_{3} / \mathrm{L}\right)$ & 74 & 60 \\
\hline $\mathrm{SST}(\mathrm{mg} / \mathrm{L})$ & 7 & 5 \\
\hline Nitrogênio Total (mg/L) & 5,07 & 6,22 \\
\hline $\mathrm{DQO}\left(\mathrm{mgO}_{2} / \mathrm{L}\right)$ & 32 & 9 \\
\hline $\mathrm{COT}(\mathrm{mgC} / \mathrm{L})$ & 7,89 & 5,74 \\
\hline Clorofila-a $(\mu \mathrm{g} / \mathrm{L})$ & $*$ N.d & 20,93 \\
\hline Microcistina $(\mu \mathrm{g} / \mathrm{L})$ & 0,38 & 0,12 \\
\hline
\end{tabular}

* N.d - Não realizado. 
É importante observar os valores de concentração de microcistina para as coletas realizadas. Vê-se que os valores encontrados $-1^{\mathrm{a}}$ coleta $0,38 \mu \mathrm{g} / \mathrm{L}$ e $2^{\mathrm{a}}$ coleta $0,12 \mu \mathrm{g} / \mathrm{L}-$ estão abaixo do limite estabelecido pela Portaria 518/04 que é igual a 1,0 $\mu \mathrm{g} / \mathrm{L}$ de microcistina. Isto justifica a necessidade de se manter a cultura de algas, pois, com a adição de parte desta cultura é possível atingir valores de toxina e algas que viabilizem a realização dos estudos.

\subsubsection{Cultura de Cianobactérias}

Desde o início da linha de pesquisa sobre remoção de algas e suas toxinas, houve dificuldade em se obter concentrações adequadas destes organismos e toxinas na água.

Sabe-se que a microcistina pode estar presente tanto na forma extracelular (dissolvida no meio) como na forma intracelular (no interior das células das algas). Por isso, buscou-se uma forma de lisar as células das algas para que a toxina contida no interior destas fosse liberada para o meio. Desta forma, seria possível preparar uma água que apresentasse concentrações de microcistina consideradas apropriadas para os estudos de remoção, ou seja, concentrações que melhor representem as concentrações possíveis de ocorrer em reservatórios com problemas relacionados à presença de microcistina em suas águas.

Inicialmente, Ferreira (2004) coletou amostras da "nata" de algas, com predominância de Microcystis, presente no reservatório de Barra Bonita para a preparação de um extrato de microcistina. Para que a concentração de microcistina fosse elevada neste extrato, romperamse as células dos organismos com a aplicação de ultra-som durante 10 min, e centrifugação a 1700 rpm para a remoção da maior parte da matéria em suspensão. Com isso, a amostra 
apresentou elevada concentração de microcistina, e poderia ser adicionada à água de Barra Bonita para o preparo da água que foi estudada.

No entanto, não só a microcistina foi liberada como alguns pigmentos intracelulares. Este fato foi constatado por Silva (2005) e Bueno (2005), que seguiram o mesmo procedimento adotado por Ferreira (2004), e observaram o aumento dos valores de cor aparente e turbidez na água preparada para seus estudos. Por este problema, houve a necessidade de se produzir uma cultura de algas que ao ser adicionada à água do reservatório proporcionaria condições - em termos de concentração de microrganismos e toxina - de aplicação nos estudos de remoção da toxina.

A cepa BB- 05 , utilizada como inóculo para o desenvolvimento da cultura, foi isolada a partir de células comprovadamente tóxicas de Microcystis sp. coletadas no Reservatório de Barra Bonita. Este material foi fornecido pelo Prof. Dr. Armando Augusto H. Vieira do Departamento de Botânica da Universidade Federal de São Carlos, (BUENO, 2005) e (SILVA, 2005).

Seguindo-se o mesmo procedimento adotado por estes autores, a cultura foi desenvolvida nas instalações construídas para este fim junto ao LATAR, sob as seguintes condições:

- Luminosidade a partir de lâmpadas brancas fluorescentes, com fotoperíodo de 12 horas claro e 12 horas escuro controlado por dispositivo eletrônico;

- $\quad$ Temperatura na faixa dos $20 \pm 1{ }^{\circ} \mathrm{C}$ controlada por climatizador;

- Aeração com bombas de aquário;

- $\mathrm{pH}$ do meio de cultura entre 7,9 e 8,1, corrigido com $\mathrm{NaOH}$. 
A Figura 4.8 mostra detalhes das instalações feitas no LATAR para o cultivo de algas. Nesta figura, pode-se ver o conjunto de lâmpadas fluorescentes, aeradores, climatizador e termômetro que são os equipamentos utilizados para manter as condições ideais de cultivo de algas.
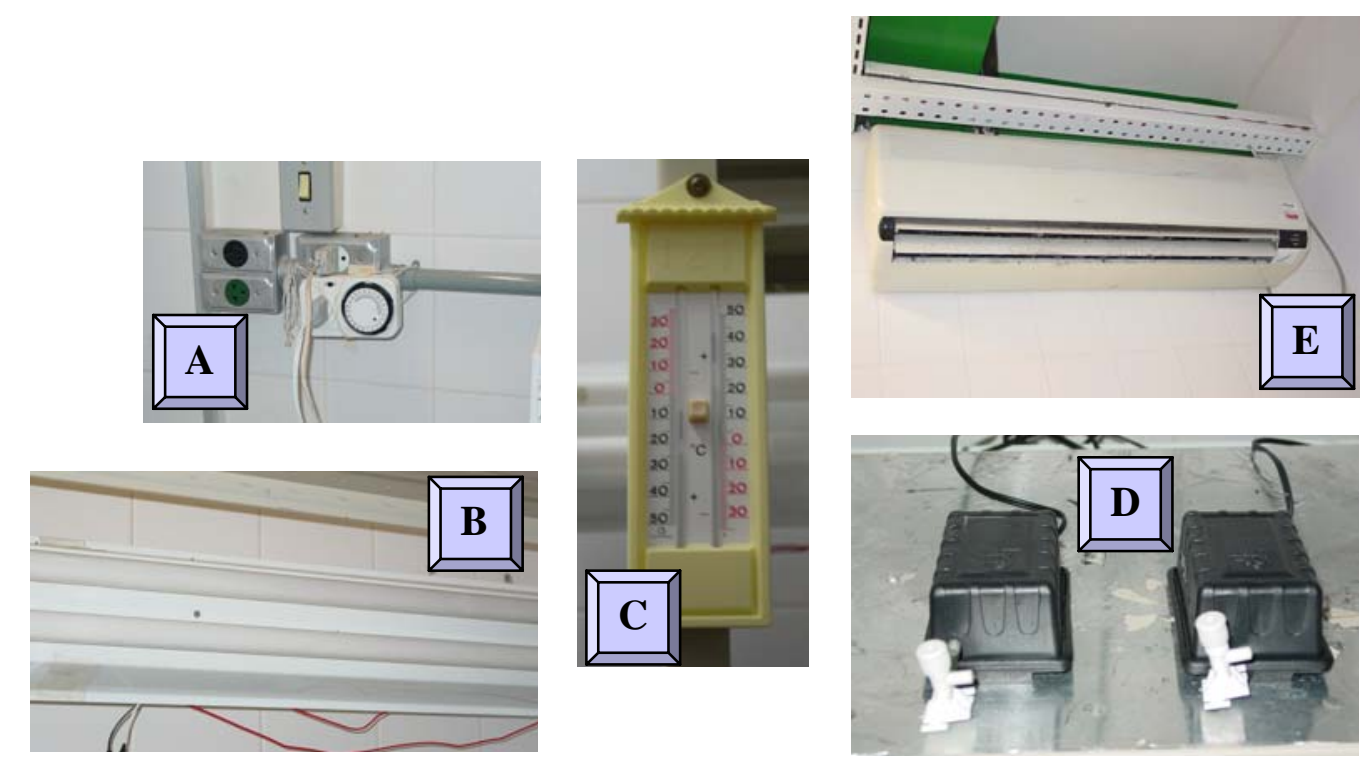

Figura 4.8: A) Temporizador para controle de iluminação; B) Lâmpadas fluorescentes; C) Termômetro; D) Aeradores; E) Climatizador.

O método Estático ou Batch utilizado para o cultivo consiste, na transferência de parcela da cultura já existente - antes de atingir a fase estacionária de crescimento - para volumes maiores de cultura enriquecidas com nutrientes. Estes nutrientes são provenientes do meio de cultura ASM-1 que foi usado para o cultivo. Era feito um acompanhamento visual da cultura de algas para identificar a coloração verde-amarelada, que ocorria dentro de 15 a 20 dias após a realização do repique. Este acompanhamento era essencial para a manutenção da cultura de Microcystis sp. O meio ASM-1 é composto por quatro soluções estoques que são adicionadas em diferentes proporções. A Tabela 4.2 apresenta a composição de cada solução estoque que compõe o meio de cultura. 
Tabela 4.2: Composição do meio ASM-1.

\begin{tabular}{|c|c|c|c|}
\hline $\begin{array}{l}\text { Solução } \\
\text { Estoque }\end{array}$ & Nutrientes & $\begin{array}{c}\text { Concentração } \\
(\mathrm{g} / \mathrm{L})\end{array}$ & $\begin{array}{c}\text { * Volume } \\
\text { Solução Estoque } \\
(\mathrm{mL})\end{array}$ \\
\hline \multirow{6}{*}{ A } & $\mathrm{NaNO}_{3}$ & 8,5 & \multirow{6}{*}{20} \\
\hline & $\mathrm{MgSO}_{4} \times 7 \mathrm{H}_{2} \mathrm{O}$ & 2,45 & \\
\hline & $\mathrm{MgCl}_{2} \times 7 \mathrm{H}_{2} \mathrm{O}$ & 2,05 & \\
\hline & $\mathrm{CaCl}_{2}$ anidro & 1,095 & \\
\hline & ou & & \\
\hline & $\mathrm{CaCl}_{2} \times 2 \mathrm{H}_{2} \mathrm{O}$ & 1,45 & \\
\hline \multirow{4}{*}{$\mathrm{B}$} & $\mathrm{KH}_{2} \mathrm{PO}_{4}$ & 8,7 & \multirow{4}{*}{2} \\
\hline & $\mathrm{Ou}$ & & \\
\hline & $\mathrm{KH}_{2} \mathrm{PO}_{4} \times 3 \mathrm{H}_{2} \mathrm{O}$ & 11,4 & \\
\hline & $\mathrm{Na}_{2} \mathrm{HPO}_{4}$ & 17,8 & \\
\hline \multirow{6}{*}{$\mathrm{C}$} & $\mathrm{H}_{3} \mathrm{BO}_{3}$ & 24,8 & \multirow{6}{*}{0,1} \\
\hline & $\mathrm{MnCl}_{2} \times 4 \mathrm{H}_{2} \mathrm{O}$ & 13,9 & \\
\hline & $\mathrm{FeCl}_{3} \times 6 \mathrm{H}_{2} \mathrm{O}$ & 10,8 & \\
\hline & $\mathrm{ZnCl}_{2}$ & 3,35 & \\
\hline & $\mathrm{CoCl}_{2} \times 6 \mathrm{H}_{2} \mathrm{O}$ & 0,19 & \\
\hline & $\mathrm{CuCl}_{2} \times 2 \mathrm{H}_{2} \mathrm{O}$ & 0,014 & \\
\hline $\mathrm{D}$ & $\mathrm{EDTAxNa}_{2}$ & 18,6 & 0,4 \\
\hline
\end{tabular}

* Volume adicionado em 1 litro de água desionizada.

O cultivo foi realizado em frascos Erlenmeyer de 2 litros, e para cada repique realizado seguiu-se o procedimento abaixo:

1) Limpeza da Vidraria: primeiramente a vidraria era tratada em solução de detergente neutro (EXTRAN 10\%) por no mínimo 12 horas, e em seguida em solução de ácido clorídrico ( $\mathrm{HCl} 3 \%)$ por no mínimo de 12 horas. Após este período o material era enxaguado 3 vezes com água de torneira e 3 vezes com água desionizada. Após as lavagens, os frascos eram fechados com filme de PVC para evitar a contaminação; 
2) Meio de Cultura: o meio de cultura era adicionado em 2 litros de água desionizada conforme os volumes apresentados na Tabela 4.2;

3) Correção do pH: após a adição do meio de cultura na água desionizada, o pH se encontrava na faixa de 6,40 a 6,60. Assim, foi aplicado $\mathrm{NaOH}$ para a correção do pH na faixa de 7,90 e 8,10 .

4) Esterilização do Meio: eram retirados $200 \mathrm{~mL}$ do meio de cultura após a correção do pH, então os frascos eram fechados com tampões (confeccionados com algodão hidrófilo e gaze) e papel alumínio fixado com fita adesiva. Então, os frascos eram autoclavados por $20 \mathrm{~min}$. a $120^{\circ} \mathrm{C}$ e $1,0 \mathrm{kgf} / \mathrm{cm}^{2}$ e posteriormente submetidos à esterilização em câmara de ultravioleta por 20 min.

5) Repique: após a vidraria ser tratada, esterilizada e apresentar-se na temperatura ambiente, os frascos eram levados para capela equipada com bico de Bunsen para a realização do repique. Para isto, eram adicionados $200 \mathrm{~mL}$ da cultura antiga (na fase estacionária de crescimento) nos novos meios preparados.

6) Desenvolvimento da cultura: após o repique, os frascos eram fechados novamente com os tampões e levados para a sala de cultivo para que fossem submetidos à aeração constante, e mantidos sob as condições controladas de temperatura e iluminação.

Um detalhe importante é a aeração dos frascos, que era realizada com bombas de aquário através de mangueiras plásticas que, em sua extremidade em contato com a cultura, possuía pipetas do tipo Pasteur. Esta vidraria recebe o mesmo tratamento aplicado nos frascos Erlenmeyer para evitar contaminação, além da necessidade de uma pequena porção de algodão hidrófilo dentro da pipeta, que filtra o ar vindo das bombas e evita a contaminação da cultura. Pode-se observar como as mangueiras de aeração foram preparadas na Figura 4.9. 
Figura 4.9: Pipeta Pasteur preparada para a aeração da cultura de algas.

A Figura 4.10 ilustra os recipientes nos quais a vidraria foi tratada, os frascos (erlenmeyer) após esterilização e no processo de desenvolvimento dos microrganismos recebendo aeração.
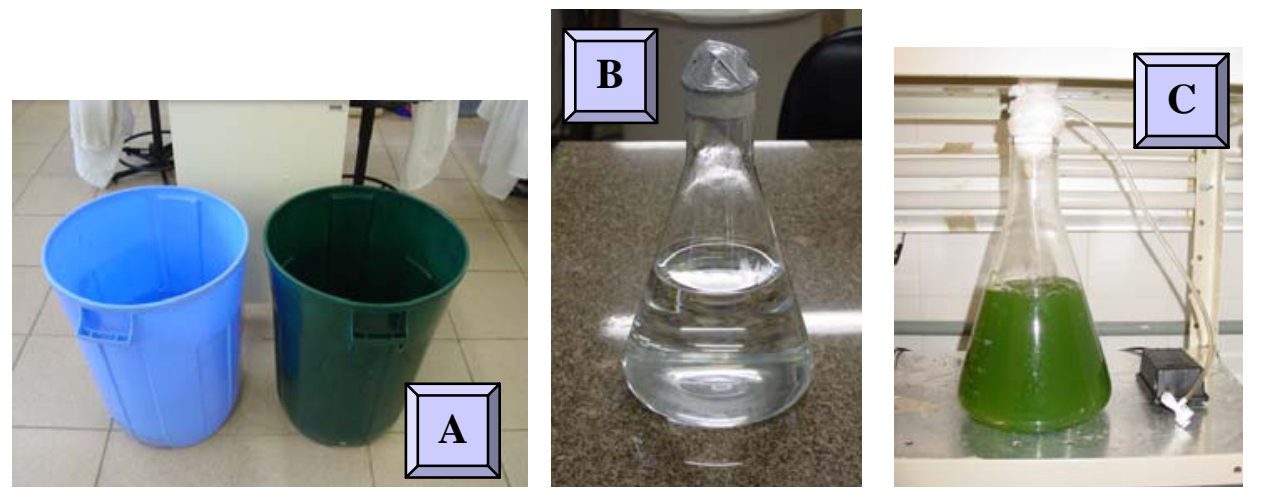

Figura 4.10: A) Recipientes para tratamento da vidraria; B) Frascos esterilizados; C) Desenvolvimento da cultura de algas.

\subsection{DESENVOLVIMENTO DA PESQUISA}

Como dito anteriormente, a pesquisa foi dividida em três partes. Nos itens subseqüentes estão detalhadas todas as partes que compuseram a pesquisa, incluindo preparo das águas de estudo, equipamentos utilizados, procedimentos adotados e o objetivo de cada fase programada. 


\subsubsection{Escolha do Carvão Ativado em Pó (CAP)}

O objetivo desta parte da pesquisa foi avaliar carvões ativados em pó produzidos a partir de diferentes matérias-prima, e que fossem aplicados no tratamento de água para abastecimento.

Para tanto, foi enviado o pedido de amostras para diversos fabricantes de CAP, que resultou na resposta de quatro empresas atuantes na área de saneamento. Assim, foram gentilmente enviadas 5 amostras de carvão, sendo que duas delas foram fornecidas pelo mesmo fabricante. As características físico-químicas de cada carvão estão listadas na Tabela 4.3. Vale lembrar que tais características foram repassadas pelos próprios fabricantes no recebimento das amostras enviadas.

Tabela 4.3: Características das amostras de CAP avaliadas de acordo com dados dos fabricantes.

\begin{tabular}{|c|c|c|c|c|c|}
\hline Características & $\begin{array}{c}\text { CAP - 1 } \\
\text { (Bonechar) }\end{array}$ & $\begin{array}{c}\mathrm{CAP}-2 \\
\text { (Carbomafra) }\end{array}$ & $\begin{array}{c}\mathrm{CAP}-3 \\
\text { (Carbomafra) }\end{array}$ & $\begin{array}{c}\text { CAP - } 4 \\
\text { (Clarifil } \\
\text { Rheiss) } \\
\end{array}$ & $\begin{array}{c}\text { CAP - 5 } \\
\text { (Pelegrini } \\
\text { Carbon) } \\
\end{array}$ \\
\hline Material & Osso & madeira & madeira & casca de coco & madeira \\
\hline Granulometria $(\%<\# 325$ mesh $)$ & - & 90 & $\min .90$ & 88,2 & 80 \\
\hline Umidade (\%) & 5 & $27-35$ & máx. 10 & 5 & $30-40$ \\
\hline Cinzas $(\%)$ & 3 & - & máx. 10 & 6,9 & 8 \\
\hline $\mathrm{N}^{\mathrm{o}}$ de Iodo (mg/g) & - & mín. 600 & mín. 800 & 954 & mín. 700 \\
\hline Indice de Fenol $(\mathrm{g} / \mathrm{L})$ & - & máx. 2,5 & - & 2,2 & - \\
\hline Eficiência Relativa ao Melaço (\%) & - & - & mín. 100 & - & - \\
\hline $\mathrm{pH}$ & - & - & - & 9,4 & alcalino \\
\hline Densidade Aparente $\left(\mathrm{g} / \mathrm{cm}^{3}\right)$ & $0,58-0,71$ & $0,20-0,75$ & - & 0,35 & mín. 0,3 \\
\hline Area Superficial Total $\left(\mathrm{m}^{2} / \mathrm{g}\right)$ & 100 & - & - & - & - \\
\hline Distribuição dos poros (nm) & $7,5-60.000$ & - & - & - & - \\
\hline Volume de poros $\left(\mathrm{cm}^{3} / \mathrm{g}\right)$ & 0,225 & - & - & - & - \\
\hline
\end{tabular}


Foram realizados os ensaios de adsorção de Iodo, Azul de Metileno e Microcistina com as cinco amostras de carvão recebidas. Os ensaios de Iodo e Azul de Metileno foram baseados nos procedimentos estabelecidos pela norma japonesa JIS K 1474 / 91.

Com os dados obtidos durante os ensaios de adsorção, foram elaboradas as isotermas de adsorção segundo o modelo de Freundlich e Langmuir para a avaliação dos CAPs. Assim, foi selecionado, aquele que apresentou maior capacidade de adsorção de todos os compostos, para que fosse aplicado nas etapas posteriores.

\subsubsection{Preparo das amostras de CAP}

Antes da realização dos ensaios de adsorção de Iodo, Azul de Metileno e Microcistina, as amostras de carvão foram separadas e identificadas em placas de vidro, para que fossem secas em estufa a $105^{\circ} \mathrm{C}$ durante 24 horas. Depois de secas, as amostras foram colocadas no dessecador até atingirem a temperatura ambiente.

Com isso, as amostras foram pesadas em balança digital com precisão de $0,0001 \mathrm{~g}$. O número de amostras pesadas e o intervalo entre cada massa variaram conforme o ensaio realizado. Os detalhes estão descritos nos itens referentes aos ensaios de adsorção dos diferentes compostos.

A Figura 4.11 mostra as placas nas quais as amostras de carvão foram separadas, identificas e secas. A balança usada na determinação das massas de carvão também está ilustrada nesta figura. 

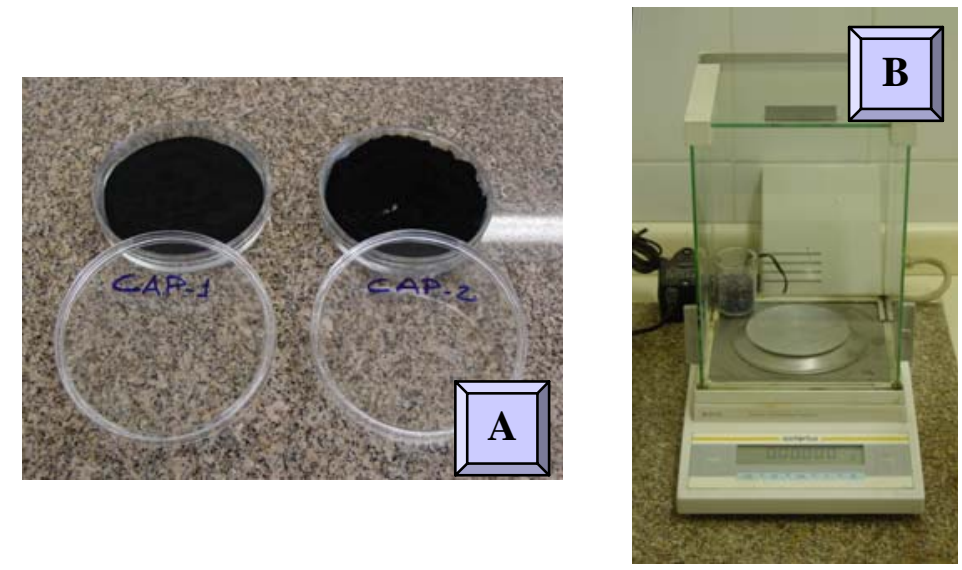

Figura 4.11: A) Placas para secagem dos CAPs; B) Balança de precisão.

\subsubsection{Número de Iodo}

Os ensaios de adsorção de Iodo visaram à determinação do Número ou Índice de Iodo. Este valor é uma medida indireta do volume de microporos (poros menores que $2 \mathrm{~nm}$ ), visto que estas moléculas requerem poros com abertura inferior a $1 \mathrm{~nm}$ para que sejam adsorvidas, (KURODA, 2006).

Segundo a norma japonesa JIS K 1474 / 91, o Número ou Índice de Iodo representa a quantidade de Iodo adsorvido em miligramas por grama de carvão ativado em pó quando a concentração de Iodo total no equilíbrio é igual a 2,5 g/L, sendo a inicial de 12,69 g/L.

Conforme o item 4.4.1.1, as amostras eram pesadas em diferentes massas com intervalo de $0,1 \mathrm{~g}$, com exceção do CAP - 1 que teve seus intervalos elevados para 1,0 g entre as massas devido a sua baixa capacidade de adsorção.

Os ensaios foram realizados em bateladas com duas massas de carvão, as quais foram colocadas em frascos do tipo erlenmeyer de $250 \mathrm{~mL}$ e fechados com tampa plástica. Então, os frascos foram levados para agitação a $30 \mathrm{rpm}$, durante $15 \mathrm{~min}$. e temperatura constante de $20^{\circ} \mathrm{C}$, na agitadora da marca Marconi, modelo Shaker MA-830. Após a agitação, as amostras foram filtradas e tituladas com solução de tiosulfato de sódio $\left(\mathrm{Na}_{2} \mathrm{~S}_{2} \mathrm{O}_{3}-0,1 \mathrm{~mol} / \mathrm{L}\right)$ até que se 
atingisse a coloração amarelo claro. Com isto, aplicava-se $1,0 \mathrm{~mL}$ de solução indicadora de amido (1\%) prosseguindo a titulação até que a amostra se tornasse incolor.

Os ensaios foram realizados até quando a concentração residual de iodo fosse inferior a 2,5 g/L, e finalmente foram elaboradas as isotermas de Langmuir e Freundlich para a determinação do Número de Iodo do CAP em questão.

A Figura 4.12 mostra o equipamento utilizado na agitação das amostras nos ensaios de adsorção. Um panorama geral das etapas que compõem o ensaio de determinação do Número de Iodo está ilustrado pela Figura 4.13.

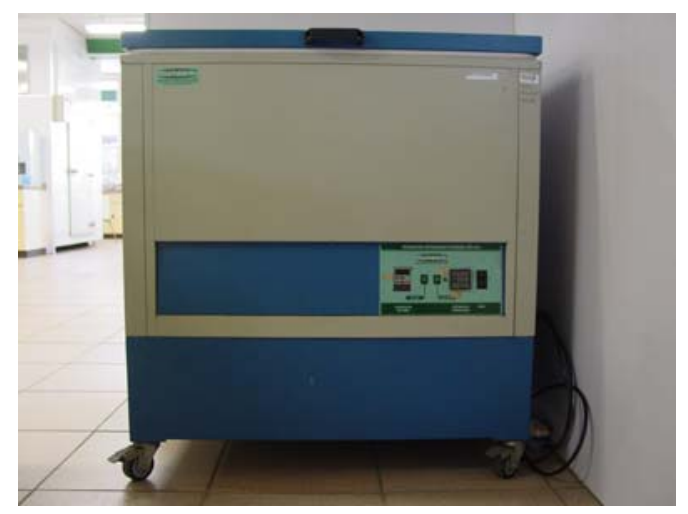

Figura 4.12: Agitador de amostras em temperatura constante.
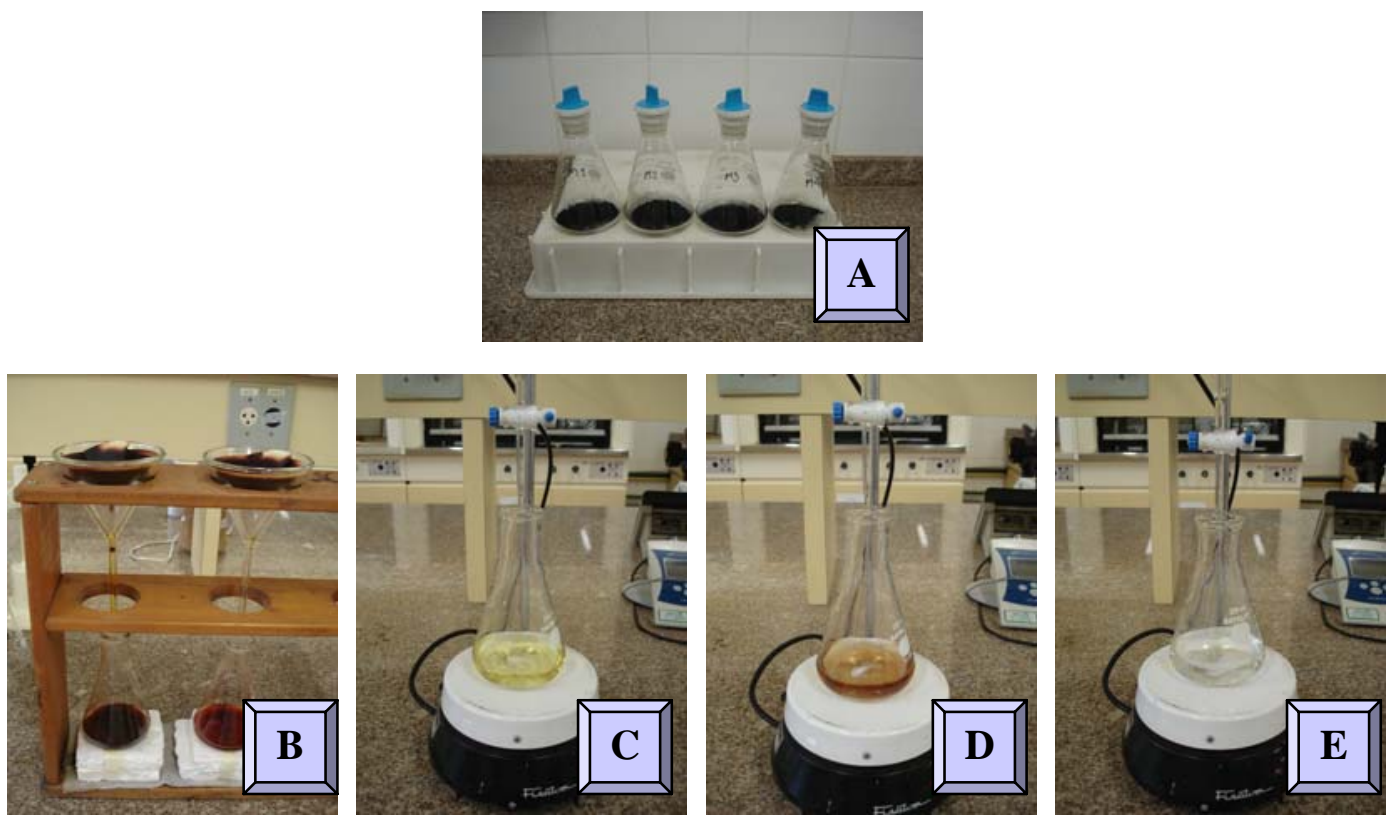

Figura 4.13: A) Frascos com as massas de CAP; B) Separação do CAP; C) Titulação até coloração amarelo palha; D) Aplicação solução indicadora de amido; E) Titulação até a eliminação da coloração azulada. 


\subsubsection{I Índice de Azul de Metileno}

O objetivo dos ensaios de adsorção de Azul de Metileno foi determinar o Número ou Índice de Azul de Metileno das amostras de carvão ativado em pó estudadas.

Assim, tem-se uma medida indireta do volume de mesoporos (poros entre $2-50 \mathrm{~nm}$ ), visto que, apesar da molécula de azul de metileno $\left(\mathrm{C}_{16} \mathrm{H}_{18} \mathrm{ClN}_{3} \mathrm{~S} \times 3 \mathrm{H}_{2} \mathrm{O}\right)$ possuir diâmetro médio igual a $0,8 \mathrm{~nm}$, ela é preferencialmente adsorvida em poros com abertura próxima a 2 nm, (BARTON, 1987 e WARHURST et al., 2001).

A norma JIS K 1474 / 91 define Índice de Azul de Metileno como: a quantidade de azul de metileno adsorvido em miligramas por grama de carvão ativado quando a concentração residual deste composto é igual a 0,24 mg/L, sendo a inicial de $1200 \mathrm{mg} / \mathrm{L}$.

Desta forma, após as amostras serem preparadas conforme o item 1.3.1.1, foram pesadas massas com intervalos de 0,02 g. Os ensaios foram conduzidos em bateladas de três massas distintas, que foram colocadas em erlenmeyers de $250 \mathrm{~mL}$ e fechados com tampa plástica. Com os frascos tampados, as amostras foram levadas para agitação a 30 r.p.m., durante $30 \mathrm{~min}$. e temperatura constante de $20^{\circ} \mathrm{C}$.

Passado este período, as amostras foram filtradas. Foi lida a absorbância do filtrado no comprimento de onda $\lambda=665 \mathrm{~nm}$, para então determinar a concentração residual de azul de metileno a partir da curva de calibração Azul de Metileno versus ABS 665 nm. As concentrações usadas para esta curva variaram entre 0,24 e $2,4 \mathrm{mg} / \mathrm{L}$ e as leituras de absorbância foram realizadas com espectrofotometro da marca HACH, modelo DR-4000U.

Os ensaios foram conduzidos até quando o residual de azul de metileno nas amostras fosse menor que $0,24 \mathrm{mg} / \mathrm{L}$, para então a elaboração das isotermas de adsorção de Langmuir e Freundlich, e determinação do Índice de Azul de Metileno dos carvões ensaiados. 
A Figura 4.14 possibilita uma visão geral das etapas do ensaio para a determinação deste índice.
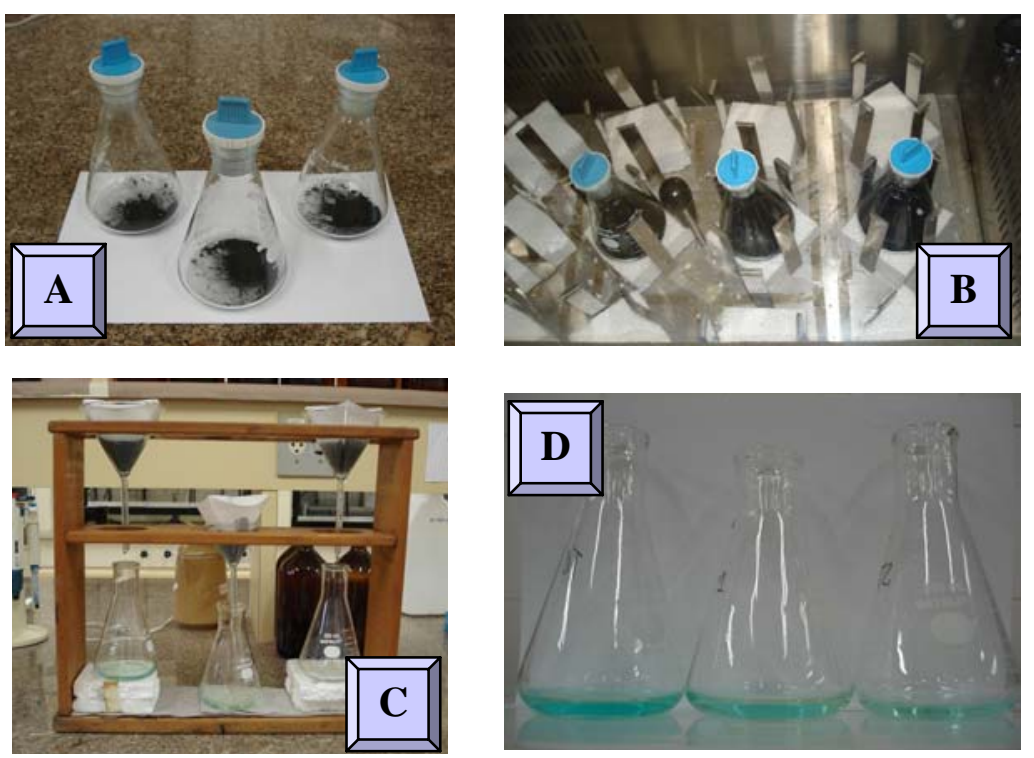

Figura 4.14: A) Frascos com as massas de CAP; B) Agitação em temperatura constante; C) Separação do CAP; D) Amostras filtradas.

\subsubsection{Adsorção de Microcistina}

O objetivo destes ensaios foi avaliar a capacidade de adsorção de microcistina de todas as amostras fornecidas. Para isto, um extrato de microcistina foi preparado conforme descrito a seguir:

- A cultura de algas foi congelada e descongelada (4 vezes);

- então, centrifugada a 3000 r.p.m. durante 30 min.;

- Filtrada em membrana com abertura média de 1,2 $\mu \mathrm{m}$;

- E filtrada, finalmente, em membrana com abertura média de $0,8 \mu \mathrm{m}$.

As amostras foram congeladas e descongeladas para romper as células das algas e assim liberar a microcistina intracelular, segundo Kuroda et al. (2005). As filtrações foram 
realizadas para remover a maior parte das partículas resultantes da lise celular, isto para evitar a possível concorrência por sítios de adsorção entre as partículas e a microcistina no carvão ativado.

O equipamento ilustrado pela Figura 4.15 foi utilizado para filtrar o extrato de microcistina para os ensaios de adsorção em CAP.
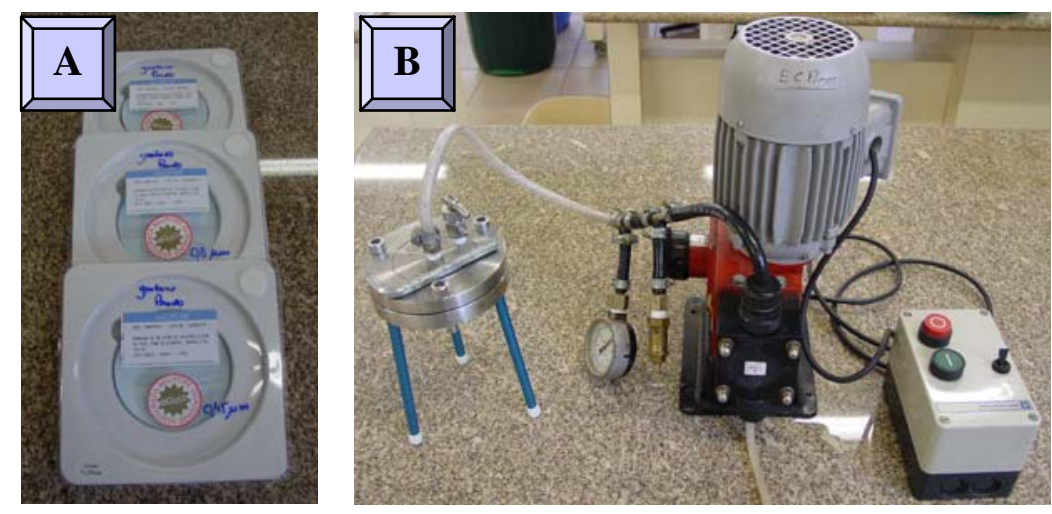

Figura 4.15: A) Membranas para filtração; B) Equipamento para microfiltração do extrato de microcistina.

As amostras foram preparadas e pesadas conforme o item 4.4.1.1. Entretanto, as massas definidas neste ensaio foram fixadas, segundo Silva (2005), em: 0,010;0,015;0,020; 0,025; 0,030 e $0,040 \mathrm{~g}$, sendo que, um frasco sem carvão ativado também foi preparado. Procedeu-se desta forma devido ao elevado custo de aquisição dos kits de microcistina utilizados para a determinação da concentração residual da toxina.

Após a determinação das massas, estas foram colocadas em frascos erlenmeyer de 250 $\mathrm{mL}$ e foi adicionado $50 \mathrm{~mL}$ do extrato de microcistina. Os frascos foram fechados com filme de PVC e papel alumínio fixado com fita adesiva e levados para agitação à 30 r.p.m., durante 72 horas em temperatura constante de $20^{\circ} \mathrm{C}$.

As amostras foram filtradas a vácuo em membrana com abertura de $0,45 \mu \mathrm{m}$ para a remoção do carvão, e então foi determinada a concentração residual de microcistina pelo 
método ELISA. Com os resultados obtidos foram elaboradas as isotermas de adsorção de microcistina, seguindo os modelos de Freundlich e Langmuir, e avaliada a capacidade de adsorção de cada carvão testado.

Os ensaios foram realizados em bateladas com as seis massas pré-definidas mais o frasco controle (frasco sem carvão). Entretanto, impôs-se uma defasagem de 40 min na colocação dos quatro primeiros frascos (controle, massas 1; 2 e 3) e o restante. Assim, foi minimizada a diferença de tempo entre o final da agitação e a filtragem das amostras.

É importante salientar que a concentração inicial de microcistina foi determinada com amostra do frasco sem carvão ativado em pó (controle), sendo que este foi submetido às mesmas condições do ensaio.

A maneira com que os frascos foram preparados, equipamento de filtração a vácuo e as membranas utilizadas para esta filtração estão ilustrados na Figura 4.16.
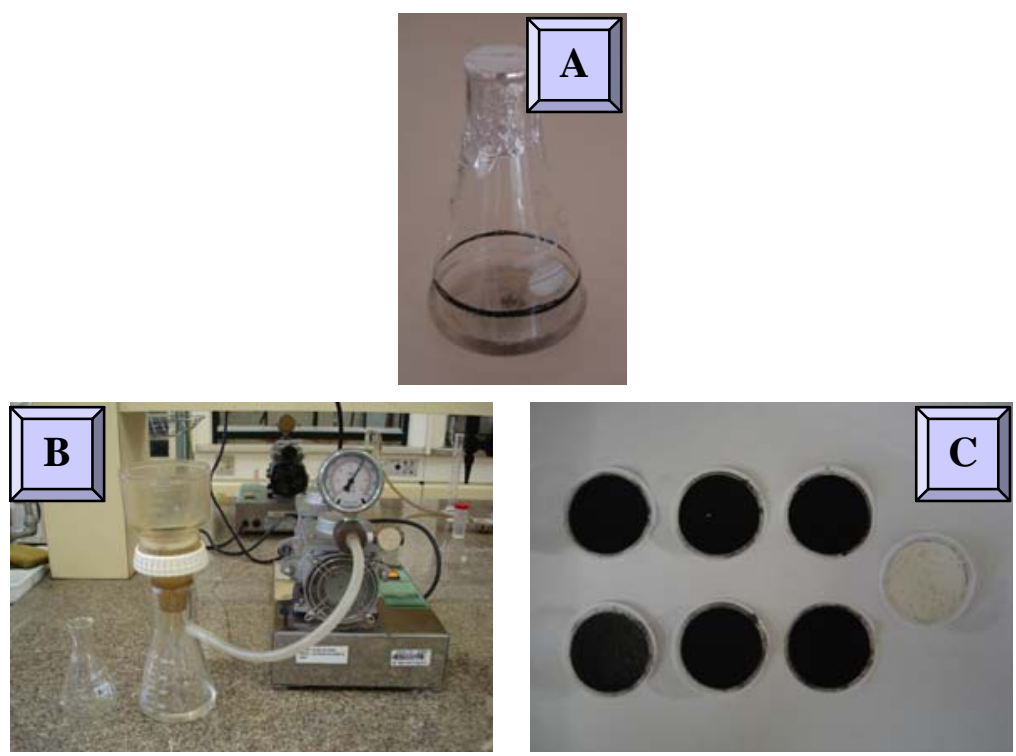

Figura 4.16: A) Frasco após a agitação em temperatura constante; B) Filtração a vácuo para separação do CAP; C) Membranas utilizadas na filtração das amostras. 


\subsubsection{Isotermas de Adsorção}

Com os resultados dos ensaios de adsorção de Iodo, Azul de Metileno e Microcistina foram elaboradas isotermas de adsorção seguindo os modelos de Freundlich e Langmuir. Assim, pode-se avaliar a capacidade de adsorção dos diferentes carvões, para então, selecionar aquele que apresentou os melhores resultados.

- Equação de Freundlich: a norma JIS K 1474 / 91 adota o modelo de Freundlich para a determinação do Numero de Iodo e Índice de Azul de Metileno. Segundo Reynolds e Richards (1995), o modelo empírico de Freundlich é definido por:

$$
q_{e}=K * C_{e}^{\frac{1}{n}}
$$

ou na forma linearizada,

$$
\log \left(q_{e}\right)=\log (K)+\frac{1}{n} \log \left(C_{e}\right)
$$

Onde:

$q_{e}(\mathrm{mg} / \mathrm{g}$ ou $\mu \mathrm{g} / \mathrm{g})=$ quantidade de adsorvato (Iodo, Azul de Metileno e Microcistina) por unidade de massa de carvão ativado;

$C_{e}(\mathrm{mg} / \mathrm{g}$ ou $\mu \mathrm{g} / \mathrm{g})=$ concentração do adsorvato (Iodo, Azul de Metileno e Microcistina) no equilíbrio;

$K$ e $n=$ constantes experimentais. 
Neste modelo, os valores de $n$ e $q_{e}$ são importantes na avaliação da capacidade de adsorção do carvão. Quanto maior o valor de $n$, maior é a afinidade do carvão com o adsorvato empregado no teste. E quanto maior o valor de $q_{e}$, quando a concentração de equilíbrio é igual a concentração inicial de adsorvato $\left(C_{e}=C_{0}\right)$, mais econômica será a aplicação do carvão na adsorção.

- Equação de Langmuir: Conforme Reynolds e Richards (1995), o modelo de Langmuir foi desenvolvida assumindo-se que: 1) existe uma área limitada para adsorção; 2) a camada adsorvida no carvão tem a espessura de uma molécula; 3) a adsorção é reversível e uma condição de equilíbrio é atingida quando a taxa de adsorção é igual à taxa de desorção. O modelo é definido por:

$$
\frac{x}{m}=\frac{a * b * C_{e}}{1+b^{*} C_{e}}
$$

que pode ser reescrita como:

$$
\frac{C_{e}}{(x / m)}=\frac{1}{a * b}+\frac{1}{a} * C_{e}
$$

Onde:

$x(\mathrm{mg} \mathrm{ou} \mu \mathrm{g})=$ massa de soluto adsorvido (Iodo, Azul de Metileno e Microcistina); $m(\mathrm{~g})=$ massa de carvão ativado;

$C_{e}(\mathrm{mg} / \mathrm{L}$ ou $\mu \mathrm{g} / \mathrm{L})=$ concentração de equilíbrio do soluto (Iodo, Azul de Metileno e Microcistina); 
$a(\mathrm{mg}$ ou $\mu \mathrm{g})=$ massa requerida de soluto adsorvido (Iodo, Azul de Metileno e Microcistina) para saturar completamente uma unidade de massa de carvão ativado; $b=$ constante experimental.

As constantes $a$ e $b$ são determinadas através do gráfico $C e /(x / m)$ versus $C e$ e a equação (4). O valor da constante $a$ é fundamental na avaliação do carvão ativado por estar relacionada com a afinidade entre o carvão e o adsorvato (Iodo, Azul de Metileno e Microcistina).

\subsubsection{ETAPA - I}

A ETAPA - I foi dividida em três fases denominadas A, B e C. Foram propostos dois fluxogramas de tratamento de água que combinam pré-cloração, aplicação de carvão ativado em pó e flotação por ar dissolvido para a remoção de microcistina e células de algas.

Para a realização da ETAPA - I foram preparadas TRÊS ÁGUAS DE ESTUDO com diferentes concentrações de microcistina. A finalidade de se preparar estas águas foi: avaliar a interferência da concentração de microcistina na remoção desta toxina através dos tratamentos propostos nas fases da ETAPA - I. Os detalhes do preparo das águas de estudo estão descritos no item 4.4.2.1.

$\mathrm{O}$ coagulante utilizado em todos os ensaios foi o cloreto férrico P.A. $\left(\mathrm{FeCl}_{3} \times 6 \mathrm{H}_{2} \mathrm{O}\right)$. Foi preparada uma solução de $20 \mathrm{~g} / \mathrm{L}$ deste sal, para que a cada $1 \mathrm{~mL}$ adicionado em 2 litros de água de estudo, resultasse na dosagem de $10 \mathrm{mg} / \mathrm{L}$ ou aproximadamente $2,07 \mathrm{mgFe} \mathrm{j}^{3+} / \mathrm{L}$.

Os parâmetros fixados para a realização da ETAPA - I foram: velocidade de rotação de mistura rápida $\left(\operatorname{Vr}_{\mathrm{MR}}=350 \mathrm{rpm}\right)$, tempo de mistura rápida $\left(\mathrm{T}_{\mathrm{MR}}=20 \mathrm{~s}\right)$, velocidade de 
rotação de floculação $\left(\operatorname{Vr}_{\mathrm{FLO}}=68 \mathrm{rpm}\right)$, tempo de floculação $\left(\mathrm{T}_{\mathrm{FLO}}=18 \mathrm{~min}\right)$, pressão na câmara de saturação $\left(\mathrm{P}_{\mathrm{SAT}}=500 \mathrm{kPa}\right)$, tempo de saturação na câmara $\left(\mathrm{T}_{\mathrm{SAT}}=15 \mathrm{~min}\right)$ e taxa de recirculação da água saturada com ar $(\mathrm{R}=8 \%)$.

Foi preparada uma solução de CAP - com o carvão selecionado para a pesquisa - para a aplicação em dosagens pré-definidas (10; 20 e $30 \mathrm{mg} / \mathrm{L})$. E para a pré-cloração foi preparada uma solução de hipoclorito de sódio $(\mathrm{NaOCl})$ que foi titulada com tiosulfato de sódio antes da aplicação nos ensaios.

A seguir, são apresentados os procedimentos adotados no preparo das águas de estudo e na execução das três fases que compuseram a ETAPA - I.

\subsubsection{Preparo das Águas de Estudo - ETAPA - I}

A água de Barra Bonita utilizada no preparo das três águas de estudo foi coletada no dia 10/09/2007. Como dito anteriormente, foram preparadas três águas com diferentes concentrações de microcistina a fim de avaliar a interferência destas concentrações na remoção da microcistina pelos tratamentos propostos.

Foram adicionadas alíquotas - em diferentes proporções - da cultura de algas e do extrato preparado a partir desta cultura. Para o extrato, parte da cultura foi congelada e descongelada quatro vezes para liberação da toxina intracelular, porém este extrato não passou pelas filtrações realizadas no item 4.4.1.4. Isto para evitar diferenças significativas nas características de sólidos suspensos entre as águas, além do fato que nas águas utilizadas para o abastecimento público, estão presentes compostos que irão competir com a microcistina pelos sítios de adsorção do carvão ativado em pó. 
Foram determinadas as concentrações de microcistina da água de Barra Bonita, da cultura de algas e do extrato, resultando em: Barra Bonita - 0,38 $\mu \mathrm{g} / \mathrm{L}$; Cultura de Algas 75,47 $\mu \mathrm{g} / \mathrm{L}$; Extrato de Microcistina - 1431,08 $\mu \mathrm{g} / \mathrm{L}$.

Portanto, as águas de estudo foram preparadas da seguinte forma:

- $\quad$ ÁGUA DE ESTUDO 1: foram preparados 76,5 litros da água de estudo 1, sendo que foram adicionados 6,5 litros da cultura de algas em 70 litros de água de Barra Bonita. A concentração de microcistina resultante da água de estudo 1 foi $6,76 \mu \mathrm{g} / \mathrm{L}$.

- $\quad$ ÁGUA DE ESTUDO 2: foram preparados 76,5 litros da água de estudo 2. Para esta água foi preparada uma mistura com a cultura de algas e o extrato, na proporção de 6,5 litros de cultura em 2 litros de extrato. Destes 8,5 litros resultantes, pegou-se o volume de 6,5 litros que foi adicionado em 70 litros de água de Barra Bonita. A concentração de microcistina resultante da água de estudo 2 foi $25,84 \mu \mathrm{g} / \mathrm{L}$.

- $\quad$ ÁGUA DE ESTUDO 3: foram preparados 76,5 litros de água de estudo 3. Da mesma forma, foi preparada a mistura entre a cultura de algas e o extrato de microcistina, entretanto foram adicionados 6,5 litros da cultura de algas em 16 litros de extrato. Destes 22,5 litros, 6,5 litros foram adicionados em 70 litros de água de Barra Bonita. A concentração de microcistina resultante da água de estudo 3 foi de 104,92 $\mu \mathrm{g} / \mathrm{L}$.

As três águas preparadas foram caracterizadas pelos seguintes parâmetros: temperatura, pH, Turbidez, cor aparente, absorbância $254 \mathrm{~nm}$, alcalinidade, SST, DQO, nitrogênio total, COT e microcistina. A Tabela 4.4 apresenta os resultados desta caracterização. 
Tabela 4.4: Caracterização das Águas de Estudo - ETAPA - I.

\begin{tabular}{|c|c|c|c|}
\hline Parâmetros & $\begin{array}{c}\text { Água de Estudo } \\
1\end{array}$ & $\begin{array}{c}\text { Água de Estudo } \\
2\end{array}$ & $\begin{array}{c}\text { Água de Estudo } \\
3\end{array}$ \\
\hline Temperatura $\left({ }^{\circ} \mathrm{C}\right)$ & 22 & 21 & 22 \\
\hline $\mathrm{pH}$ & 7,50 & 7,03 & 7,33 \\
\hline Cor Aparente (uC) & 586 & 452 & 315 \\
\hline Turbidez (uT) & 54,6 & 47,3 & 28,4 \\
\hline Absorbância 254 nm & 0,236 & 0,278 & 0,209 \\
\hline Alcalinidade $\left(\mathrm{mg} \mathrm{CaCO}_{3} / \mathrm{L}\right)$ & 93 & 87 & 90 \\
\hline $\mathrm{SST}(\mathrm{mg} / \mathrm{L})$ & 25 & 33 & 18 \\
\hline Nitrogênio Total (mg/L) & 6,40 & 6,20 & 6,42 \\
\hline $\mathrm{DQO}\left(\mathrm{mgO}_{2} / \mathrm{L}\right)$ & 81 & 92 & 72 \\
\hline $\mathrm{COT}(\mathrm{mgC} / \mathrm{L})$ & 8,15 & 8,50 & 8,88 \\
\hline Microcistina $(\mu \mathrm{g} / \mathrm{L})$ & 6,76 & 25,84 & 104,92 \\
\hline
\end{tabular}

\subsubsection{FASE - A}

A FASE - A consistiu na definição da dosagem ótima de coagulante que foi aplicada nos ensaios das FASES - B e C. Como foram preparadas três águas de estudo, esta escolha foi realizada para todas as águas.

Assim, para a definição da dosagem ótima de cloreto férrico, foram testadas as dosagens de 6,$20 ; 8,26 ; 10,33 ; 12,40 ; 14,47 ; 16,54 ; 18,61$ e $20,68 \mathrm{mgFe}^{3+} / \mathrm{L}$ para cada água de estudo. 
A mistura rápida foi realizada no jarteste, e depois a amostra foi transferida para o flotateste para que fosse realizada a floculação da água e posterior flotação. As amostras flotadas foram coletadas em duas velocidades de flotação, sendo: $\mathrm{V}_{1}=18 \mathrm{~cm} / \mathrm{min}$ (ou 10,8 $\mathrm{m} / \mathrm{h}$ ) e $\mathrm{V}_{2}=12 \mathrm{~cm} / \mathrm{min}($ ou $7,2 \mathrm{~m} / \mathrm{h})$. Finalmente, as amostras flotadas foram levadas para centrifugação.

Os ensaios foram monitorados com leituras do $\mathrm{pH}$ de coagulação, cor aparente e turbidez das amostras de água flotada e centrifugada, sendo que, os critérios para a escolha da dosagem ótima de coagulante foram os limites de cor aparente e turbidez, iguais a $15 \mathrm{uC}$ e 1 uT respectivamente, estabelecidos pela Portaria 518 do Ministério da Saúde .

A Figura 4.17 mostra o fluxograma que detalha os ensaios realizados para a escolha da dosagem ótima de cloreto férrico, no qual estão os parâmetros de ensaio fixados para esta fase. 


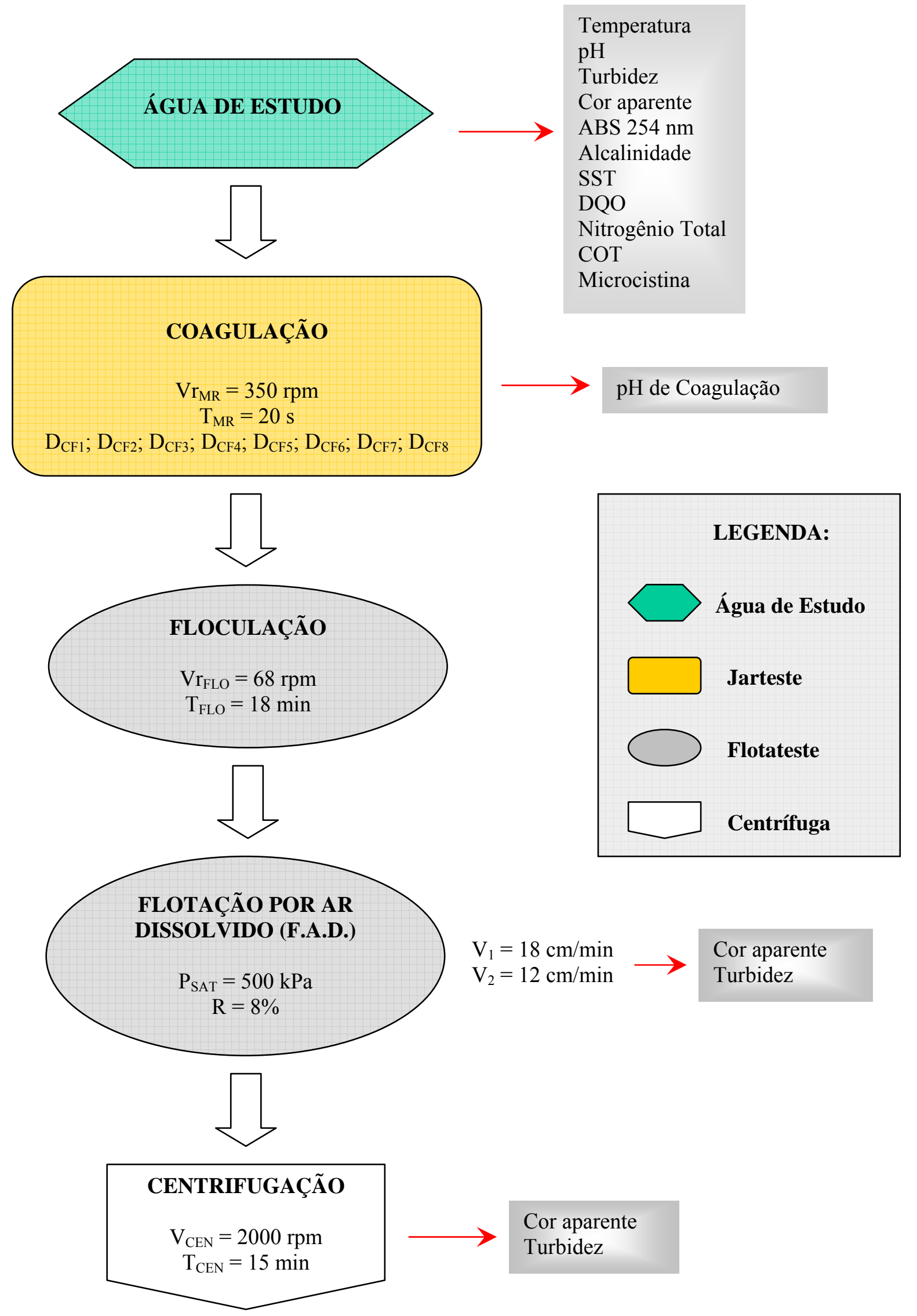

Figura 4.17: Fluxograma dos ensaios da FASE - A da ETAPA - I. 


\subsubsection{FASE - B}

A FASE - B é referente ao primeiro sistema de tratamento simulado em laboratório, que consistiu no tratamento da água com e sem aplicação do CAP e da pré-cloração antes da mistura rápida. $\mathrm{O}$ objetivo desta fase foi avaliar a eficiência na remoção de microcistina da água de estudo, além da interferência da concentração desta toxina na qualidade da água tratada.

Para tanto, em cada água de estudo preparada, foram testadas três dosagens de carvão ativado (10; 20 e $30 \mathrm{mg} / \mathrm{L})$ com tempo de contato de 50 segundos. Logo em seguida, foi realizada a pré-cloração com $3,0 \mathrm{mgCl}_{2} / \mathrm{L}$ de cloro livre e que teve seu tempo de contato fixado em 10 segundos. Decorrido este tempo, foi realizada então a mistura rápida com a dosagem ótima de coagulante definida para cada água nos ensaios da FASE - A. A floculação foi iniciada logo após a mistura rápida para que finalmente as amostras fossem centrifugadas e assim, fosse caracterizada a água tratada.

As etapas de adsorção e pré-cloração foram realizadas aplicando-se a mesma velocidade de rotação de mistura rápida $\left(\mathrm{Vr}_{\mathrm{MR}}=350 \mathrm{rpm}\right)$. Para os ensaios, foi utilizado 1 litro de água de estudo e as etapas do tratamento de adsorção, pré-cloração, mistura rápida e floculação, foram realizadas no jarteste. O flotateste não foi utilizado para a floculação e flotação da água pois este equipamento é calibrado para ensaiar 2 litros de amostra, o que resultaria em grande volume de água de estudo necessária, inviabilizando-se assim a realização da ETAPA - I da forma que foi proposta. Logo após a floculação realizada no jarteste, as amostras foram centrifugadas com o intuito de simular a separação dos sólidos realizada, anteriormente, pela flotação por ar dissolvido e centrifugação. Ressalta-se que, o foco da investigação experimental da FASE B foi a avaliação da influência da dosagem de CAP (três dosagens aplicadas antes da mistura rápida) na eficiência da remoção de 
microcistina sem e com etapa de pré-cloração, conforme ilustrado no fluxograma mostrado na Figura 4.18.

Quando realizada a pré-cloração, foi aplicada solução de metabissulfito de sódio, na amostra centrifugada, para encerrar a reação do cloro residual após o tempo de contato de aproximadamente $35 \mathrm{~min}$, e com isso realizar as leituras de microcistina das amostras.

Os ensaios foram monitorados pelos parâmetros de $\mathrm{pH}$ de coagulação, cor aparente, turbidez, absorbância em 254 nm e microcistina da água centrifugada.

A Figura 4.18 apresenta o fluxograma de ensaio aplicado para a avaliação do processo de tratamento proposto para esta FASE - B. Estão descritos na Figura 4.18 os parâmetros de mistura rápida, floculação e centrifugação, bem como as dosagens de carvão ativado em pó e pré-cloração aplicados durante os ensaios. 


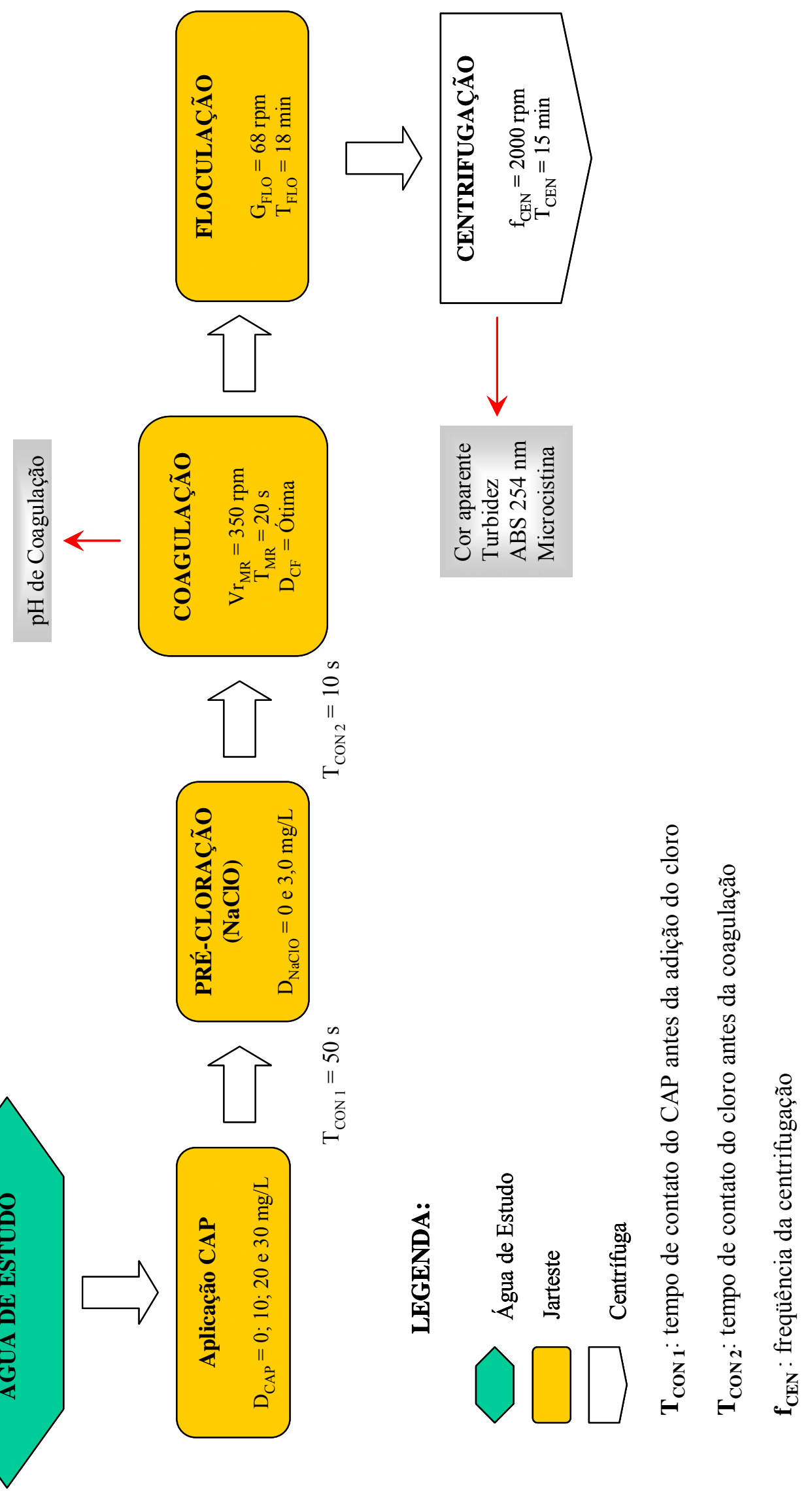

Figura 4.18: Fluxograma dos ensaios da FASE - B da ETAPA - I. 


\subsubsection{FASE - C}

$\mathrm{Na}$ FASE - C foram realizados os ensaios referentes ao segundo processo de tratamento de água proposto. Esta fase também consistiu na adoção ou não da pré-cloração e da adsorção com CAP. No entanto, foi mudado o ponto de aplicação do oxidante e do carvão ativado em relação à fase anterior. Nesta fase, o CAP foi aplicado após a coagulação, mantendo-se as mesmas dosagens de cloro (pré-cloração) e as mesmas dosagens de CAP. Ou seja, a FASE - C diferiu da FASE - B apenas no que concerne ao ponto de aplicação do CAP conforme ilustrado na Figura 4.19.

Assim, para as três águas de estudo preparadas, o tratamento foi iniciado com a précloração aplicando-se $3,0 \mathrm{mgCl}_{2} / \mathrm{L}$ de cloro livre com tempo de contato de 10 segundos, após isto, realizou-se a mistura rápida com a dosagem ótima de cloreto férrico estabelecida na FASE - A (Água de Estudo $1-14,47 \mathrm{mgFe}^{3+} / \mathrm{L}$; Água de Estudo $2-14,47 \mathrm{mgFe}^{3+} / \mathrm{L}$ e água de Estudo 3 - 18,61 $\mathrm{mgFe}^{3+} / \mathrm{L}$ ). Logo após a mistura rápida foram avaliadas três dosagens de CAP $(10 ; 20$ e $30 \mathrm{mg} / \mathrm{L})$ com tempo de contato de 10 segundos, passado este tempo, iniciouse a floculação para posterior centrifugação das amostras. Quando foi executada a précloração, no final do tratamento também foi aplicada solução de metabissulfito de sódio para parar a reação do oxidante, tendo em vista que as amostras eram armazenadas até que fosse realizada a determinação das concentrações de microcistina.

Pelo mesmo motivo apresentado no item referente à FASE - B, os ensaios foram conduzidos com 1 litro de amostra. As etapas de pré-cloração, mistura rápida, adsorção em CAP e floculação também foram realizadas no jarteste. Sendo que o gradiente médio de velocidade de mistura rápida foi mantido para a pré-cloração e adsorção.

Os ensaios foram monitorados pelos parâmetros de $\mathrm{pH}$ de coagulação, cor aparente, turbidez, absorbância em 254 nm e concentração de microcistina da água centrifugada. 
O fluxograma do tratamento simulado em laboratório é apresentado na Figura 4.19, e nela são apresentados todos os parâmetros de mistura rápida, floculação e centrifugação fixados para o tratamento, além das análises realizadas para o monitoramento dos ensaios. 

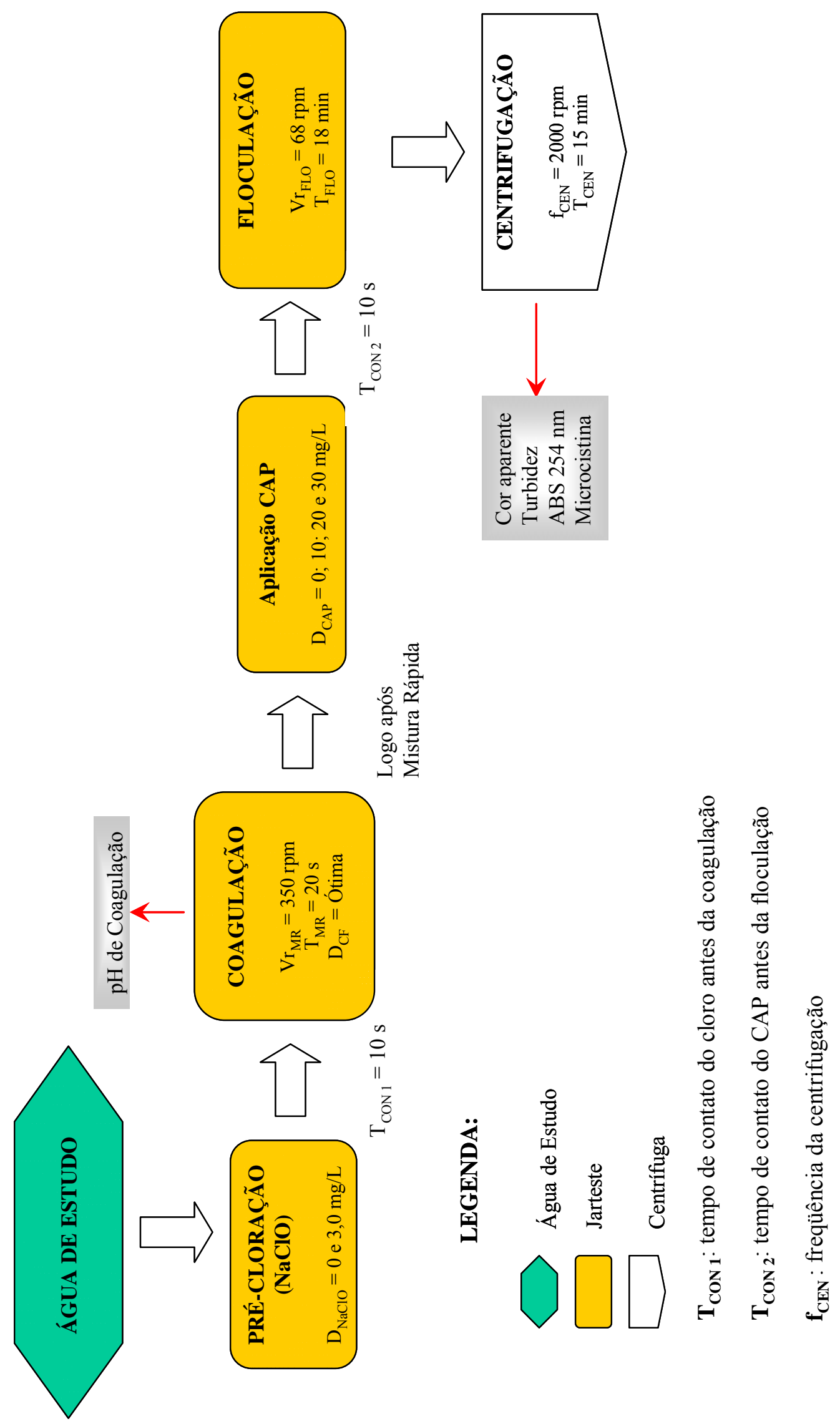

Figura 4.19: Fluxograma dos ensaios da FASE - C da ETAPA - I. 


\subsubsection{ETAPA - II}

A ETAPA - II foi dividida em duas fases denominadas A e B. A FASE - A consistiu na escolha da dosagem ótima de cloreto férrico, visto que para a realização da ETAPA -II foi realizada uma nova coleta de água em Barra Bonita.

$\mathrm{Na}$ FASE - B foi repetido o fluxograma de tratamento executado na FASE - C da ETAPA - I por ter apresentado os melhores resultados em termos de cor aparente, turbidez e concentração de microcistina da água produzida durante a ETAPA - I. Entretanto, foram estudadas duas dosagens de oxidante $(3,0$ e $6,0 \mathrm{mg} / \mathrm{L})$ e para a adsorção foi aplicada a dosagem de carvão estimada para que o residual de microcistina, em cada uma das três águas preparadas, fosse igual a $1 \mu \mathrm{g} / \mathrm{L}$, valor este definido como máximo permito em águas de abastecimento pela Portaria 518 do Ministério da Saúde. Os detalhes da estimativa da dosagem de carvão ativado aplicada em cada água, bem como do preparo destas águas de estudo, são apresentados no item 4.4.3.1.

Os parâmetros - velocidade de rotação de mistura rápida $\left(\operatorname{Vr}_{M R}\right)$, tempo de mistura rápida $\left(\mathrm{T}_{\mathrm{MR}}\right)$, velocidade de rotação de floculação $\left(\mathrm{Vr}_{\mathrm{FLO}}\right)$, tempo de floculação $\left(\mathrm{T}_{\mathrm{FLO}}\right)$, pressão na câmara de saturação $\left(\mathrm{P}_{\mathrm{SAT}}\right)$, tempo de saturação na câmara $\left(\mathrm{T}_{\mathrm{SAT}}\right)$ e taxa de recirculação da água saturada com ar $(\mathrm{R})$ - foram os mesmos aplicados na realização da ETAPA - I. A pré-cloração, mistura rápida e adsorção em CAP foram realizadas no jarteste e posteriormente as amostras foram transferidas para o flotateste para assim prosseguir com a floculação e flotação por ar dissolvido. Finalmente, as amostras flotadas foram centrifugadas para simulação da etapa de clarificação final (em substituição da etapa de filtração em sistemas reais), e assim foram realizadas as caracterizações programadas. 


\subsubsection{Preparo das Águas de Estudo - ETAPA - II}

A água utilizada para a realização dos ensaios da ETAPA - II foi coletada no dia 01/11/2007. Da mesma forma, foram preparadas três águas de estudo com diferentes concentrações de microcistina com a mesma finalidade de avaliar a interferência dessas concentrações na remoção da cianotoxina.

Para o preparo das águas, seguiu-se o mesmo procedimento adotado anteriormente (item 4.4.2.1), ou seja, foram adicionadas porções da cultura de algas e do extrato a fim de se obter diferentes concentrações de microcistina. Procedeu-se da mesma forma para preparar o extrato de microcistina a partir da cultura de algas

- $\quad$ ÁGUA DE ESTUDO 1: foram preparados 76,5 litros da água de estudo 1, com a adição de 6,5 litros da cultura de algas em 70 litros de água de Barra Bonita. Tendo como resultado a concentração de microcistina da água de estudo 1 igual a 5,58 $\mu \mathrm{g} / \mathrm{L}$.

- $\quad$ ÁGUA DE ESTUDO 2: foram preparados 76,5 litros da água de estudo 2. Para esta água foi preparada uma mistura com a cultura de algas e o extrato, na proporção de 6,5 litros de cultura em 2 litros de extrato. Destes 8,5 litros resultantes, 6,5 litros foram adicionados em 70 litros de água de Barra Bonita. A concentração de microcistina resultante da água de estudo 2 foi $21,40 \mu \mathrm{g} / \mathrm{L}$.

- $\quad$ ÁGUA DE ESTUDO 3: foram preparados 76,5 litros de água de estudo 3. Da mesma forma, foi preparada a mistura entre a cultura de algas e o extrato de microcistina, entretanto foram adicionados 6,5 litros da cultura de algas em 16 litros de extrato. Destes 22,5 litros, um volume de 6,5 litros foi adicionado em 70 litros de água de Barra Bonita. A concentração de microcistina resultante da água de estudo 3 foi 86,90 $\mu \mathrm{g} / \mathrm{L}$. 
As três águas preparadas foram caracterizadas pelos seguintes parâmetros: temperatura, pH, turbidez, cor aparente, absorbância 254 nm, alcalinidade, SST, DQO, nitrogênio total, COT, microcistina e clorofila- $a$. A Tabela 4 apresenta os resultados desta caracterização.

Tabela 4.5:Caracterização das Águas de Estudo - ETAPA - II.

\begin{tabular}{|c|c|c|c|}
\hline Parâmetros & $\begin{array}{c}\text { Água de Estudo } \\
1\end{array}$ & $\begin{array}{c}\text { Água de Estudo } \\
2\end{array}$ & $\begin{array}{c}\text { Água de Estudo } \\
3\end{array}$ \\
\hline Temperatura $\left({ }^{\circ} \mathrm{C}\right)$ & 23 & 22 & 22,5 \\
\hline $\mathrm{pH}$ & 7,26 & 7,15 & 7,02 \\
\hline Cor aparente (uC) & 502 & 430 & 301 \\
\hline Turbidez (uT) & 52,8 & 42,8 & 25,3 \\
\hline Absorbância 254 nm & 0,290 & 0,278 & 0,268 \\
\hline Alcalinidade $\left(\mathrm{mg} \mathrm{CaCO}_{3} / \mathrm{L}\right)$ & 48 & 41 & 40 \\
\hline $\mathrm{SST}(\mathrm{mg} / \mathrm{L})$ & 37 & 27 & 9 \\
\hline Nitrogênio Total (mg/L) & 7,35 & 7,40 & 7,57 \\
\hline $\mathrm{DQO}\left(\mathrm{mgO}_{2} / \mathrm{L}\right)$ & 65 & 50 & 36 \\
\hline $\mathrm{COT}(\mathrm{mgC} / \mathrm{L})$ & 7,96 & 8,76 & 10,15 \\
\hline Microcistina $(\mu \mathrm{g} / \mathrm{L})$ & 5,58 & 21,40 & 86,94 \\
\hline Clorofila-a $(\mu \mathrm{g} / \mathrm{L})$ & 345,96 & 323,64 & 133,92 \\
\hline
\end{tabular}




\subsubsection{Estimativa da Dosagem de Carvão Ativado em Pó}

Segundo Di Bernardo \& Dantas (2005), assumindo-se que o equilíbrio do carvão ativado em pó com a substância orgânica que se pretende remover ocorra com um tempo de contato mínimo - variando entre 10 minutos até duas horas - a estimativa da dosagem mínima de carvão ativado necessária para a adsorção de uma substância qualquer é dada por:

$$
D_{\text {CAPmín }}=\frac{C_{0}-C_{e}}{q_{e, \text { máx }}}
$$

em que:

$D_{\text {CAPmín }}(\mathrm{mg} / \mathrm{L})=$ dosagem mínima de CAP;

$C_{0}$ e $C_{e}(\mu \mathrm{g} / \mathrm{L})=$ concentrações de microcistina no afluente e no efluente, respectivamente;

$q_{e, \text { máx }}(\mu \mathrm{g} / \mathrm{g})=$ capacidade máxima de adsorção.

Para a estimativa da dosagem mínima de CAP que foi aplicada em cada água de estudo assumiu-se que: 1) os valores adotados para $C_{0}$ seriam as concentrações de microcistina caracterizadas para as águas de estudo da ETAPA - I, ou seja, Água de Estudo 1 $=6,76 \mu \mathrm{g} / \mathrm{L}$, Água de Estudo $2=25,84 \mu \mathrm{g} / \mathrm{L}$ e Água de Estudo $3=104,92 \mu \mathrm{g} / \mathrm{L} ; 2$ ). Para a determinação de $q_{e, \text { máx }}$, a concentração de microcistina no equilíbrio seria igual a $1 \mu \mathrm{g} / \mathrm{L}$.

Como o carvão selecionado foi o CAP - 4, utilizou-se a isoterma de Freundlich, definida para este carvão após os ensaios de adsorção de microcistina, definida pela expressão: 
$q_{e}=1075,47 * C_{e}^{0,4712}$

equação (6)

Sendo:

$q_{e}(\mu \mathrm{g} / \mathrm{g})=$ massa de microcistina adsorvida por massa de carvão ativado;

$C_{e}(\mu \mathrm{g} / \mathrm{L})=$ concentração de microcistina no final do tratamento.

A Tabela 4.6 apresenta as dosagens definidas para a realização da ETAPA - II.

Tabela 4.6: Dosagens de CAP.

\begin{tabular}{ccccc}
\hline \hline $\begin{array}{c}\text { Águas de } \\
\text { Estudo }\end{array}$ & $* \mathrm{Co}(\mu \mathrm{g} / \mathrm{L})$ & $* * \mathrm{Ce}(\mu \mathrm{g} / \mathrm{L})$ & $\begin{array}{c}\text { DCAP }(\mathrm{mg} / \mathrm{L}) \\
\text { calculado }\end{array}$ & $\begin{array}{c}\text { DCAP }(\mathrm{mg} / \mathrm{L}) \\
\text { adotado }\end{array}$ \\
\hline \hline $\begin{array}{c}\text { Água de Estudo } \\
1\end{array}$ & 6,76 & 1,00 & 5,36 & 5 \\
$\begin{array}{c}\text { Água de Estudo } \\
2\end{array}$ & 25,84 & 1,00 & 23,09 & 25 \\
$\begin{array}{c}\text { Água de Estudo } \\
3\end{array}$ & 104,92 & 1,00 & 96,62 & 100 \\
\hline
\end{tabular}

* Valores adotados a partir da ETAPA - I.

** Valor máximo estabelecido pela Portaria 518 / 04 do Ministério da Saúde $(1 \mu \mathrm{g} / \mathrm{L})$.

\subsubsection{FASE - A}

Nesta fase foi definida a dosagem ótima de cloreto férrico que foi aplicada em cada água preparada na FASE - B desta ETAPA - II. Procedeu-se desta forma por ter sido realizada nova coleta de água em Barra Bonita. Entretanto, para esta escolha de dosagem foi ensaiado o fluxograma completo de tratamento, escolhido entre os dois avaliados na etapa anterior, sendo que, foi aplicada a maior dosagem de hipoclorito de sódio $(6,0 \mathrm{mg} / \mathrm{L})$ e a dosagem de carvão definida para cada água. O que justificou a tomada desta decisão foi a alteração do pH de coagulação devido à aplicação do oxidante observada na ETAPA - I, visto 
a piora da qualidade da água tratada, em termos de cor aparente e turbidez, com a alteração do pH de coagulação.

Assim, as dosagens de cloreto férrico avaliadas para as Águas de Estudo 1 e 2 foram: 10,$33 ; 12,40 ; 14,47 ; 16,54 ; 18,61 ; 20,68 ; 22,75$ e $24,82 \mathrm{mgFe}^{3+} / \mathrm{L}$. E para a Água de Estudo 3 : 20,$68 ; 22,75 ; 24,82 ; 26,89 ; 28,96 ; 31,03 ; 33,10$ e $35,17 \mathrm{mgFe}^{3+} / \mathrm{L}$.

Os parâmetros de mistura rápida, floculação, flotação por ar dissolvido e centrifugação foram mantidos iguais aos definidos anteriormente, sendo que as amostras foram coletadas na velocidade de flotação $\mathrm{V}_{2}=12 \mathrm{~cm} / \mathrm{min}($ ou $7,2 \mathrm{~m} / \mathrm{h}$ ).

Os ensaios foram monitorados com leituras do $\mathrm{pH}$ de coagulação, cor aparente e turbidez das amostras de água flotada e centrifugada, sendo que, os critérios para a escolha da dosagem ótima de coagulante foram os limites de cor aparente e turbidez, iguais a $15 \mathrm{uC}$ e 1 uT respectivamente, estabelecidos pela Portaria 518 do Ministério da Saúde .

A Figura 4.20 apresenta o fluxograma aplicado para a escolha da dosagem de coagulante com todos os parâmetros fixados para a realização destes ensaios. 


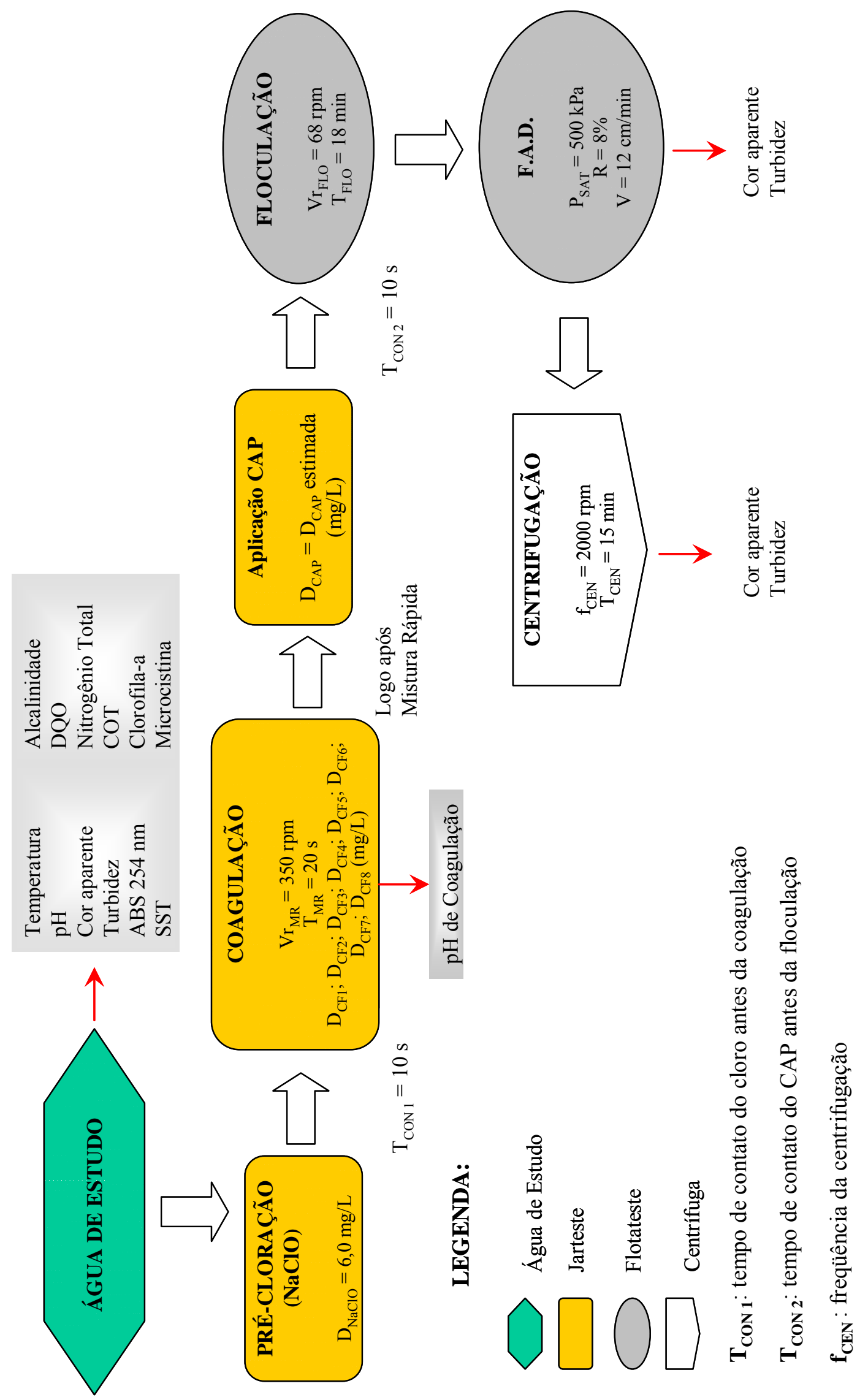

Figura 4.20: Fluxograma dos ensaios da FASE - A da ETAPA - II. 


\subsubsection{FASE - B}

Nesta fase foi repetido o fluxograma de tratamento, entre os que foram avaliados na ETAPA - I, que apresentou os melhores resultados em termos de cor aparente, turbidez e residual de microcistina na água tratada.

As três águas preparadas foram submetidas ao tratamento composto por pré-cloração, mistura rápida, adsorção em CAP, floculação, flotação por ar dissolvido e centrifugação. Foram avaliadas duas dosagens de oxidante $(3,0$ e 6,0 mg/L) combinadas com a aplicação da dosagem mínima estimada de CAP para que o residual de microcistina fosse igual a $1 \mu \mathrm{g} / \mathrm{L}$.

As dosagens de carvão estimadas estão apresentadas na Tabela 4.6 do item 4.4.3.2. Para a mistura rápida foram definidas como dosagens ótimas de cloreto férrico: Água de Estudo $1-14,47 \mathrm{mgFe}^{3+} / \mathrm{L}$, Água de Estudo $2-20,68 \mathrm{mgFe}^{3+} / \mathrm{L}$ e Água de Estudo $3-24,82$ $\mathrm{mgFe}^{3+} / \mathrm{L}$

Para avaliação do tratamento de cada água, as amostras flotadas foram coletadas com a velocidade de flotação igual a $\mathrm{V}=12 \mathrm{~cm} / \mathrm{min}$ e analisadas segundo os parâmetros de cor aparente, turbidez, absorbância em 254 nm, COT e concentração de microcistina. Após a centrifugação as amostras foram caracterizadas por cor aparente, turbidez, absorbância em 254 nm, DQO, nitrogênio total, cloro residual, COT, clorofila- $a$, trialometanos e concentração de microcistina.

A Figura 4.21 apresenta os detalhes referentes aos parâmetros fixados para o tratamento composto, incluindo as análises realizadas em cada etapa e os equipamentos utilizados em cada fase do tratamento. 

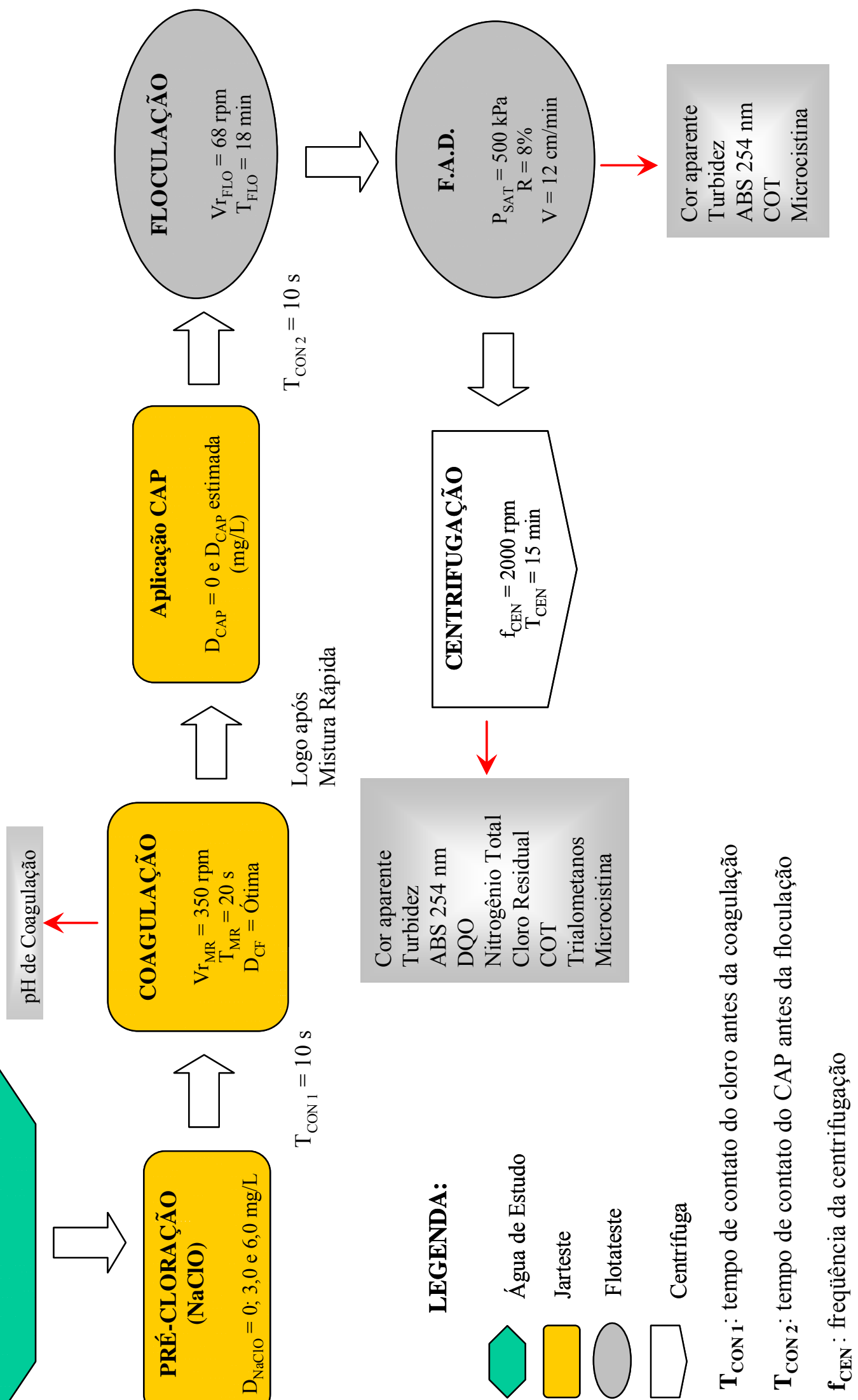

Figura 4.21: Fluxograma dos ensaios da FASE - B da ETAPA - II. 


\section{RESULTADOS E DISCUSSÃO}

Neste capítulo são apresentados os resultados obtidos nas diferentes etapas da pesquisa. Com o intuito de facilitar a compreensão e esclarecer os objetivos que norteiam cada etapa cumprida neste trabalho, os resultados são apresentados em forma de tabelas e gráficos seguidos de discussão e análise dos mesmos.

\subsection{ESCOLHA DO CARVÃO ATIVADO EM PÓ (CAP)}

Os carvões ativados em pó avaliados nesta pesquisa foram produzidos a partir de diferentes matérias-primas e aplicados no tratamento de água para abastecimento. Foram realizados ensaios de adsorção de iodo, azul de metileno e microcistina para avaliar e selecionar o carvão que foi empregado nos ensaios de tratabilidade. O número de iodo (NI) e o índice de azul de metileno (IAM) foram definidos a partir da elaboração das isotermas de Freundlich. Seguiram-se os procedimentos estabelecidos pela norma japonesa JIS 1474 / 91 para a realização dos ensaios de adsorção. 


\subsubsection{Adsorção de Iodo}

A concentração residual de iodo foi determinada por titulação volumétrica com tiossulfato de sódio e solução indicadora de amido. Os ensaios foram realizados até o momento em que a concentração residual de iodo se apresentasse abaixo de $2,5 \mathrm{~g} / \mathrm{L}$, isto explica a diferença do número de massas pesadas para cada carvão. Entretanto, as isotermas apresentam no mínimo quatro pontos conforme orientação da norma.

Apresentam-se as Tabelas 5.1, 5.2, 5.3, 5.4 e 5.5 que contém os dados necessários para a elaboração das isotermas de Freundlich e Langmuir. Após cada tabela seguem as isotermas de adsorção, de ambos os modelos, definidas para cada CAP ensaiado.

Tabela 5.1: Adsorção de Iodo - CAP 1 (osso).

Condições do ensaio: Tempo - 15 min; Agitação - 30 rpm; Temperatura $-20{ }^{\circ} \mathrm{C}$.

\begin{tabular}{ccccc}
\hline \hline & $\begin{array}{c}\text { Massa CAP } \\
(\mathrm{g})\end{array}$ & $\begin{array}{c}\mathrm{Ce} \\
(\mathrm{g} / \mathrm{L})\end{array}$ & $\begin{array}{c}\mathrm{qe}=\mathrm{X} / \mathrm{m} \\
(\mathrm{mg} / \mathrm{g})\end{array}$ & $\mathrm{Ce} /(\mathrm{X} / \mathrm{m})$ \\
\hline \hline Co & - & 12,09 & - & - \\
M1 & 0,80050 & 9,40 & 167,83 & 0,05604 \\
M2 & 1,00075 & 9,04 & 152,56 & 0,05924 \\
M3 & 2,00053 & 7,08 & 125,16 & 0,05660 \\
M4 & 3,00077 & 5,37 & 111,93 & 0,04801 \\
M5 & 4,00037 & 3,79 & 103,81 & 0,03647 \\
M6 & 5,00015 & 2,69 & 94,04 & 0,02857 \\
M7 & 6,00082 & 1,83 & 85,48 & 0,02143 \\
\hline
\end{tabular}


CAP - 1

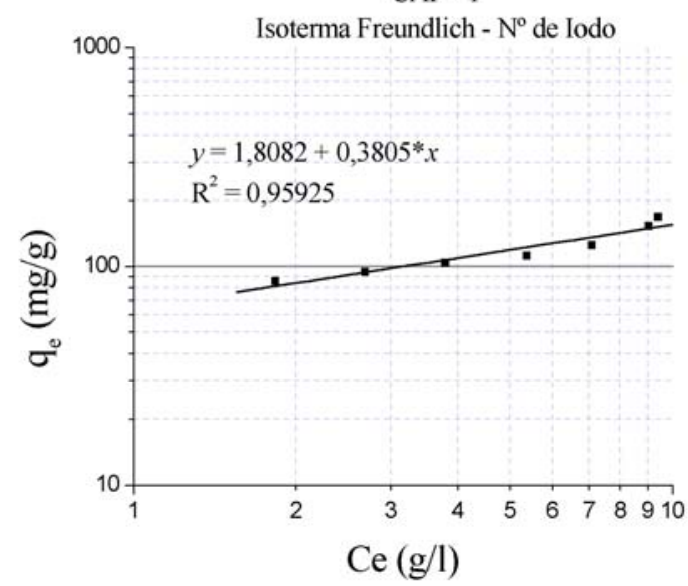

CAP - 1

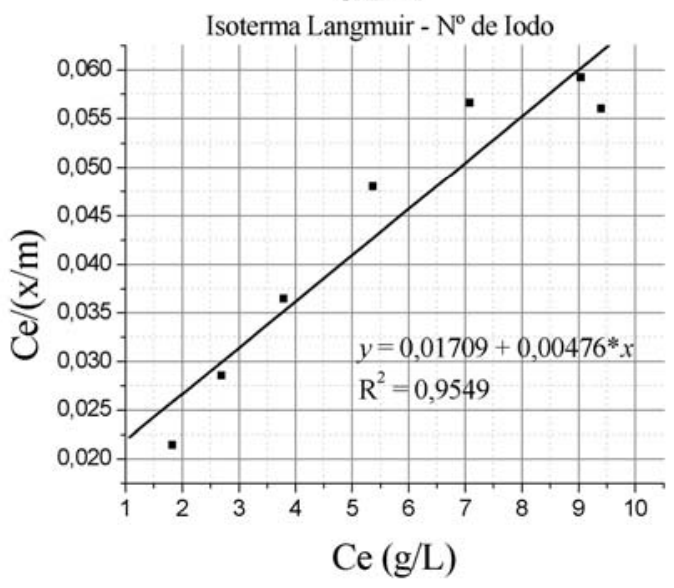

Figura 5.1: Isoterma de Freundlich (NI) - CAP 1. Figura 5.2: Isoterma de Langmuir (NI) - CAP 1.

Tabela 5.2: Adsorção de Iodo - CAP 2 (madeira).

Condições do ensaio: Tempo - 15 min; Agitação - $30 \mathrm{rpm}$; Temperatura $-20^{\circ} \mathrm{C}$.

\begin{tabular}{ccccc}
\hline \hline & $\begin{array}{c}\text { Massa CAP } \\
(\mathrm{g})\end{array}$ & $\begin{array}{c}\mathrm{Ce} \\
(\mathrm{g} / \mathrm{L})\end{array}$ & $\begin{array}{c}\mathrm{qe}=\mathrm{X} / \mathrm{m} \\
(\mathrm{mg} / \mathrm{g})\end{array}$ & $\mathrm{Ce} /(\mathrm{X} / \mathrm{m})$ \\
\hline \hline Co & - & 11,97 & - & - \\
M1 & 0,10050 & 9,89 & 1032,99 & 0,00958 \\
M2 & 0,20065 & 8,55 & 852,18 & 0,01003 \\
M3 & 0,30025 & 7,21 & 793,22 & 0,00908 \\
M4 & 0,40029 & 5,98 & 747,54 & 0,00801 \\
M5 & 0,50053 & 4,76 & 719,84 & 0,00662 \\
M6 & 0,60039 & 3,66 & 691,65 & 0,00530 \\
M7 & 0,70073 & 2,69 & 662,33 & 0,00406 \\
M8 & 0,80087 & 1,83 & 632,89 & 0,00289 \\
M9 & 0,90078 & 1,22 & 596,59 & 0,00205 \\
\hline
\end{tabular}

CAP - 2

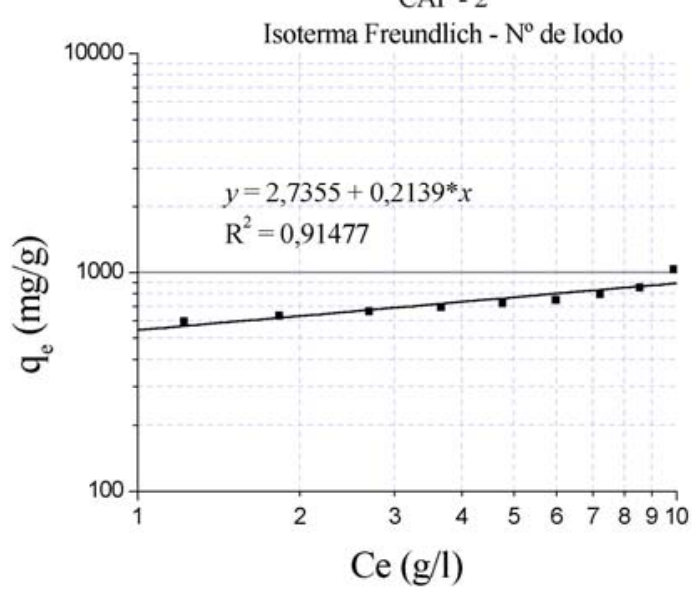

CAP - 2

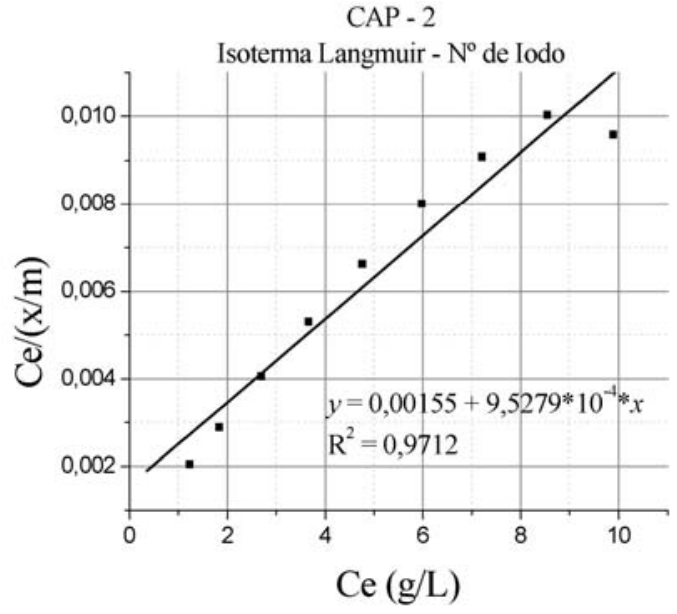

Figura 5.3: Isoterma de Freundlich (NI) - CAP 2. Figura 5.4: Isoterma de Langmuir (NI) - CAP 2. 
Tabela 5.3: Adsorção de Iodo - CAP 3 (madeira).

Condições do ensaio: Tempo - $15 \mathrm{~min}$; Agitação - $30 \mathrm{rpm}$; Temperatura $-20^{\circ} \mathrm{C}$.

\begin{tabular}{ccccc}
\hline \hline & $\begin{array}{c}\text { Massa CAP } \\
(\mathrm{g})\end{array}$ & $\begin{array}{c}\mathrm{Ce} \\
(\mathrm{g} / \mathrm{L})\end{array}$ & $\begin{array}{c}\mathrm{qe}=\mathrm{X} / \mathrm{m} \\
(\mathrm{mg} / \mathrm{g})\end{array}$ & $\mathrm{Ce} /(\mathrm{X} / \mathrm{m})$ \\
\hline \hline $\mathrm{C}_{0}$ & - & 11,85 & - & - \\
$\mathrm{M}_{1}$ & 0,40092 & 4,27 & 944,38 & 0,00453 \\
$\mathrm{M}_{2}$ & 0,50057 & 3,05 & 878,38 & 0,00348 \\
$\mathrm{M} 3$ & 0,60106 & 2,08 & 812,80 & 0,00255 \\
$\mathrm{M} 4$ & 0,70066 & 1,22 & 758,27 & 0,00161 \\
\hline
\end{tabular}

CAP - 3

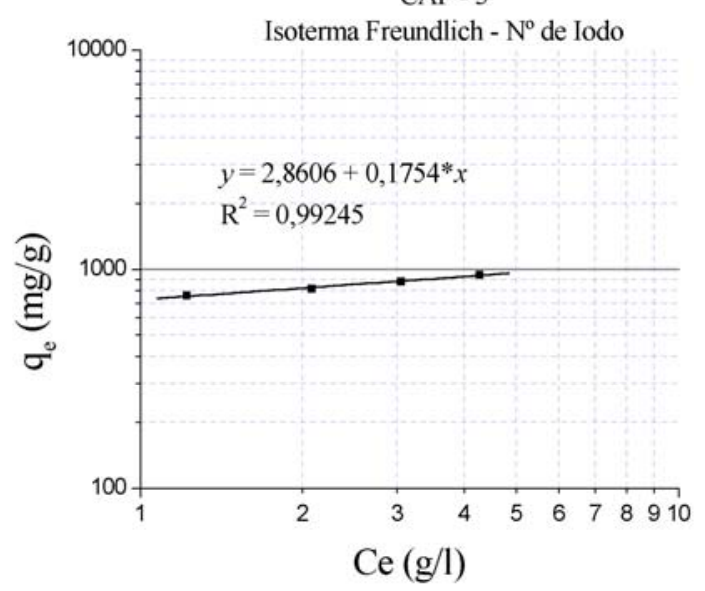

CAP - 3

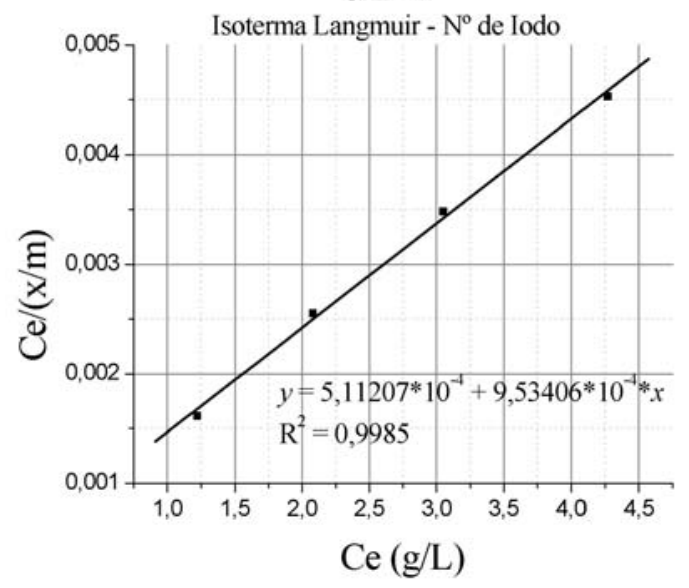

Figura 5.5: Isoterma de Freundlich (NI) - CAP 3. Figura 5.6: Isoterma de Langmuir (NI) - CAP 3.

Tabela 5.4: Adsorção de Iodo - CAP 4 (casca de coco).

Condições do ensaio: Tempo - 15 min; Agitação - $30 \mathrm{rpm}$; Temperatura $-20^{\circ} \mathrm{C}$.

\begin{tabular}{ccccc}
\hline \hline & $\begin{array}{c}\text { Massa CAP } \\
(\mathrm{g})\end{array}$ & $\begin{array}{c}\mathrm{Ce} \\
(\mathrm{g} / \mathrm{L})\end{array}$ & $\begin{array}{c}\mathrm{qe}=\mathrm{X} / \mathrm{m} \\
(\mathrm{mg} / \mathrm{g})\end{array}$ & $\mathrm{Ce} /(\mathrm{X} / \mathrm{m})$ \\
\hline \hline $\mathrm{C}_{0}$ & - & 11,60 & - & - \\
$\mathrm{M}_{1}$ & 0,30139 & 6,11 & 911,79 & 0,00670 \\
$\mathrm{M}_{2}$ & 0,40105 & 4,40 & 898,39 & 0,00489 \\
$\mathrm{M}_{3}$ & 0,50173 & 3,05 & 852,00 & 0,00358 \\
$\mathrm{M}_{4}$ & 0,60145 & 1,95 & 802,12 & 0,00244 \\
\hline
\end{tabular}



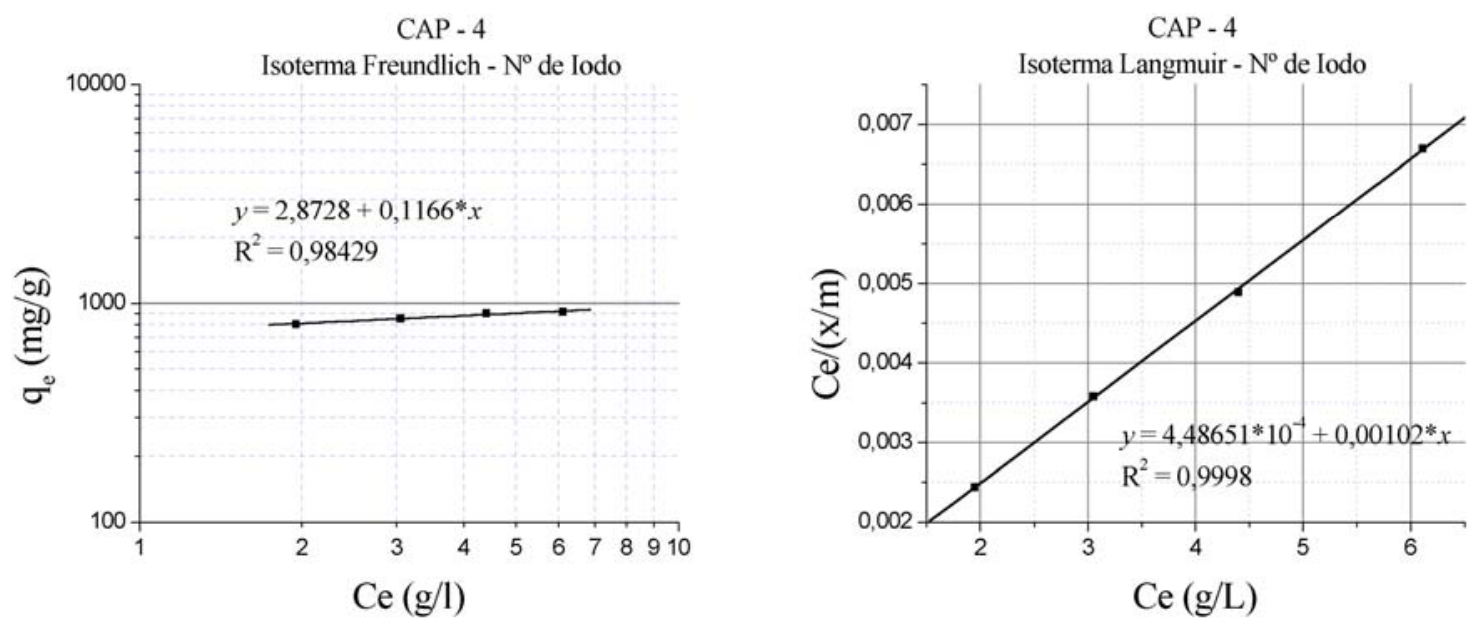

Figura 5.7: Isoterma de Freundlich (NI) - CAP 4. Figura 5.8: Isoterma de Langmuir (NI) - CAP 4.

Tabela 5.5: Adsorção de Iodo - CAP 5 (madeira).

Condições do ensaio: Tempo - 15 min; Agitação - $30 \mathrm{rpm}$; Temperatura $-20^{\circ} \mathrm{C}$.

\begin{tabular}{ccccc}
\hline \hline & $\begin{array}{c}\text { Massa CAP } \\
(\mathrm{g})\end{array}$ & $\begin{array}{c}\mathrm{Ce} \\
(\mathrm{g} / \mathrm{L})\end{array}$ & $\begin{array}{c}\mathrm{qe}=\mathrm{X} / \mathrm{m} \\
(\mathrm{mg} / \mathrm{g})\end{array}$ & $\mathrm{Ce} /(\mathrm{X} / \mathrm{m})$ \\
\hline \hline $\mathrm{C}_{0}$ & - & 11,85 & - & - \\
$\mathrm{M} 1$ & 0,30123 & 5,74 & 1013,64 & 0,00566 \\
$\mathrm{M}_{2}$ & 0,40068 & 4,27 & 944,95 & 0,00452 \\
$\mathrm{M} 3$ & 0,50173 & 2,81 & 900,69 & 0,00312 \\
$\mathrm{M} 4$ & 0,60046 & 1,71 & 844,13 & 0,00203 \\
\hline
\end{tabular}
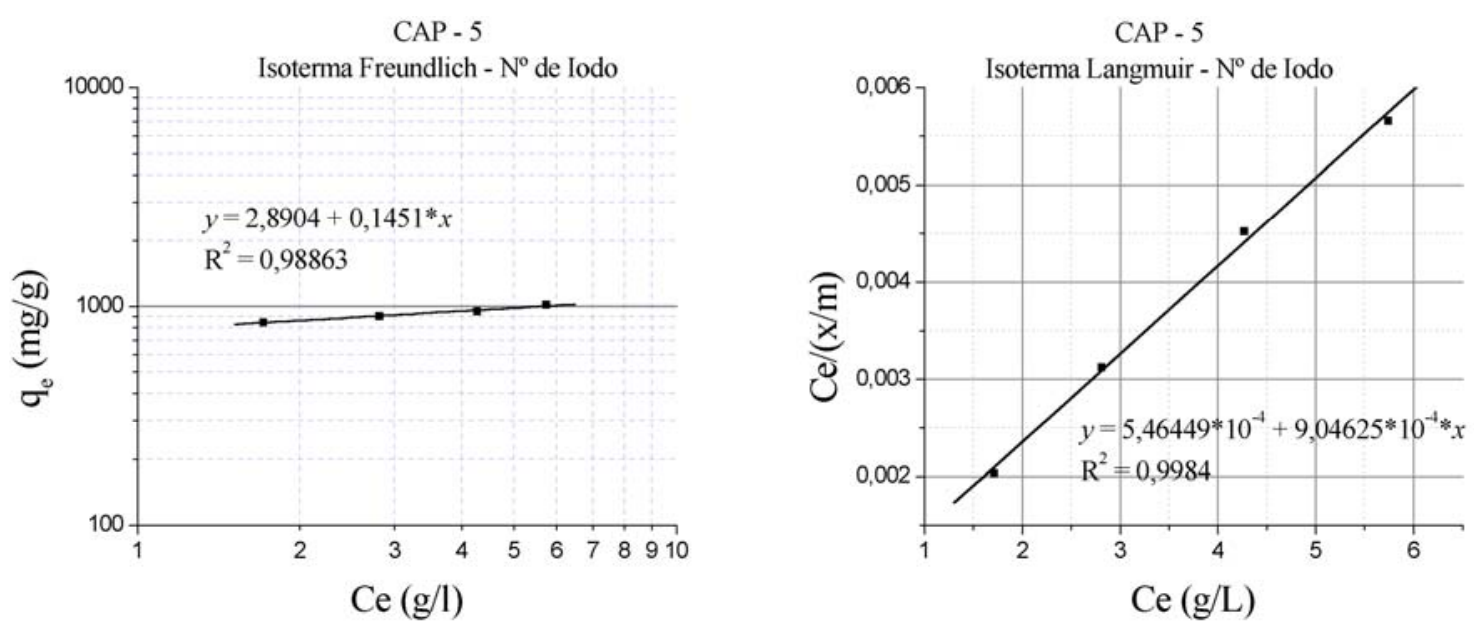

Figura 5.9: Isoterma de Freundlich (NI) - CAP 5. Figura 5.10: Isoterma de Langmuir (NI) - CAP 5. 
Primeiramente, com os dados das Figuras 5.1, 5.3, 5.5, 5.7 e 5.9 foi possível determinar a equação de Freundlich - definida por $q_{e}=K^{*} C_{e}^{\frac{1}{n}}-$ e conseqüentemente o número de iodo para cada CAP avaliado. Tais equações são apresentadas na Tabela 5.6.

Tabela 5.6: Parâmetros da Equação de Freundlich e Número de Iodo (NI).

\begin{tabular}{ccccccc}
\hline \hline \multicolumn{7}{c}{ Equação de Freundlich } \\
\hline \hline Carvão & $\begin{array}{c}\text { Matéria- } \\
\text { prima }\end{array}$ & $1 / \mathrm{n}$ & $\mathrm{n}$ & $\mathrm{k}$ & Eq. Freundlich & $\begin{array}{c}\mathrm{N}^{\mathrm{o}} \mathrm{de} \text { Iodo } \\
(\mathrm{mg} / \mathrm{g})\end{array}$ \\
\hline \hline CAP - 1 & osso & 0,3805 & 2,628 & 64,30 & $q_{e}=64,30 \times C e^{0,3805}$ & 91,12 \\
CAP - 2 & madeira & 0,2139 & 4,675 & 543,88 & $q_{e}=543,88 \times C e^{0,2139}$ & 661,64 \\
CAP - 3 & madeira & 0,1754 & 5,701 & 725,44 & $q_{e}=725,44 \times C e^{0,1754}$ & 851,92 \\
CAP - 4 & coco & 0,1166 & 8,576 & 746,11 & $q_{e}=746,11 \times C e^{0,1166}$ & 830,24 \\
CAP - 5 & madeira & 0,1451 & 6,892 & 776,96 & $q_{e}=776,96 \times C e^{0,1451}$ & 887,44 \\
\hline
\end{tabular}

Os resultados da Tabela 5.6 mostram que os carvões de origem vegetal apresentam maiores números de iodo quando comparados ao carvão de osso. Esta característica de baixo NI (igual a $91,12 \mathrm{mg} / \mathrm{g}$ ) também foi verificada por Silva et al. (2007), que avaliaram diferentes CAP e determinaram valor semelhante de NI para o carvão de osso igual a $93 \pm 13$ mg/g. Kuroda et al. (2005) constataram valores ainda menores para carvões ativados granulares e pulverizados iguais a $21,00 \pm 0,29 \mathrm{mg} / \mathrm{g}$ e $12,10 \pm 0,06 \mathrm{mg} / \mathrm{g}$, respectivamente.

Observa-se que os carvões CAP - 2 e CAP - 3, que são produzidos pelo mesmo fabricante e mesma matéria-prima, apresentaram NI significativamente diferentes, 661,64 e $851,92 \mathrm{mg} / \mathrm{g}$, respectivamente, provavelmente devido à diferenças nos processos de ativação dos mesmos.

O CAP - 4 (coco) apresentou o valor de NI igual a $830,24 \mathrm{mg} / \mathrm{g}$ superior ao encontrado por Silva et al. (2007) igual a $748 \pm 14 \mathrm{mg} / \mathrm{g}$ e também superior aos encontrados por Kuroda et al. (2005) igual a 770,09 $\pm 3,22 \mathrm{mg} / \mathrm{g}$ para carvões produzidos a partir de coco. 
Com relação à isoterma de Langmuir, definida por $\frac{x}{m}=\frac{a * b * C_{e}}{1+b * C_{e}}$, é importante a avaliação do parâmetro $a$ que se refere à massa de adsorvato necessária para saturar uma unidade de massa de carvão, e o parâmetro $b$ que está relacionado à energia de ligação do adsorvato com o carvão. Com os dados das Figuras 5.2, 5.4, 5.6, 5.8 e 5.10 foi possível determinar as equações de Langmuir apresentadas na Tabela 5.7.

Tabela 5.7: Parâmetros da Equação de Langmuir para adsorção de iodo.

\begin{tabular}{ccccc}
\hline \hline & \multicolumn{3}{c}{ Equação de Langmuir } \\
\hline \hline Carvão & $\begin{array}{c}\text { Matéria- } \\
\text { prima }\end{array}$ & $\begin{array}{c}\mathrm{a} \\
(\mathrm{mg} / \mathrm{g})\end{array}$ & $\mathrm{b}$ & Eq. Langmuir \\
\hline \hline CAP - 1 & osso & 210,08 & 0,279 & $X / m=(58,51 \times \mathrm{Ce}) /(1+0,279 \times \mathrm{Ce})$ \\
CAP - 2 & madeira & 1049,55 & 0,615 & $X / m=(645,16 \times \mathrm{Ce}) /(1+0,615 \times \mathrm{Ce})$ \\
CAP - 3 & madeira & 1048,87 & 1,865 & $X / m=(1956,15 \times \mathrm{Ce}) /(1+1,865 \times \mathrm{Ce})$ \\
CAP - 4 & coco & 980,39 & 2,273 & $X / m=(2228,90 \times \mathrm{Ce}) /(1+2,273 \times \mathrm{Ce})$ \\
CAP - 5 & madeira & 1105,43 & 1,655 & $X / m=(1829,99 \times \mathrm{Ce}) /(1+1,655 \times \mathrm{Ce})$ \\
\hline
\end{tabular}

Analisando os parâmetros $a$ da Tabela 5.7, fica claro que os carvões de origem vegetal apresentaram melhor desempenho na adsorção de iodo. O CAP - 1 foi o que apresentou menor capacidade de adsorção igual a 210,08 mg/g e menor energia de ligação determinada pelo parâmetro $b(0,279)$. È interessante o fato dos CAP - 2 e 3 ter praticamente o mesmo valor de $a$ igual a 1049,55 e $1048,87 \mathrm{mg} / \mathrm{g}$, respectivamente, entretanto vê-se a diferença na energia de ligação dos carvões, CAP - 2 igual a 0,615 e CAP - 3 igual 1,865, o que pode estar relacionado com a diferença da forma de ativação de cada carvão e, conseqüentemente, com o NI definido para os mesmos.

Já o CAP - 4 de coco mostrou a maior energia de ligação $(b=2,273)$ entre as amostras de carvão, a qual pode estar relacionada com a afinidade do carvão pelo adsorvato constatada pelo parâmetro $n$ da isoterma de Freundlich apresentada anteriormente $(n=8,576)$. 


\subsubsection{Adsorção de Azul de Metileno}

Este índice foi determinado pela isoterma de Freundlich, plotando-se em gráfico bilog, a concentração de equilíbrio (Ce) no eixo x em $\mathrm{mg} / \mathrm{L}$ versus a quantidade adsorvida por unidade de carvão $\left(\mathrm{q}_{\mathrm{e}}\right)$ no eixo y em $\mathrm{mg} / \mathrm{g}$. Os ensaios foram realizados até que a concentração residual das amostras estivesse inferior a $0,24 \mathrm{mg} / \mathrm{L}$.

A seguir, têm-se as Tabelas 5.8; 5.9; 5.10; 5.11 e 5.12 nas quais estão apresentados os resultados dos ensaios utilizados para a elaboração das isotermas de Freundlich e Langmuir.

Tabela 5.8: Adsorção de Azul de Metileno - CAP 1 (osso).

Condições do ensaio: Tempo - 30 min; Agitação - 30 rpm; Temperatura - $20{ }^{\circ} \mathrm{C}$.

\begin{tabular}{|c|c|c|c|c|c|c|c|c|c|}
\hline & $\begin{array}{l}\text { Massa } \\
\text { CAP (g) }\end{array}$ & $\begin{array}{c}\mathrm{Ce} \\
(\mathrm{mg} / \mathrm{L})\end{array}$ & $\begin{array}{c}\mathrm{q}_{\mathrm{e}}=\mathrm{X} / \mathrm{m} \\
(\mathrm{mg} / \mathrm{g})\end{array}$ & $\mathrm{Ce} /(\mathrm{X} / \mathrm{m})$ & & $\begin{array}{c}\text { Massa } \\
\text { CAP (g) }\end{array}$ & $\begin{array}{c}\mathrm{Ce} \\
(\mathrm{mg} / \mathrm{L})\end{array}$ & $\begin{array}{c}\mathrm{q}_{\mathrm{e}}=\mathrm{X} / \mathrm{m} \\
(\mathrm{mg} / \mathrm{g})\end{array}$ & $\mathrm{Ce} /(\mathrm{X} / \mathrm{m})$ \\
\hline $\mathrm{Co}_{0}$ & - & 1200,00 & - & - & M16 & 0,73064 & 0,97 & 41,03 & 0,02364 \\
\hline $\mathrm{M}_{1}$ & 0,50045 & 16,50 & 59,12 & 0,27908 & M17 & 0,74075 & 0,99 & 40,47 & 0,02446 \\
\hline $\mathrm{M}_{2}$ & 0,55055 & 6,80 & 54,18 & 0,12550 & $\mathrm{M}_{18}$ & 0,75066 & 0,96 & 39,93 & 0,02404 \\
\hline $\mathrm{M} 3$ & 0,60080 & 3,60 & 49,78 & 0,07231 & M19 & 0,76092 & 0,63 & 39,41 & 0,01599 \\
\hline $\mathrm{M}_{4}$ & 0,61050 & 3,70 & 48,99 & 0,07553 & $\mathrm{M}_{20}$ & 0,77085 & 0,53 & 38,90 & 0,01362 \\
\hline M5 & 0,62040 & 3,20 & 48,23 & 0,06635 & $\mathrm{M}_{21}$ & 0,78030 & 0,6 & 38,43 & 0,01561 \\
\hline M6 & 0,63087 & 2,04 & 47,47 & 0,04297 & $\mathrm{M}_{22}$ & 0,79082 & 0,52 & 37,92 & 0,01371 \\
\hline $\mathrm{M}_{7}$ & 0,64090 & 2,41 & 46,72 & 0,05159 & $\mathrm{M}_{23}$ & 0,80025 & 0,49 & 37,47 & 0,01308 \\
\hline $\mathrm{M}_{8}$ & 0,65048 & 2,25 & 46,03 & 0,04888 & $\mathrm{M}_{24}$ & 0,81023 & 0,55 & 37,01 & 0,01486 \\
\hline M9 & 0,66030 & 1,56 & 45,37 & 0,03438 & $\mathrm{M}_{25}$ & 0,82025 & 0,59 & 36,56 & 0,01614 \\
\hline $\mathrm{M}_{10}$ & 0,67065 & 1,37 & 44,68 & 0,03066 & $\mathrm{M}_{26}$ & 0,83033 & 0,56 & 36,11 & 0,01551 \\
\hline $\mathrm{M}_{11}$ & 0,68074 & 1,38 & 44,02 & 0,03135 & $\mathrm{M}_{27}$ & 0,84066 & 0,48 & 35,67 & 0,01346 \\
\hline $\mathrm{M}_{12}$ & 0,69078 & 1,21 & 43,39 & 0,02789 & $\mathrm{M}_{28}$ & 0,85017 & 0,5 & 35,27 & 0,01418 \\
\hline $\mathrm{M}_{13}$ & 0,70035 & 1,03 & 42,80 & 0,02407 & $\mathrm{M}_{29}$ & 0,86087 & 0,48 & 34,83 & 0,01378 \\
\hline $\mathrm{M}_{14}$ & 0,71090 & 1,04 & 42,16 & 0,02467 & $\mathrm{M}_{30}$ & 0,87027 & 0,55 & 34,46 & 0,01596 \\
\hline M15 & 0,72065 & 1,07 & 41,59 & 0,02573 & & & & & \\
\hline
\end{tabular}


CAP - 1

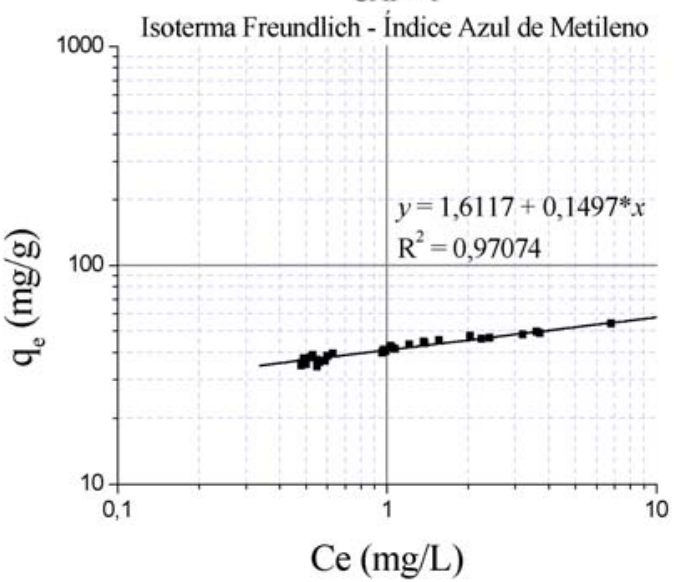

Figura 5.11: Isoterma de Freundlich (IAM) - CAP 1.
CAP - 1

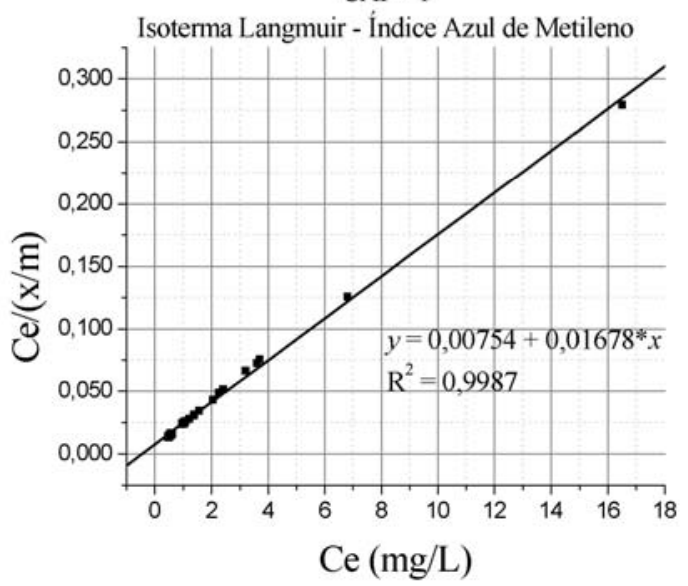

Figura 5.12: Isoterma de Langmuir (IAM) - CAP 1.

Tabela 5.9: Adsorção de Azul de Metileno - CAP 2 (madeira).

Condições do ensaio: Tempo - 30 min; Agitação - $30 \mathrm{rpm}$; Temperatura $-20{ }^{\circ} \mathrm{C}$.

\begin{tabular}{ccccc}
\hline \hline & $\begin{array}{c}\text { Massa CAP } \\
(\mathrm{g})\end{array}$ & $\begin{array}{c}\mathrm{Ce} \\
(\mathrm{mg} / \mathrm{L})\end{array}$ & $\begin{array}{c}\mathrm{qe}=\mathrm{X} / \mathrm{m} \\
(\mathrm{mg} / \mathrm{g})\end{array}$ & $\mathrm{Ce} /(\mathrm{X} / \mathrm{m})$ \\
\hline \hline Co & - & 1200,00 & - & - \\
M1 & 0,25057 & 2,08 & 119,52 & 0,01740 \\
M2 & 0,26025 & 0,91 & 115,19 & 0,00790 \\
M3 & 0,27022 & 0,69 & 110,96 & 0,00622 \\
M4 & 0,28088 & 0,47 & 106,77 & 0,00440 \\
M5 & 0,29033 & 0,31 & 103,30 & 0,00300 \\
M6 & 0,30015 & 0,30 & 99,93 & 0,00300 \\
M7 & 0,31075 & 0,22 & 96,52 & 0,00228 \\
M8 & 0,32045 & 0,23 & 93,60 & 0,00246 \\
M9 & 0,33057 & 0,19 & 90,74 & 0,00209 \\
\hline
\end{tabular}

CAP - 2

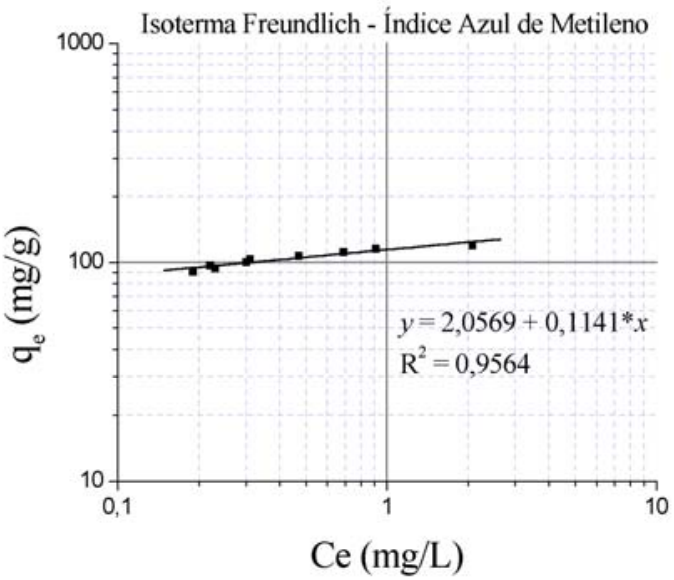

Figura 5.13: Isoterma de Freundlich (IAM) - CAP 2.
CAP - 2

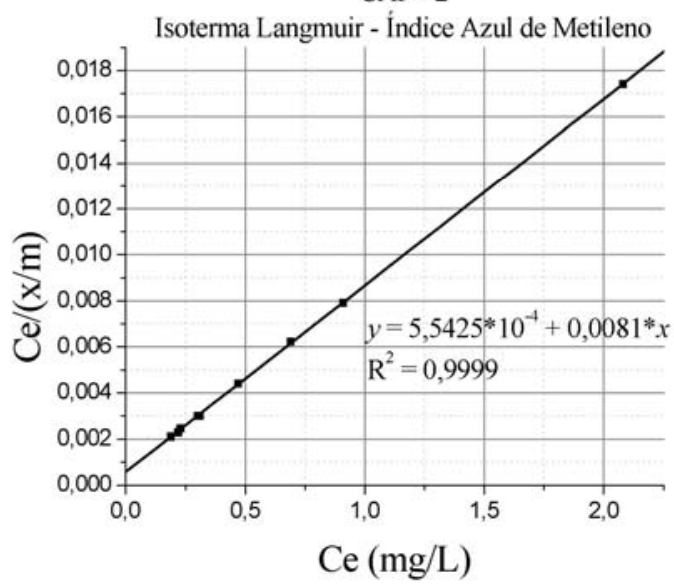

Figura 5.14: Isoterma de Langmuir (IAM) - CAP 2. 
Tabela 5.10: Adsorção de Azul de Metileno - CAP 3 (madeira).

Condições do ensaio: Tempo - $30 \mathrm{~min}$; Agitação - $30 \mathrm{rpm}$; Temperatura $-20^{\circ} \mathrm{C}$.

\begin{tabular}{ccccc}
\hline & $\begin{array}{c}\text { Massa CAP } \\
(\mathrm{g})\end{array}$ & $\begin{array}{c}\mathrm{Ce} \\
(\mathrm{mg} / \mathrm{L})\end{array}$ & $\begin{array}{c}\mathrm{qe}=\mathrm{X} / \mathrm{m} \\
(\mathrm{mg} / \mathrm{g})\end{array}$ & $\mathrm{Ce} /(\mathrm{X} / \mathrm{m})$ \\
\hline $\mathrm{C}_{0}$ & - & 1200,00 & - & - \\
M1 & 0,10076 & 6,60 & 296,10 & 0,02229 \\
M2 & 0,11050 & 1,19 & 271,22 & 0,00439 \\
M3 & 0,12045 & 0,31 & 249,00 & 0,00124 \\
M4 & 0,13071 & 0,31 & 229,46 & 0,00135 \\
M5 & 0,14042 & 0,16 & 213,62 & 0,00075 \\
M6 & 0,15049 & 0,14 & 199,33 & 0,00070 \\
\hline
\end{tabular}

CAP - 3

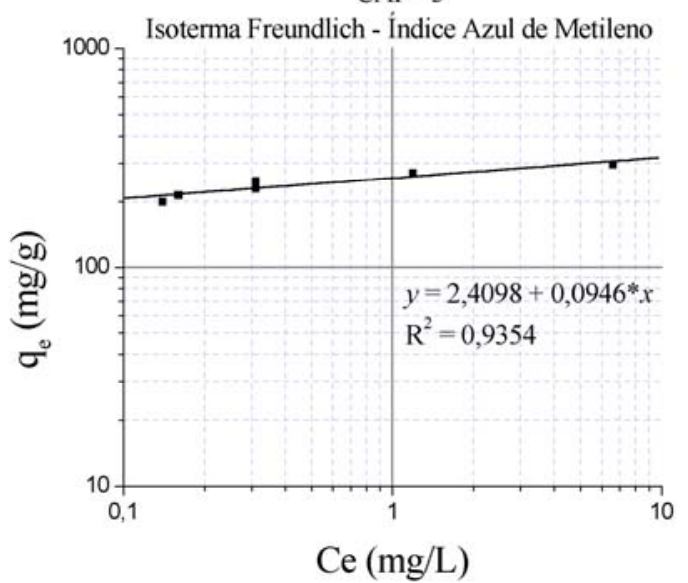

Figura 5.15: Isoterma de Freundlich (IAM) - CAP 3.
CAP -3

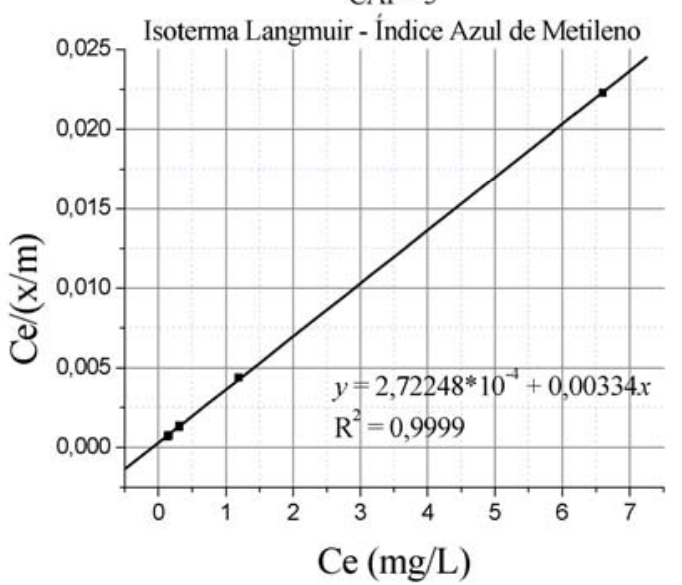

Figura 5.16: Isoterma de Langmuir(IAM) - CAP 3.

Tabela 5.11: Adsorção de Azul de Metileno - CAP 4 (casca de coco). Condições do ensaio: Tempo - $30 \mathrm{~min}$; Agitação $-30 \mathrm{rpm}$; Temperatura $-20^{\circ} \mathrm{C}$.

\begin{tabular}{ccccc}
\hline & $\begin{array}{c}\text { Massa CAP } \\
(\mathrm{g})\end{array}$ & $\begin{array}{c}\mathrm{Ce} \\
(\mathrm{mg} / \mathrm{L})\end{array}$ & $\begin{array}{c}\mathrm{qe}=\mathrm{X} / \mathrm{m} \\
(\mathrm{mg} / \mathrm{g})\end{array}$ & $\mathrm{Ce} /(\mathrm{X} / \mathrm{m})$ \\
\hline \hline Co & - & 1200,00 & - & - \\
M1 & 0,10038 & 2,90 & 298,14 & 0,00973 \\
M2 & 0,11072 & 0,59 & 270,82 & 0,00218 \\
M3 & 0,12087 & 0,18 & 248,16 & 0,00073 \\
M4 & 0,13045 & 0,30 & 229,92 & 0,00130 \\
M5 & 0,14048 & 0,16 & 213,53 & 0,00075 \\
M6 & 0,15046 & 0,13 & 199,37 & 0,00065 \\
\hline
\end{tabular}


CAP - 4

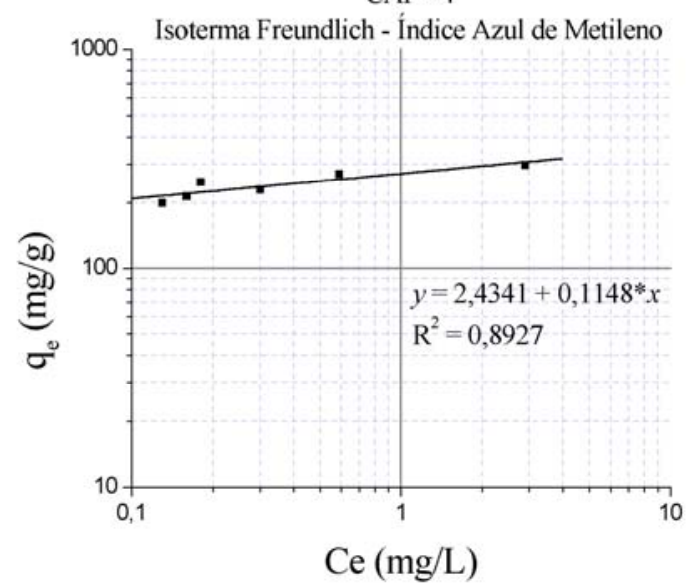

Figura 5.17: Isoterma de Freundlich (IAM) - CAP 4.

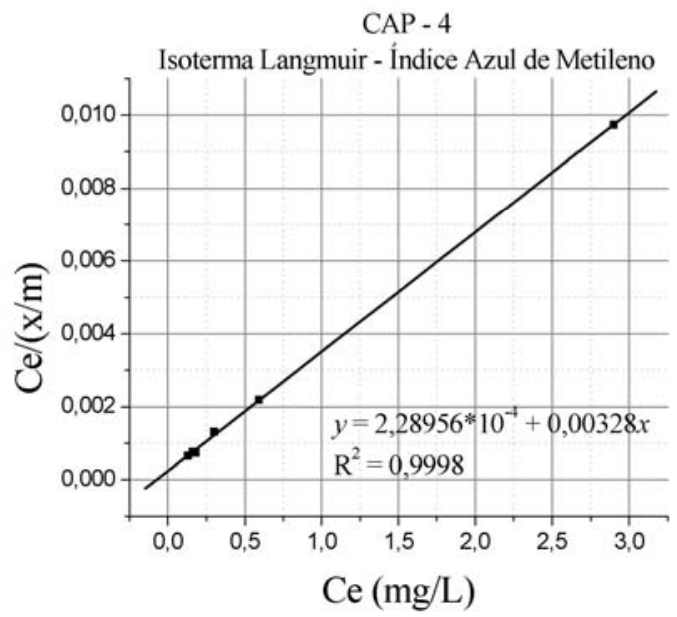

Figura 5.18: Isoterma de Langmuir (IAM) - CAP 4.

Tabela 5.12: Adsorção de Azul de Metileno - CAP 5 (madeira).

Condições do ensaio: Tempo - 30 min; Agitação - $30 \mathrm{rpm}$; Temperatura $-20^{\circ} \mathrm{C}$.

\begin{tabular}{ccccc}
\hline \hline & $\begin{array}{c}\text { Massa CAP } \\
(\mathrm{g})\end{array}$ & $\begin{array}{c}\mathrm{Ce} \\
(\mathrm{mg} / \mathrm{L})\end{array}$ & $\begin{array}{c}\mathrm{qe}=\mathrm{X} / \mathrm{m} \\
(\mathrm{mg} / \mathrm{g})\end{array}$ & $\mathrm{Ce} /(\mathrm{X} / \mathrm{m})$ \\
& & & & \\
\hline \hline Co & - & 1200,00 & - & - \\
M1 & 0,11066 & 13,70 & 268,01 & 0,05112 \\
M2 & 0,12080 & 4,40 & 247,43 & 0,01778 \\
M3 & 0,13020 & 1,48 & 230,13 & 0,00643 \\
M4 & 0,14045 & 0,88 & 213,44 & 0,00412 \\
M5 & 0,15077 & 0,36 & 198,92 & 0,00181 \\
M6 & 0,16045 & 0,28 & 186,93 & 0,00150 \\
M7 & 0,17018 & 0,15 & 176,26 & 0,00085 \\
M8 & 0,18037 & 0,13 & 166,31 & 0,00078 \\
\hline
\end{tabular}

CAP - 5

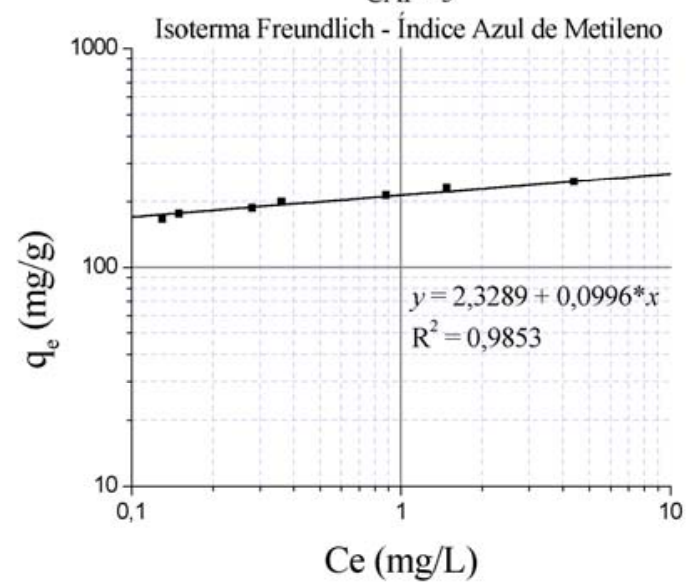

Figura 5.19: Isoterma de Freundlich (IAM) - CAP 5.
CAP - 5

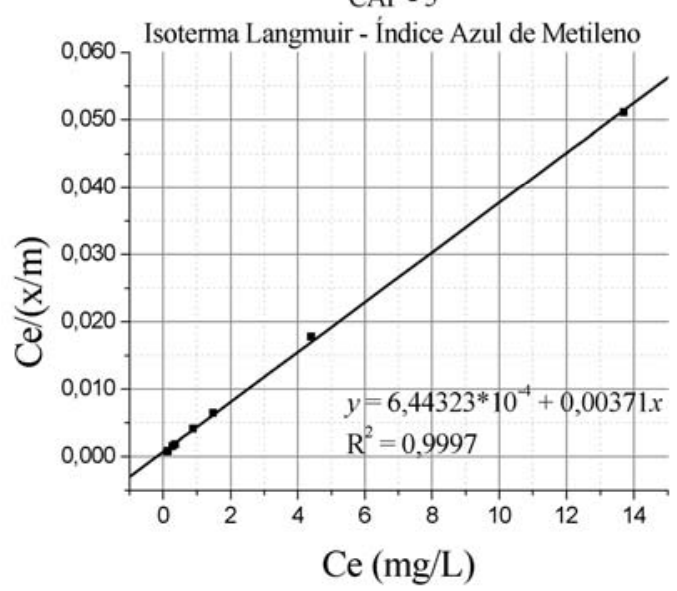

Figura 5.20: Isoterma de Langmuir (IAM) - CAP 5. 
Com os dados das Figuras $5.11 ; 5.13 ; 5.15 ; 5.17$ e 5.19 foi possível a determinar as equações de Freundlich e definir o índice de azul de metileno (IAM) para os cinco carvões ativados em pó estudados, como mostrado pela Tabela 5.13.

Tabela 5.13: Parâmetros da Equação de Freundlich e Índice de Azul de Metileno (IAM).

\begin{tabular}{ccccccc}
\hline \hline \multicolumn{7}{c}{ Equação Freundlich } \\
\hline \hline Carvão & $\begin{array}{c}\text { Matéria- } \\
\text { prima }\end{array}$ & $1 / \mathrm{n}$ & $\mathrm{n}$ & $\mathrm{k}$ & Eq. Freundlich & $\begin{array}{c}\text { Índice de } \\
\text { Azul de } \\
\text { Metileno } \\
(\mathrm{mg} / \mathrm{g})\end{array}$ \\
\hline \hline CAP - 1 & osso & 0,1497 & 6,680 & 40,90 & $q_{e}=40,90 \times C e^{0,1497}$ & 33,03 \\
CAP - 2 & madeira & 0,1141 & 8,764 & 114,00 & $q_{e}=114,00 \times C e^{0,1141}$ & 96,87 \\
CAP - 3 & madeira & 0,0946 & 10,571 & 256,92 & $q_{e}=256,92 \times C e^{0,0946}$ & 224,47 \\
CAP - 4 & coco & 0,1148 & 8,711 & 271,71 & $q_{e}=271,71 \times C e^{0,1148}$ & 230,65 \\
CAP - 5 & madeira & 0,0996 & 10,040 & 213,26 & $q_{e}=213,26 \times C e^{0,0996}$ & 185,00 \\
\hline
\end{tabular}

Os carvões de origem vegetal apresentaram melhor desempeno na adsorção de azul de metileno como ocorreu anteriormente com o iodo. Da mesma forma, o CAP - 1 (osso) teve o pior desempenho no IAM $(33,03 \mathrm{mg} / \mathrm{g})$ entre os carvões testados. Kuroda et al. (2005) também verificaram, em seus estudos com diferentes CAP, a baixa capacidade de adsorção de azul de metileno com índice da ordem de $11,42 \pm 0,32 \mathrm{mg} / \mathrm{g}$ para carvão granular e $15,79 \pm$ 0,44 mg/g para o carvão ativado em pó. De acordo com esses resultados, Silva et al. (2007) definiu o IAM igual a $50 \pm 5 \mathrm{mg} / \mathrm{g}$ para carvão ativado em pó proveniente de osso.

È interessante observar que o carvão ativado a partir de coco, CAP - 4, apresentou o melhor desempenho na adsorção de azul de metileno, com IAM igual a 230,65 mg/g apesar de não apresentar o maior valor $n$ igual 8,711 que se refere à afinidade pelo adsorvato. Mas este fato também foi verificado por Silva et al. (2007) que observaram o maior valor de IAM, igual a $124 \pm 27 \mathrm{mg} / \mathrm{g}$, entre os cinco carvões testados (2 CAP de madeira, 1 de coco, 1 de 
osso e 1 mineral). Nos estudos de Kuroda et al. (2005), o carvão ativado granular de coco foi um dos dois selecionados (entre 10 tipos de carvões avaliados) com IAM igual a 80,82 $\pm 2,24$ $\mathrm{mg} / \mathrm{g}$ para prosseguir nos ensaios de adsorção de microcistina, devido ao fato de o IAM estar relacionado com o volume de mesoporos.

Os carvões de madeira CAP - 2 e 3, que foram fornecidos pelo mesmo fabricante, apresentaram diferentes características no IAM e afinidade do carvão pelo adsorvato (parâmetro $n$ ), fato que foi observado pelo número de iodo e que está relacionado aos distintos processos de ativação que as matérias-primas são submetidas. A influência do processo de ativação de carvões foi demonstrada no estudo realizado por Baçaoui et al. (2001), que ao produzirem carvão ativado a partir de caroço de azeitona, verificaram uma faixa de adsorção de azul de metileno de 115 e $490 \mathrm{mg} / \mathrm{g}$ com a variação do tempo de ativação entre 30 e 70 minutos e a variação da temperatura de ativação entre 750 e $850{ }^{\circ} \mathrm{C}$.

A partir das Figuras 5.12; 5.14; 5.16; 5.18 e 5.20 foram definidas as equações de Langmuir para os carvões ativados testados. Os parâmetros e as equações, seguindo este modelo, estão descritos na Tabela 5.14.

Tabela 5.14: Parâmetros da Equação de Langmuir para adsorção de azul de metileno.

\begin{tabular}{ccccc}
\hline \hline & \multicolumn{3}{c}{ Equação Langmuir } \\
\hline \hline Carvão & $\begin{array}{c}\text { Matéria- } \\
\text { prima }\end{array}$ & $\begin{array}{c}\mathrm{a} \\
(\mathrm{mg} / \mathrm{g})\end{array}$ & $\mathrm{b}$ & Eq. Langmuir \\
\hline \hline CAP - 1 & osso & 59,59 & 2,225 & $X / m=(132,63 \times \mathrm{Ce}) /(1+2,225 \times \mathrm{Ce})$ \\
CAP - 2 & madeira & 123,46 & 14,614 & $X / m=(1804,24 \times \mathrm{Ce}) /(1+14,614 \times \mathrm{Ce})$ \\
CAP - 3 & madeira & 299,40 & 12,268 & $X / m=(3673,12 \times \mathrm{Ce}) /(1+12,268 \times \mathrm{Ce})$ \\
CAP - 4 & coco & 304,88 & 14,326 & $X / m=(4367,65 \times \mathrm{Ce}) /(1+14,326 \times \mathrm{Ce})$ \\
CAP - 5 & madeira & 269,54 & 5,758 & $X / m=(1552,02 \times \mathrm{Ce}) /(1+5,758 \times \mathrm{Ce})$ \\
\hline
\end{tabular}


Segundo o modelo de Langmuir, os carvões de origem vegetal também apresentaram melhor desempenho na adsorção de azul de metileno conforme o parâmetro $a$, (ver Tabela 5.14). O parâmetro a (quantidade de adsorvato necessária para saturar uma unidade de carvão ativado) da equação de Langmuir seguiu o mesmo comportamento do índice de azul de metileno (IAM) definido pela equação de Freundlich, seguindo a ordem decrescente: CAP - 4 $>\mathrm{CAP}-3>\mathrm{CAP}-5>\mathrm{CAP}-2>\mathrm{CAP}-1$. Novamente, o carvão de osso, CAP -1 , apresentou pior desempenho na adsorção do azul de metileno $(59,59 \mathrm{mg} / \mathrm{g})$ com a menor energia de ligação definida pelo parâmetro $b$ (2,225). Já o CAP -4 (coco) teve o melhor desempenho no ensaio de adsorção tendo $a=304,88 \mathrm{mg} / \mathrm{g}$, apresentando o segundo maior valor da energia de ligação $b=14,326$.

\subsubsection{Adsorção de Microcistina}

Foram realizados ensaios de adsorção de microcistina com todas as amostras fornecidas de carvão ativado em pó. O objetivo foi avaliar a capacidade de adsorção desta toxina para cada tipo de carvão.

Para a realização dos ensaios, cinco massas de carvão ativado foram fixadas devido ao elevado custo de aquisição dos kits para determinação de microcistina, e após os ensaios, foram elaboradas as isotermas de adsorção segundo os modelos de Freundlich e Langmuir para que fossem feitas as devidas avaliações e, finalmente, a escolha do tipo de carvão que foi aplicado nos ensaios de tratabilidade.

As Tabelas 5.15; 5.16; 5.17; 5.18 e 5.19 apresentam os resultados dos ensaios de adsorção de microcistina para cada carvão ensaiado. 
Tabela 5.15: Adsorção de Microcistina - CAP 1 (osso).

Condições do ensaio: Tempo - 72 horas; Agitação - 30 rpm; Temperatura $-20{ }^{\circ} \mathrm{C}$.

\begin{tabular}{ccccc}
\hline \hline & $\begin{array}{c}\text { Massa CAP } \\
(\mathrm{g})\end{array}$ & $\begin{array}{c}\mathrm{Ce} \\
(\mu \mathrm{g} / \mathrm{L})\end{array}$ & $\begin{array}{c}\mathrm{qe}=\mathrm{X} / \mathrm{m} \\
(\mu \mathrm{g} / \mathrm{g})\end{array}$ & $\mathrm{Ce} /(\mathrm{X} / \mathrm{m})$ \\
& & 1035,07 & - & - \\
\hline \hline Co & - & 691,63 & 1646,38 & 0,42009 \\
M1 & 0,01043 & 1472,28 & 0,39804 \\
M2 & 0,01525 & 586,02 & 1425 \\
M3 & 0,02013 & 461,45 & 1424,79 & 0,32387 \\
M4 & 0,02527 & 83,60 & 1882,60 & 0,04441 \\
M5 & 0,03034 & 79,32 & 1575,06 & 0,05036 \\
M6 & 0,04037 & 35,14 & 1238,46 & 0,02837 \\
\hline
\end{tabular}
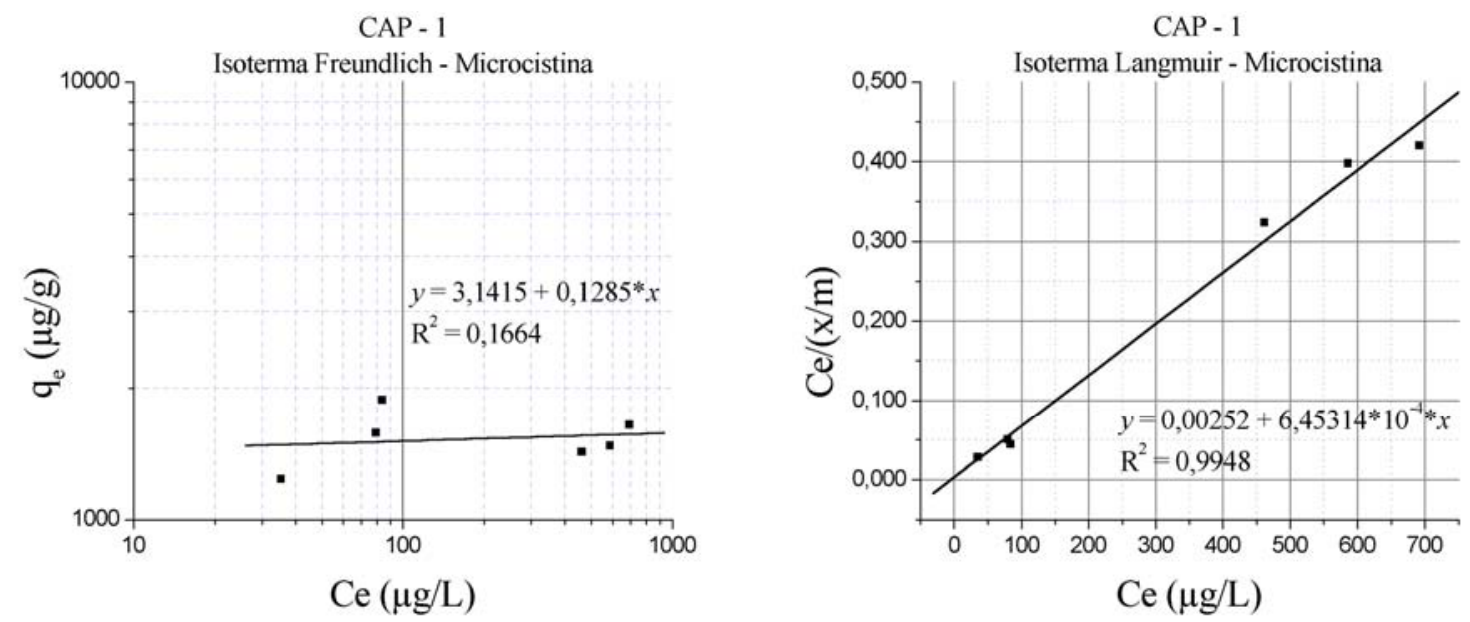

Figura 5.21: Isoterma de Freundlich (MC) - CAP 1. Figura 5.22: Isoterma de Langmuir (MC) - CAP 1.

Tabela 5.16: Adsorção de Microcistina - CAP 2 (madeira).

Condições do ensaio: Tempo - 72 horas; Agitação - $30 \mathrm{rpm}$; Temperatura $-20^{\circ} \mathrm{C}$.

\begin{tabular}{ccccc}
\hline \hline & $\begin{array}{c}\text { Massa CAP } \\
(\mathrm{g})\end{array}$ & $\begin{array}{c}\mathrm{Ce} \\
(\mu \mathrm{g} / \mathrm{L})\end{array}$ & $\begin{array}{c}\mathrm{qe}_{\mathrm{e}}=\mathrm{X} / \mathrm{m} \\
(\mu \mathrm{g} / \mathrm{g})\end{array}$ & $\mathrm{Ce} /(\mathrm{X} / \mathrm{m})$ \\
& & & & \\
\hline $\mathrm{C}_{0}$ & - & 1035,07 & - & - \\
M1 & 0,01079 & 477,15 & 2585,35 & 0,18456 \\
M2 & 0,01535 & 185,79 & 2766,37 & 0,06716 \\
M3 & 0,02038 & 67,34 & 2374,21 & 0,02836 \\
M4 & 0,02544 & 21,65 & 1991,78 & 0,01087 \\
M5 & 0,03049 & 10,81 & 1679,66 & 0,00643 \\
M6 & 0,04047 & 4,20 & 1273,62 & 0,00330 \\
\hline
\end{tabular}


CAP - 2

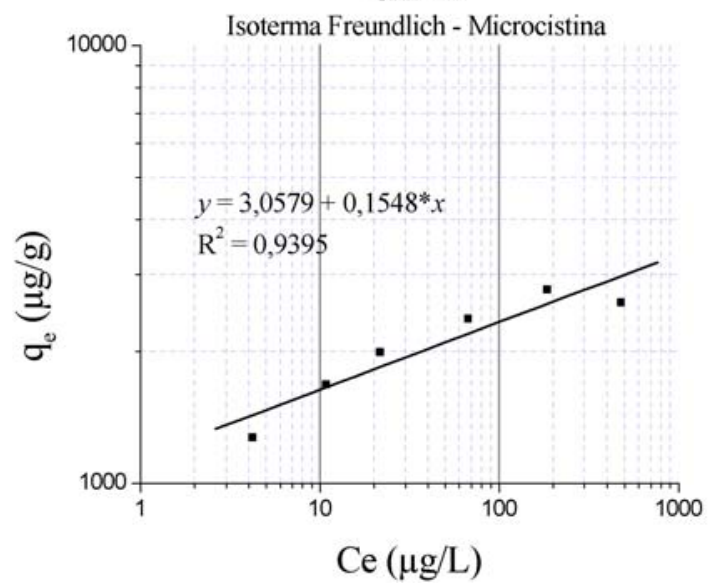

Figura 5.23: Isoterma de Freundlich (MC) - CAP 2.
CAP - 2

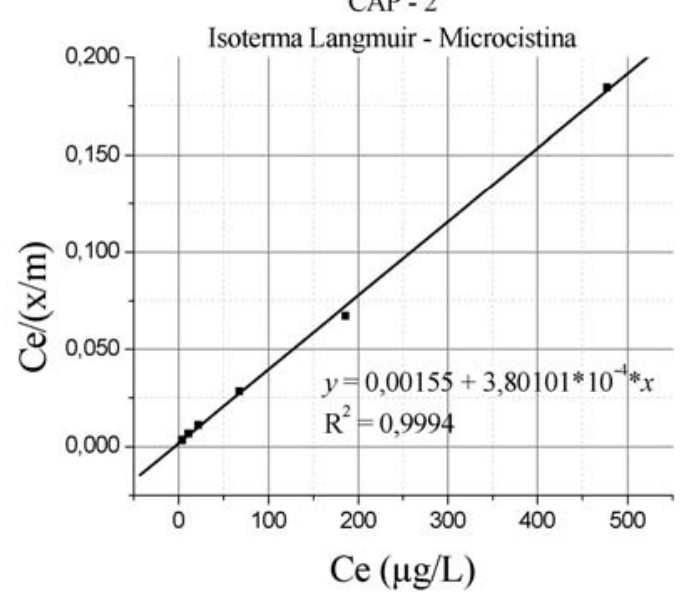

Figura 5.24: Isoterma de Langmuir (MC) - CAP 2.

Tabela 5.17: Adsorção de Microcistina - CAP 3 (madeira).

Condições do ensaio: Tempo - 72 horas; Agitação - $30 \mathrm{rpm}$; Temperatura $-20{ }^{\circ} \mathrm{C}$.

\begin{tabular}{ccccc}
\hline \hline & $\begin{array}{c}\text { Massa CAP } \\
(\mathrm{g})\end{array}$ & $\begin{array}{c}\mathrm{Ce} \\
(\mu \mathrm{g} / \mathrm{L})\end{array}$ & $\begin{array}{c}\mathrm{qe}=\mathrm{X} / \mathrm{m} \\
(\mu \mathrm{g} / \mathrm{g})\end{array}$ & $\mathrm{Ce} /(\mathrm{X} / \mathrm{m})$ \\
& & & & \\
\hline \hline Co & - & 808,20 & - & - \\
M1 & 0,01047 & 12,91 & 3797,97 & 0,00340 \\
M2 & 0,01543 & 7,93 & 2593,25 & 0,00306 \\
M3 & 0,02022 & 10,13 & 1973,47 & 0,00513 \\
M4 & 0,02516 & 1,59 & 1602,96 & 0,00099 \\
M5 & 0,03028 & 1,10 & 1332,74 & 0,00082 \\
M6 & 0,04013 & 1,05 & 1005,67 & 0,00105 \\
\hline
\end{tabular}

CAP - 3

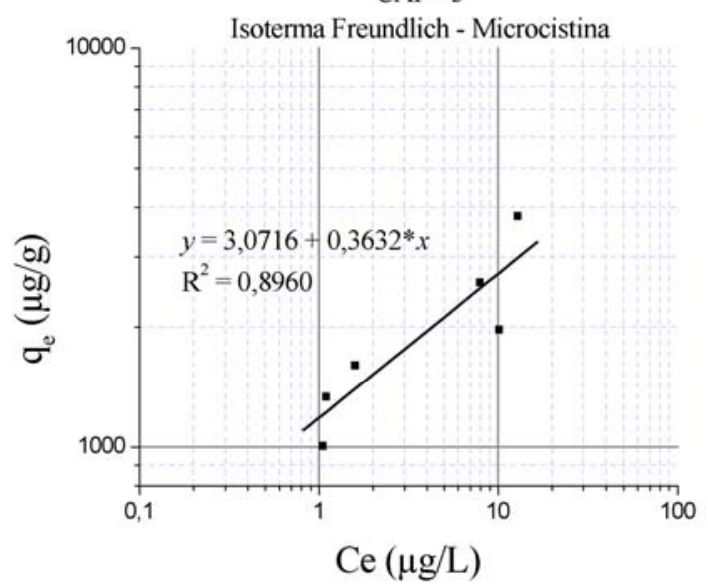

Figura 5.25: Isoterma de Freundlich (MC) - CAP 3.

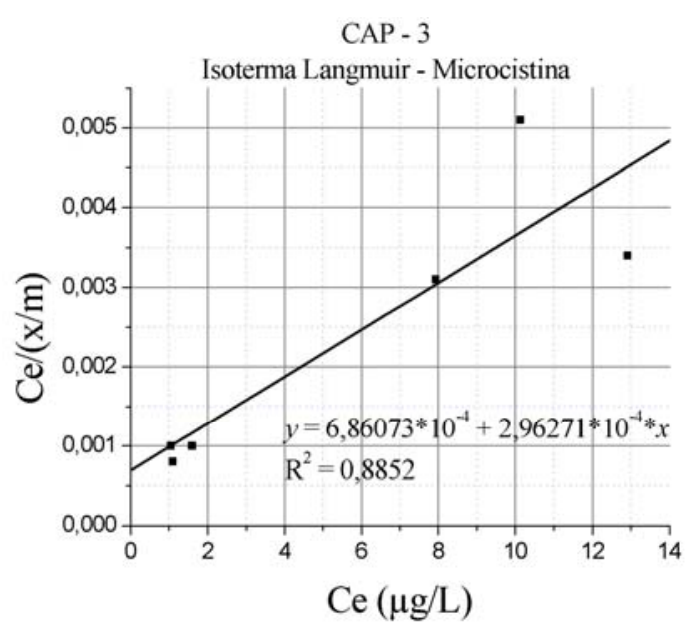

Figura 5.26: Isoterma de Langmuir (MC) - CAP 3. 
Tabela 5.18: Adsorção de Microcistina - CAP 4 (casca de coco).

Condições do ensaio: Tempo - 72 horas; Agitação - 30 rpm; Temperatura $-20^{\circ} \mathrm{C}$.

\begin{tabular}{ccccc}
\hline \hline & $\begin{array}{c}\text { Massa CAP } \\
(\mathrm{g})\end{array}$ & $\begin{array}{c}\mathrm{Ce} \\
(\mu \mathrm{g} / \mathrm{L})\end{array}$ & $\begin{array}{c}\mathrm{qe}=\mathrm{X} / \mathrm{m} \\
(\mu \mathrm{g} / \mathrm{g})\end{array}$ & $\mathrm{Ce} /(\mathrm{X} / \mathrm{m})$ \\
\hline \hline $\mathrm{C}_{0}$ & - & 910,53 & - & - \\
M1 & 0,01018 & 14,28 & 4402,02 & 0,00324 \\
M2 & 0,01534 & 9,71 & 2936,17 & 0,00331 \\
M3 & 0,02039 & 6,82 & 2216,07 & 0,00308 \\
M4 & 0,02521 & 1,85 & 1802,23 & 0,00102 \\
M5 & 0,03049 & 1,91 & 1490,03 & 0,00128 \\
M6 & 0,04016 & 1,55 & 1131,69 & 0,00137 \\
\hline
\end{tabular}

CAP - 4

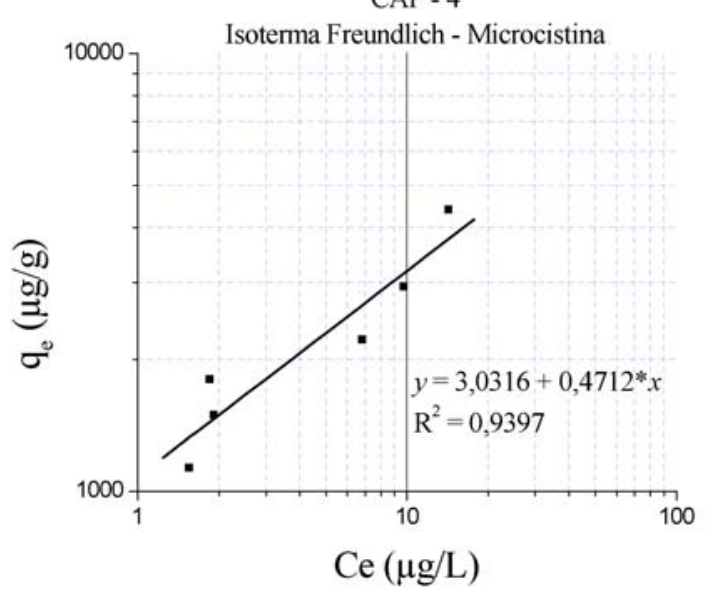

Figura 5.27: Isoterma de Freundlich (MC) - CAP 4.

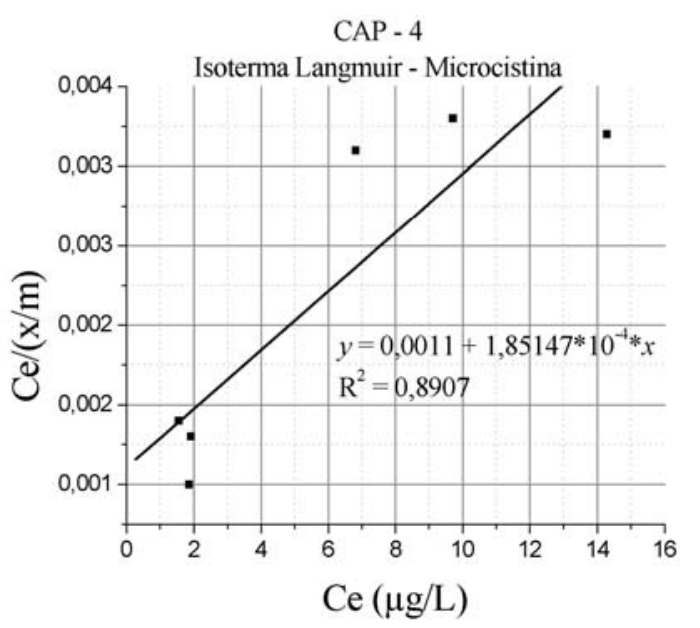

Figura 5.28: Isoterma de Langmuir (MC) - CAP 4.

Tabela 5.19: Adsorção de Microcistina - CAP 5 (madeira).

Condições do ensaio: Tempo - 72 horas; Agitação - $30 \mathrm{rpm}$; Temperatura $-20^{\circ} \mathrm{C}$.

\begin{tabular}{ccccc}
\hline & $\begin{array}{c}\text { Massa CAP } \\
(\mathrm{g})\end{array}$ & $\begin{array}{c}\mathrm{Ce} \\
(\mu \mathrm{g} / \mathrm{L})\end{array}$ & $\begin{array}{c}\mathrm{qe}=\mathrm{X} / \mathrm{m} \\
(\mu \mathrm{g} / \mathrm{g})\end{array}$ & $\mathrm{Ce} /(\mathrm{X} / \mathrm{m})$ \\
\hline \hline $\mathrm{C}_{0}$ & - & 910,53 & - & - \\
M1 & 0,01010 & 45,09 & 4284,34 & 0,01053 \\
$\mathrm{M} 2$ & 0,01538 & 12,40 & 2919,80 & 0,00425 \\
M3 & 0,02018 & 9,56 & 2232,35 & 0,00428 \\
M4 & 0,02540 & 2,20 & 1788,05 & 0,00123 \\
M5 & 0,03055 & 1,48 & 1487,81 & 0,00099 \\
M6 & 0,04023 & 1,21 & 1130,15 & 0,00107 \\
\hline
\end{tabular}




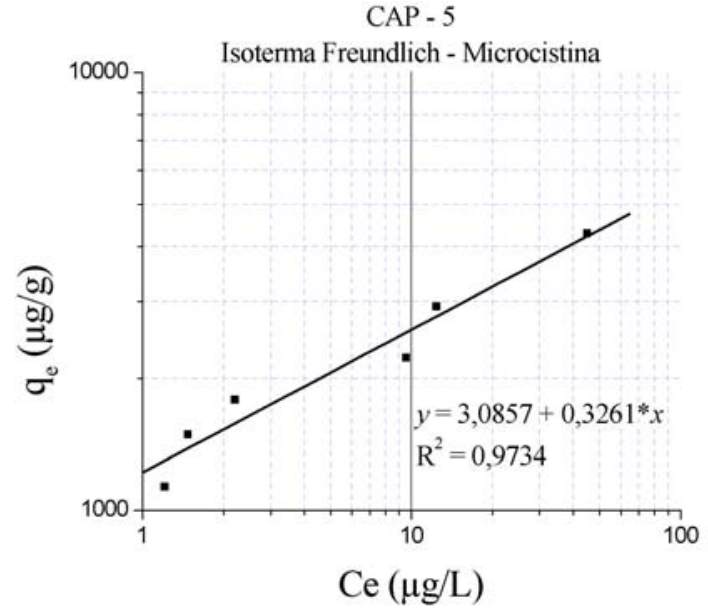

Figura 5.29: Isoterma de Freundlich (MC) - CAP 5.

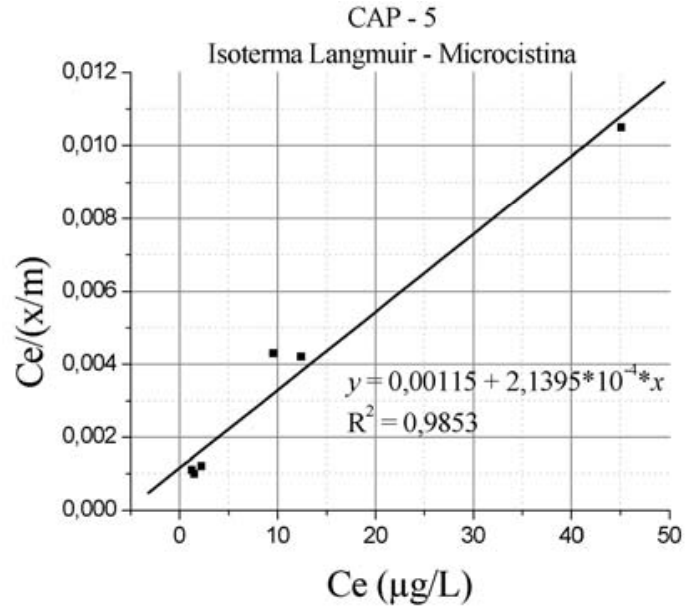

Figura 5.30: Isoterma de Langmuir(MC)-CAP 5.

Com as equações de ajuste das Figuras 5.21; 5.23; 5.25; 5.27 e 5.29 foram definidas as equações de Freundlich para os carvões ensaiados, as quais estão apresentadas na Tabela 5.20.

Tabela 5.20: Parâmetros da Equação de Freundlich e Adsorção Máxima de Microcistina.

\begin{tabular}{ccccccc}
\hline \hline \multicolumn{7}{c}{ Equação Freundlich } \\
\hline \hline Carvão & $\begin{array}{c}\text { Matéria- } \\
\text { prima }\end{array}$ & $1 / \mathrm{n}$ & $\mathrm{n}$ & $\mathrm{k}$ & Eq. Freundlich & $\begin{array}{c}* \\
\text { qe max }= \\
\mathrm{MC} \\
(\mu \mathrm{g} / \mathrm{g})\end{array}$ \\
\hline \hline CAP - 1 & osso & 0,1285 & 7,782 & 1385,16 & $q_{e}=1385,16 \times C e^{0,1285}$ & 3380,05 \\
CAP - 2 & madeira & 0,1548 & 6,460 & 1142,62 & $q_{e}=1142,62 \times C e^{0,1548}$ & 3346,72 \\
CAP - 3 & madeira & 0,3632 & 2,753 & 1179,23 & $q_{e}=1179,23 \times C e^{0,3632}$ & 13415,58 \\
CAP - 4 & coco & 0,4712 & 2,122 & 1075,47 & $q_{e}=1075,47 \times C e^{0,4712}$ & 26669,68 \\
CAP - 5 & madeira & 0,3261 & 3,067 & 1218,15 & $q_{e}=1218,15 \times C e^{0,3261}$ & 11238,97 \\
\hline
\end{tabular}

$* \mathrm{q}_{\mathrm{e}}$ max. de microcistina para $\mathrm{Ce}=\mathrm{Co}$.

Para avaliar a capacidade de adsorção de microcistina foi determinado o valor máximo de $\mathrm{q}_{\mathrm{e}}$ max. $(\mu \mathrm{g} / \mathrm{g})$. Diferente do número de iodo e do índice de azul de metileno, não é citado nenhum valor de concentração residual para se definir um índice de microcistina. Assim, segui-se a orientação de Reynolds e Richards (1995). Estes autores afirmam que para avaliar a viabilidade de aplicação de um carvão ativado na adsorção de certa substância deve-se adotar a concentração de equilíbrio $(\mathrm{Ce})$ igual à concentração inicial $(\mathrm{Co})$ da solução de estudo, 
sendo que, o carvão que apresentar maior valor de $\mathrm{q}_{\mathrm{e}}$ será o mais adequado para adsorção da substância em questão. Assim, adotou-se a concentração inicial (Co) do extrato de microcistina adicionado em cada carvão ensaiado. Tais concentrações estão apresentadas nas tabelas de adsorção de microcistina apresentadas nas Tabelas 5.15; 5.16; 5.17; 5.18 e 5.19.

Conforme a Tabela 5.20, os carvões ativados de origem vegetal apresentaram melhor desempenho na adsorção de microcistina, com exceção do CAP - 2 (madeira) que apresentou o pior desempenho.

O CAP - 1 apresentou baixo desempenho na adsorção de microcistina, sendo a adsorção máxima $\mathrm{q}_{\mathrm{e}}=3380,05 \mu \mathrm{g} / \mathrm{g} \approx 3,38 \mu \mathrm{g} / \mathrm{mg}$.

Os carvões ativados de madeira CAP - 3 e CAP - 5 apresentaram características semelhantes na adsorção de microcistina ( $\mathrm{q}_{\mathrm{e}}$ max.) iguais a $13415,58 \mu \mathrm{g} / \mathrm{g} \approx 13,42 \mu \mathrm{g} / \mathrm{mg} \mathrm{e}$ $11238,97 \mu \mathrm{g} / \mathrm{g} \approx 11,24 \mu \mathrm{g} / \mathrm{mg}$, respectivamente. Kuroda et al. (2005) obtiveram resultados semelhantes de adsorção máxima de microcistina, da ordem de $10 \mu \mathrm{g} / \mathrm{mg}$, para carvões ativados em pó oriundos de madeira. Entretanto, Donati et al. (1994) e Pendleton et al. (2001) obtiveram resultados superiores aos anteriores, $\mathrm{q}_{\mathrm{e}}$ max. igual a 280 e $200 \mu \mathrm{g} / \mathrm{mg}$, respectivamente, para CAP provenientes de madeira.

O carvão de coco (CAP - 4) foi o que apresentou melhor desempenho com adsorção máxima de microcistina igual a 26669,68 $\mu \mathrm{g} / \mathrm{g} \approx 26,67 \mu \mathrm{g} / \mathrm{mg}$. Já Kuroda et al. (2005) verificaram que o carvão ativado granular de coco não apresentou bons resultados na adsorção de microcistina, sendo a adsorção máxima resultante em aproximadamente $2,0 \mu \mathrm{g} / \mathrm{mg}$.

Donati et al. (1994) e Pendleton et al. (2001) encontraram valores máximos de adsorção de microcistina, para carvões ativados de coco, iguais a 40 e $22 \mu \mathrm{g} / \mathrm{mg}$, respectivamente. É importante ressaltar que estes autores realizaram seus ensaios com solução de microcistina padronizadas adicionadas em água pura, ou seja, sem a influência de outras 
substâncias que competem pelos sítios de adsorção do carvão ativado. Isto pode explicar as diferenças nas características de adsorção, sobretudo nos carvões ativados de madeira.

As equações de Langmuir foram definidas baseadas nas Figuras 5.22; 5.24; 5.26; 5.28 e 5.30. As equações estão apresentadas na Tabela 5.21.

Tabela 5.21: Parâmetros da Equação de Langmuir para adsorção de microcistina.

\begin{tabular}{ccccc}
\hline \hline & \multicolumn{3}{c}{ Equação Langmuir } \\
\hline \hline Carvão & $\begin{array}{c}\text { Matéria- } \\
\text { prima }\end{array}$ & $\begin{array}{c}\mathrm{a} \\
(\mu \mathrm{g} / \mathrm{g})\end{array}$ & $\mathrm{b}$ & Eq. Langmuir \\
\hline \hline CAP - 1 & osso & 1549,63 & 0,256 & $X / m=(396,83 \times \mathrm{Ce}) /(1+0,256 \times C e)$ \\
CAP - 2 & madeira & 2630,88 & 0,245 & $X / m=(645,16 \times C e) /(1+0,245 \times C e)$ \\
CAP - 3 & madeira & 3375,29 & 0,432 & $X / m=(1457,57 \times C e) /(1+0,432 \times C e)$ \\
CAP - 4 & coco & 5401,11 & 0,168 & $X / m=(909,09 \times C e) /(1+0,168 \times C e)$ \\
CAP - 5 & madeira & 4673,99 & 0,186 & $X / m=(869,57 \times C e) /(1+0,186 \times C e)$ \\
\hline
\end{tabular}

Os carvões vegetais apresentaram melhor desempenho na adsorção de microcistina pelo ajuste de Langmuir.

Apesar de o CAP - 4 apresentar a menor energia de ligação $(b=0,168)$, este apresentou a maior quantidade de microcistina adsorvida por unidade de carvão $(a=5401,11$ $\mu \mathrm{g} / \mathrm{g})$. O CAP - 1 apresentou baixa capacidade de adsorção $(a=1549,63 \mu \mathrm{g} / \mathrm{g})$, entretanto, apresentou a segunda maior energia de ligação com microcistina $(b=0,256)$ quando comparado com os demais carvões ativados.

A Figura 5.31 mostra os resultados finais da caracterização dos carvões ativados em pó em termos de número de iodo (NI em mg/g), índice de azul de metileno (IAM em mg/g) e adsorção máxima de microcistina ( $\mathrm{MC}$ em $\mu \mathrm{g} / \mathrm{mg}$ ) utilizando as isotermas de Freundlich. 


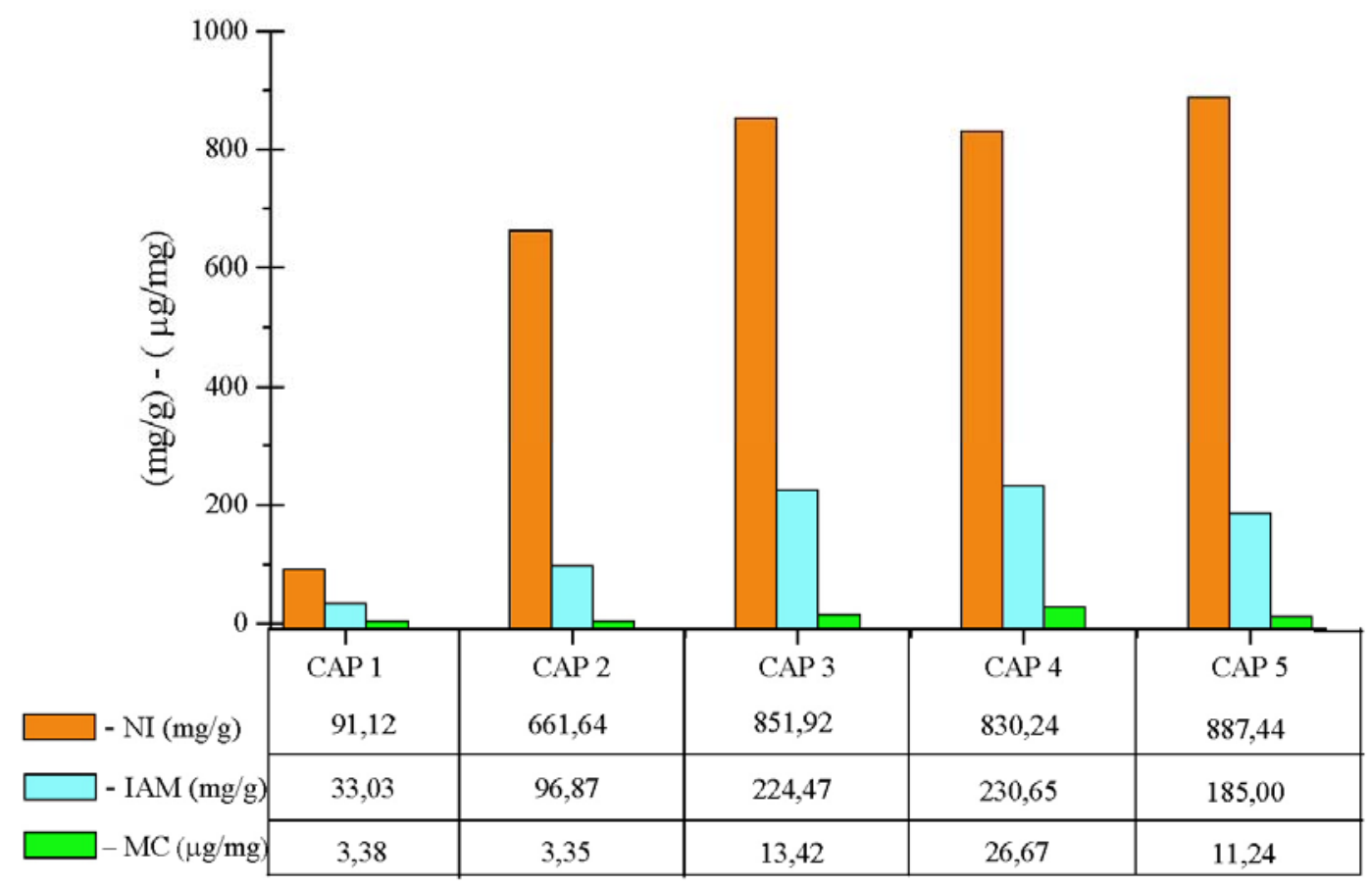

Figura 5.31: $\mathrm{N}^{\circ}$ de Iodo, Índice de Azul de Metileno e Adsorção Máxima de Microcistina dos carvões ativados amostrados.

Após a realização dos ensaios de adsorção de azul de metileno e microcistina, é possível inferir que o índice de azul de metileno é um bom indicador da qualidade dos carvões, quanto ao volume de mesoporos, e conseqüentemente como parâmetro de seleção de carvões ativados para aplicação na adsorção de microcistina. A Tabela 5.22 mostra o resultado da determinação da correlação entre o IAM e MC.

Tabela 5.22: Determinação da correlação entre IAM e MC.

\begin{tabular}{|c|c|c|c|c|}
\hline Carvão & $\begin{array}{c}\text { IAM } \\
(\mathrm{mg} / \mathrm{g})\end{array}$ & $\begin{array}{c}\mathrm{MC} \\
(\mu \mathrm{g} / \mathrm{g})\end{array}$ & & \\
\hline CAP - 1 & 33,03 & 3380,05 & Covariância $\left(I A M, q_{e} M C\right)=$ & 547544 \\
\hline CAP - 2 & 96,87 & 3346,72 & Desv. Padrão IAM = & 77,07 \\
\hline CAP - 3 & 224,47 & 13415,58 & Desv. Padrão $M C=$ & 8558,10 \\
\hline CAP - 4 & 230,65 & 26669,68 & $r=$ & 0,830 \\
\hline CAP - 5 & 185,00 & 11238,97 & & \\
\hline
\end{tabular}


A Figura 5.32 ilustra a correlação entre o índice de azul de metileno e adsorção de microcistina determinados para os carvões ensaiados.

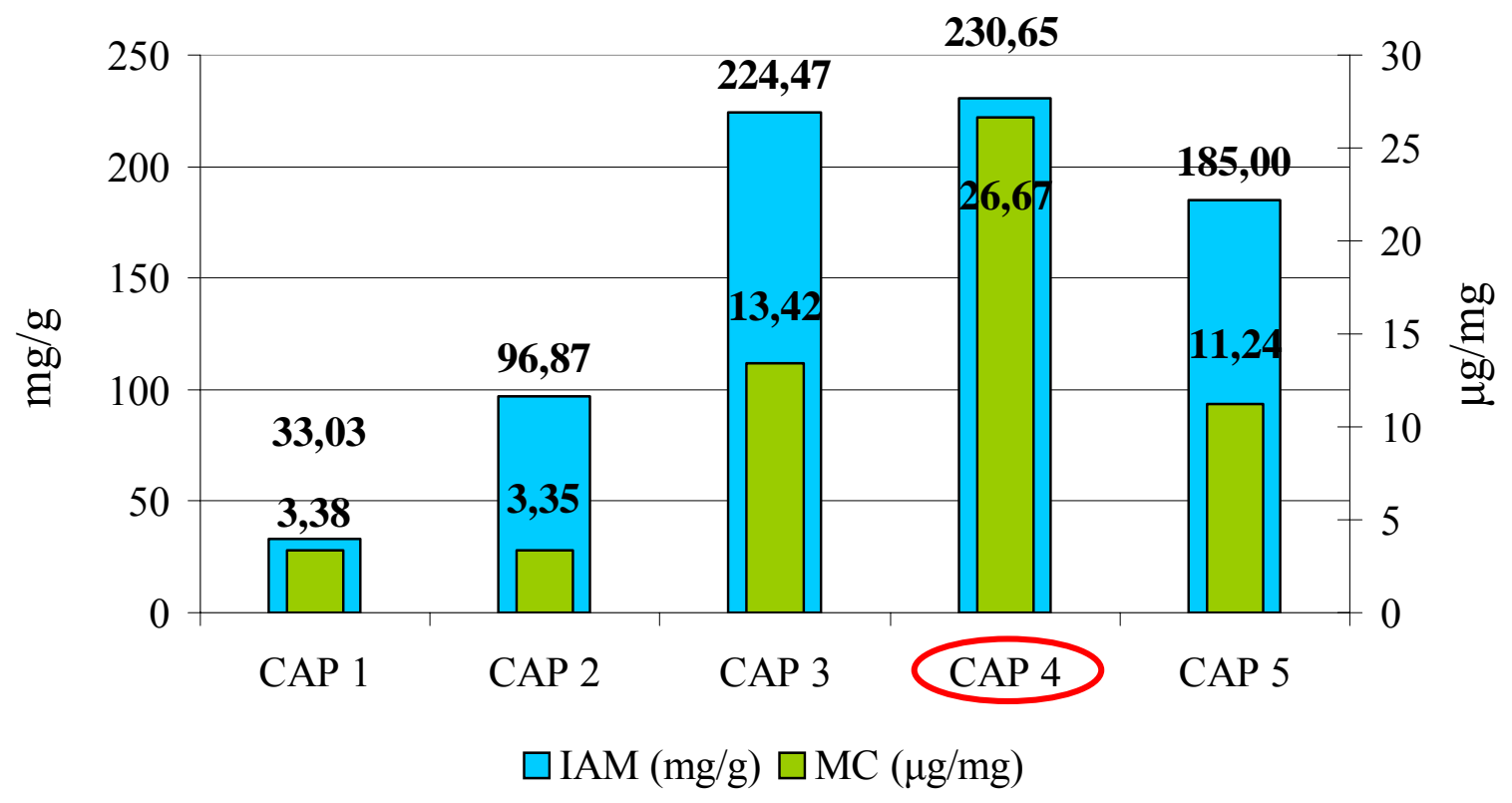

Figura 5.32: Valores de Índice de Azul de Metileno e Adsorção Máxime de Microcistina.

Com os resultados da Tabela 5.22 e pela Figura 5.32 se vê que houve uma boa correlação $(r=0,83)$ entre o IAM e MC como confirmado em diversos estudos. Esta correlação ficou prejudicada apenas pelo CAP - 1 (osso), pois, acredita-se que sua capacidade de adsorção seja menor que $3,38 \mu \mathrm{g} / \mathrm{mg}$ frente ao coeficiente $\mathrm{R}^{2}=0,1664$ resultante do ajuste de Freundlich para os ensaios de adsorção de microcistina deste carvão ativado.

Após todo o estudo realizado com cada amostra de carvão fornecida, o CAP selecionado para a aplicação nos ensaios de tratabilidade foi o CAP - 4 de coco que apresentou as seguintes características: número de iodo $(\mathbf{N I})=\mathbf{8 3 0 , 2 4} \mathbf{~ m g} / \mathbf{g}$; índice de azul de metileno $(\mathbf{I A M})=\mathbf{2 3 0 , 6 5} \mathbf{~ m g} / \mathbf{g}$; adsorção máxima de microcistina $\left(\mathbf{q}_{\mathbf{e}} \mathbf{m a x}=\mathbf{M C}\right)=\mathbf{2 6 , 6 7}$ $\mu \mathrm{\mu} / \mathrm{mg}$. 


\subsection{RESULTADOS DA ETAPA - I}

Como descrito no capítulo Material e Métodos, a ETAPA - I foi dividida em três fases: A, B e C. Para a realização de cada fase foram preparadas três águas de estudo com diferentes concentrações de microcistina.

Com o objetivo de facilitar a apresentação e discussão dos resultados, estes serão apresentados em itens separados para cada água de estudo. Contudo, após a apresentação dos dados da terceira água de estudo, terá um item que resumirá e apresentará as principais informações e decisões tomadas em cada fase concluída.

A ETAPA - I foi marcada por alguns imprevistos e escolhas não acertadas que interferiram, de certa forma, em alguns resultados esperados. Primeiramente, as três águas de estudo foram preparadas ao mesmo tempo para que fossem armazenadas em câmara fria com temperatura de $4^{\circ} \mathrm{C}$ - até a realização dos ensaios. No entanto, este equipamento não funcionou adequadamente e as águas sofreram visível alteração de suas características iniciais até a realização dos ensaios.

Não aplicar a maior dosagem de CAP $(30 \mathrm{mg} / \mathrm{L})$ e o oxidante $\left(3,0 \mathrm{mgCl}_{2} / \mathrm{L}\right.$ de cloro livre) foram escolhas ruins na estratégia de definição da dosagem de coagulante (FASE - A). Pois, sabendo-se da interferência do oxidante no pH de coagulação, as dosagens de coagulante definidas como ótimas não foram capazes de proporcionar condições ideais para a coagulação das três águas de estudo.

Outros fatores que interferiram na qualidade da Água de Estudo 1, foram erros na dosagem de coagulante e oxidante (FASE - B e C) que levaram ao atraso dos ensaios, devido às repetições que se fizeram necessárias quando tais falhas foram detectadas. 
Contudo, pôde-se avaliar qual fluxograma de tratamento produziu água com melhores características conforme os parâmetros avaliados, além da experiência adquirida, que possibilitou a realização de uma nova campanha de ensaios (ETAPA - II) com procedimentos mais acertados.

\subsubsection{FASE - A}

O objetivo da FASE - A foi escolher a dosagem ótima de coagulante (cloreto férrico) a ser aplicada nas fases posteriores da ETAPA - I. Para tanto, foram variadas oito dosagens de coagulante $\left(6,20 ; 8,26 ; 10,33 ; 12,40 ; 14,47 ; 16,54 ; 18,61\right.$ e $\left.20,68 \mathrm{mgFe}^{3+} / \mathrm{L}\right)$ para as três águas de estudo preparadas. Conforme já descrito em detalhes no item 4, a mistura rápida foi realizada em agitadores separados do flotateste, e a floculação e flotação por ar dissolvido foram realizadas no flotateste. As amostras foram coletadas com duas velocidades de flotação $\left(\mathrm{V}_{1}=18,0 \mathrm{~cm} / \mathrm{min}\right.$ e $\left.\mathrm{V}_{2}=12,0 \mathrm{~cm} / \mathrm{min}\right)$. Após a flotação as amostras foram centrifugadas. Os ensaios foram monitorados pelos parâmetros de pH de coagulação, turbidez e cor aparente das amostras flotadas e centrifugadas. Os limites adotados como referência, para turbidez e cor aparente, são os estabelecidos pela Portaria 518 / 04 do Ministério da Saúde, sendo, turbidez igual a $1 \mathrm{uT}$ e cor aparente igual a $15 \mathrm{uC}$.

\subsubsection{1. Água de Estudo 1 (FASE - A)}

As características da Água de Estudo - 1 quanto aos parâmetros avaliados foram: $\mathrm{pH}$ 7,50; turbidez - 54,6 uT; cor aparente - $586 \mathrm{uC}$. 
As Figuras 5.33 e 5.34 apresentam os resultados de turbidez residual para as duas velocidades analisadas das amostras flotadas e centrifugadas, respectivamente.

Turbidez das Amostras Flotadas

Água de Estudo - 1

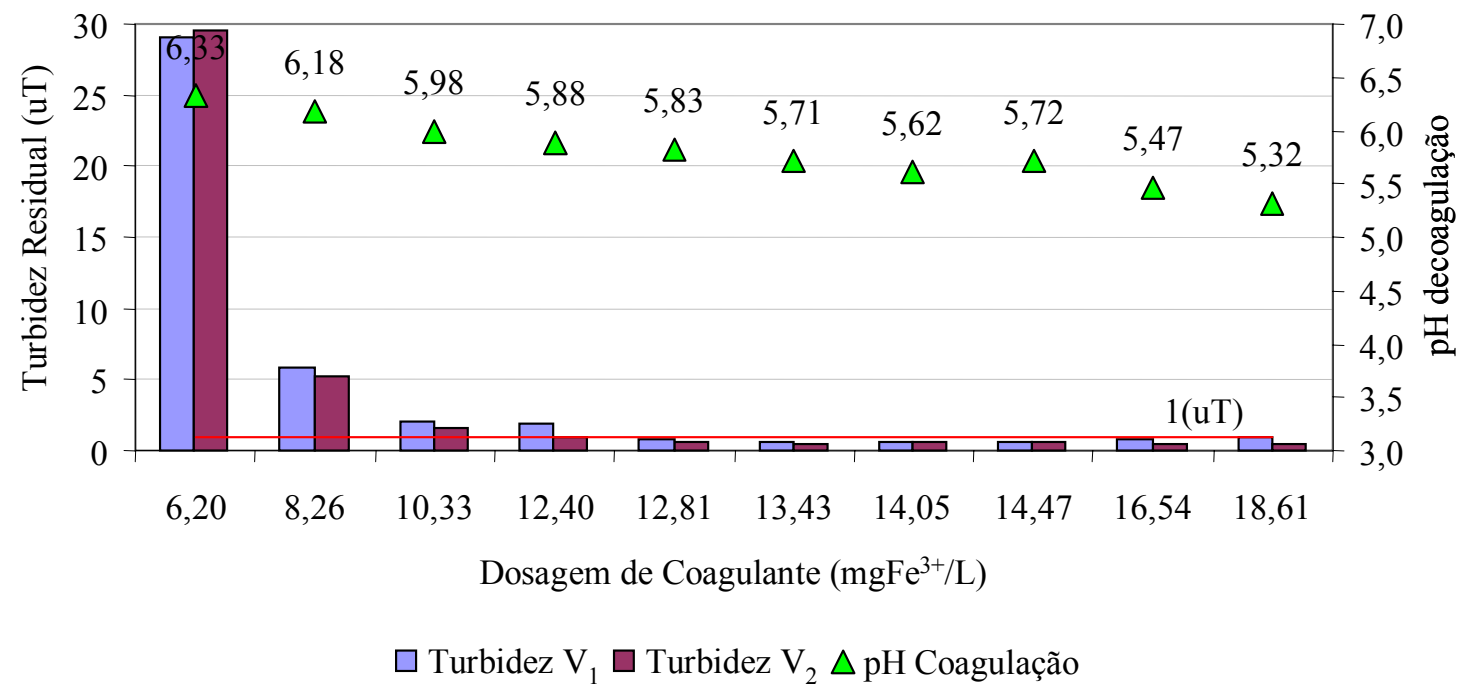

Figura 5.33: Turbidez residual das amostras flotadas e pH de coagulação.

Turbidez da Água de Estudo $1=54,6(\mathrm{uT}) ; \mathrm{MC}=6,76 \mu \mathrm{g} / \mathrm{L}$.

Condições do ensaio: Coagulação $\left(\mathrm{Vr}_{\mathrm{MR}}=350 \mathrm{rpm} ; \mathrm{T}_{\mathrm{MR}}=20 \mathrm{~s}\right)$; Floculação $\left(\mathrm{Vr}_{\mathrm{FLO}}=68 \mathrm{rpm} ; \mathrm{T}_{\mathrm{FLO}}=18 \mathrm{~min}\right)$; $\mathrm{FAD}\left(\mathrm{p}_{\mathrm{SAT}}=500 \mathrm{kPa} ; \mathrm{R}=8 \% ; \mathrm{V}_{1}=18,0 \mathrm{~cm} / \mathrm{min} ; \mathrm{V}_{2}=12,0 \mathrm{~cm} / \mathrm{min}\right)$.

Turbidez das Amostras Centrifugadas

Água de Estudo - 1

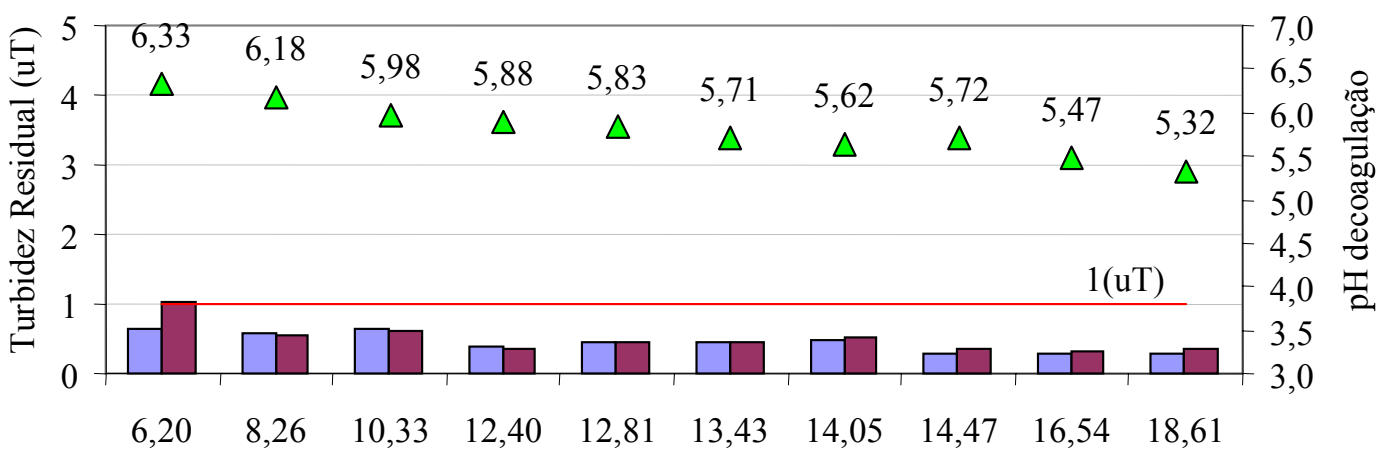

Dosagem de Coagulante $\left(\mathrm{mgFe}^{3+} / \mathrm{L}\right)$

$\square$ Turbidez $V_{1} \square$ Turbidez $V_{2} \Delta$ pH Coagulação

Figura 5.34: Turbidez residual das amostras centrifugadas e $\mathrm{pH}$ de coagulação.

Turbidez da Água de Estudo 1 = 54,6 (uT); MC = 6,76 $\mu \mathrm{g} / \mathrm{L}$.

Condições do ensaio: Coagulação $\left(\mathrm{Vr}_{\mathrm{MR}}=350 \mathrm{rpm} ; \mathrm{T}_{\mathrm{MR}}=20 \mathrm{~s}\right)$; Floculação $\left(\operatorname{Vr}_{\mathrm{FLO}}=68 \mathrm{rpm} ; \mathrm{T}_{\mathrm{FLO}}=18 \mathrm{~min}\right)$;

$\mathrm{FAD}\left(\mathrm{p}_{\mathrm{SAT}}=500 \mathrm{kPa} ; \mathrm{R}=8 \% ; \mathrm{V}_{1}=18,0 \mathrm{~cm} / \mathrm{min} ; \mathrm{V}_{2}=12,0 \mathrm{~cm} / \mathrm{min}\right) ;$ Centrifugação $\left(\mathrm{f}_{\mathrm{CEN}}=2000 \mathrm{rpm} ; \mathrm{T}_{\mathrm{CEN}}=15 \mathrm{~min}\right)$. 
As Figuras 5.35 e 5.36 mostram, respectivamente, os resultados de cor aparente residual das amostras flotadas e centrifugadas de ambas as velocidades analisadas.

Cor Aparente das Amostras Flotadas

Água de Estudo - 1

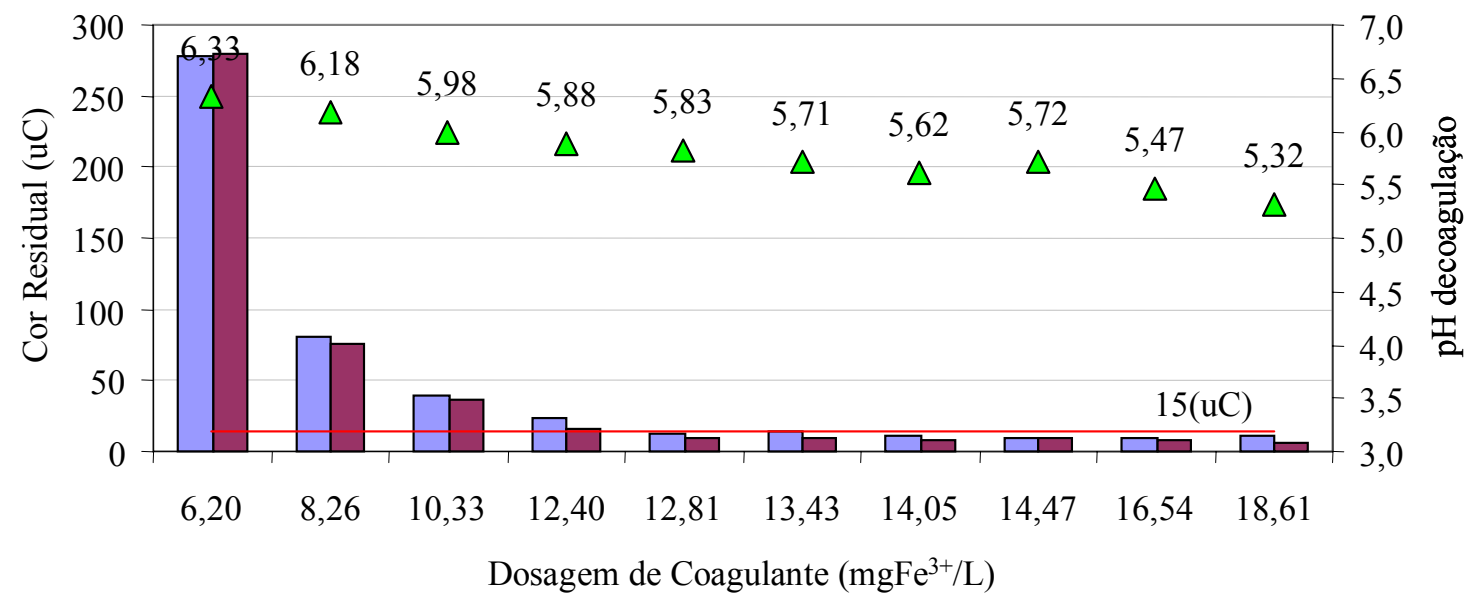

$\square$ Cor Aparente $\mathrm{V}_{1} \square$ Cor Aparente $\mathrm{V}_{2} \triangle \mathrm{pH}$ Coagulação

Figura 5.35: Cor aparente residual das amostras flotadas e $\mathrm{pH}$ de coagulação.

Cor aparente da Água de Estudo $1=586(\mathrm{uC}) ; \mathrm{MC}=6,76 \mu \mathrm{g} / \mathrm{L}$.

Condições do ensaio: Coagulação $\left(\mathrm{Vr}_{\mathrm{MR}}=350 \mathrm{rpm} ; \mathrm{T}_{\mathrm{MR}}=20 \mathrm{~s}\right)$; Floculação $\left(\mathrm{Vr}_{\mathrm{FLO}}=68 \mathrm{rpm} ; \mathrm{T}_{\mathrm{FLO}}=18 \mathrm{~min}\right)$;

$\mathrm{FAD}\left(\mathrm{p}_{\mathrm{SAT}}=500 \mathrm{kPa} ; \mathrm{R}=8 \% ; \mathrm{V}_{1}=18,0 \mathrm{~cm} / \mathrm{min} ; \mathrm{V}_{2}=12,0 \mathrm{~cm} / \mathrm{min}\right)$

Cor Aparente das Amostras Centrifugadas

Água de Estudo - 1

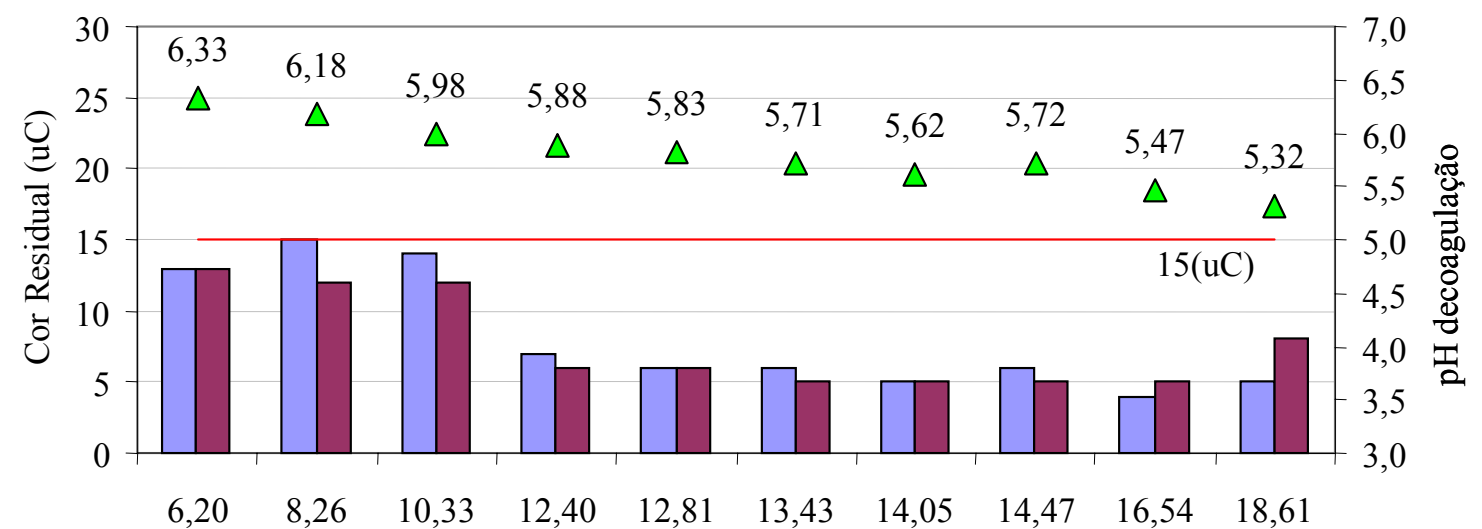

Dosagem de Coagulante $\left(\mathrm{mgFe}^{3+} / \mathrm{L}\right)$

$\square$ Cor Aparente $V_{1} \square$ Cor Aparente $V_{2} \triangle$ pH Coagulação

Figura 5.36: Cor aparente residual das amostras centrifugadas e $\mathrm{pH}$ de coagulação.

Cor aparente da Água de Estudo $1=586(\mathrm{uC}) ; \mathrm{MC}=6,76 \mu \mathrm{g} / \mathrm{L}$.

Condições do ensaio: Coagulação $\left(\mathrm{Vr}_{\mathrm{MR}}=350 \mathrm{rpm} ; \mathrm{T}_{\mathrm{MR}}=20 \mathrm{~s}\right)$; Floculação $\left(\mathrm{Vr}_{\mathrm{FLO}}=68 \mathrm{rpm}\right.$; $\left.\mathrm{T}_{\mathrm{FLO}}=18 \mathrm{~min}\right)$; $\mathrm{FAD}\left(\mathrm{p}_{\mathrm{SAT}}=500 \mathrm{kPa} ; \mathrm{R}=8 \% ; \mathrm{V}_{1}=18,0 \mathrm{~cm} / \mathrm{min} ; \mathrm{V}_{2}=12,0 \mathrm{~cm} / \mathrm{min}\right) ;$ Centrifugação $\left(\mathrm{f}_{\mathrm{CEN}}=2000 \mathrm{rpm} ; \mathrm{T}_{\mathrm{CEN}}=15 \mathrm{~min}\right)$. 
Analisando-se a Figura 5.33, percebe-se que para $\mathrm{V}_{1}=18,0 \mathrm{~cm} / \mathrm{min}$ as amostras flotadas apresentaram valores de turbidez abaixo de 1 uT a partir da dosagem de coagulante igual a $12,81 \mathrm{mgFe}^{3+} / \mathrm{L}$ (Turbidez residual $=0,77 \mathrm{uT}$ e $\mathrm{pH}$ de coagulação $=5,83$ ). Já para a velocidade $\mathrm{V}_{2}=12,0 \mathrm{~cm} / \mathrm{min}$, com dosagens a partir de $12,40 \mathrm{mgFe}^{3+} / \mathrm{L}$ se obteve resultados satisfatórios (abaixo do limite de referência) de turbidez residual das amostras flotadas (Turbidez residual $=0,96 \mathrm{uT}$ e $\mathrm{pH}$ de coagulação $=5,88$ ). Após a centrifugação das amostras (Figura 5.34) com dosagens acima de $8,26 \mathrm{mgFe}^{3+} / \mathrm{L}$ ambas as velocidades apresentaram valores de turbidez residual menores que $0,65 \mathrm{uT}$.

Em termos de cor aparente, as amostras flotadas em ambas as velocidades (Figura 5.35) apresentaram resultados abaixo de $15(\mathrm{uC})$ com dosagens a partir de $12,81 \mathrm{mgFe}^{3+} / \mathrm{L}$. E para as amostras centrifugadas (Figura 5.36), todas as dosagens testadas forneceram amostras com cor aparente residual menor ou igual a $15(\mathrm{uC})$.

Visto que nos ensaios seguintes (Fase B e C) seriam aplicados oxidante e carvão ativado em pó, o que implicaria na alteração do pH de coagulação e aumento de cor e turbidez, escolheu-se a dosagem de $14,47 \mathrm{mgFe}^{3+} / \mathrm{L}$ de coagulante para água de estudo 1.

\subsubsection{2. Água de Estudo 2 (FASE - A)}

As características da Água de Estudo - 2 são: pH - 7,03; turbidez - 47,3 uT; cor aparente $-452 \mathrm{uC}$.

A turbidez residual das amostras flotadas (velocidades $V_{1}$ e $V_{2}$ ) e centrifugadas são apresentadas, respectivamente, nas Figuras 5.37 e 5.38 . 
Turbidez das Amostras Flotadas

Água de Estudo - 2

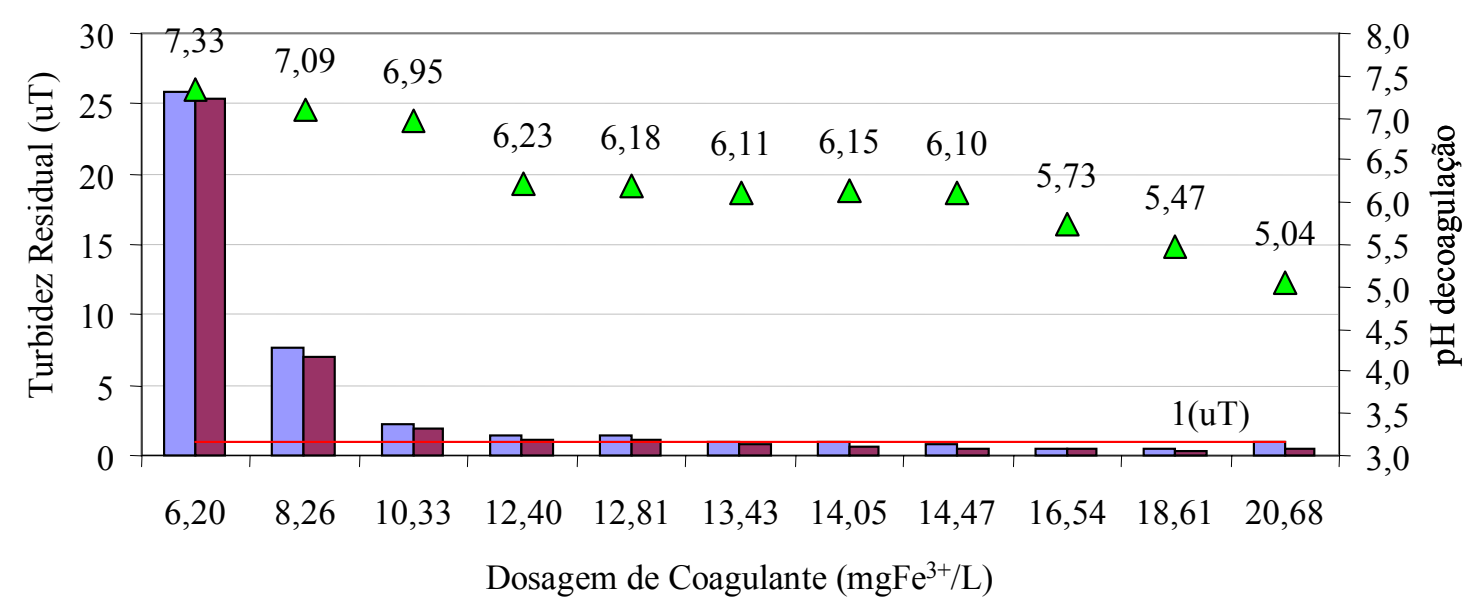

$\square$ Turbidez $\mathrm{V}_{1} \square$ Turbidez $\mathrm{V}_{2} \Delta \mathrm{pH}$ Coagulação

Figura 5.37: Turbidez residual das amostras flotadas e pH de coagulação.

Turbidez da Água de Estudo $2=47,3$ (uT); $\mathrm{MC}=25,84 \mu \mathrm{g} / \mathrm{L}$.

Condições do ensaio: Coagulação $\left(\mathrm{Vr}_{\mathrm{MR}}=350 \mathrm{rpm} ; \mathrm{T}_{\mathrm{MR}}=20 \mathrm{~s}\right)$; Floculação $\left(\mathrm{Vr}_{\mathrm{FLO}}=68 \mathrm{rpm}\right.$; $\left.\mathrm{T}_{\mathrm{FLO}}=18 \mathrm{~min}\right)$;

$\operatorname{FAD}\left(\mathrm{p}_{\mathrm{SAT}}=500 \mathrm{kPa} ; \mathrm{R}=8 \% ; \mathrm{V}_{1}=18,0 \mathrm{~cm} / \mathrm{min} ; \mathrm{V}_{2}=12,0 \mathrm{~cm} / \mathrm{min}\right)$.

Turbidez das Amostras Centrifugadas

Água de Estudo - 2

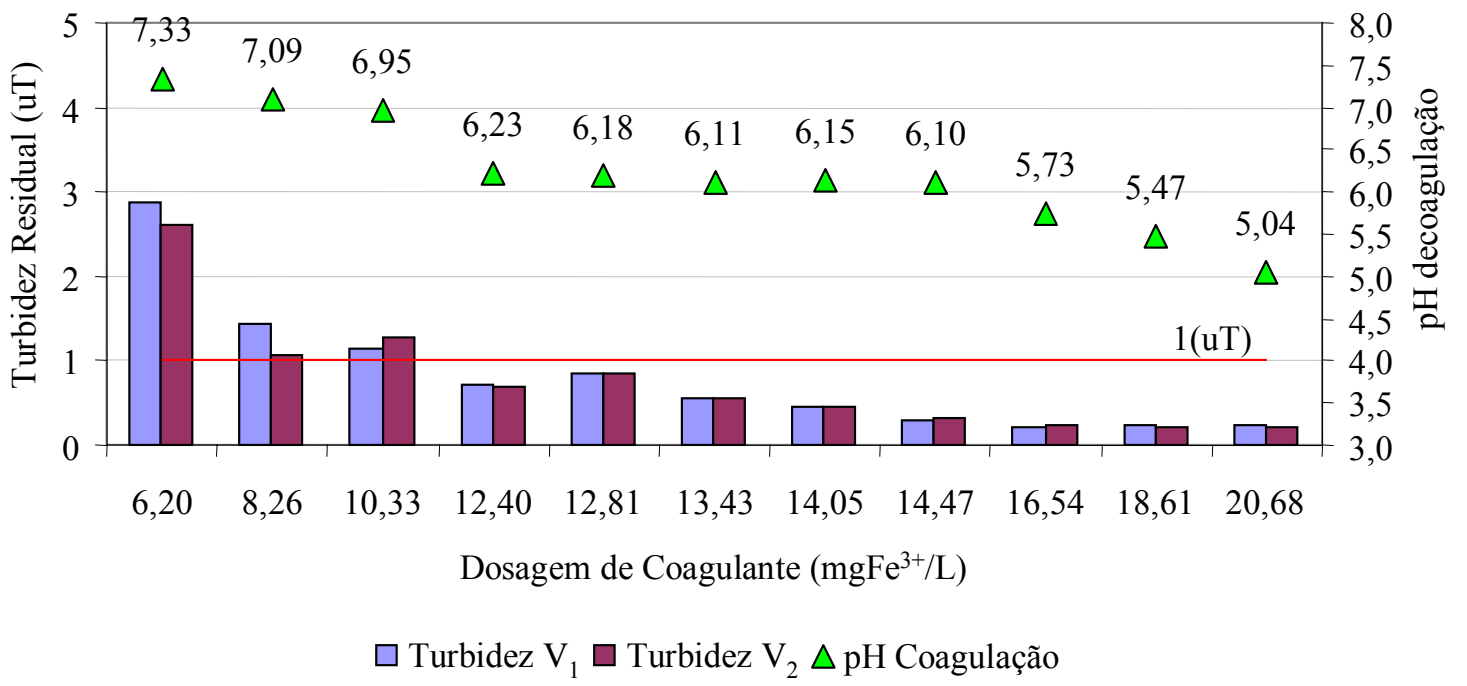

Figura 5.38: Turbidez residual das amostras centrifugadas e $\mathrm{pH}$ de coagulação.

Turbidez da Água de Estudo $2=47,3$ (uT); MC $=25,84 \mu \mathrm{g} / \mathrm{L}$.

Condições do ensaio: Coagulação $\left(\operatorname{Vr}_{\mathrm{MR}}=350 \mathrm{rpm} ; \mathrm{T}_{\mathrm{MR}}=20 \mathrm{~s}\right)$; Floculação $\left(\mathrm{Vr}_{\mathrm{FLO}}=68 \mathrm{rpm} ; \mathrm{T}_{\mathrm{FLO}}=18 \mathrm{~min}\right)$;

$\mathrm{FAD}\left(\mathrm{p}_{\mathrm{SAT}}=500 \mathrm{kPa} ; \mathrm{R}=8 \% ; \mathrm{V}_{1}=18,0 \mathrm{~cm} / \mathrm{min} ; \mathrm{V}_{2}=12,0 \mathrm{~cm} / \mathrm{min}\right)$; Centrifugação ( $\left.\mathrm{f}_{\mathrm{CEN}}=2000 \mathrm{rpm} ; \mathrm{T}_{\mathrm{CEN}}=15 \mathrm{~min}\right)$. 
As Figuras 5.39 e 5.40 apresentam, respectivamente, os resultados de cor aparente residual das amostras flotadas e centrifugadas.

Cor Aparente das Amostras Flotadas

Água de Estudo - 2

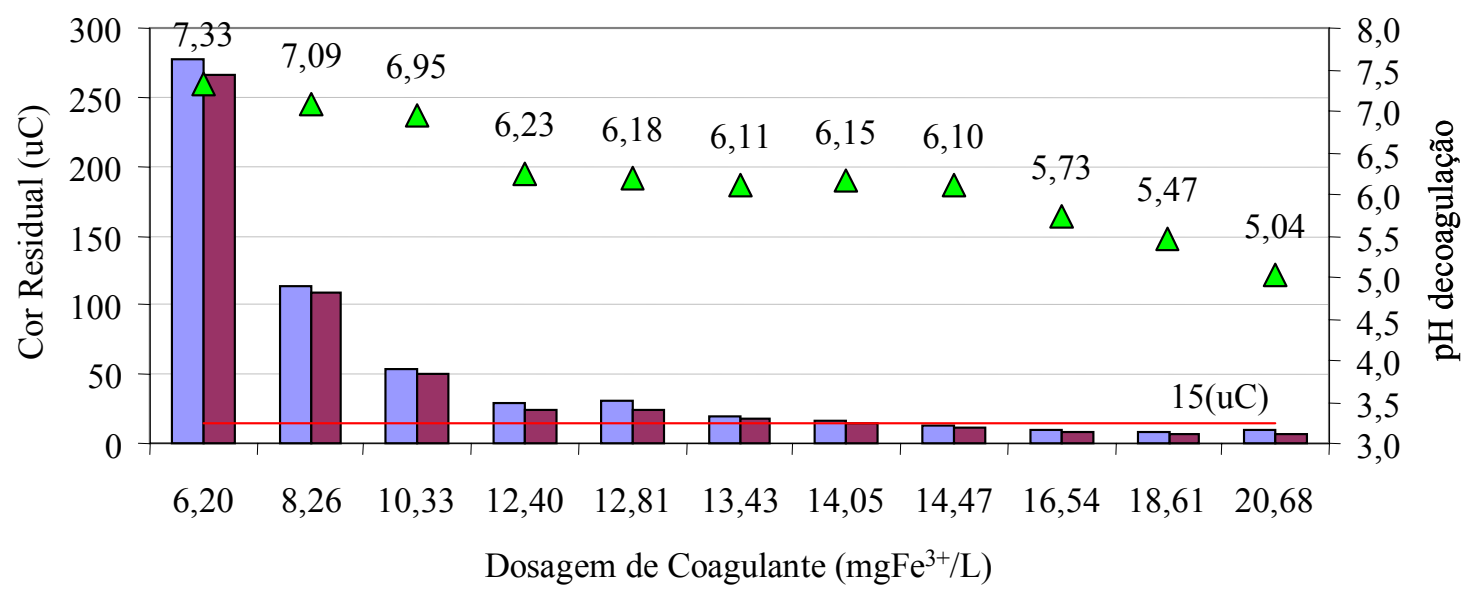

$\square$ Cor Aparente $\mathrm{V}_{1} \square$ Cor Aparente $\mathrm{V}_{2} \Delta \mathrm{pH}$ Coagulação

Figura 5.39: Cor aparente residual das amostras flotadas e pH de coagulação.

Cor aparente da Água de Estudo $2=452(\mathrm{uC}) ; \mathrm{MC}=25,84 \mu \mathrm{g} / \mathrm{L}$.

Condições do ensaio: Coagulação $\left(\mathrm{Vr}_{\mathrm{MR}}=350 \mathrm{rpm} ; \mathrm{T}_{\mathrm{MR}}=20 \mathrm{~s}\right)$; Floculação $\left(\mathrm{Vr}_{\mathrm{FLO}}=68 \mathrm{rpm} ; \mathrm{T}_{\mathrm{FLO}}=18 \mathrm{~min}\right)$; $\mathrm{FAD}\left(\mathrm{p}_{\mathrm{SAT}}=500 \mathrm{kPa} ; \mathrm{R}=8 \% ; \mathrm{V}_{1}=18,0 \mathrm{~cm} / \mathrm{min} ; \mathrm{V}_{2}=12,0 \mathrm{~cm} / \mathrm{min}\right)$.

Cor Aparente das Amostras Centrifugadas

Água de Estudo - 2

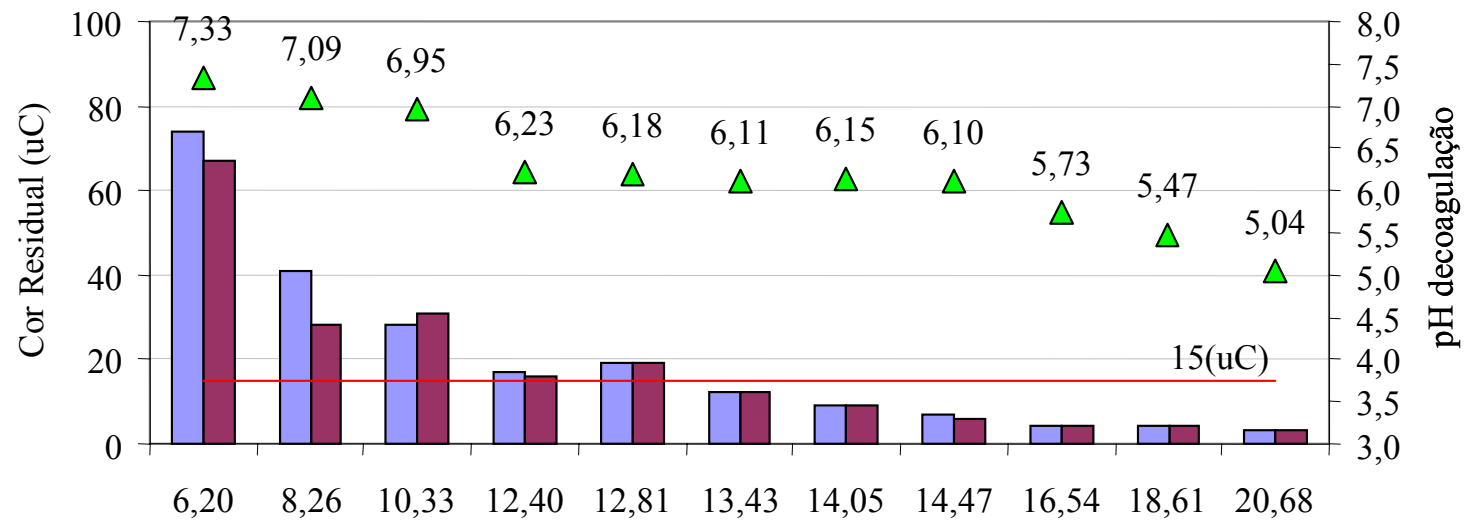

Dosagem de Coagulante $\left(\mathrm{mgFe}^{3+} / \mathrm{L}\right)$

$\square$ Cor Aparente $\mathrm{V}_{1} \square$ Cor Aparente $\mathrm{V}_{2} \triangle \mathrm{pH}$ Coagulação

Figura 5.40: Cor aparente residual das amostras centrifugadas e pH de coagulação.

Cor aparente da Água de Estudo $2=452(\mathrm{uC}) ; \mathrm{MC}=25,84 \mu \mathrm{g} / \mathrm{L}$.

Condições do ensaio: Coagulação $\left(\operatorname{Vr}_{\mathrm{MR}}=350 \mathrm{rpm} ; \mathrm{T}_{\mathrm{MR}}=20 \mathrm{~s}\right) ;$ Floculação $\left(\mathrm{Vr}_{\mathrm{FLO}}=68 \mathrm{rpm} ; \mathrm{T}_{\mathrm{FLO}}=18 \mathrm{~min}\right)$; $\mathrm{FAD}\left(\mathrm{p}_{\mathrm{SAT}}=500 \mathrm{kPa} ; \mathrm{R}=8 \% ; \mathrm{V}_{1}=18,0 \mathrm{~cm} / \mathrm{min} ; \mathrm{V}_{2}=12,0 \mathrm{~cm} / \mathrm{min}\right) ;$ Centrifugação $\left(\mathrm{f}_{\mathrm{CEN}}=2000 \mathrm{rpm} ; \mathrm{T}_{\mathrm{CEN}}=15 \mathrm{~min}\right)$. 
Conforme a Figura 5.37, as amostras, flotadas na velocidade $\mathrm{V}_{1}$, apresentaram valores de turbidez residual menor que $1 \mathrm{uT}$ a partir da dosagem de coagulante de $14,05 \mathrm{mgFe}{ }^{3+} / \mathrm{L}$ (Turbidez igual a $0,9 \mathrm{uT}$ ), entretanto, com dosagens a partir de $13,43 \mathrm{mgFe} \mathrm{s}^{3+} / \mathrm{L}$ produziram turbidez residual menor que $0,84 \mathrm{uT}$ para as amostras flotadas com a velocidade $\mathrm{V}_{2}$. Com a centrifugação (Figura 5.38), as amostras coaguladas com dosagens a partir de $12,40 \mathrm{mgFe} \mathrm{ge}^{3+} / \mathrm{L}$ de cloreto férrico forneceram residuais de cor aparente menor que 0,71 uT para ambas as velocidades de flotação.

Tendo-se como limite de cor aparente o valor de $15(\mathrm{uC})$, a Figura 5.39 mostra que foi necessário dosar pelo menos $14,47 \mathrm{mgFe}^{3+} / \mathrm{L}$ de coagulante para que fossem coletadas amostras flotadas com valores inferiores ao limite estabelecido, sendo que o valor de cor aparente residual para $\mathrm{V}_{1}$ foi de $13 \mathrm{uC}$ e $\mathrm{V}_{2}$ igual a $11 \mathrm{uC}$ para a dosagem de $14,47 \mathrm{mgFe}^{3+} / \mathrm{L}$ de coagulante. Contudo, após a centrifugação (Figura 5.40), as amostras coaguladas com $13,43 \mathrm{mgFe}^{3+} / \mathrm{L}$ apresentaram residuais de cor aparente menores que o limite estabelecido para os ensaios.

Pelo mesmo motivo da aplicação de oxidante e CAP nas fases posteriores, adotou-se 14,47 $\mathrm{mgFe}^{3+} / \mathrm{L}$ de cloreto férrico para a Água de Estudo 2.

\subsubsection{3. Água de Estudo 3 (FASE - A)}

As características da Água de Estudo - 3 são: pH - 7,33; turbidez - 28,4 uT; cor aparente $-315 \mathrm{uC}$.

A Figura 5.41 apresenta os resultados de turbidez residual para as amostras flotadas em ambas as velocidades, e a Figura 5.42 para as amostras após a centrifugação. 
Turbidez das Amostras Flotadas

Água de Estudo - 3

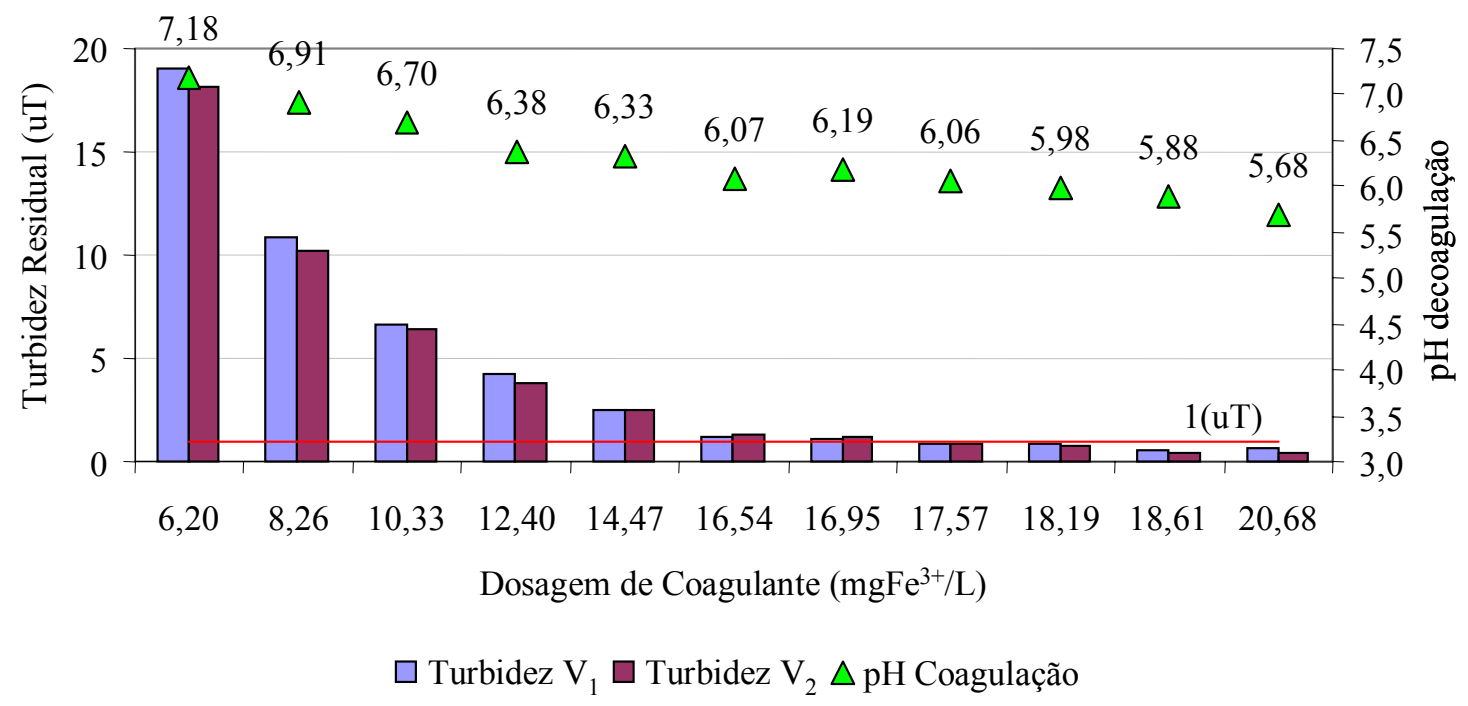

Figura 5.41: Turbidez residual das amostras flotadas e pH de coagulação.

Turbidez da Água de Estudo $3=28,4(\mathrm{uT}) ; \mathrm{MC}=104,92 \mu \mathrm{g} / \mathrm{L}$.

Condições do ensaio: Coagulação $\left(\mathrm{Vr}_{\mathrm{MR}}=350 \mathrm{rpm} ; \mathrm{T}_{\mathrm{MR}}=20 \mathrm{~s}\right)$; Floculação $\left(\mathrm{Vr}_{\mathrm{FLO}}=68 \mathrm{rpm} ; \mathrm{T}_{\mathrm{FLO}}=18 \mathrm{~min}\right)$;

$\mathrm{FAD}\left(\mathrm{p}_{\mathrm{SAT}}=500 \mathrm{kPa} ; \mathrm{R}=8 \% ; \mathrm{V}_{1}=18,0 \mathrm{~cm} / \mathrm{min} ; \mathrm{V}_{2}=12,0 \mathrm{~cm} / \mathrm{min}\right)$.

Turbidez das Amostras Centrifugadas

Água de Estudo - 3

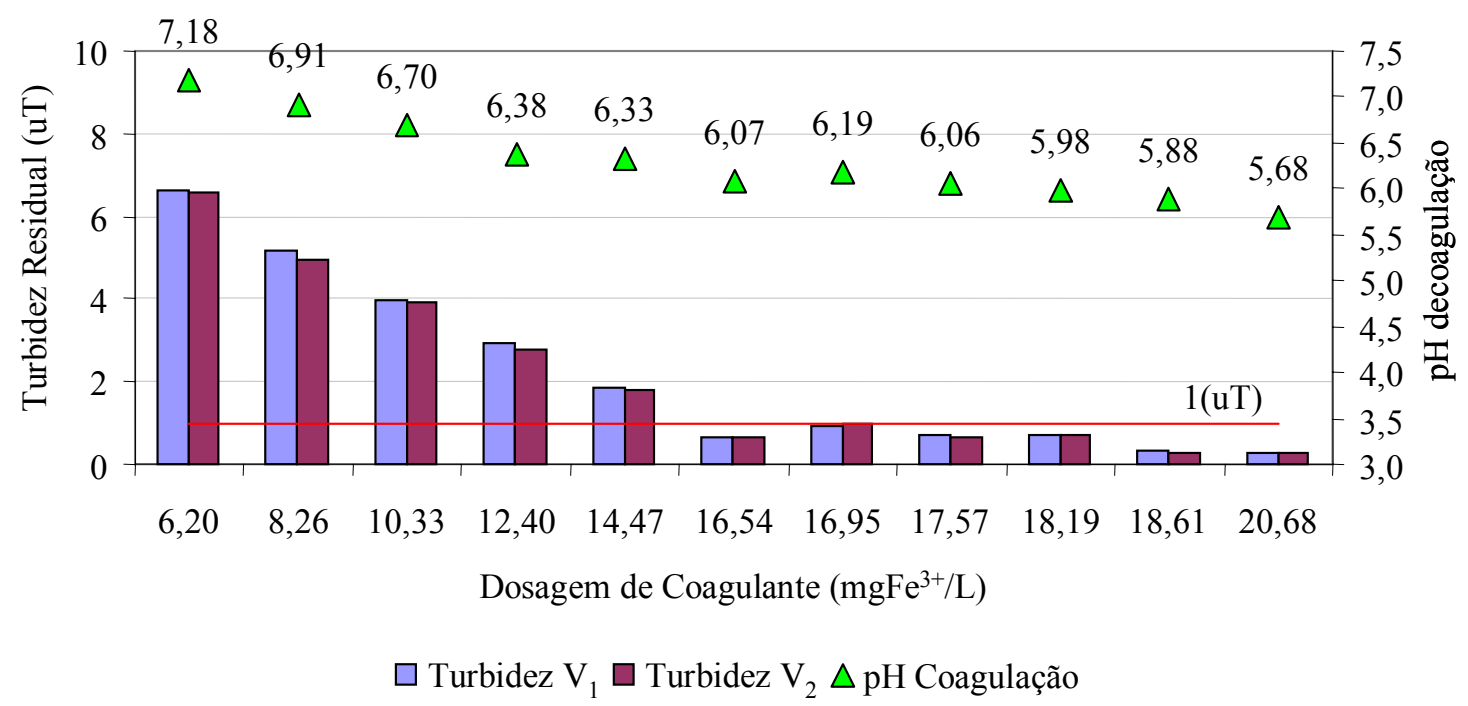

Figura 5.42: Turbidez residual das amostras centrifugadas e pH de coagulação.

Turbidez da Água de Estudo $3=28,4$ (uT); MC = 104,92 $\mu \mathrm{g} / \mathrm{L}$.

Condições do ensaio: Coagulação $\left(\mathrm{Vr}_{\mathrm{MR}}=350 \mathrm{rpm} ; \mathrm{T}_{\mathrm{MR}}=20 \mathrm{~s}\right)$; Floculação $\left(\mathrm{Vr}_{\mathrm{FLO}}=68 \mathrm{rpm}\right.$; $\left.\mathrm{T}_{\mathrm{FLO}}=18 \mathrm{~min}\right)$; $\mathrm{FAD}\left(\mathrm{p}_{\mathrm{SAT}}=500 \mathrm{kPa} ; \mathrm{R}=8 \% ; \mathrm{V}_{1}=18,0 \mathrm{~cm} / \mathrm{min} ; \mathrm{V}_{2}=12,0 \mathrm{~cm} / \mathrm{min}\right) ;$ Centrifugação $\left(\mathrm{f}_{\mathrm{CEN}}=2000 \mathrm{rpm} ; \mathrm{T}_{\mathrm{CEN}}=15 \mathrm{~min}\right)$. 
As Figuras 5.43 e 5.44 apresentam, respectivamente, os resultados de cor aparente residual das amostras flotadas e centrifugadas.

Cor Aparente das Amostras Flotadas

Água de Estudo - 3

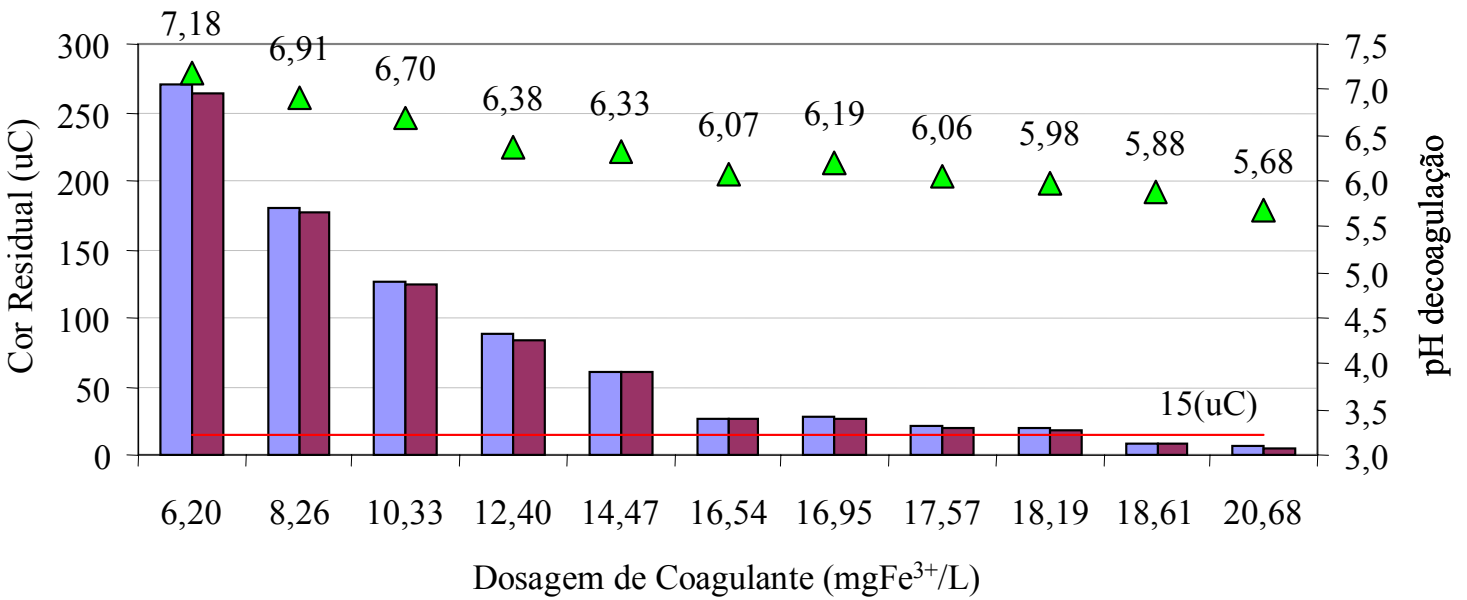

$\square$ Cor Aparente $V_{1} \square$ Cor Aparente $V_{2} \triangle p H$ Coagulação

Figura 5.43: Cor aparente residual das amostras flotadas e pH de coagulação.

Cor aparente da Água de Estudo $3=315(\mathrm{uC}) ; \mathrm{MC}=104,92 \mu \mathrm{g} / \mathrm{L}$.

Condições do ensaio: Coagulação $\left(\mathrm{Vr}_{\mathrm{MR}}=350 \mathrm{rpm} ; \mathrm{T}_{\mathrm{MR}}=20 \mathrm{~s}\right)$; Floculação $\left(\mathrm{Vr}_{\mathrm{FLO}}=68 \mathrm{rpm} ; \mathrm{T}_{\mathrm{FLO}}=18 \mathrm{~min}\right)$;

$\mathrm{FAD}\left(\mathrm{p}_{\mathrm{SAT}}=500 \mathrm{kPa} ; \mathrm{R}=8 \% ; \mathrm{V}_{1}=18,0 \mathrm{~cm} / \mathrm{min} ; \mathrm{V}_{2}=12,0 \mathrm{~cm} / \mathrm{min}\right)$.

Cor Aparente das Amostras Centrifugadas

Água de Estudo - 3

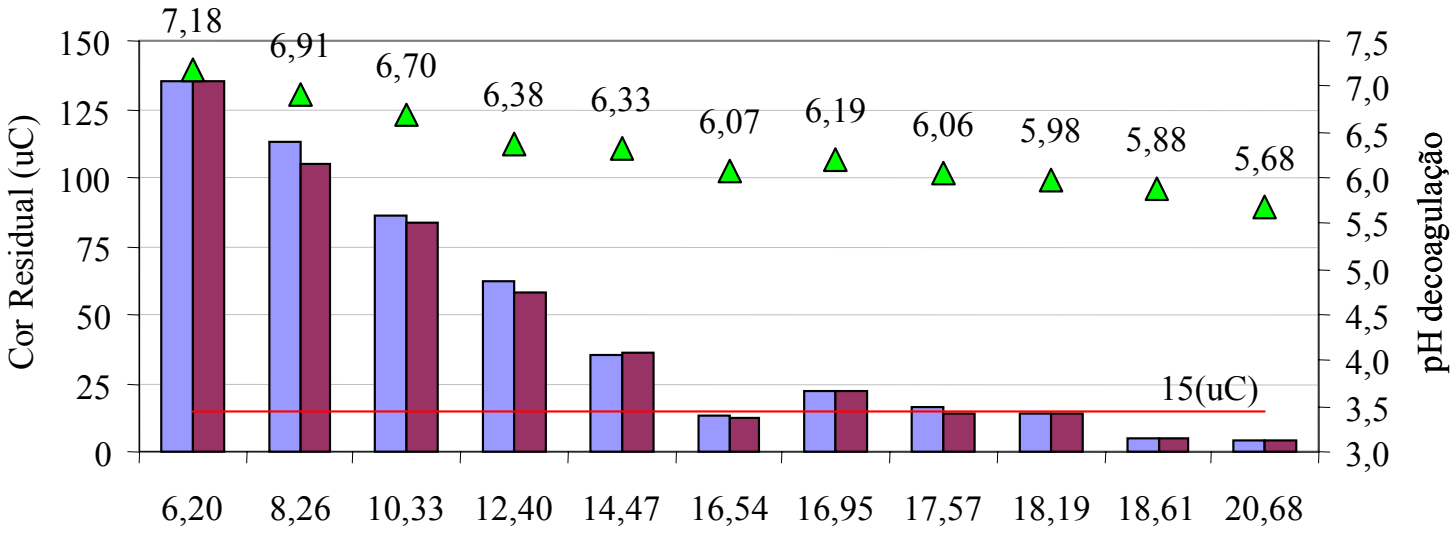

Dosagem de Coagulante $\left(\mathrm{mgFe}^{3+} / \mathrm{L}\right)$

$\square$ Cor Aparente $V_{1} \square$ Cor Aparente $V_{2} \triangle p H$ Coagulação

Figura 5.44: Cor aparente residual das amostras centrifugadas e $\mathrm{pH}$ de coagulação.

Cor aparente da Água de Estudo $3=315(\mathrm{uC}) ; \mathrm{MC}=104,92 \mu \mathrm{g} / \mathrm{L}$.

Condições do ensaio: Coagulação $\left(\mathrm{Vr}_{\mathrm{MR}}=350 \mathrm{rpm} ; \mathrm{T}_{\mathrm{MR}}=20 \mathrm{~s}\right)$; Floculação $\left(\mathrm{Vr}_{\mathrm{FLO}}=68 \mathrm{rpm} ; \mathrm{T}_{\mathrm{FLO}}=18 \mathrm{~min}\right)$; $\operatorname{FAD}\left(\mathrm{p}_{\mathrm{SAT}}=500 \mathrm{kPa} ; \mathrm{R}=8 \% ; \mathrm{V}_{1}=18,0 \mathrm{~cm} / \mathrm{min} ; \mathrm{V}_{2}=12,0 \mathrm{~cm} / \mathrm{min}\right) ;$ Centrifugação $\left(\mathrm{f}_{\mathrm{CEN}}=2000 \mathrm{rpm} ; \mathrm{T}_{\mathrm{CEN}}=15 \mathrm{~min}\right)$. 
Conforme a Figura 5.41, as amostras flotadas nas velocidades $V_{1}$ e $V_{2}$ atingiram valores de turbidez inferiores a $1 \mathrm{uT}$ com dosagens a partir de $18,19 \mathrm{mgFe} \mathrm{g}^{3+} / \mathrm{L}$. Com a centrifugação, vê-se pela Figura 5.42, que foi possível se obter amostras flotadas com turbidez inferior a $1 \mathrm{uT}$ com $16,54 \mathrm{mgFe}^{3+} / \mathrm{L}$ de cloreto férrico. Para $\mathrm{V}_{1}$ e $\mathrm{V}_{2}$ a turbidez residual foi igual a 0,64 uT. Em termos de cor aparente, a Figura 5.43 mostra que somente aplicando-se $18,61 \mathrm{mgFe}^{3+} / \mathrm{L}$ de cloreto férrico foi possível produzir amostras flotadas com cor aparente inferior a $15 \mathrm{uC}$ para as velocidades $\mathrm{V}_{1}$ e $\mathrm{V}_{2}$. Não houve melhora significativa com a centrifugação das amostras, visto que, somente ao aplicar $18,19 \mathrm{mgFe}^{3+} / \mathrm{L}$ de coagulante, obteve-se cor aparente abaixo do limite estabelecido $\left(\mathrm{V}_{1}\right.$ cor aparente igual a $5 \mathrm{uC} ; \mathrm{V}_{2}$ cor aparente igual a $5 \mathrm{uC}$ ).

Diante disto, a dosagem adotada para a Água de Estudo 3 foi de $18,61 \mathrm{mgFe}^{3+} / \mathrm{L}$ de coagulante.

\subsubsection{Resumo dos Resultados da FASE - A / ETAPA - I}

Após a realização dos ensaios de flotateste seguidos da centrifugação das amostras, as dosagens de cloreto férrico escolhidas para a aplicação nas Fases B e C foram:

- $\quad$ ÁGUA DE ESTUDO - 1: dosagem de $\mathrm{FeCl}_{3}=14,47 \mathrm{mgFe}^{3+} / \mathrm{L}$;

- $\quad$ ÁGUA DE ESTUDO - 2: dosagem de $\mathrm{FeCl}_{3}=14,47 \mathrm{mgFe}^{3+} / \mathrm{L}$;

- $\quad$ ÁGUA DE ESTUDO - 3: dosagem de $\mathrm{FeCl}_{3}=18,61 \mathrm{mgFe}^{3+} / \mathrm{L}$.

A velocidade de flotação adotada para os ensaios posteriores foi a $\mathrm{V}=12 \mathrm{~cm} / \mathrm{min}$, devido aos resultados apresentados em termos de cor aparente e turbidez. 


\subsubsection{FASE - B}

O fluxograma que descreve esta fase está apresentado no capítulo Material e Métodos. De forma resumida os ensaios seguiram a seguinte seqüência: aplicação de CAP $(0 ; 10 ; 20$ e $30 \mathrm{mg} / \mathrm{L})$ com tempo de contato de $50 \mathrm{~s} \rightarrow$ pré-oxidação com hipoclorito de sódio $(0$ e 3,0 $\left.\mathrm{mgCl}_{2} / \mathrm{L}\right)$ com tempo de contato de $10 \mathrm{~s} \rightarrow$ coagulação com cloreto férrico $\left(14,47 \mathrm{mgFe}^{3+} / \mathrm{L}\right)$ $\rightarrow$ floculação $\rightarrow$ centrifugação. Os ensaios foram realizados com as três águas preparadas com o objetivo de avaliar a influência da concentração de microcistina no tratamento proposto.

Todo o tratamento, em escala de bancada, foi realizado com 1 litro de amostra no equipamento jarteste, devido ao grande volume de água de estudo necessário para cumprir a grade de ensaio proposta.

Os ensaios foram monitorados pelos parâmetros: $\mathrm{pH}$ de coagulação e cor aparente, turbidez, absorbância 254 nm e concentração de microcistina das amostras centrifugadas.

\subsubsection{1. Á́gua de Estudo 1 (FASE - B)}

As características da Água de Estudo - 1, referentes aos parâmetros avaliados, são: pH - 7,50; cor aparente - 586 uC; turbidez - 54,6 uT, absorbância 254 nm - 0,236; concentração de microcistina $-6,76 \mu \mathrm{g} / \mathrm{L}$.

A Tabela 5.23 apresenta os valores dos resultados dos ensaios da FASE - B da ETAPA - I para a água de estudo 1. 
Tabela 5.23: Valores dos resultados da FASE - B da ETAPA - I para Água de Estudo - 1.

\begin{tabular}{cccccccc}
\hline $\begin{array}{c}\text { Dosagem } \\
\mathrm{FeCl}_{3} \\
\left(\mathrm{mgFe}^{3+} / \mathrm{L}\right)\end{array}$ & $\begin{array}{c}\mathrm{CAP} \\
(\mathrm{mg} / \mathrm{L})\end{array}$ & $\begin{array}{c}\text { Dosagem } \\
\mathrm{Cl}_{2} \text { ativo } \\
\left(\mathrm{mgCl}_{2} / \mathrm{L}\right)\end{array}$ & $\mathrm{pH}$ & $\begin{array}{c}\text { Turbidez } \\
(\mathrm{uT})\end{array}$ & Cor $(\mathrm{uC})$ & $\begin{array}{c}\mathrm{ABS} \\
254 \mathrm{~nm}\end{array}$ & $\begin{array}{c}\mathrm{MC} \\
(\mu \mathrm{g} / \mathrm{L})\end{array}$ \\
\hline 14,47 & 0 & 0 & 7,22 & 0,99 & 22 & 0,082 & 2,71 \\
14,47 & 10 & 0 & 7,01 & 0,67 & 13 & 0,074 & 0,57 \\
14,47 & 20 & 0 & 6,84 & 1,72 & 11 & 0,049 & 0,88 \\
14,47 & 30 & 0 & 6,22 & 0,89 & 12 & 0,044 & 3,74 \\
\hline 14,47 & 0 & 3,0 & 7,26 & 3,15 & 92 & 0,440 & 0,20 \\
14,47 & 10 & 3,0 & 6,98 & 3,65 & 98 & 0,470 & 0,09 \\
14,47 & 20 & 3,0 & 7,29 & 3,66 & 105 & 0,500 & 0,08 \\
14,47 & 30 & 3,0 & 6,98 & 3,04 & 85 & 0,394 & 0,17 \\
\hline
\end{tabular}

Com os resultados da Tabela 5.23 foi possível elaborar as Figuras 5.45; 5.46; 5.47 e 5.48 .

Valores de turbidez e pH de coagulação

Água de Estudo 1

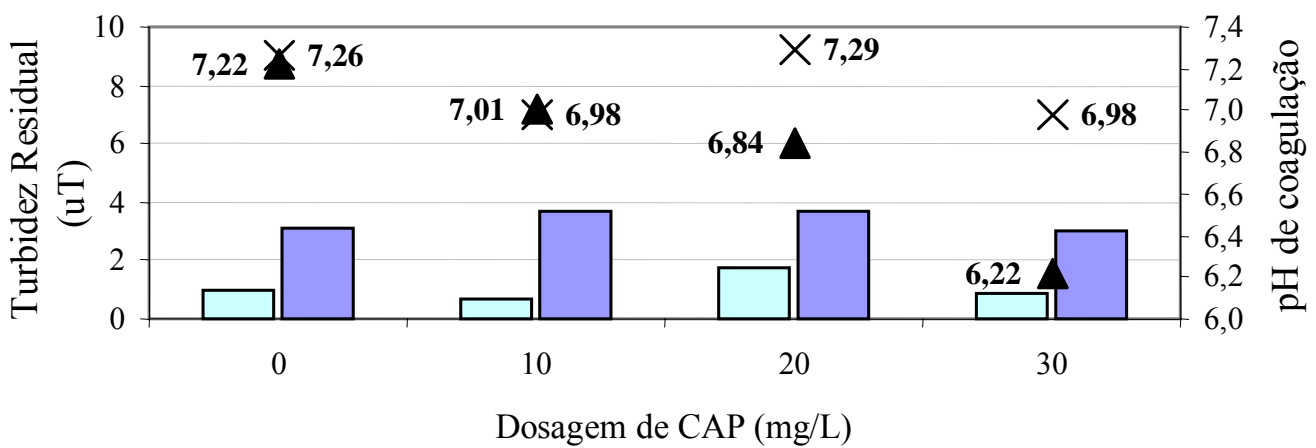

पTurb. $\left(0 \mathrm{mgCl}_{2} / \mathrm{L}\right) \quad \square$ Turb. $\left(3,0 \mathrm{mgCl}_{2} / \mathrm{L}\right) \quad \boldsymbol{\Delta} \mathrm{pH}\left(0 \mathrm{mgCl}_{2} / \mathrm{L}\right) \quad \times \mathrm{pH}\left(3,0 \mathrm{mgCl}_{2} / \mathrm{L}\right)$

Figura 5.45: Valores de turbidez e pH de coagulação - amostras centrifugadas - Água de Estudo - 1 . Água de estudo 1: Turbidez $=54,6 \mathrm{uT} ; \mathrm{MC}=6,76 \mu \mathrm{g} / \mathrm{L}$.

Condições do ensaio: Aplicação de $\mathrm{CAP}(10,20$ e $30 \mathrm{mg} / \mathrm{L})$; Pré-cloração $\left(3,0 \mathrm{mgCl}_{2} / \mathrm{L}\right)$; Coagulação $\left(\mathrm{D}_{\mathrm{FeCl}}=\right.$ $\left.14,47 \mathrm{mgFe} e^{3+} / \mathrm{L} ; \mathrm{Vr}_{\mathrm{MR}}=350 \mathrm{rpm} ; \mathrm{T}_{\mathrm{MR}}=20 \mathrm{~s}\right)$; Floculação $\left(\mathrm{Vr}_{\mathrm{FLO}}=68 \mathrm{rpm} ; \mathrm{T}_{\mathrm{FLO}}=18 \mathrm{~min}\right)$; Centrifugação $\left(\mathrm{f}_{\mathrm{CEN}}=\right.$ $2000 \mathrm{rpm} ; \mathrm{T}_{\mathrm{CEN}}=15 \mathrm{~min}$ ). 
Valores de cor aparente e pH de coagulação

Água de Estudo 1

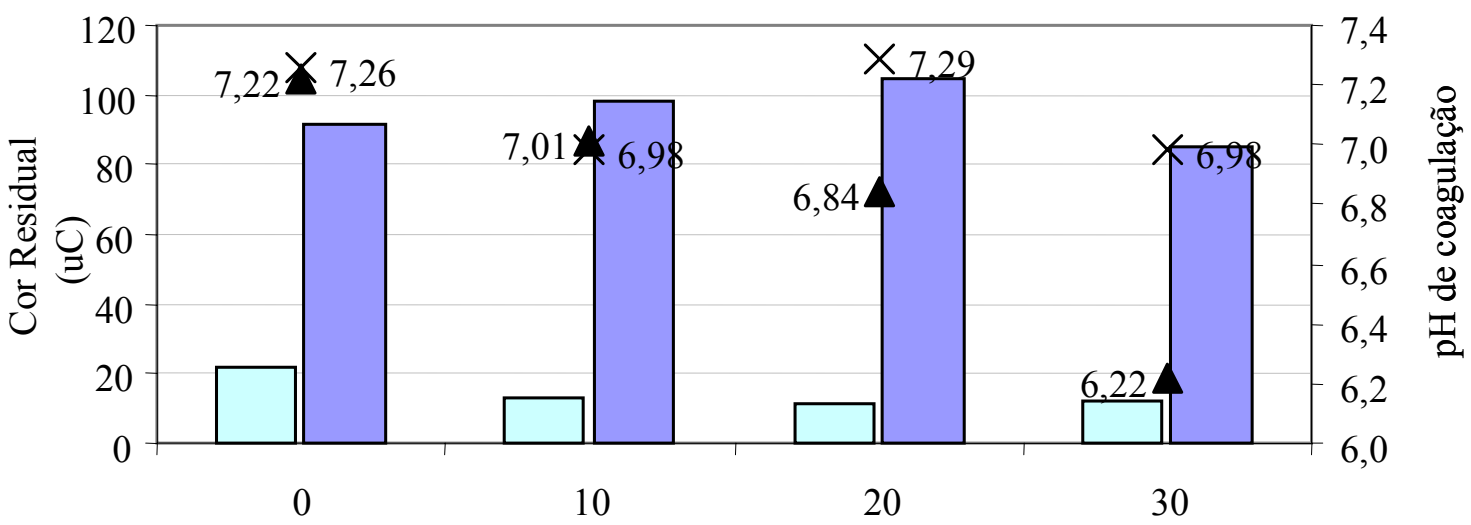

Dosagem de CAP $(\mathrm{mg} / \mathrm{L})$

$\square \operatorname{Cor}\left(0 \mathrm{mgCl}_{2} / \mathrm{L}\right) \quad \square \operatorname{Cor} \mathrm{Cl} 2\left(3,0 \mathrm{mgCl}_{2} / \mathrm{L}\right) \Delta \mathrm{pH}\left(0 \mathrm{mgCl}_{2} / \mathrm{L}\right) \times \mathrm{pH} \mathrm{Cl} 2\left(3,0 \mathrm{mgCl}_{2} / \mathrm{L}\right)$

Figura 5.46: Valores de cor aparente e pH de coagulação - amostras centrifugadas - Água de Estudo - 1. Água de estudo 1: Cor aparente $=586 \mathrm{uC} ; \mathrm{MC}=6,76 \mu \mathrm{g} / \mathrm{L}$.

Condições do ensaio: Aplicação de CAP $(10,20$ e $30 \mathrm{mg} / \mathrm{L})$; Pré-cloração $\left(3,0 \mathrm{mgCl}_{2} / \mathrm{L}\right)$; Coagulação $\left(\mathrm{D}_{\mathrm{FeCl}}=\right.$ $\left.14,47 \mathrm{mgFe} e^{3+} / \mathrm{L} ; \mathrm{Vr}_{\mathrm{MR}}=350 \mathrm{rpm} ; \mathrm{T}_{\mathrm{MR}}=20 \mathrm{~s}\right)$; Floculação $\left(\mathrm{Vr}_{\mathrm{FLO}}=68 \mathrm{rpm} ; \mathrm{T}_{\mathrm{FLO}}=18 \mathrm{~min}\right)$; Centrifugação $\left(\mathrm{f}_{\mathrm{CEN}}=\right.$ $\left.2000 \mathrm{rpm} ; \mathrm{T}_{\mathrm{CEN}}=15 \mathrm{~min}\right)$.

Valores de ABS $254 \mathrm{~nm}$ e pH de coagulação Água de Estudo 1

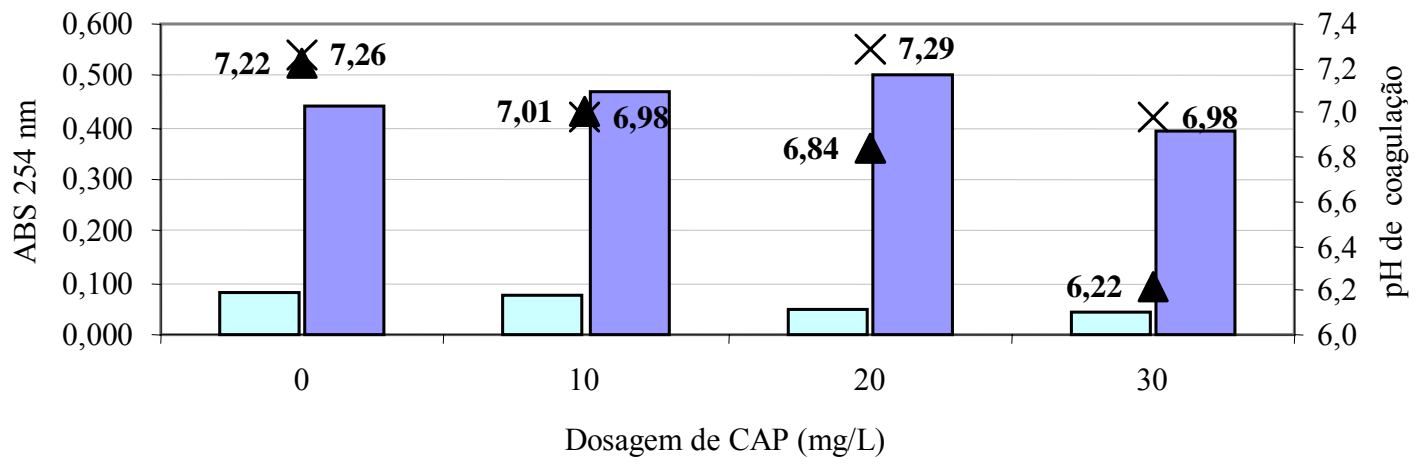

$\square$ ABS $254\left(0 \mathrm{mgCl}_{2} / \mathrm{L}\right) \square \mathrm{ABS} 254\left(3,0 \mathrm{mgCl}_{2} / \mathrm{L}\right) \Delta \mathrm{pH}\left(0 \mathrm{mgCl}_{2} / \mathrm{L}\right) \times \mathrm{pH}\left(3,0 \mathrm{mgCl} \mathrm{L}_{2} / \mathrm{L}\right)$

Figura 5.47: Valores de ABS $254 \mathrm{~nm}$ e pH de coagulação - amostras centrifugadas - Água de Estudo - 1. Água de estudo 1: ABS $254 \mathrm{~nm}=0,236 ; \mathrm{MC}=6,76 \mu \mathrm{g} / \mathrm{L}$.

Condições do ensaio: Aplicação de CAP $(10,20$ e $30 \mathrm{mg} / \mathrm{L})$; Pré-cloração $\left(3,0 \mathrm{mgCl}_{2} / \mathrm{L}\right)$; Coagulação $\left(\mathrm{D}_{\mathrm{FeCl} 13}=\right.$ $\left.14,47 \mathrm{mgFe} e^{3+} / \mathrm{L} ; \mathrm{Vr}_{\mathrm{MR}}=350 \mathrm{rpm} ; \mathrm{T}_{\mathrm{MR}}=20 \mathrm{~s}\right)$; Floculação $\left(\mathrm{Vr}_{\mathrm{FLO}}=68 \mathrm{rpm} ; \mathrm{T}_{\mathrm{FLO}}=18 \mathrm{~min}\right)$; Centrifugação $\left(\mathrm{f}_{\mathrm{CEN}}=\right.$ $\left.2000 \mathrm{rpm} ; \mathrm{T}_{\mathrm{CEN}}=15 \mathrm{~min}\right)$. 
Valores de MC

Água de Estudo 1

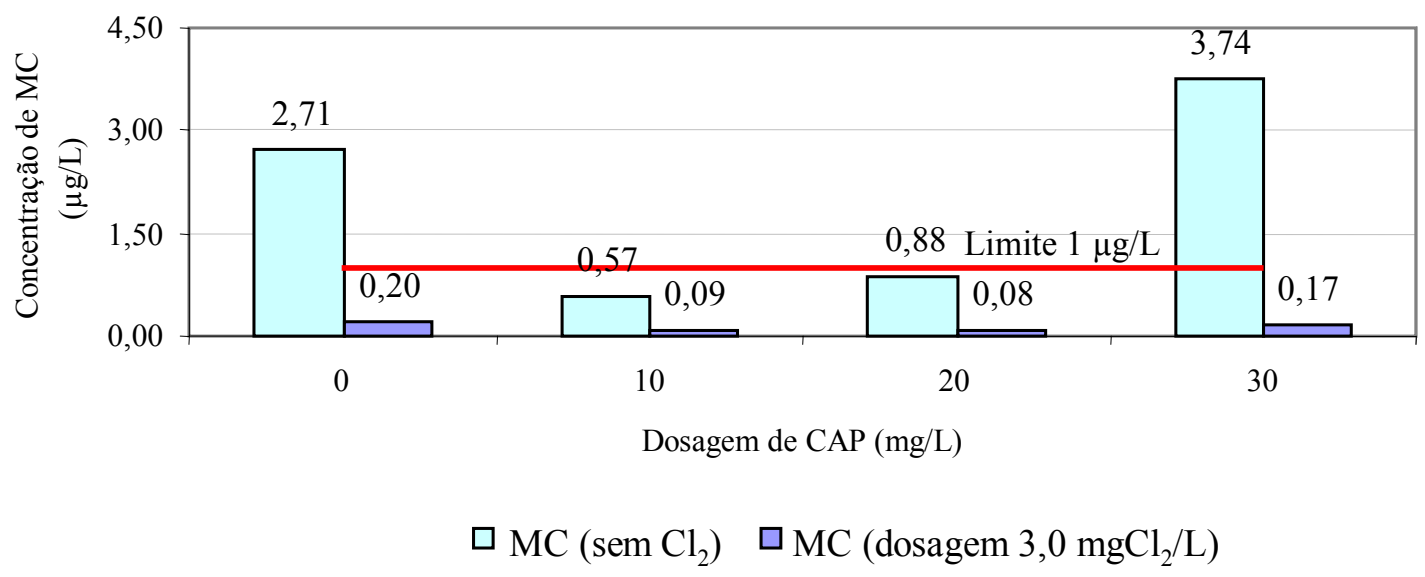

Figura 5.48: Valores de concentração de microcistina (MC) - amostras centrifugadas - Água de Estudo - 1. Água de estudo $1: \mathrm{MC}=6,76 \mu \mathrm{g} / \mathrm{L}$.

Condições do ensaio: Aplicação de CAP (10, 20 e $30 \mathrm{mg} / \mathrm{L})$; Pré-cloração $\left(3,0 \mathrm{mgCl}_{2} / \mathrm{L}\right)$; Coagulação $\left(\mathrm{D}_{\mathrm{FeCl}}=\right.$ $\left.14,47 \mathrm{mgFe} e^{3+} / \mathrm{L} ; \mathrm{Vr}_{\mathrm{MR}}=350 \mathrm{rpm} ; \mathrm{T}_{\mathrm{MR}}=20 \mathrm{~s}\right)$; Floculação $\left(\mathrm{Vr}_{\mathrm{FLO}}=68 \mathrm{rpm} ; \mathrm{T}_{\mathrm{FLO}}=18 \mathrm{~min}\right)$; Centrifugação $\left(\mathrm{f}_{\mathrm{CEN}}=\right.$ $\left.2000 \mathrm{rpm} ; \mathrm{T}_{\mathrm{CEN}}=15 \mathrm{~min}\right)$.

Para auxiliar na apresentação dos dados, nas figuras em que estão apresentados os valores de $\mathrm{pH}$ de coagulação, este dado é colocado à direita do marcador do gráfico para os ensaios sem a aplicação de hipoclorito de sódio. Já nos ensaios em que se aplicou o oxidante, o pH de coagulação é apresentado à esquerda do marcador do gráfico.

Conforme os resultados apresentados, vê-se que o pH de coagulação tem fundamental importância na qualidade da água tratada. O oxidante aplicado tem característica alcalina, visto o aumento do $\mathrm{pH}$ de coagulação com a aplicação do hipoclorito antes da mistura rápida. $\mathrm{O}$ valor do $\mathrm{pH}$ de coagulação, da Água de Estudo 1, foi igual a 5,72 para $14,47 \mathrm{mgFe} \mathrm{s}^{3+} / \mathrm{L}$ durante a escolha da dosagem de coagulante (FASE - A).

Na Figura 5.45, percebe-se que elevou a turbidez da água tratada com o aumento da dosagem de CAP sem a aplicação de hipoclorito de sódio na pré-cloração da água de estudo. Esta figura mostra a clara interferência do $\mathrm{pH}$ de coagulação na qualidade da água produzida, sendo que, com a aplicação de $3 \mathrm{mg} / \mathrm{L}$ de oxidante (hipoclorito de sódio) ocorreu uma piora nos valores de turbidez residual das amostras. Todos os valores de turbidez resultaram acima 
de 1 uT com a aplicação do oxidante, indicando que maiores dosagens de coagulante seriam requeridas, provavelmente pela ação alcalinizante do hipoclorito de sódio.

Com relação ao parâmetro de cor aparente (Figura 5.46), o aumento da dosagem de carvão não prejudicou a qualidade da água tratada, sendo que os valores resultaram entre 11 e $13 \mathrm{uC}$ quando foi dosado CAP. Entretanto, nos ensaios com pré-cloração, as amostras apresentaram elevados valores de cor aparente com e sem a aplicação do carvão. Os valores de cor aparente ficaram entre 85 e $105 \mathrm{uC}$.

O valor da absorbância no comprimento de onda $\lambda=254 \mathrm{~nm}$ é um indicador da matéria orgânica dissolvida na água. Vê-se pela Figura 5.47, que houve redução dos valores de absorbância com o aumento da dosagem de carvão ativado sem a aplicação de hipoclorito de sódio. O que não ocorreu quando foram aplicados $3,0 \mathrm{mg} / \mathrm{L}$ de hipoclorito, visto que tais valores de absorbância resultaram maiores que na condição anterior.

Quando foram aplicados 10 e $20 \mathrm{mg} / \mathrm{L}$ de CAP o residual de microcistina foi inferior a $1 \mu \mathrm{g} / \mathrm{L}$. Por outro lado, a aplicação de oxidante proporcionou resultados abaixo de $1 \mu \mathrm{g} / \mathrm{L}$ mesmo sem a aplicação do carvão ativado (Figura 5.48). A melhor situação, em termos de concentração residual e microcistina, foi obtida com a aplicação de $10 \mathrm{mg} / \mathrm{L}$ de CAP associada à pré-oxidação com $3,0 \mathrm{mgCl}_{2} / \mathrm{L}$. Nesse caso, obteve-se residual de microcistina de $0,092 \mu \mathrm{g} / \mathrm{L}$.

\subsubsection{2. Água de Estudo 2 (FASE - B)}

As características da Água de Estudo - 2 são: $\mathrm{pH}$ - 7,03; cor aparente - 452 uC; turbidez - 47,3 uT, absorbância 254 nm - 0,278; concentração de microcistina - 25,84 $\mu \mathrm{g} / \mathrm{L}$. 
Os resultados da FASE - B da ETAPA - I, para a água de estudo 2, estão apresentados na Tabela 5.24.

Tabela 5.24: Valores dos resultados da FASE - B da ETAPA - I para Água de Estudo - 2.

\begin{tabular}{cccccccc}
\hline \hline $\begin{array}{c}\text { Dosagem } \\
\mathrm{FeCl}_{3} \\
\left(\mathrm{mgFe}^{3+} / \mathrm{L}\right)\end{array}$ & $\begin{array}{c}\mathrm{CAP} \\
(\mathrm{mg} / \mathrm{L})\end{array}$ & $\begin{array}{c}\text { Dosagem } \\
\mathrm{Cl}_{2} \text { ativo } \\
\left(\mathrm{mgCl}_{2} / \mathrm{L}\right)\end{array}$ & $\mathrm{pH}$ & $\begin{array}{c}\text { Turbidez } \\
(\mathrm{uT})\end{array}$ & Cor $(\mathrm{uC})$ & $\begin{array}{c}\mathrm{ABS} \\
254 \mathrm{~nm}\end{array}$ & $\begin{array}{c}\mathrm{MC} \\
(\mu \mathrm{g} / \mathrm{L})\end{array}$ \\
\hline \hline 14,47 & 0 & 0 & 7,21 & 4,57 & 33 & 0,075 & 15,95 \\
14,47 & 10 & 0 & 6,69 & 1,98 & 25 & 0,063 & 5,28 \\
14,47 & 20 & 0 & 7,35 & 2,76 & 27 & 0,066 & 6,63 \\
14,47 & 30 & 0 & 7,27 & 1,39 & 12 & 0,058 & 3,03 \\
\hline 14,47 & 0 & 3,0 & 7,30 & 5,48 & 43 & 0,092 & 0,78 \\
14,47 & 10 & 3,0 & 7,19 & 9,17 & 77 & 0,084 & 0,39 \\
14,47 & 20 & 3,0 & 7,45 & 3,53 & 33 & 0,082 & 0,75 \\
14,47 & 30 & 3,0 & 7,25 & 2,49 & 36 & 0,087 & 0,42 \\
\hline
\end{tabular}

Com os resultados da Tabela 5.24, foram elaboradas as Figuras 5.49; 5.50; 5.51 e 5.52.

Valores de turbidez e pH de coagulação

Água de Estudo 2

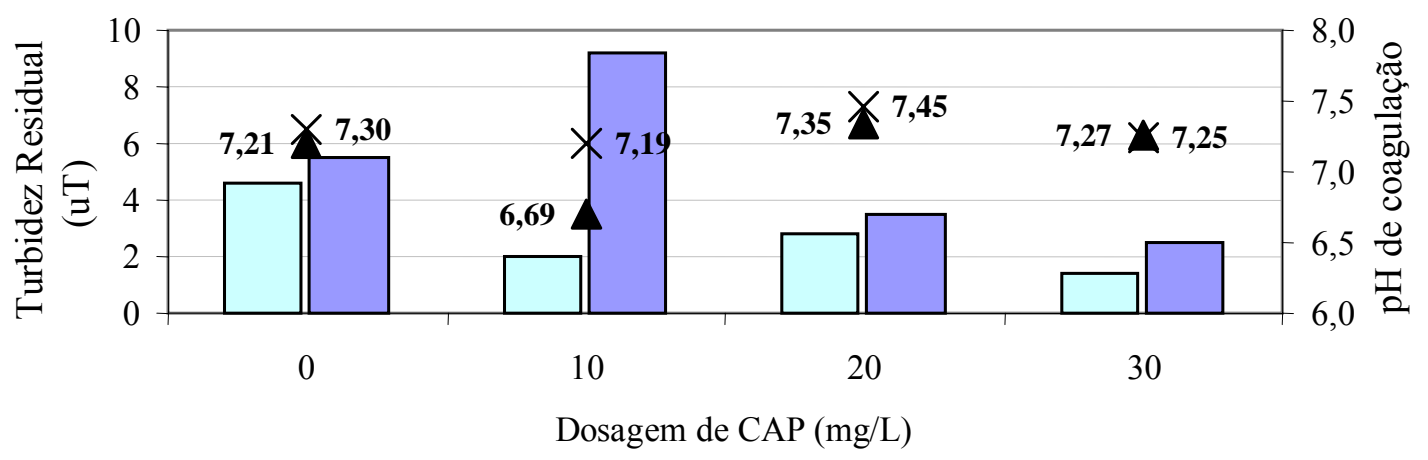

$\square$ Turb. $\left(0 \mathrm{mgCl}_{2} / \mathrm{L}\right) \quad \square$ Turb. $\left(3,0 \mathrm{mgCl}_{2} / \mathrm{L}\right) \quad \boldsymbol{\Delta} \mathrm{pH}\left(0 \mathrm{mgCl}_{2} / \mathrm{L}\right) \quad \times \mathrm{pH}\left(3,0 \mathrm{mgCl}_{2} / \mathrm{L}\right)$

Figura 5.49: Valores de turbidez e pH de coagulação - amostras centrifugadas - Água de Estudo - 2. Água de estudo 2: Turbidez $=47,3 \mathrm{uT} ; \mathrm{MC}=25,84 \mu \mathrm{g} / \mathrm{L}$.

Condições do ensaio: Aplicação de CAP (10, 20 e $30 \mathrm{mg} / \mathrm{L})$; Pré-cloração $\left(3,0 \mathrm{mgCl}_{2} / \mathrm{L}\right)$; Coagulação $\left(\mathrm{D}_{\mathrm{FeCl}}=\right.$ $\left.14,47 \mathrm{mgFe} e^{3+} / \mathrm{L} ; \mathrm{Vr}_{\mathrm{MR}}=350 \mathrm{rpm} ; \mathrm{T}_{\mathrm{MR}}=20 \mathrm{~s}\right)$; Floculação $\left(\mathrm{Vr}_{\mathrm{FLO}}=68 \mathrm{rpm} ; \mathrm{T}_{\mathrm{FLO}}=18 \mathrm{~min}\right)$; Centrifugação $\left(\mathrm{f}_{\mathrm{CEN}}=\right.$ $\left.2000 \mathrm{rpm} ; \mathrm{T}_{\mathrm{CEN}}=15 \mathrm{~min}\right)$. 
Valores de cor aparente e pH de coagulação

Água de Estudo 2

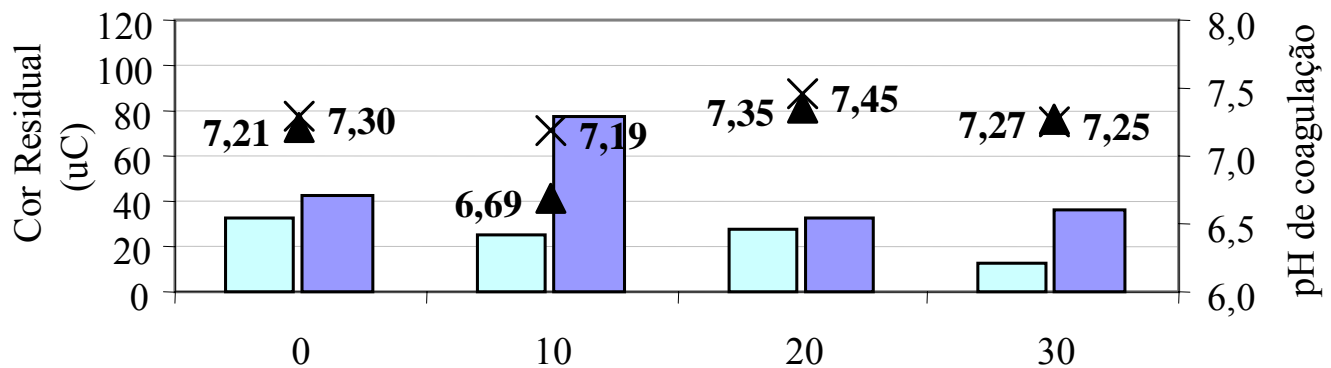

Dosagem de CAP $(\mathrm{mg} / \mathrm{L})$

$\square \operatorname{Cor}\left(0 \mathrm{mgCl}_{2} / \mathrm{L}\right) \quad \square \operatorname{Cor} \mathrm{Cl} 2\left(3,0 \mathrm{mgCl}_{2} / \mathrm{L}\right) \quad \mathbf{\Delta}_{\mathrm{pH}}\left(0 \mathrm{mgCl}_{2} / \mathrm{L}\right) \quad \times \mathrm{pH}(3,0 \mathrm{mgCl} / \mathrm{L})$

Figura 5.50: Valores de cor aparente e pH de coagulação - amostras centrifugadas - Água de Estudo - 2. Água de estudo 2: Cor aparente $=452 \mathrm{uC} ; \mathrm{MC}=25,84 \mu \mathrm{g} / \mathrm{L}$.

Condições do ensaio: Aplicação de CAP (10, 20 e $30 \mathrm{mg} / \mathrm{L})$; Pré-cloração $\left(3,0 \mathrm{mgCl}_{2} / \mathrm{L}\right)$; Coagulação $\left(\mathrm{D}_{\mathrm{FeCl}}=\right.$ $\left.14,47 \mathrm{mgFe} e^{3+} / \mathrm{L} ; \mathrm{Vr}_{\mathrm{MR}}=350 \mathrm{rpm} ; \mathrm{T}_{\mathrm{MR}}=20 \mathrm{~s}\right)$; Floculação $\left(\mathrm{Vr}_{\mathrm{FLO}}=68 \mathrm{rpm} ; \mathrm{T}_{\mathrm{FLO}}=18 \mathrm{~min}\right)$; Centrifugação $\left(\mathrm{f}_{\mathrm{CEN}}=\right.$ $\left.2000 \mathrm{rpm} ; \mathrm{T}_{\mathrm{CEN}}=15 \mathrm{~min}\right)$.

Valores de ABS $254 \mathrm{~nm}$ e pH de coagulação

Água de Estudo 2

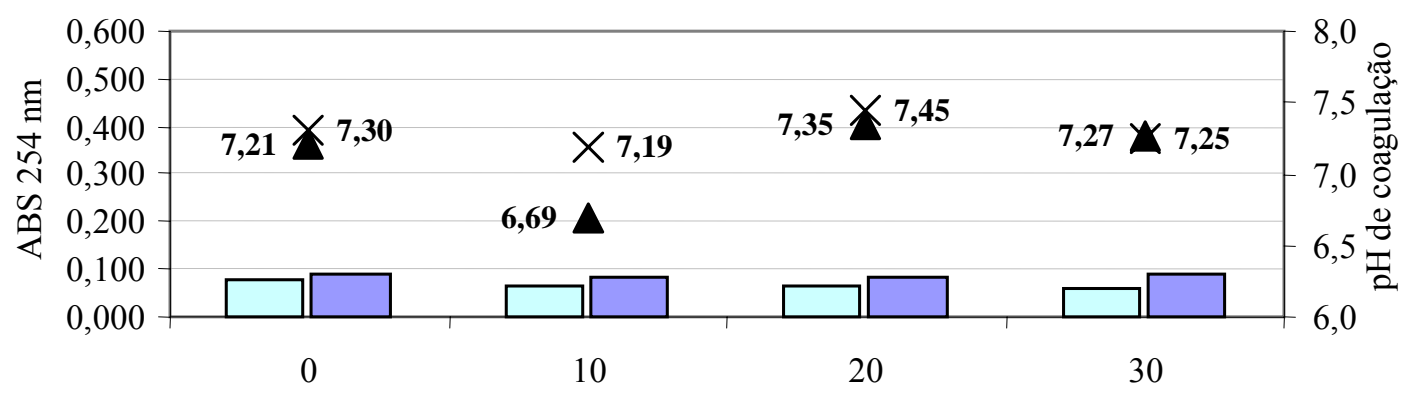

Dosagem de CAP (mg/L)

$\square$ ABS $254\left(0 \mathrm{mgCl}_{2} / \mathrm{L}\right) \square \mathrm{ABS} 254\left(3,0 \mathrm{mgCl}_{2} / \mathrm{L}\right) \Delta \mathrm{pH}\left(0 \mathrm{mgCl}_{2} / \mathrm{L}\right) \times \mathrm{pH}\left(3,0 \mathrm{mgCl}_{2} / \mathrm{L}\right)$

Figura 5.51: Valores de ABS $254 \mathrm{~nm}$ e pH de coagulação - amostras centrifugadas - Água de Estudo - 2. Água de estudo 2: ABS $254 \mathrm{~nm}=0,278 ; \mathrm{MC}=25,84 \mu \mathrm{g} / \mathrm{L}$.

Condições do ensaio: Aplicação de CAP (10, 20 e $30 \mathrm{mg} / \mathrm{L})$; Pré-cloração $\left(3,0 \mathrm{mgCl}_{2} / \mathrm{L}\right)$; Coagulação $\left(\mathrm{D}_{\mathrm{FeCl}}=\right.$ $\left.14,47 \mathrm{mgFe}^{3+} / \mathrm{L} ; \mathrm{Vr}_{\mathrm{MR}}=350 \mathrm{rpm} ; \mathrm{T}_{\mathrm{MR}}=20 \mathrm{~s}\right) ;$ Floculação $\left(\mathrm{Vr}_{\mathrm{FLO}}=68 \mathrm{rpm} ; \mathrm{T}_{\mathrm{FLO}}=18 \mathrm{~min}\right)$; Centrifugação ( $\mathrm{f}_{\mathrm{CEN}}=$ $\left.2000 \mathrm{rpm} ; \mathrm{T}_{\mathrm{CEN}}=15 \mathrm{~min}\right)$. 


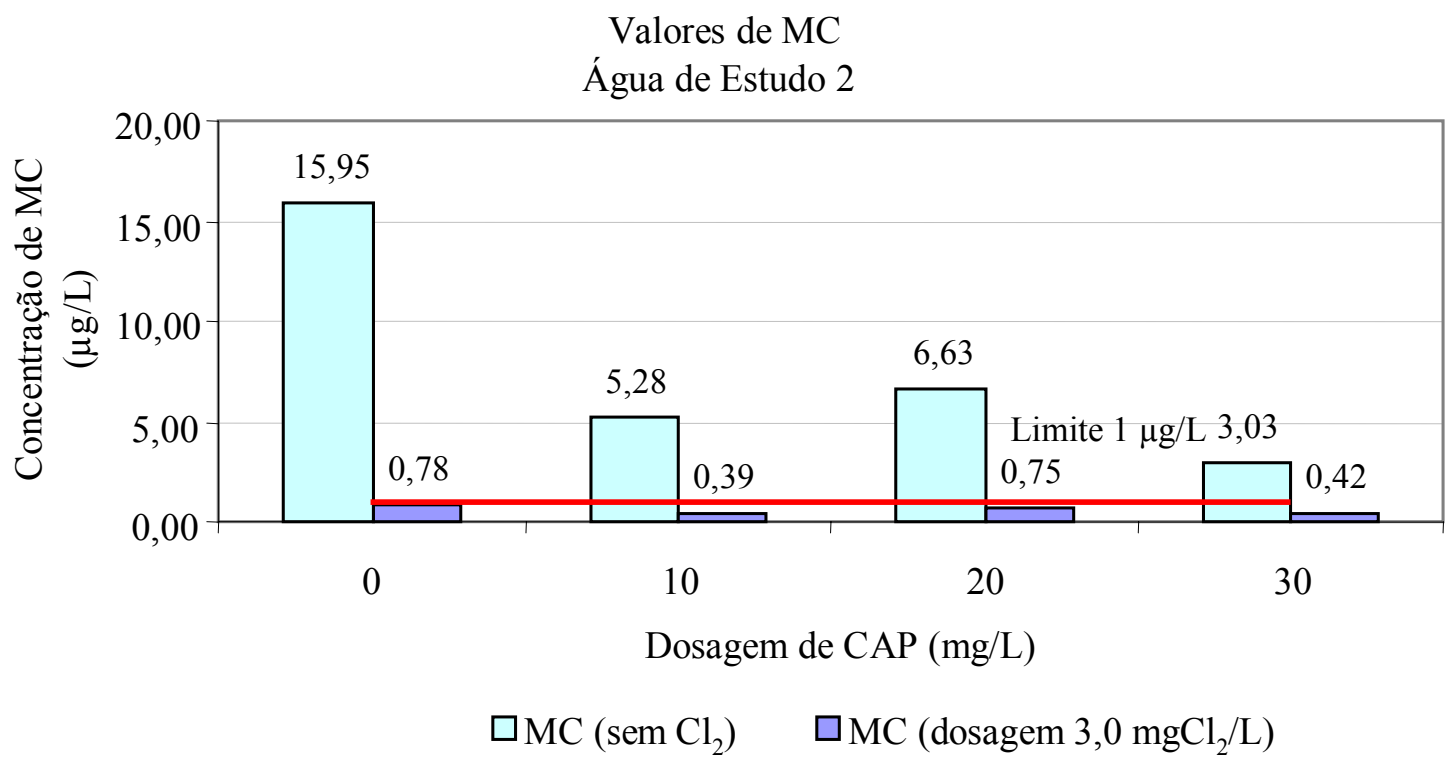

Figura 5.52: Valores de concentração de microcistina (MC) - amostras centrifugadas - Água de Estudo - 2. Água de estudo $2: \mathrm{MC}=25,84 \mu \mathrm{g} / \mathrm{L}$.

Condições do ensaio: Aplicação de CAP (10, 20 e $30 \mathrm{mg} / \mathrm{L})$; Pré-cloração $\left(3,0 \mathrm{mgCl}_{2} / \mathrm{L}\right)$; Coagulação $\left(\mathrm{D}_{\mathrm{FeCl}}=\right.$ $\left.14,47 \mathrm{mgFe} e^{3+} / \mathrm{L} ; \mathrm{Vr}_{\mathrm{MR}}=350 \mathrm{rpm} ; \mathrm{T}_{\mathrm{MR}}=20 \mathrm{~s}\right)$; Floculação $\left(\mathrm{Vr}_{\mathrm{FLO}}=68 \mathrm{rpm} ; \mathrm{T}_{\mathrm{FLO}}=18 \mathrm{~min}\right)$; Centrifugação $\left(\mathrm{f}_{\mathrm{CEN}}=\right.$ $\left.2000 \mathrm{rpm} ; \mathrm{T}_{\mathrm{CEN}}=15 \mathrm{~min}\right)$.

A aplicação do oxidante interferiu de forma negativa no tratamento da água de estudo - 2, segundo os parâmetros de turbidez, cor aparente e absorbância 254 nm, como observado nos resultados da água de estudo -1 .

Todos os valores de turbidez, dos ensaios sem aplicação do oxidante, resultaram acima do limite estabelecido para este parâmetro (1 uT). E novamente foi verificada a influência negativa do oxidante nos residuais de turbidez das amostras centrifugadas, fato que está relacionado à variação do $\mathrm{pH}$ de coagulação (Figura 5.49). Esta influência pode ser confirmada nos dados de cor aparente (Figura 5.50), visto que as amostras apresentaram maiores valores de cor quando foi aplicado o hipoclorito de sódio. O melhor resultado de cor aparente foi com a aplicação de $30 \mathrm{mg} / \mathrm{L}$ de CAP sem oxidante (cor parente $=12 \mathrm{uC}$ ).

A Figura 5.51 mostra que o aumento da dosagem de CAP não alterou significativamente os resultados de ABS $254 \mathrm{~nm}$ comparadas com a amostra sem CAP. Nos ensaios sem a aplicação de hipoclorito de sódio os valores variaram entre 0,058 e 0,075 . A 
aplicação do oxidante não prejudicou, de forma relevante, a caracterização das amostras segundo este parâmetro. Os valores de absorbância ficaram entre 0,082 e 0,092.

Conforme a Figura 5.52, os ensaios, em que foi aplicado somente o carvão ativado em pó, não foram capazes de reduzir a concentração de microcistina abaixo de $1 \mu \mathrm{g} / \mathrm{L}$. O melhor resultado foi com a aplicação de $30 \mathrm{mg} / \mathrm{L}$ de CAP, com remoção de aproximadamente $88 \%$ que representa a concentração residual de microcistina igual a 3,03 $\mu \mathrm{g} / \mathrm{L}$. Quando foi combinada a adsorção e a pré-oxidação, todos os resultados ficaram abaixo do limite estabelecido, sendo que, a aplicação de $30 \mathrm{mg} / \mathrm{L}$ de $\mathrm{CAP}$ e $3,0 \mathrm{mgCl}_{2} / \mathrm{L}$ de cloro livre resultou em um residual de $0,417 \mu \mathrm{g} / \mathrm{L}$, aproximadamente $98 \%$ de remoção.

\subsubsection{3. Água de Estudo 3 (FASE - B)}

As características da Água de Estudo - 3 são: $\mathrm{pH}$ - 7,33; cor aparente - 315 uC; turbidez - 28,4 uT, absorbância 254 nm - 0,209; concentração de microcistina - 104,92 $\mu \mathrm{g} / \mathrm{L}$.

A Tabela 5.25 apresenta os resultados da FASE - B da ETAPA - I para a Água de Estudo -3

Tabela 5.25: Valores dos resultados da FASE - B da ETAPA - I para Água de Estudo - 3.

\begin{tabular}{cccccccc}
\hline \hline $\begin{array}{c}\text { Dosagem } \\
\mathrm{FeCl}_{3} \\
(\mathrm{mgFe} / \mathrm{L})\end{array}$ & $\begin{array}{c}\mathrm{CAP} \\
(\mathrm{mg} / \mathrm{L})\end{array}$ & $\begin{array}{c}\text { Dosagem } \\
\mathrm{Cl}_{2} \text { ativo } \\
\left(\mathrm{mgCl}_{2} / \mathrm{L}\right)\end{array}$ & $\mathrm{pH}$ & $\begin{array}{c}\text { Turbidez } \\
(\mathrm{uT})\end{array}$ & $\mathrm{Cor}(\mathrm{uC})$ & $\begin{array}{c}\mathrm{ABS} \\
254 \mathrm{~nm}\end{array}$ & $\begin{array}{c}\mathrm{MC} \\
(\mu \mathrm{g} / \mathrm{L})\end{array}$ \\
\hline \hline 18,61 & 0 & 0 & 6,33 & 6,21 & 31 & 0,096 & 3,81 \\
18,61 & 10 & 0 & 6,23 & 3,96 & 22 & 0,073 & 7,47 \\
18,61 & 20 & 0 & 6,25 & 3,68 & 31 & 0,083 & 6,69 \\
18,61 & 30 & 0 & 6,20 & 1,24 & 16 & 0,065 & 1,93 \\
\hline 18,61 & 0 & 3,0 & 6,21 & 4,76 & 55 & 0,127 & 2,73 \\
18,61 & 10 & 3,0 & 6,07 & 5,92 & 60 & 0,128 & 2,93 \\
18,61 & 20 & 3,0 & 6,28 & 9,3 & 93 & 0,138 & 7,96 \\
18,61 & 30 & 3,0 & 6,18 & 5,36 & 80 & 0,114 & 1,86 \\
\hline
\end{tabular}


As Figuras $5.53 ; 5.54 ; 5.55$ e 5.56 foram elaboradas a partir dos dados apresentados na

Tabela 5.25.

Valores de turbidez e pH de coagulação

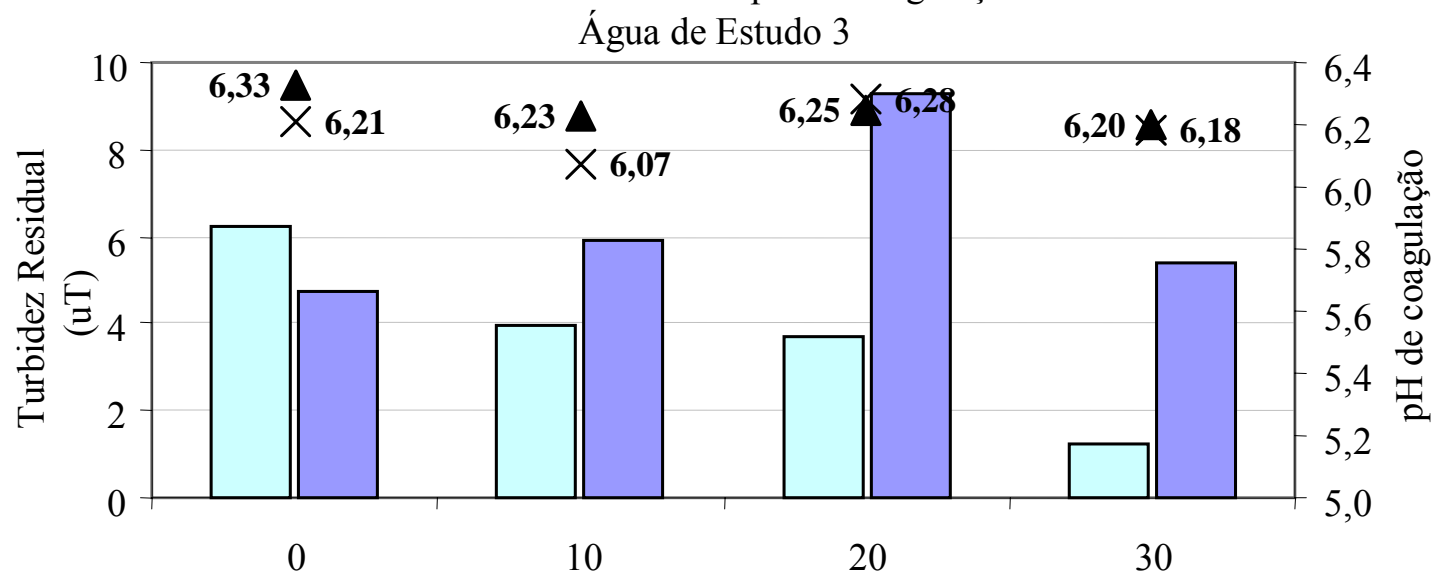

Dosagem de CAP (mg/L)

$\square$ Turb. $\left(0 \mathrm{mgCl}_{2} / \mathrm{L}\right) \quad \square$ Turb. $\left(3,0 \mathrm{mgCl}_{2} / \mathrm{L}\right) \quad \boldsymbol{\Delta} \mathrm{pH}\left(0 \mathrm{mgCl}_{2} / \mathrm{L}\right) \quad \times \mathrm{pH}\left(3,0 \mathrm{mgCl}_{2} / \mathrm{L}\right)$

Figura 5.53: Valores de turbidez e pH de coagulação - amostras centrifugadas - Água de Estudo - 3. Água de estudo 3: Turbidez $=28,4 \mathrm{uT} ; \mathrm{MC}=104,92 \mu \mathrm{g} / \mathrm{L}$.

Condições do ensaio: Aplicação de CAP $(10,20$ e $30 \mathrm{mg} / \mathrm{L})$; Pré-cloração $\left(3,0 \mathrm{mgCl}_{2} / \mathrm{L}\right)$; Coagulação $\left(\mathrm{D}_{\mathrm{FeCl}}=\right.$ $\left.18,61 \mathrm{mgFe}^{3+} / \mathrm{L} ; \mathrm{Vr}_{\mathrm{MR}}=350 \mathrm{rpm} ; \mathrm{T}_{\mathrm{MR}}=20 \mathrm{~s}\right)$; Floculação $\left(\mathrm{Vr}_{\mathrm{FLO}}=68 \mathrm{rpm} ; \mathrm{T}_{\mathrm{FLO}}=18 \mathrm{~min}\right)$; Centrifugação $\left(\mathrm{f}_{\mathrm{CEN}}=\right.$ $\left.2000 \mathrm{rpm} ; \mathrm{T}_{\mathrm{CEN}}=15 \mathrm{~min}\right)$.

Valores de cor aparente e pH de coagulação

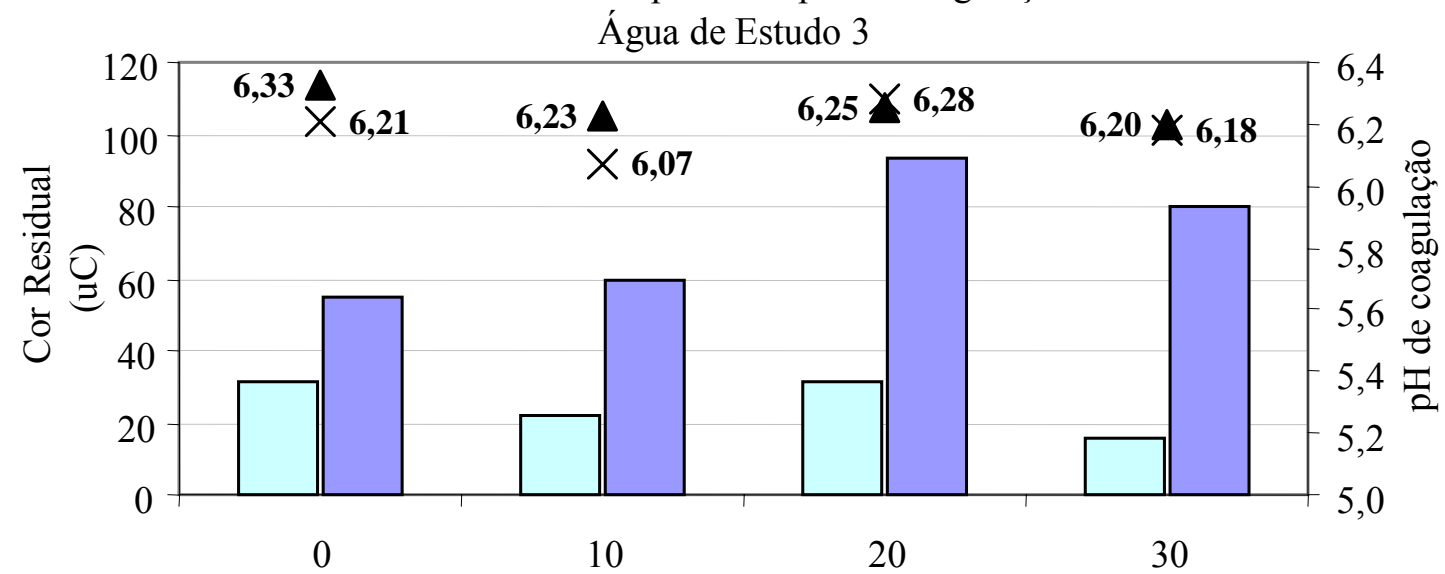

Dosagem de CAP (mg/L)

$\square \operatorname{Cor}\left(0 \mathrm{mgCl}_{2} / \mathrm{L}\right) \quad \square \operatorname{Cor} \mathrm{Cl} 2\left(3,0 \mathrm{mgCl}_{2} / \mathrm{L}\right) \quad \Delta \mathrm{pH}\left(0 \mathrm{mgCl}_{2} / \mathrm{L}\right) \quad \times \mathrm{pH}\left(3,0 \mathrm{mgCl}_{2} / \mathrm{L}\right)$

Figura 5.54: Valores de cor aparente e pH de coagulação - amostras centrifugadas - Água de Estudo - 3. Água de estudo 3: Cor aparente $=315 \mathrm{uC} ; \mathrm{MC}=104,92 \mu \mathrm{g} / \mathrm{L}$.

Condições do ensaio: Aplicação de CAP (10, 20 e $30 \mathrm{mg} / \mathrm{L})$; Pré-cloração $\left(3,0 \mathrm{mgCl}_{2} / \mathrm{L}\right)$; Coagulação $\left(\mathrm{D}_{\mathrm{FeCl}}=\right.$ $\left.18,61 \mathrm{mgFe} e^{3+} / \mathrm{L} ; \mathrm{Vr}_{\mathrm{MR}}=350 \mathrm{rpm} ; \mathrm{T}_{\mathrm{MR}}=20 \mathrm{~s}\right) ;$ Floculação $\left(\mathrm{Vr}_{\mathrm{FLO}}=68 \mathrm{rpm} ; \mathrm{T}_{\mathrm{FLO}}=18 \mathrm{~min}\right)$; Centrifugação $\left(\mathrm{f}_{\mathrm{CEN}}=\right.$ $\left.2000 \mathrm{rpm} ; \mathrm{T}_{\mathrm{CEN}}=15 \mathrm{~min}\right)$. 
Valores de ABS254nm e pH de coagulação

Água de Estudo 3

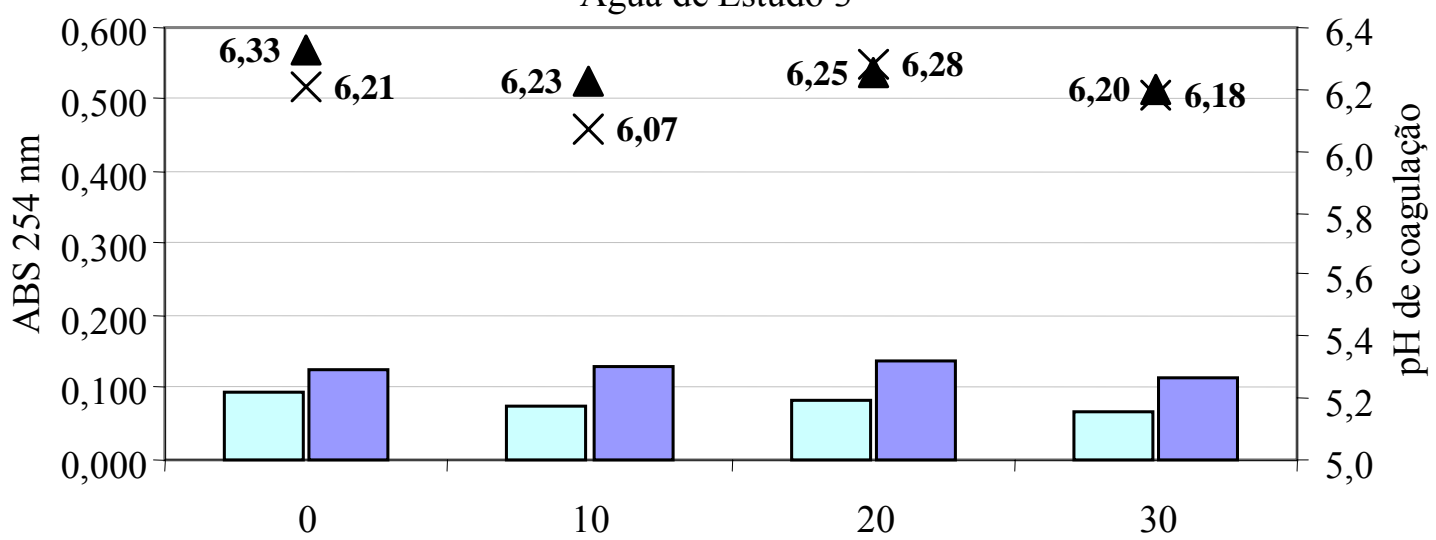

Dosagem de CAP (mg/L)

$\square$ ABS $254\left(0 \mathrm{mgCl}_{2} / \mathrm{L}\right) \quad \square \mathrm{ABS} 254\left(3,0 \mathrm{mgCl}_{2} / \mathrm{L}\right) \quad \boldsymbol{\Delta} \mathrm{pH}\left(0 \mathrm{mgCl}_{2} / \mathrm{L}\right) \quad \times \mathrm{pH}\left(3,0 \mathrm{mgCl}_{2} / \mathrm{L}\right)$

Figura 5.55: Valores de ABS $254 \mathrm{~nm}$ e pH de coagulação - amostras centrifugadas - Água de Estudo - 3 . Água de estudo 3: ABS $254 \mathrm{~nm}=0,209 ; \mathrm{MC}=104,92 \mu \mathrm{g} / \mathrm{L}$.

Condições do ensaio: Aplicação de CAP $(10,20$ e $30 \mathrm{mg} / \mathrm{L})$; Pré-cloração $\left(3,0 \mathrm{mgCl}_{2} / \mathrm{L}\right)$; Coagulação $\left(\mathrm{D}_{\mathrm{FeCl}}=\right.$ $\left.18,61 \mathrm{mgFe}^{3+} / \mathrm{L} ; \mathrm{Vr}_{\mathrm{MR}}=350 \mathrm{rpm} ; \mathrm{T}_{\mathrm{MR}}=20 \mathrm{~s}\right) ;$ Floculação $\left(\mathrm{Vr}_{\mathrm{FLO}}=68 \mathrm{rpm} ; \mathrm{T}_{\mathrm{FLO}}=18 \mathrm{~min}\right)$; Centrifugação ( $\mathrm{f}_{\mathrm{CEN}}=$ $\left.2000 \mathrm{rpm} ; \mathrm{T}_{\mathrm{CEN}}=15 \mathrm{~min}\right)$.

Valores de MC

Água de Estudo 3

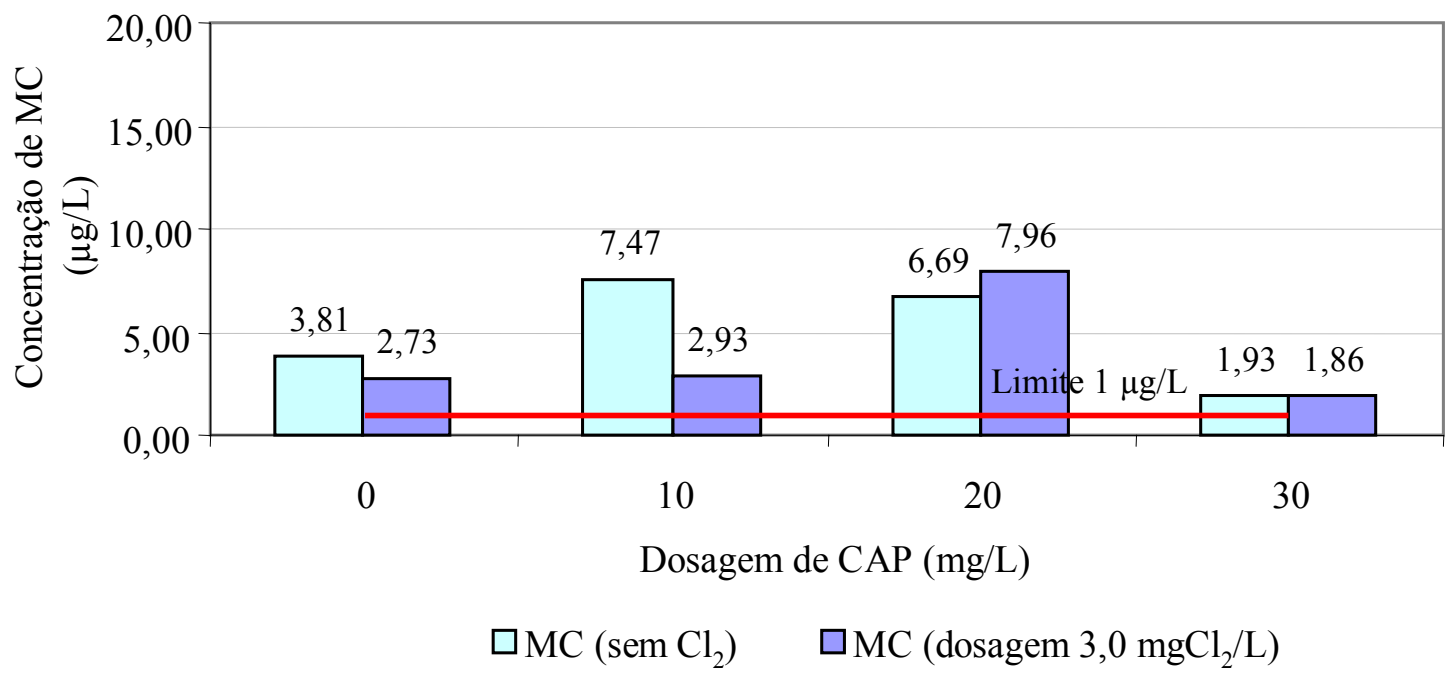

Figura 5.56: Valores de concentração de microcistina (MC) - amostras centrifugadas - Água de Estudo - 3. Água de estudo 3: $\mathrm{MC}=104,92 \mu \mathrm{g} / \mathrm{L}$.

Condições do ensaio: Aplicação de CAP (10, 20 e $30 \mathrm{mg} / \mathrm{L})$; Pré-cloração $\left(3,0 \mathrm{mgCl}_{2} / \mathrm{L}\right)$; Coagulação $\left(\mathrm{D}_{\mathrm{FeCl}}=\right.$ $\left.18,61 \mathrm{mgFe} / 3^{3+} / \mathrm{Vr}_{\mathrm{MR}}=350 \mathrm{rpm} ; \mathrm{T}_{\mathrm{MR}}=20 \mathrm{~s}\right) ;$ Floculação $\left(\mathrm{Vr}_{\mathrm{FLO}}=68 \mathrm{rpm} ; \mathrm{T}_{\mathrm{FLO}}=18 \mathrm{~min}\right) ;$ Centrifugação $\left(\mathrm{f}_{\mathrm{CEN}}=\right.$ $\left.2000 \mathrm{rpm} ; \mathrm{T}_{\mathrm{CEN}}=15 \mathrm{~min}\right)$. 
A mesma interferência, da aplicação de hipoclorito de sódio, ocorreu nos ensaios com a água de estudo - 3 conforme os parâmetros de turbidez, cor aparente e absorbância em 254 nm.

A Figura 5.53 mostra que com o aumento da dosagem de carvão sem oxidante, obtevese melhores resultados de turbidez residual, sendo o menor valor de turbidez $(1,24 \mathrm{uT})$ quando foi aplicado $30 \mathrm{mg} / \mathrm{L}$ de CAP. A tendência de piora na turbidez residual dos ensaios em que foi aplicado hipoclorito de sódio se confirmou, com exceção do ensaio sem CAP. A cor aparente, das amostras centrifugadas (Figura 5.54), seguiu a mesma tendência de piora dos seus valores com a aplicação do oxidante, causada pela mudança do pH de coagulação com a aplicação deste produto.

Já o aumento da dosagem de CAP sem a oxidação, diminuiu os valores de ABS 254 nm (Figura 5.55), atingindo o menor valor igual a 0,065 (remoção de 68 \%) com a aplicação de $30 \mathrm{mg} / \mathrm{L}$ de CAP. Para esta dosagem de CAP combinada com 3,0 $\mathrm{mgCl}_{2} / \mathrm{L}$ de cloro livre a remoção diminuiu para $45 \%$.

Pela Figura 5.56, vê-se que nenhuma das dosagens de carvão ativado em pó, mesmo quando combinadas com 3,0 $\mathrm{mg} / \mathrm{L}$ de hipoclorito de sódio, foram capazes de reduzir a concentração de microcistina a níveis inferiores a $1 \mu \mathrm{g} / \mathrm{L}$. O melhor resultado de residual de microcistina foi com a aplicação de $30 \mathrm{mg} / \mathrm{L}$ de CAP e $3,0 \mathrm{mgCl}_{2} / \mathrm{L}$ de oxidante, com remoção de aproximadamente 98\%, no entanto, com residual de 1,86 $\mu \mathrm{g} / \mathrm{L}$.

\subsubsection{Resumo dos Resultados da FASE - B / ETAPA - I}

Os resultados mostraram que houve piora nos parâmetros de turbidez, cor aparente e absorbância em 254 nm, nos ensaios em que foram combinadas a aplicação do CAP e 
hipoclorito de sódio, para as três águas preparadas. Isto se justifica pelo $\mathrm{pH}$ de coagulação nestes ensaios, que não foi similar ao $\mathrm{pH}$ definido na escolha da dosagem de coagulante realizada para cada água. Este parâmetro é de fundamental importância para a desestabilização das partículas suspensas e dissolvidas na água bruta.

Com relação à remoção de microcistina pelo tratamento realizado na $\mathrm{FASE}-\mathrm{B}$, os resultados mostram que, para a Água de Estudo -1 (MC inicial 6,76 $\mu \mathrm{g} / \mathrm{L}$ ) somente a aplicação de $10 \mathrm{mg} / \mathrm{L}$ de CAP reduziu a concentração da $\mathrm{MC}$ para $0,57 \mu \mathrm{g} / \mathrm{L}$ (remoção de aproximadamente 91\%), sendo desnecessária a aplicação de oxidante. Com o aumento da concentração de microcistina, representado pela Água de Estudo - 2 (MC inicial 25,84 $\mu \mathrm{g} / \mathrm{L}$ ), a adsorção em CAP não foi suficiente para atender o limite de $1 \mu \mathrm{g} / \mathrm{L}$, entretanto, aplicando-se somente o oxidante, a concentração de toxina resultou em $0,78 \mu \mathrm{g} / \mathrm{L}$ (remoção de aproximadamente 97 \%). Já para a Água de Estudo - 3 (MC inicial 104,92 $\mu \mathrm{g} / \mathrm{L}$ ), mesmo combinando a pré-cloração com a adsorção em CAP, não foi possível reduzir a concentração de microcistina a níveis ideais. O maior índice de remoção foi atingido com $30 \mathrm{mg} / \mathrm{L}$ de CAP e 3,0 mg/L de oxidante, sendo que a concentração residual de microcistina foi de $1,86 \mu \mathrm{g} / \mathrm{L}$ equivalente a $98 \%$ de remoção.

\subsubsection{FASE - C}

Esta fase consistiu na mudança do ponto de aplicação do hipoclorito de sódio e do carvão ativado em pó. Os ensaios foram realizados, com as três águas preparadas, seguindo a ordem: pré-cloração com hipoclorito de sódio $\left(3,0 \mathrm{mgCl}_{2} / \mathrm{L}\right)$ com tempo de contato de $10 \mathrm{~s}$ $\rightarrow$ coagulação com cloreto férrico $\left(14,47 \mathrm{mgFe}^{3+} / \mathrm{L}\right) \rightarrow$ aplicação de CAP logo após a mistura rápida $(0 ; 10 ; 20$ e $30 \mathrm{mg} / \mathrm{L})$ com tempo de contato de $50 \mathrm{~s} \rightarrow$ floculação $\rightarrow$ 
centrifugação. Da mesma forma, as etapas de pré-cloração, mistura rápida, adsorção e floculação foram realizadas no equipamento jarteste com 1 litro de amostra de água de estudo.

Os ensaios foram monitorados pelos parâmetros: pH de coagulação e cor aparente, turbidez, absorbância 254 nm e concentração de microcistina das amostras centrifugadas.

\subsubsection{1. Á́gua de Estudo 1 (FASE - C)}

As características da Água de Estudo - 1, referentes aos parâmetros avaliados, são: pH - 7,50; cor aparente - 586 uC; turbidez - 54,6 uT, absorbância 254 nm - 0,236; concentração de microcistina $-6,76 \mu \mathrm{g} / \mathrm{L}$.

A Tabela 5.26 apresenta os resultados da FASE - C da ETAPA - I para a Água de Estudo - 1.

Tabela 5.26: Valores dos resultados da FASE - C da ETAPA - I para Água de Estudo - 1.

\begin{tabular}{cccccccc}
\hline \hline $\begin{array}{c}\text { Dosagem } \\
\mathrm{FeCl}_{3} \\
\left(\mathrm{mgFe}^{3+} / \mathrm{L}\right)\end{array}$ & $\begin{array}{c}\mathrm{CAP} \\
(\mathrm{mg} / \mathrm{L})\end{array}$ & $\begin{array}{c}\text { Dosagem } \\
\mathrm{Cl}_{2} \text { ativo } \\
\left(\mathrm{mgCl}_{2} / \mathrm{L}\right)\end{array}$ & $\mathrm{pH}$ & $\begin{array}{c}\text { Turbidez } \\
(\mathrm{uT})\end{array}$ & Cor $(\mathrm{uC})$ & $\begin{array}{c}\mathrm{ABS} \\
254 \mathrm{~nm}\end{array}$ & $\begin{array}{c}\mathrm{MC} \\
(\mu \mathrm{g} / \mathrm{L})\end{array}$ \\
\hline \hline 14,47 & 0 & 0 & 7,36 & 0,65 & 9 & 0,068 & 0,841 \\
14,47 & 10 & 0 & 7,20 & 1,14 & 9 & 0,059 & 0,962 \\
14,47 & 20 & 0 & 6,79 & 1,07 & 8 & 0,052 & 0,479 \\
14,47 & 30 & 0 & 6,33 & 1,17 & 7 & 0,047 & 0,407 \\
\hline 14,47 & 0 & 3,0 & 6,79 & 3,68 & 97 & 0,471 & 0,160 \\
14,47 & 10 & 3,0 & 6,58 & 3,49 & 99 & 0,458 & 0,116 \\
14,47 & 20 & 3,0 & 7,15 & 4,59 & 102 & 0,455 & 0,120 \\
14,47 & 30 & 3,0 & 6,64 & 4,51 & 97 & 0,403 & 0,116 \\
\hline
\end{tabular}

As Figuras 5.57; 5.58; 5.59 e 5.60 foram elaboradas a partir dos dados apresentados na Tabela 5.26. 
Valores de turbidez e pH de coagulação

Água de Estudo 1

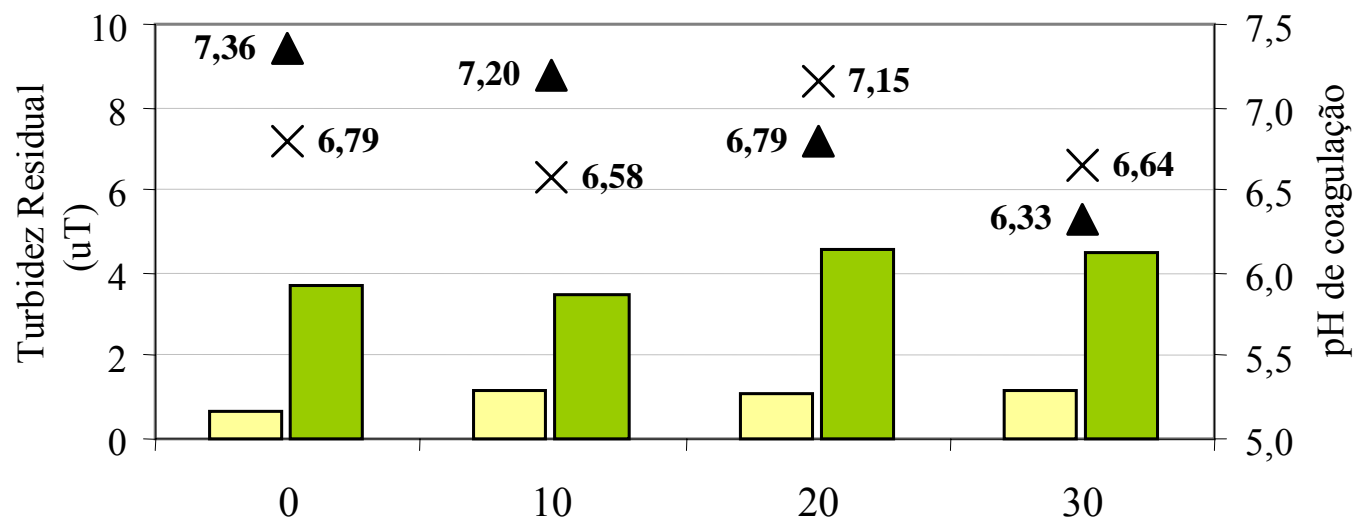

Dosagem de CAP (mg/L)

$\square$ Turb. $\left(0 \mathrm{mgCl}_{2} / \mathrm{L}\right) \quad \square$ Turb. $\left(3,0 \mathrm{mgCl}_{2} / \mathrm{L}\right) \quad \Delta \mathrm{pH}\left(0 \mathrm{mgCl}_{2} / \mathrm{L}\right) \quad \times \mathrm{pH}\left(3,0 \mathrm{mgCl}_{2} / \mathrm{L}\right)$

Figura 5.57: Valores de turbidez e pH de coagulação - amostras centrifugadas - Água de Estudo - 1. Água de estudo 1: Turbidez $=54,6 \mathrm{uT} ; \mathrm{MC}=6,76 \mu \mathrm{g} / \mathrm{L}$.

Condições do ensaio: Pré-cloração $(3,0 \mathrm{mgCl} 2 / \mathrm{L})$; Coagulação $\left(\mathrm{D}_{\mathrm{FeCl}}=14,47 \mathrm{mgFe} \mathrm{ge}^{3+} / \mathrm{L} ; \mathrm{Vr}_{\mathrm{MR}}=350 \mathrm{rpm} ; \mathrm{T}_{\mathrm{MR}}=\right.$ 20 s); Aplicação de $\operatorname{CAP}(10,20$ e $30 \mathrm{mg} / \mathrm{L})$; Floculação $\left(\mathrm{Vr}_{\mathrm{FLO}}=68 \mathrm{rpm} ; \mathrm{T}_{\mathrm{FLO}}=18 \mathrm{~min}\right)$; Centrifugação ( $\mathrm{f}_{\mathrm{CEN}}=$ $\left.2000 \mathrm{rpm} ; \mathrm{T}_{\mathrm{CEN}}=15 \mathrm{~min}\right)$.

Valores de cor aparente e pH de coagulação

Água de Estudo 1

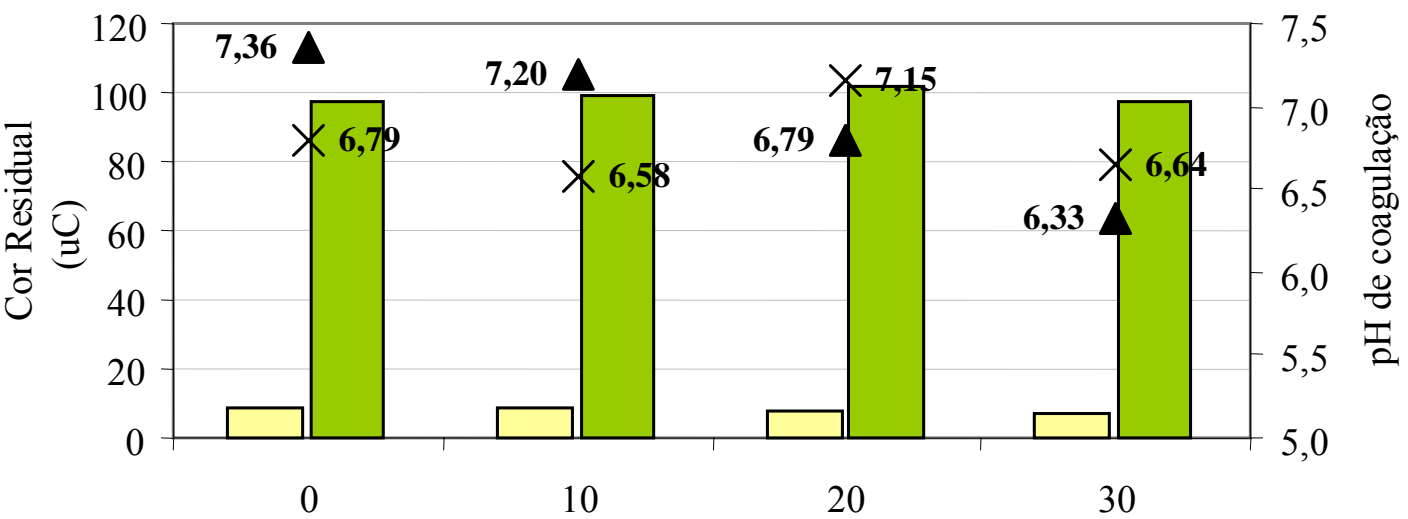

Dosagem de CAP (mg/L)

$\square \operatorname{Cor}\left(0 \mathrm{mgCl}_{2} / \mathrm{L}\right) \quad \square \operatorname{Cor} \mathrm{Cl} 2\left(3,0 \mathrm{mgCl}_{2} / \mathrm{L}\right) \quad \boldsymbol{\Delta} \mathrm{pH}\left(0 \mathrm{mgCl}_{2} / \mathrm{L}\right) \quad \times \mathrm{pH}\left(3,0 \mathrm{mgCl}_{2} / \mathrm{L}\right)$

Figura 5.58: Valores de cor aparente e pH de coagulação - amostras centrifugadas - Água de Estudo - 1. Água de estudo 1: Cor aparente $=586 \mathrm{uC} ; \mathrm{MC}=6,76 \mu \mathrm{g} / \mathrm{L}$.

Condições do ensaio: Pré-cloração $(3,0 \mathrm{mgCl} / \mathrm{L})$; Coagulação $\left(\mathrm{D}_{\mathrm{FeCl} 13}=14,47 \mathrm{mgFe}^{3+} / \mathrm{L} ; \mathrm{Vr}_{\mathrm{MR}}=350 \mathrm{rpm} ; \mathrm{T}_{\mathrm{MR}}=\right.$ 20 s); Aplicação de $\operatorname{CAP}(10,20$ e $30 \mathrm{mg} / \mathrm{L})$; Floculação $\left(\mathrm{Vr}_{\mathrm{FLO}}=68 \mathrm{rpm} ; \mathrm{T}_{\mathrm{FLO}}=18 \mathrm{~min}\right)$; Centrifugação ( $\mathrm{f}_{\mathrm{CEN}}=$ $\left.2000 \mathrm{rpm} ; \mathrm{T}_{\mathrm{CEN}}=15 \mathrm{~min}\right)$. 
Valores de ABS $254 \mathrm{~nm}$ e pH de coagulação

Água de Estudo 1

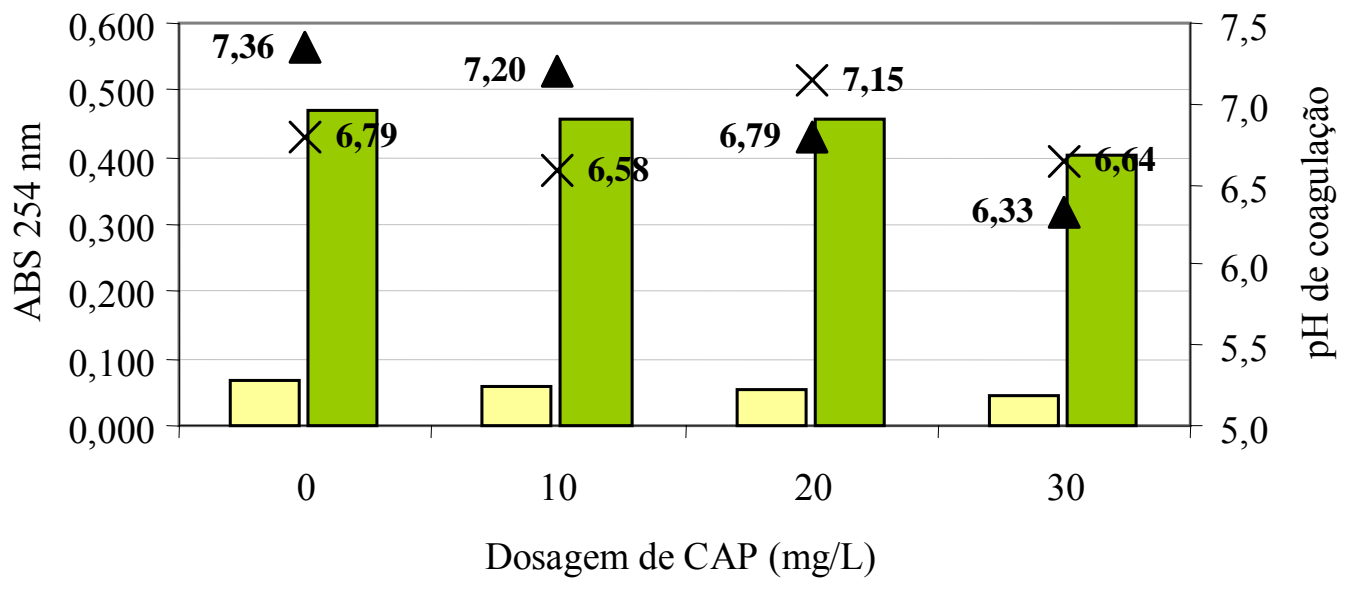

ABS $254\left(0 \mathrm{mgCl}_{2} / \mathrm{L}\right) \square \mathrm{ABS} 254\left(3,0 \mathrm{mgCl}_{2} / \mathrm{L}\right) \boldsymbol{\Delta} \mathrm{pH}\left(0 \mathrm{mgCl}_{2} / \mathrm{L}\right) \times \mathrm{pH}(3,0 \mathrm{mgCl} / \mathrm{L})$

Figura 5.59: Valores de ABS $254 \mathrm{~nm}$ e pH de coagulação - amostras centrifugadas - Água de Estudo - 1. Água de estudo 1: ABS $254 \mathrm{~nm}=0,236 ; \mathrm{MC}=6,76 \mu \mathrm{g} / \mathrm{L}$.

Condições do ensaio: Pré-cloração $(3,0 \mathrm{mgCl} / \mathrm{L})$; Coagulação $\left(\mathrm{D}_{\mathrm{FeCl} 13}=14,47 \mathrm{mgFe}^{3+} / \mathrm{L} ; \mathrm{Vr}_{\mathrm{MR}}=350 \mathrm{rpm} ; \mathrm{T}_{\mathrm{MR}}=\right.$ $20 \mathrm{~s})$; Aplicação de CAP (10, 20 e $30 \mathrm{mg} / \mathrm{L})$; Floculação $\left(\operatorname{Vr}_{\mathrm{FLO}}=68 \mathrm{rpm} ; \mathrm{T}_{\mathrm{FLO}}=18 \mathrm{~min}\right)$; Centrifugação ( $\mathrm{f}_{\mathrm{CEN}}=$ $\left.2000 \mathrm{rpm} ; \mathrm{T}_{\mathrm{CEN}}=15 \mathrm{~min}\right)$.

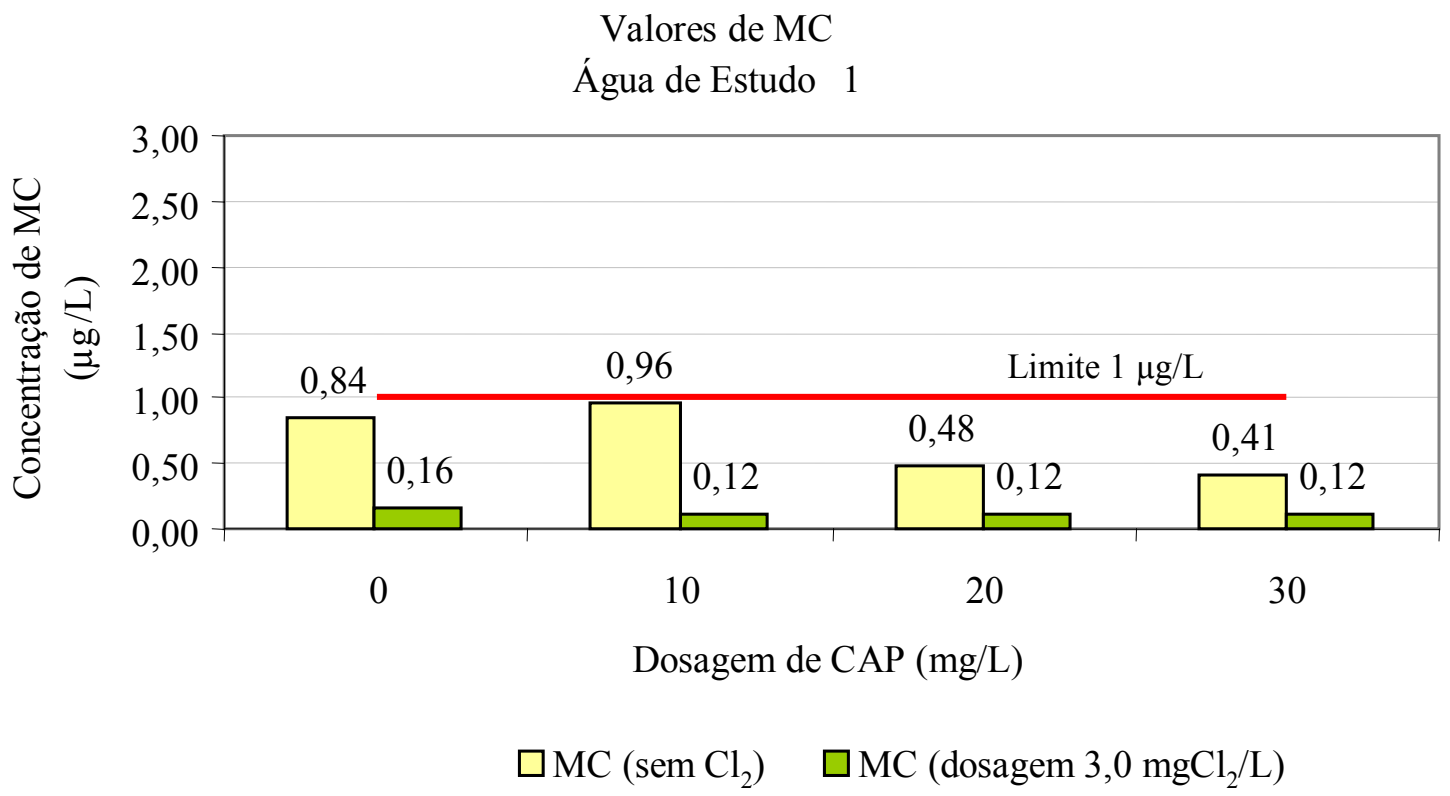

Figura 5.60: Valores de concentração de microcistina (MC) - amostras centrifugadas - Água de Estudo - 1. Água de estudo $1: \mathrm{MC}=6,76 \mu \mathrm{g} / \mathrm{L}$.

Condições do ensaio: Pré-cloração $(3,0 \mathrm{mgCl} / 2 / \mathrm{L})$; Coagulação $\left(\mathrm{D}_{\mathrm{FeCl}}=14,47 \mathrm{mgFe} \mathrm{ge}^{3+} / \mathrm{L} ; \mathrm{Vr}_{\mathrm{MR}}=350 \mathrm{rpm} ; \mathrm{T}_{\mathrm{MR}}=\right.$ $20 \mathrm{~s})$; Aplicação de $\operatorname{CAP}(10,20$ e $30 \mathrm{mg} / \mathrm{L})$; Floculação $\left(\operatorname{Vr}_{\mathrm{FLO}}=68 \mathrm{rpm} ; \mathrm{T}_{\mathrm{FLO}}=18 \mathrm{~min}\right)$; Centrifugação $\left(\mathrm{f}_{\mathrm{CEN}}=\right.$ $\left.2000 \mathrm{rpm} ; \mathrm{T}_{\mathrm{CEN}}=15 \mathrm{~min}\right)$. 
A mudança no ponto de aplicação do carvão ativado em pó contribuiu, de forma geral, para a melhora dos resultados de turbidez, cor aparente e absorbância em 254 nm. No entanto, a pré-cloração interferiu negativamente nestes parâmetros como foi observado nos ensaios da FASE - B.

Com a Figura 5.57 é possível observar que o aumento da dosagem de carvão ativado em pó prejudicou as características das amostras centrifugadas durante os ensaios sem précloração. Contudo, estes valores se mantiveram relativamente constantes, variando entre 1,07 e 1,17 uT para as três dosagens de CAP. Diante da pré-cloração, os valores de turbidez residual se elevaram devido à influência do hipoclorito de sódio no pH de coagulação. Já os resultados de cor aparente (Figura 5.58), mantiveram-se abaixo de $15 \mathrm{uC}$ durante os ensaios em que foi aplicado somente o CAP, inclusive o aumento da dosagem de carvão não prejudicou o tratamento da água segundo este parâmetro, tendo-se o melhor resultado igual a $7 \mathrm{uC}$ com a aplicação de $30 \mathrm{mg} / \mathrm{L}$ de CAP. A aplicação do oxidante promoveu o aumento dos valores de cor aparente residual em todos os ensaios em que esta etapa foi realizada.

Avaliando-se a absorbância em 254 nm pela Figura 5.59, o aumento da dosagem de CAP não reduziu substancialmente os valores das amostras centrifugadas, pois sem CAP e sem pré-cloração o valor da ABS $254 \mathrm{~nm}$ ficou igual a 0,068, já ao aplicar $30 \mathrm{mg} / \mathrm{L}$ de CAP este valor resultou em 0,047 . A pré-cloração também elevou os valores de absorbância em $254 \mathrm{~nm}$, como ocorreu com os parâmetros de cor aparente e turbidez, das amostras centrifugadas.

A aplicação de $10 \mathrm{mg} / \mathrm{L}$ de CAP, sem pré-cloração, foi suficiente para reduzir a concentração de microcistina para $0,96 \mu \mathrm{g} / \mathrm{L}(\approx 86 \%$ de remoção). Contudo, quando foi realizada somente a pré-cloração com a dosagem de 3,0 mg/L, o residual de microcistina foi ainda menor com concentração de $0,47 \mu \mathrm{g} / \mathrm{L}$ sendo que a eficiência aumentou para $93 \%$ (Figura 5.60). 


\subsubsection{2. Água de Estudo 2 (FASE - C)}

As características da Água de Estudo - 2 são: pH - 7,03; cor aparente - 452 uC; turbidez - 47,3 uT, absorbância $254 \mathrm{~nm}$ - 0,278; concentração de microcistina - 25,84 $\mu \mathrm{g} / \mathrm{L}$.

Os resultados da FASE - C da ETAPA - I, para a Água de Estudo - 2, estão apresentados na Tabela 5.27.

Tabela 5.27: Valores dos resultados da FASE - C da ETAPA - I para Água de Estudo - 2.

\begin{tabular}{cccccccc}
\hline \hline $\begin{array}{c}\text { Dosagem } \\
\mathrm{FeCl}_{3} \\
\left(\mathrm{mgFe}^{3+} / \mathrm{L}\right)\end{array}$ & $\begin{array}{c}\mathrm{CAP} \\
(\mathrm{mg} / \mathrm{L})\end{array}$ & $\begin{array}{c}\text { Dosagem } \\
\mathrm{Cl}_{2} \text { ativo } \\
\left(\mathrm{mgCl}_{2} / \mathrm{L}\right)\end{array}$ & $\mathrm{pH}$ & $\begin{array}{c}\text { Turbidez } \\
(\mathrm{uT})\end{array}$ & Cor $(\mathrm{uC})$ & $\begin{array}{c}\mathrm{ABS} \\
254 \mathrm{~nm}\end{array}$ & $\begin{array}{c}\mathrm{MC} \\
(\mu \mathrm{g} / \mathrm{L})\end{array}$ \\
\hline \hline 14,47 & 0 & 0 & 6,38 & 2,92 & 30 & 0,085 & 3,965 \\
14,47 & 10 & 0 & 6,29 & 1,45 & 18 & 0,069 & 2,460 \\
14,47 & 20 & 0 & 7,16 & 2,48 & 10 & 0,062 & 0,790 \\
14,47 & 30 & 0 & 7,02 & 0,91 & 11 & 0,055 & 0,427 \\
\hline 14,47 & 0 & 3,0 & 6,66 & 2,16 & 26 & 0,129 & 0,823 \\
14,47 & 10 & 3,0 & 6,15 & 1,69 & 27 & 0,126 & 0,230 \\
14,47 & 20 & 3,0 & 7,30 & 2,49 & 29 & 0,118 & 0,255 \\
14,47 & 30 & 3,0 & 7,12 & 3,17 & 30 & 0,108 & 0,210 \\
\hline
\end{tabular}

As Figuras $5.61 ; 5.62 ; 5.63$ e 5.64 foram elaboradas a partir dos dados apresentados pela Tabela 5.27. 
Valores de turbidez e pH de coagulação

Água de Estudo 2

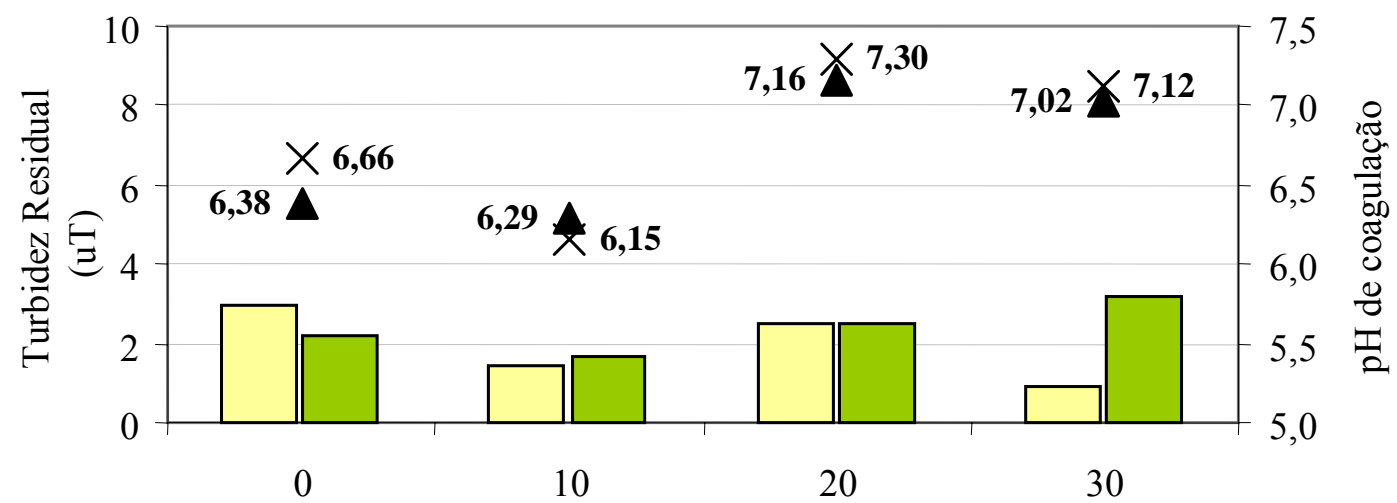

Dosagem de CAP (mg/L)

$\square$ Turb. $\left(0 \mathrm{mgCl}_{2} / \mathrm{L}\right) \quad \square$ Turb. $\left(3,0 \mathrm{mgCl}_{2} / \mathrm{L}\right) \quad \boldsymbol{\Delta} \mathrm{pH}\left(0 \mathrm{mgCl}_{2} / \mathrm{L}\right) \quad \times \mathrm{pH}\left(3,0 \mathrm{mgCl}_{2} / \mathrm{L}\right)$

Figura 5.61: Valores de turbidez e pH de coagulação - amostras centrifugadas - Água de Estudo - 2.

Água de estudo 2: Turbidez $=47,3 \mathrm{uT} ; \mathrm{MC}=25,84 \mu \mathrm{g} / \mathrm{L}$.

Condições do ensaio: Pré-cloração $(3,0 \mathrm{mgCl} 2 / \mathrm{L})$; Coagulação $\left(\mathrm{D}_{\mathrm{FeCl}}=14,47 \mathrm{mgFe} \mathrm{ge}^{3+} / \mathrm{L} ; \mathrm{Vr}_{\mathrm{MR}}=350 \mathrm{rpm} ; \mathrm{T}_{\mathrm{MR}}=\right.$ 20 s); Aplicação de $\operatorname{CAP}(10,20$ e $30 \mathrm{mg} / \mathrm{L})$; Floculação $\left(\mathrm{Vr}_{\mathrm{FLO}}=68 \mathrm{rpm} ; \mathrm{T}_{\mathrm{FLO}}=18 \mathrm{~min}\right)$; Centrifugação ( $\mathrm{f}_{\mathrm{CEN}}=$ $\left.2000 \mathrm{rpm} ; \mathrm{T}_{\mathrm{CEN}}=15 \mathrm{~min}\right)$.

Valores de cor aparente e pH de coagulação

Água de Estudo 2

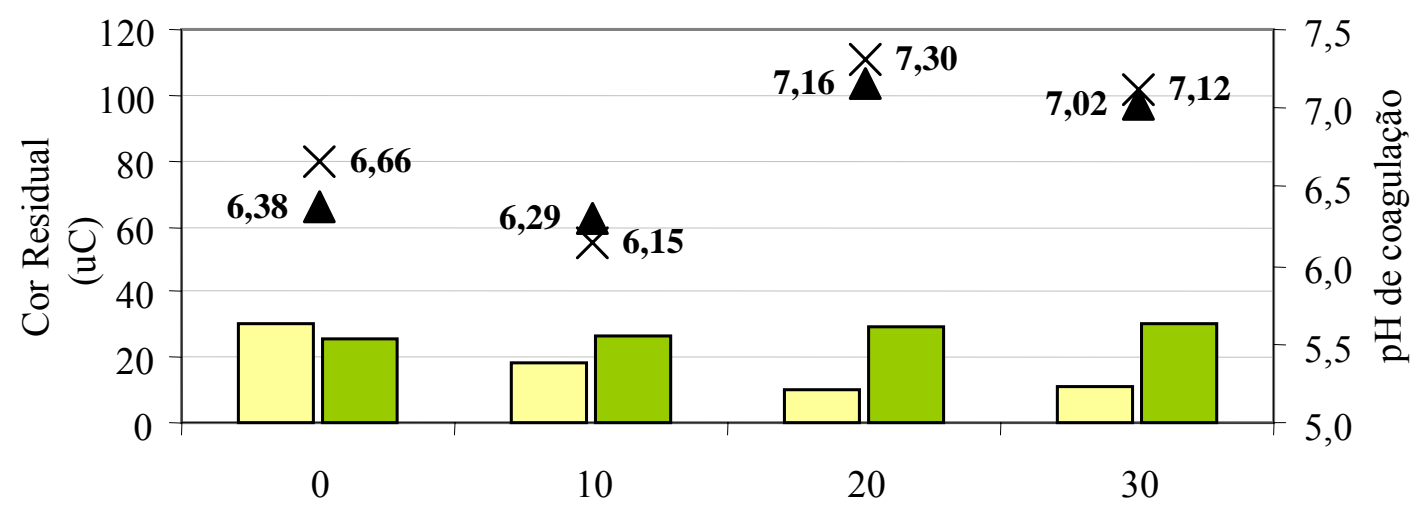

Dosagem de CAP (mg/L)

$\square \operatorname{Cor}\left(0 \mathrm{mgCl}_{2} / \mathrm{L}\right) \quad \square \operatorname{Cor} \mathrm{Cl} 2\left(3,0 \mathrm{mgCl}_{2} / \mathrm{L}\right) \quad \mathbf{\Delta} \mathrm{pH}\left(0 \mathrm{mgCl}_{2} / \mathrm{L}\right) \quad \times \mathrm{pH}\left(3,0 \mathrm{mgCl}_{2} / \mathrm{L}\right)$

Figura 5.62: Valores de cor aparente e pH de coagulação - amostras centrifugadas - Água de Estudo - 2. Água de estudo 2: Cor aparente $=452 \mathrm{uC} ; \mathrm{MC}=25,84 \mu \mathrm{g} / \mathrm{L}$.

Condições do ensaio: Pré-cloração $(3,0 \mathrm{mgCl} / \mathrm{L})$; Coagulação $\left(\mathrm{D}_{\mathrm{FeCl} 13}=14,47 \mathrm{mgFe} \mathrm{ge}^{3+} / \mathrm{L} ; \mathrm{Vr}_{\mathrm{MR}}=350 \mathrm{rpm} ; \mathrm{T}_{\mathrm{MR}}=\right.$ 20 s); Aplicação de CAP (10, 20 e $30 \mathrm{mg} / \mathrm{L})$; Floculação $\left(\mathrm{Vr}_{\mathrm{FLO}}=68 \mathrm{rpm} ; \mathrm{T}_{\mathrm{FLO}}=18 \mathrm{~min}\right)$; Centrifugação $\left(\mathrm{f}_{\mathrm{CEN}}=\right.$ $\left.2000 \mathrm{rpm} ; \mathrm{T}_{\mathrm{CEN}}=15 \mathrm{~min}\right)$. 
Valores de ABS $254 \mathrm{~nm}$ e pH de coagulação

Água de Estudo 2

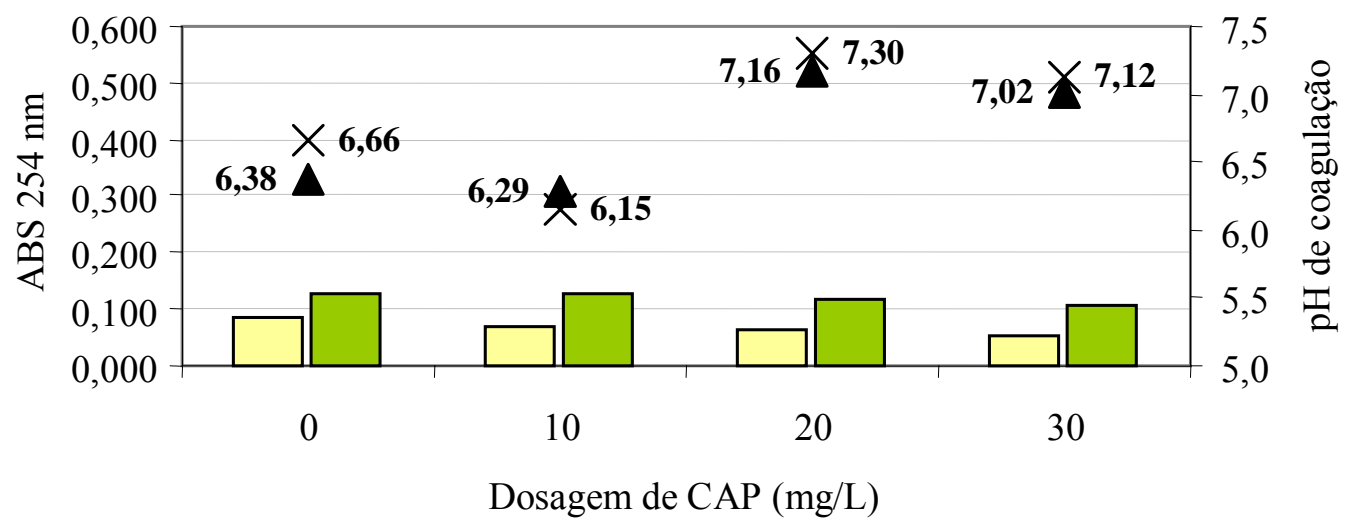

$\square$ ABS $254\left(0 \mathrm{mgCl}_{2} / \mathrm{L}\right) \square \mathrm{ABS} 254\left(3,0 \mathrm{mgCl}_{2} / \mathrm{L}\right) \mathbf{\Delta} \mathrm{pH}\left(0 \mathrm{mgCl}_{2} / \mathrm{L}\right) \times \mathrm{pH}\left(3,0 \mathrm{mgCl}_{2} / \mathrm{L}\right)$

Figura 5.63: Valores de ABS $254 \mathrm{~nm}$ e pH de coagulação - amostras centrifugadas - Água de Estudo - 2. Água de estudo 2: ABS $254 \mathrm{~nm}=0,278 ; \mathrm{MC}=25,84 \mu \mathrm{g} / \mathrm{L}$.

Condições do ensaio: Pré-cloração $(3,0 \mathrm{mgCl} 2 / \mathrm{L})$; Coagulação $\left(\mathrm{D}_{\mathrm{FeCl} 13}=14,47 \mathrm{mgFe}^{3+} / \mathrm{L} ; \mathrm{Vr}_{\mathrm{MR}}=350 \mathrm{rpm} ; \mathrm{T}_{\mathrm{MR}}=\right.$ $20 \mathrm{~s}$ ); Aplicação de CAP (10, 20 e $30 \mathrm{mg} / \mathrm{L})$; Floculação $\left(\operatorname{Vr}_{\mathrm{FLO}}=68 \mathrm{rpm} ; \mathrm{T}_{\mathrm{FLO}}=18 \mathrm{~min}\right)$; Centrifugação ( $\mathrm{f}_{\mathrm{CEN}}=$ $\left.2000 \mathrm{rpm} ; \mathrm{T}_{\mathrm{CEN}}=15 \mathrm{~min}\right)$.

Valores de MC

Água de Estudo 2

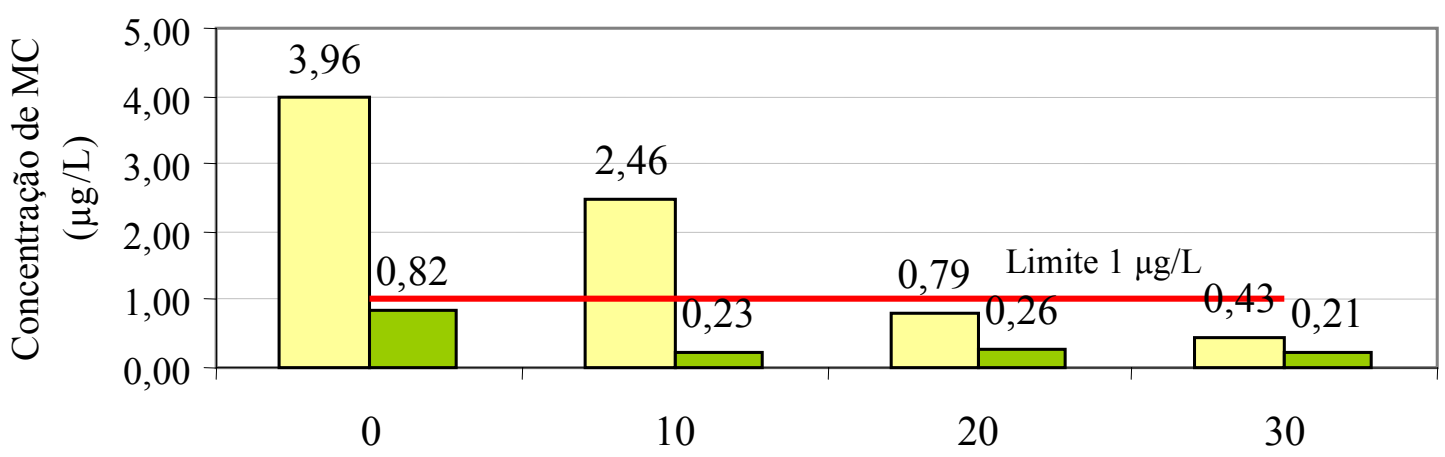

Dosagem de CAP (mg/L)

$$
\square \mathrm{MC}\left(\mathrm{sem} \mathrm{Cl}_{2}\right) \quad \square \mathrm{MC}\left(\text { dosagem } 3,0 \mathrm{mgCl}_{2} / \mathrm{L}\right)
$$

Figura 5.64: Valores de microcistina (MC) - amostras centrifugadas - Água de Estudo - 2.

Água de estudo 2: $\mathrm{MC}=25,84 \mu \mathrm{g} / \mathrm{L}$.

Condições do ensaio: Pré-cloração $(3,0 \mathrm{mgCl} / \mathrm{L}) ;$ Coagulação $\left(\mathrm{D}_{\mathrm{FeCl}}=14,47 \mathrm{mgFe}^{3+} / \mathrm{L} ; \mathrm{Vr}_{\mathrm{MR}}=350 \mathrm{rpm} ; \mathrm{T}_{\mathrm{MR}}=\right.$ $20 \mathrm{~s})$; Aplicação de CAP $(10,20$ e $30 \mathrm{mg} / \mathrm{L})$; Floculação $\left(\operatorname{Vr}_{\mathrm{FLO}}=68 \mathrm{rpm} ; \mathrm{T}_{\mathrm{FLO}}=18 \mathrm{~min}\right)$; Centrifugação $\left(\mathrm{f}_{\mathrm{CEN}}=\right.$ $\left.2000 \mathrm{rpm} ; \mathrm{T}_{\mathrm{CEN}}=15 \mathrm{~min}\right)$. 
A Figura 5.61 mostra que a menor turbidez residual, igual a $0,91 \mathrm{uT}$, foi obtida com a aplicação de $30 \mathrm{mg} / \mathrm{L}$ de carvão ativado sem a pré-cloração. Contudo, quando foi realizada a pré-cloração este valor ultrapassou o limite de $1 \mathrm{uT}$. No caso da cor aparente das amostras centrifugadas (Figura 5.62), obteve-se o menor valor, igual a $10 \mathrm{uC}$, quando foram dosados 20 mg/L de carvão. E da mesma forma, quando foi realizada a aplicação do oxidante, este valor resultou superior ao limite de $15 \mathrm{uC}$ conforme pode ser verificado pelo gráfico referente a este parâmetro (Figura 5.62).

Em termos de absorbância em $254 \mathrm{~nm}$, o aumento da dosagem de carvão ativado proporcionou a redução destes valores nos ensaios em que não foi aplicado o oxidante. $\mathrm{O}$ menor valor registrado foi com a aplicação de $30 \mathrm{mg} / \mathrm{L}$ de CAP, sendo a absorbância igual a 0,055. Mas com esta dosagem de CAP combinada com a pré-cloração, o valor da absorbância se elevou para 0,108 .

A configuração de tratamento, proposta pela FASE - C, possibilitou a redução da concentração inicial de microcistina de $25,84 \mu \mathrm{g} / \mathrm{L}$ para valores abaixo de $1 \mu \mathrm{g} / \mathrm{L}$ com apenas o carvão ativado. Pela Figura 5.64, percebe-se que o aumento da dosagem de CAP reduziu a concentração de toxina nas amostras. Aplicando-se $20 \mathrm{mg} / \mathrm{L}$ de CAP a concentração residual de microcistina foi de $0,79 \mu \mathrm{g} / \mathrm{L}$ (remoção de $\approx 97 \%$ ). Contudo, ao combinar a pré-cloração com a dosagem de $10 \mathrm{mg} / \mathrm{L}$ de CAP, a concentração de microcistina ficou igual a $0,23 \mu \mathrm{g} / \mathrm{L}$.

\subsubsection{3. Água de Estudo 3 (FASE - C)}

As características da Água de Estudo - 3 são: pH - 7,33; cor aparente - 315 uC; turbidez - 28,4 uT, absorbância 254 nm - 0,209; concentração de microcistina - 104,92 $\mu \mathrm{g} / \mathrm{L}$. 
A Tabela 5.28 apresenta os resultados da FASE - C da ETAPA - I para a Água de Estudo - 3 .

Tabela 5.28: Valores dos resultados da FASE - C da ETAPA - I para Água de Estudo - 3.

\begin{tabular}{cccccccc}
\hline \hline $\begin{array}{c}\text { Dosagem } \\
\mathrm{FeCl}_{3} \\
\left(\mathrm{mgFe}^{3+} / \mathrm{L}\right)\end{array}$ & $\begin{array}{c}\mathrm{CAP} \\
(\mathrm{mg} / \mathrm{L})\end{array}$ & $\begin{array}{c}\text { Dosagem } \\
\mathrm{Cl}_{2} \text { ativo } \\
\left(\mathrm{mgCl}_{2} / \mathrm{L}\right)\end{array}$ & $\mathrm{pH}$ & $\begin{array}{c}\text { Turbidez } \\
(\mathrm{uT})\end{array}$ & Cor $(\mathrm{uC})$ & $\begin{array}{c}\mathrm{ABS} \\
254 \mathrm{~nm}\end{array}$ & $\begin{array}{c}\mathrm{MC} \\
(\mu \mathrm{g} / \mathrm{L})\end{array}$ \\
\hline 18,61 & 0 & 0 & 6,17 & 1,61 & 22 & 0,096 & 3,714 \\
18,61 & 10 & 0 & 6,16 & 1,62 & 20 & 0,087 & 3,227 \\
18,61 & 20 & 0 & 6,24 & 1,73 & 25 & 0,105 & 3,672 \\
18,61 & 30 & 0 & 6,23 & 3,66 & 29 & 0,103 & 1,431 \\
\hline 18,61 & 0 & 3,0 & 6,12 & 2,5 & 40 & 0,131 & 2,726 \\
18,61 & 10 & 3,0 & 6,10 & 2,98 & 35 & 0,099 & 2,895 \\
18,61 & 20 & 3,0 & 6,17 & 3,17 & 28 & 0,104 & 3,079 \\
18,61 & 30 & 3,0 & 6,09 & 2,68 & 28 & 0,094 & 1,571 \\
\hline
\end{tabular}

As Figuras 5.65; 5.66; 5.67 e 5.68 foram elaboradas a partir dos dados apresentados pela Tabela 5.28.

Valores de turbidez e pH de coagulação

Água de Estudo 3

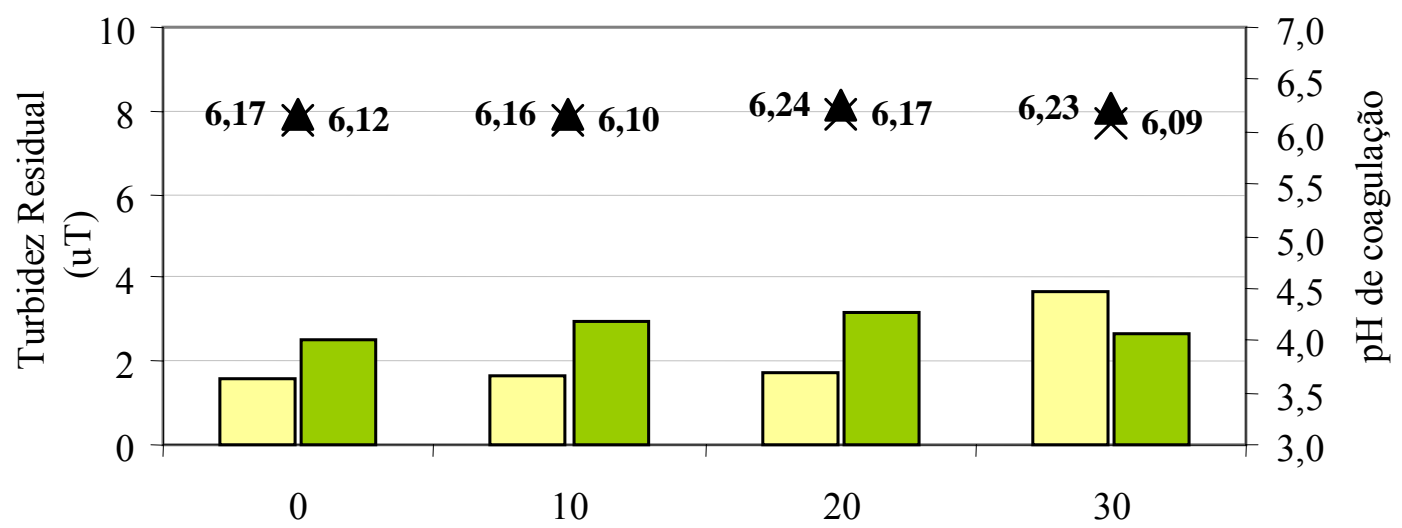

Dosagem de CAP $(\mathrm{mg} / \mathrm{L})$

$\square$ Turb. $\left(0 \mathrm{mgCl}_{2} / \mathrm{L}\right) \quad \square$ Turb. $\left(3,0 \mathrm{mgCl}_{2} / \mathrm{L}\right) \quad \boldsymbol{\Delta} \mathrm{pH}\left(0 \mathrm{mgCl}_{2} / \mathrm{L}\right) \quad \times \mathrm{pH}\left(3,0 \mathrm{mgCl}_{2} / \mathrm{L}\right)$

Figura 5.65: Valores de turbidez e pH de coagulação - amostras centrifugadas - Água de Estudo - 3. Água de estudo 3: Turbidez $=28,4 \mathrm{uT} ; \mathrm{MC}=104,92 \mu \mathrm{g} / \mathrm{L}$.

Condições do ensaio: Pré-cloração $\left(3,0 \mathrm{mgCl}_{2} / \mathrm{L}\right)$; Coagulação $\left(\mathrm{D}_{\mathrm{FeCl} 3}=18,61 \mathrm{mgFe}^{3+} / \mathrm{L} ; \mathrm{Vr}_{\mathrm{MR}}=350 \mathrm{rpm} ; \mathrm{T}_{\mathrm{MR}}=\right.$ $20 \mathrm{~s})$; Aplicação de CAP (10, 20 e $30 \mathrm{mg} / \mathrm{L})$; Floculação $\left(\operatorname{Vr}_{\mathrm{FLO}}=68 \mathrm{rpm} ; \mathrm{T}_{\mathrm{FLO}}=18 \mathrm{~min}\right)$; Centrifugação ( $\mathrm{f}_{\mathrm{CEN}}=$ $2000 \mathrm{rpm} ; \mathrm{T}_{\mathrm{CEN}}=15 \mathrm{~min}$ ). 
Valores de cor aparente e $\mathrm{pH}$ de coagulação

Água de Estudo 3

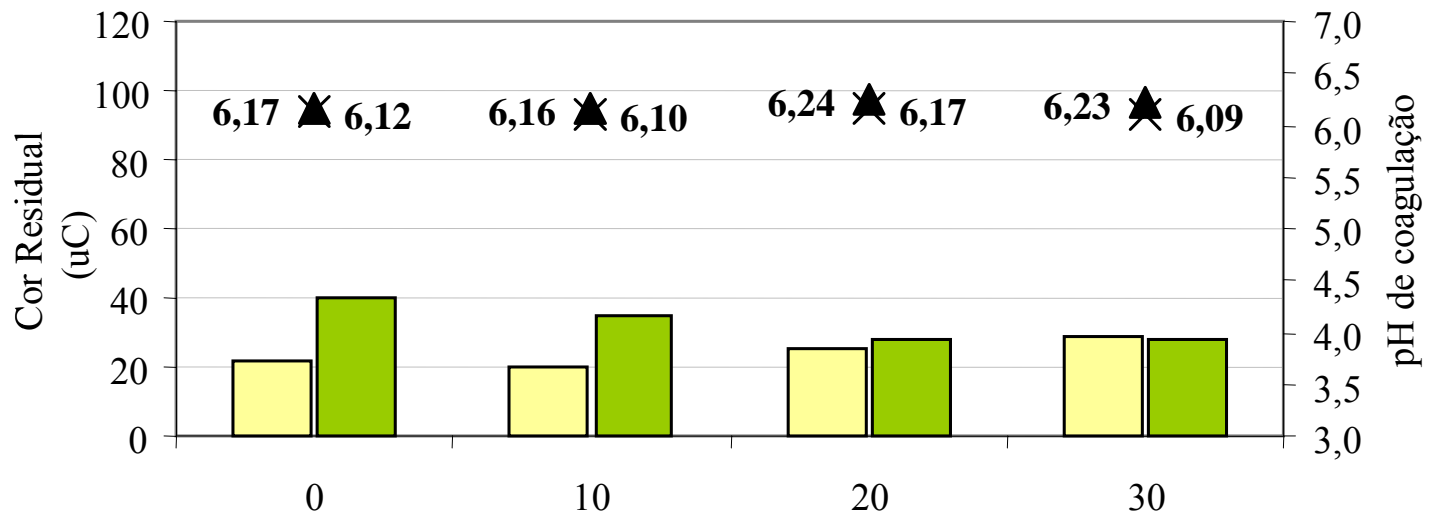

Dosagem de CAP (mg/L)

$\square \operatorname{Cor}\left(0 \mathrm{mgCl}_{2} / \mathrm{L}\right) \quad \square \operatorname{Cor} \mathrm{Cl} 2\left(3,0 \mathrm{mgCl}_{2} / \mathrm{L}\right) \quad \boldsymbol{\Delta} \mathrm{pH}\left(0 \mathrm{mgCl}_{2} / \mathrm{L}\right) \quad \times \mathrm{pH}(3,0 \mathrm{mgCl} / \mathrm{L})$

Figura 5.66: Valores de cor aparente e pH de coagulação - amostras centrifugadas - Água de Estudo - 3 . Água de estudo 3: Cor aparente $=315 \mathrm{uC} ; \mathrm{MC}=104,92 \mu \mathrm{g} / \mathrm{L}$.

Condições do ensaio: Pré-cloração $(3,0 \mathrm{mgCl} / \mathrm{L})$; Coagulação $\left(\mathrm{D}_{\mathrm{FeCl} 3}=18,61 \mathrm{mgFe} \mathrm{ge}^{3+} / \mathrm{L} ; \mathrm{Vr}_{\mathrm{MR}}=350 \mathrm{rpm} ; \mathrm{T}_{\mathrm{MR}}=\right.$ 20 s); Aplicação de $\operatorname{CAP}(10,20$ e $30 \mathrm{mg} / \mathrm{L})$; Floculação $\left(\mathrm{Vr}_{\mathrm{FLO}}=68 \mathrm{rpm} ; \mathrm{T}_{\mathrm{FLO}}=18 \mathrm{~min}\right)$; Centrifugação ( $\mathrm{f}_{\mathrm{CEN}}=$ $\left.2000 \mathrm{rpm} ; \mathrm{T}_{\mathrm{CEN}}=15 \mathrm{~min}\right)$.

Valores de ABS $254 \mathrm{~nm}$ e pH de coagulação

Água de Estudo 3

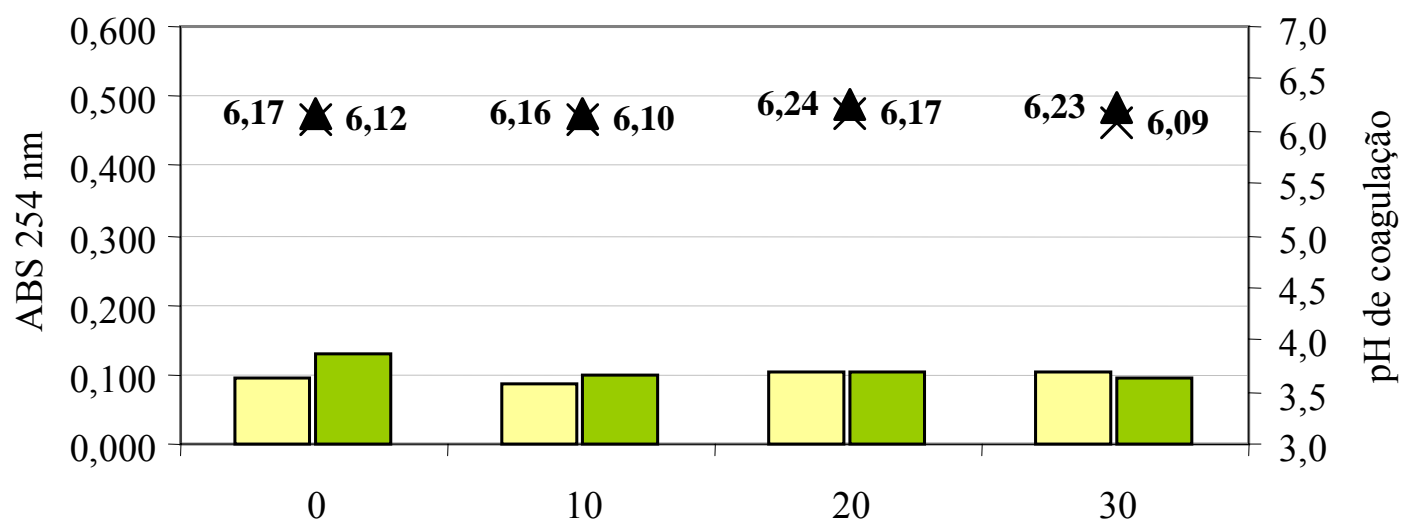

Dosagem de CAP (mg/L)

$\square$ ABS $254\left(0 \mathrm{mgCl}_{2} / \mathrm{L}\right) \square \mathrm{ABS} 254\left(3,0 \mathrm{mgCl}_{2} / \mathrm{L}\right) \mathbf{\Delta} \mathrm{pH}\left(0 \mathrm{mgCl}_{2} / \mathrm{L}\right) \times \mathrm{pH}\left(3,0 \mathrm{mgCl}_{2} / \mathrm{L}\right)$

Figura 5.67: Valores de ABS $254 \mathrm{~nm}$ e pH de coagulação - amostras centrifugadas - Água de Estudo - 3. Água de estudo 3: ABS $254 \mathrm{~nm}=0,209 ; \mathrm{MC}=104,92 \mu \mathrm{g} / \mathrm{L}$.

Condições do ensaio: Pré-cloração $(3,0 \mathrm{mgCl} / \mathrm{L})$; Coagulação $\left(\mathrm{D}_{\mathrm{FeCl} 13}=18,61 \mathrm{mgFe}^{3+} / \mathrm{L} ; \mathrm{Vr}_{\mathrm{MR}}=350 \mathrm{rpm} ; \mathrm{T}_{\mathrm{MR}}=\right.$ 20 s); Aplicação de $\operatorname{CAP}(10,20$ e $30 \mathrm{mg} / \mathrm{L})$; Floculação $\left(\mathrm{Vr}_{\mathrm{FLO}}=68 \mathrm{rpm} ; \mathrm{T}_{\mathrm{FLO}}=18 \mathrm{~min}\right)$; Centrifugação $\left(\mathrm{f}_{\mathrm{CEN}}=\right.$ $\left.2000 \mathrm{rpm} ; \mathrm{T}_{\mathrm{CEN}}=15 \mathrm{~min}\right)$. 


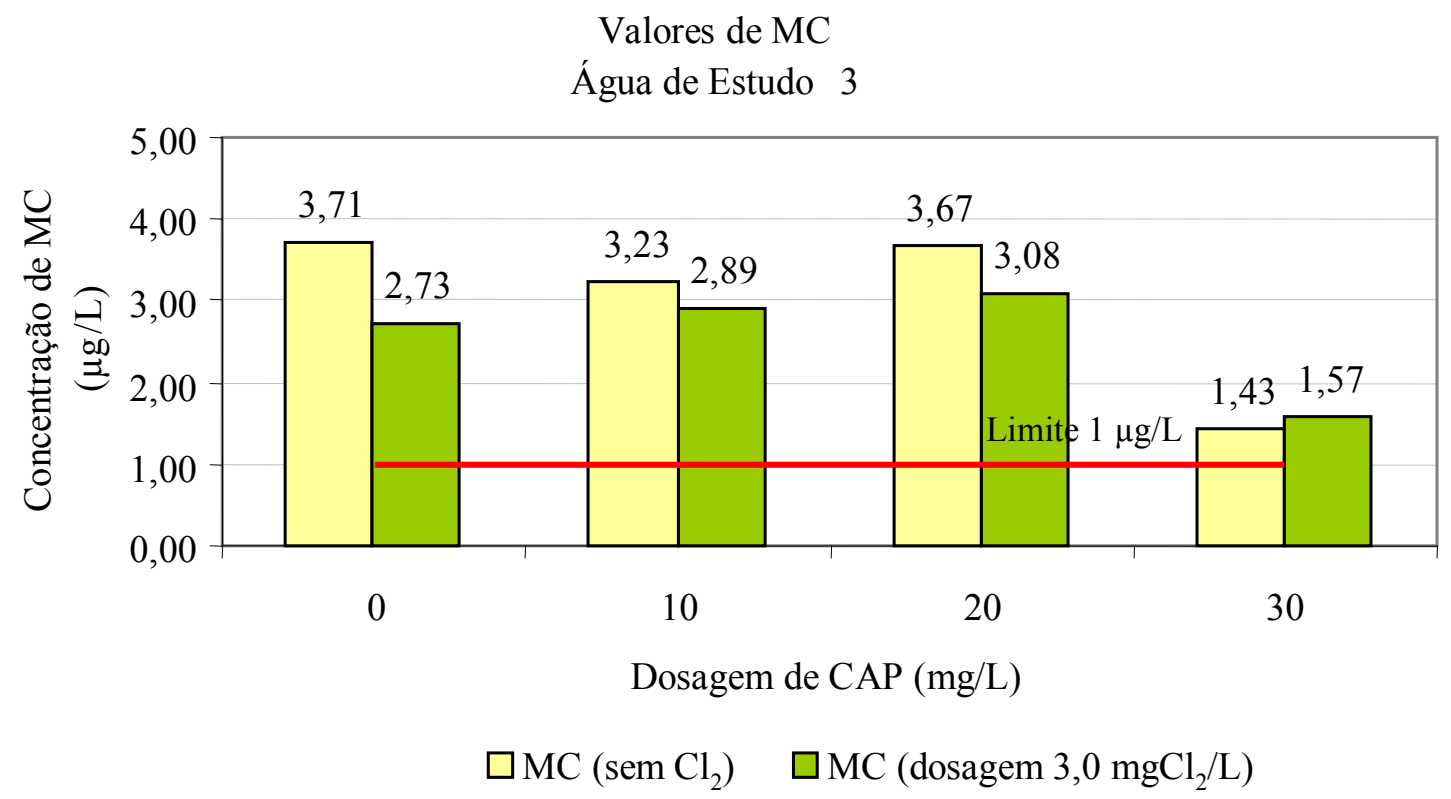

Figura 5.68: Valores de concentração de microcistina (MC) - amostras centrifugadas - Água de Estudo - 3. Água de estudo 3: $\mathrm{MC}=104,92 \mu \mathrm{g} / \mathrm{L}$.

Condições do ensaio: Pré-cloração $(3,0 \mathrm{mgCl} 2 / \mathrm{L})$; Coagulação $\left(\mathrm{D}_{\mathrm{FeCl} 13}=18,61 \mathrm{mgFe}^{3+} / \mathrm{L} ; \mathrm{Vr}_{\mathrm{MR}}=350 \mathrm{rpm} ; \mathrm{T}_{\mathrm{MR}}=\right.$ $20 \mathrm{~s}$ ); Aplicação de CAP (10, 20 e $30 \mathrm{mg} / \mathrm{L})$; Floculação $\left(\operatorname{Vr}_{\mathrm{FLO}}=68 \mathrm{rpm}\right.$; $\left.\mathrm{T}_{\mathrm{FLO}}=18 \mathrm{~min}\right)$; Centrifugação ( $\mathrm{f}_{\mathrm{CEN}}=$ $\left.2000 \mathrm{rpm} ; \mathrm{T}_{\mathrm{CEN}}=15 \mathrm{~min}\right)$.

Percebe-se, pelos resultados dos ensaios realizados com a Água de Estudo - 3, que a aplicação do hipoclorito de sódio não causou grandes variações no $\mathrm{pH}$ de coagulação, desta forma, a aplicação do oxidante não teve um impacto tão negativo quanto nas outras águas de estudo preparadas.

O aumento da dosagem de CAP, durante os ensaios sem a pré-cloração, causou o aumento nos residuais de turbidez e cor aparente das amostras centrifugadas conforme mostram as Figuras 5.65 e 5.66, respectivamente. Ocorreu o aumento do valor de ambos os parâmetros com a aplicação do oxidante, contudo, este aumento foi menos significante quando comparado com as Águas de Estudo - 2 e 3.

Para os valores de absorbância em 254 nm, vê-se a uma tendência, menos acentuada, do aumento dos valores observados com o incremento da dosagem de carvão ativado. Os valores de absorbância também aumentaram após pré-cloração, no entanto este aumento se comportou de forma similar ao observado para a turbidez e cor aparente. 
O melhor resultado para o residual de microcistina, somente com a adsorção em CAP, foi de $1,43 \mu \mathrm{g} / \mathrm{L}$. Para tanto foi necessário aplicar $30 \mathrm{mg} / \mathrm{L}$ de carvão ativado. Pela Figura 5.68, percebe-se que a concentração inicial de microcistina igual a 104,92 $\mu \mathrm{g} / \mathrm{L}$ não foi reduzida abaixo de $1 \mu \mathrm{g} / \mathrm{L}$ em nenhum dos ensaios conduzidos com a Água de Estudo - 3 . Porém, deve-se lembrar que em sistemas reais, após a pré-clarificação (aqui realizada com a centrifugação) existem as etapas de filtração seguida da pós-cloração e correção final do pH, ou seja, a pós-cloração constituiria uma etapa adicional de remoção de microcistina.

\subsubsection{Resumo dos Resultados da FASE - C / ETAPA - I}

Os resultados da FASE - C mostram que a pré-oxidação, com o hipoclorito de sódio, influencia no pH de coagulação e que diminui, de forma geral, a qualidade da água tratada em termos de turbidez, cor aparente e absorbância em $254 \mathrm{~nm}$. Contudo, a mudança no ponto de aplicação do carvão ativado em pó apresentou amostras com qualidade superior às observadas durante a FASE - B conforme os parâmetros de turbidez, cor aparente e ABS 254 nm. Inclusive com a aplicação do hipoclorito de sódio.

Em termos de remoção de microcistina, o tratamento aplicado na FASE - C se mostrou mais eficiente, principalmente com o aumento da concentração inicial de microcistina, quando comparado com a fase anterior. Para a Água de Estudo - 1, somente a adsorção com 10 mg/L de CAP reduziu a concentração de microcistina para 0,962 $\mu \mathrm{g} / \mathrm{L}$. Não foi necessária a pré-cloração, na Água de Estudo - 2, para reduzir a concentração inicial de 25,84 $\mu \mathrm{g} / \mathrm{L}$ para menos de $1 \mu \mathrm{g} / \mathrm{L}$. Aplicando-se $20 \mathrm{mg} / \mathrm{L}$ de CAP a amostra apresentou residual de $0,79 \mu \mathrm{g} / \mathrm{L}$ de microcistina. Mas para a Água de Estudo - 3 a configuração do 
tratamento desta fase também não foi suficiente para obter valores de concentração de microcistina abaixo de $1,0 \mu \mathrm{g} / \mathrm{L}$.

Como o objetivo da ETAPA - I foi avaliar e selecionar um dos tratamentos propostos pelas FASES - B e C, diante dos resultados dos ensaios apresentados para todas as águas preparadas, concluiu-se que o fluxograma elaborado para a FASE - C se mostrou mais promissor para repetição na ETAPA - II.

\subsection{RESULTADOS DA ETAPA - II}

A ETAPA - II foi dividida em duas fases: FASE - A e B. A FASE - A consistiu na escolha da dosagem ótima de coagulante que foi aplicada em cada água de estudo preparada. Na FASE - B foi repetido o fluxograma de tratamento que apresentou os melhores resultados (durante a ETAPA - I) em termos de turbidez, cor aparente, ABS $254 \mathrm{~nm}$ e residual de microcistina das amostras centrifugadas. Lembrando-se que nesta ETAPA - II a etapa de préclarificação por centrifugação foi substituída pela flotação por ar dissolvido, sendo as amostras, em seguida, submetidas à centrifugação.

\subsubsection{FASE - A}

A escolha da dosagem ótima de coagulante, para cada água de estudo, foi feita com ensaios de jarteste e flotateste. Diante da interferência da aplicação do hipoclorito de sódio no pH de coagulação, foi aplicada a maior dosagem de oxidante $\left(6,0 \mathrm{mgCl}_{2} / \mathrm{L}\right.$ de cloro livre $)$ e a 
dosagem de CAP estimada, para cada água, durante a escolha da dosagem de cloreto férrico. Procedeu-se desta forma para que, a dosagem de cloreto férrico determinada para cada água fornecesse: a) condições favoráveis em termos de $\mathrm{pH}$ de coagulação diante da interferência negativa do hipoclorito de sódio neste parâmetro; b) dosagem suficiente de coagulante para reduzir a turbidez e cor aparente, relacionadas à adição de CAP, em níveis abaixo dos limites determinados para tais parâmetros.

Assim, para a escolha da dosagem ótima de coagulante para cada água, os ensaios foram realizados com: pré-cloração com hipoclorito de sódio $(6,0 \mathrm{mgCl} / 2$ de cloro livre $)$ com tempo de contato de $10 \mathrm{~s} \rightarrow$ coagulação com cloreto férrico (avaliação de 8 dosagens de coagulante) $\rightarrow$ aplicação de CAP logo após a mistura rápida (dosagem estimada de CAP) com tempo de contato de $50 \mathrm{~s} \rightarrow$ floculação $\rightarrow$ flotação por ar dissolvido $(\mathrm{V}=12 \mathrm{~cm} / \mathrm{min})$ $\rightarrow$ centrifugação.

Os ensaios foram monitorados pelos parâmetros de pH de coagulação, turbidez e cor aparente das amostras flotadas e centrifugadas.

\subsubsection{1. Água de Estudo 1 (FASE - A)}

As características da Água de Estudo - 1 quanto aos parâmetros avaliados são: pH 7,26; turbidez - 52,8 uT; cor aparente - $502 \mathrm{uC}$.

A Figura 5.69 apresenta os dados de turbidez residual para as amostras flotadas e centrifugadas. A Figura 5.70 mostra os valores de cor aparente para estas mesmas amostras. 
Turbidez das amostras flotadas e centrifugadas

Água de Estudo 1

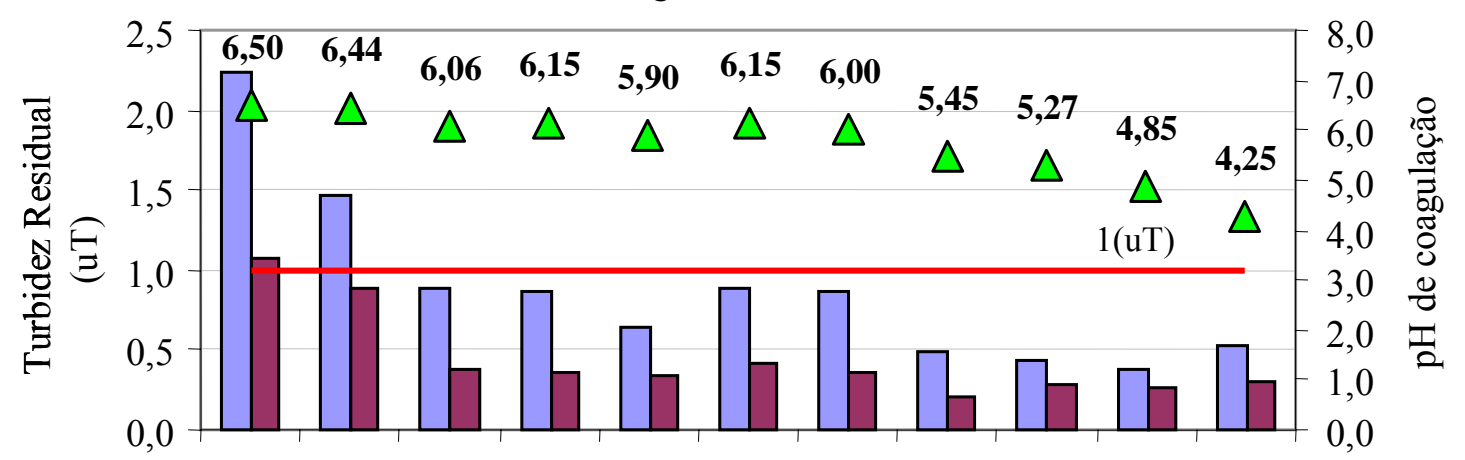

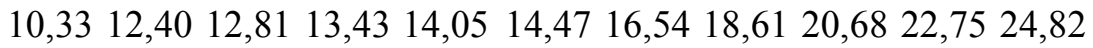

Dosagem de Coagulante $\left(\mathrm{mgFe}^{3+} / \mathrm{L}\right)$

$\square$ Turbidez Flot. $\quad \square$ Turbidez Cent. $\Delta$ pH de Coagulação

Figura 5.69: Turbidez residual das amostras flotadas e centrifugadas e $\mathrm{pH}$ de coagulação.

Água de estudo 1: Turbidez $=52,8 \mathrm{uT} ; \mathrm{MC}=5,58 \mu \mathrm{g} / \mathrm{L}$.

Condições do ensaio: Pré-cloração $\left(6,0 \mathrm{mgCl}_{2} / \mathrm{L}\right)$; Coagulação $\left(\mathrm{Vr}_{\mathrm{MR}}=350 \mathrm{rpm} ; \mathrm{T}_{\mathrm{MR}}=20 \mathrm{~s}\right)$; Aplicação de CAP

$(5 \mathrm{mg} / \mathrm{L}) ;$ Floculação $\left(\mathrm{Vr}_{\mathrm{FLO}}=68 \mathrm{rpm} ; \mathrm{T}_{\mathrm{FLO}}=18 \mathrm{~min}\right) ; \mathrm{FAD}\left(\mathrm{p}_{\mathrm{SAT}}=500 \mathrm{kPa} ; \mathrm{R}=8 \% ; \mathrm{V}_{2}=12,0 \mathrm{~cm} / \mathrm{min}\right)$

Centrifugação ( $\left.\mathrm{f}_{\mathrm{CEN}}=2000 \mathrm{rpm} ; \mathrm{T}_{\mathrm{CEN}}=15 \mathrm{~min}\right)$.

Cor aparente das amostras flotadas e centrifugadas

Água de Estudo 1

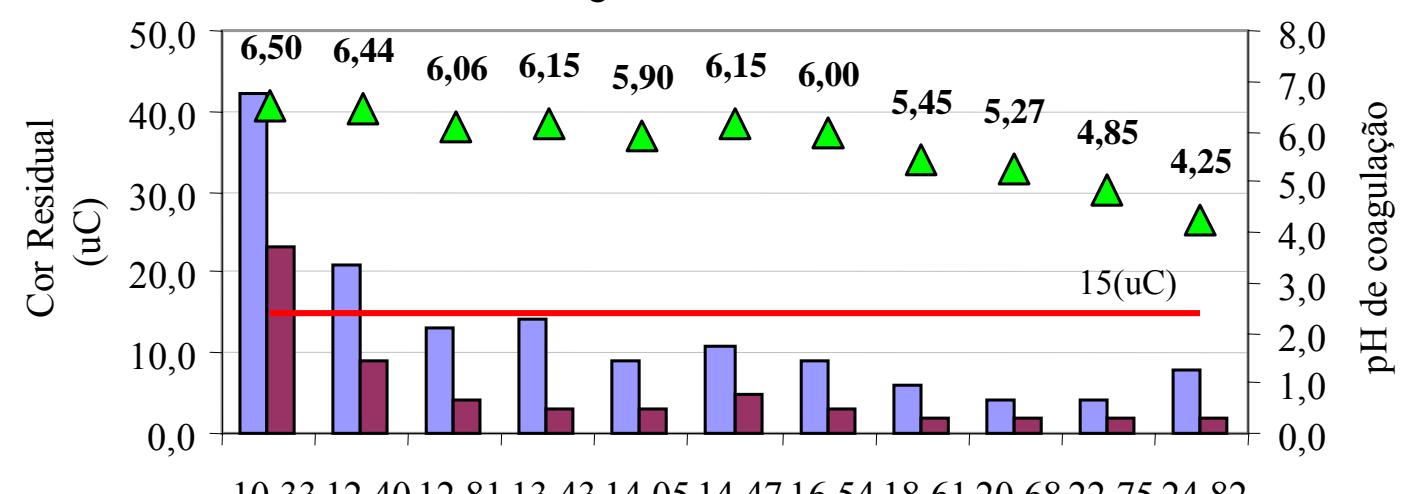

$10,3312,4012,8113,4314,0514,4716,5418,6120,6822,7524,82$

Dosagem de Coagulante $\left(\mathrm{mgFe}^{3+} / \mathrm{L}\right)$

$\square$ Cor aparente Flot. $\quad \square$ Cor aparente Cent. $\quad \Delta$ pH de Coagulação

Figura 5.70: Cor aparente residual das amostras flotadas e centrifugadas e pH de coagulação. Água de estudo 1: Cor aparente $=502 \mathrm{uC} ; \mathrm{MC}=5,58 \mu \mathrm{g} / \mathrm{L}$.

Condições do ensaio: Pré-cloração $\left(6,0 \mathrm{mgCl}_{2} / \mathrm{L}\right)$; Coagulação $\left(\mathrm{Vr}_{\mathrm{MR}}=350 \mathrm{rpm} ; \mathrm{T}_{\mathrm{MR}}=20 \mathrm{~s}\right)$; Aplicação de CAP

$(5 \mathrm{mg} / \mathrm{L}) ;$ Floculação $\left(\mathrm{Vr}_{\mathrm{FLO}}=68 \mathrm{rpm} ; \mathrm{T}_{\mathrm{FLO}}=18 \mathrm{~min}\right) ; \mathrm{FAD}\left(\mathrm{p}_{\mathrm{SAT}}=500 \mathrm{kPa} ; \mathrm{R}=8 \% ; \mathrm{V}_{2}=12,0 \mathrm{~cm} / \mathrm{min}\right)$

Centrifugação ( $\left.\mathrm{f}_{\mathrm{CEN}}=2000 \mathrm{rpm} ; \mathrm{T}_{\mathrm{CEN}}=15 \mathrm{~min}\right)$.

É possível perceber pelas Figuras 5.69 e 5.70 a tendência na redução do pH de coagulação da água com o aumento da dosagem de coagulante. Comparando-se os resultados 
de pH observados nesta FASE - A da ETAPA - II com a fase homônima da ETAPA - I, é possível verificar a diferença no valor de $\mathrm{pH}$ de coagulação, para uma mesma dosagem de coagulante, quando é aplicado o hipoclorito de sódio. Por exemplo, para esta Água de Estudo - 1 a dosagem de cloreto férrico selecionada nesta fase foi a de $14,47 \mathrm{mgFe}^{3+} / \mathrm{L}$ de coagulante como ocorreu na FASE - A da ETAPA - I. Contudo, o pH de coagulação para esta dosagem de coagulante na FASE - A da ETAPA - I foi igual a 5,72. Já para esta mesma dosagem de 14,47 $\mathrm{mgFe}^{3+} / \mathrm{L}$ de coagulante nesta FASE - A da ETAPA - II o pH de coagulação foi de 6,15 .

A Figura 5.69 mostra os valores de turbidez residual para a amostra flotada e centrifugada com $14,47 \mathrm{mgFe}^{3+} / \mathrm{L}$ de coagulante, sendo iguais a 0,89 uT e $0,41 \mathrm{uT}$, respectivamente. Para a cor aparente residual destas amostras, os valores ficaram em 11 e 5 $\mathrm{uC}$, respectivamente. Estes resultados justificam a escolha desta dosagem para aplicação na próxima fase para a Água de Estudo - 1, pois atendem aos limites impostos para estes parâmetros.

\subsubsection{2. Água de Estudo 2 (FASE - A)}

As características da Água de Estudo - 2 são: pH - 7,15; turbidez - 42,8 uT; cor aparente $-430 \mathrm{uC}$.

As Figuras 5.71 e 5.72 mostram, respectivamente, os resultados de turbidez e cor aparente residuais para a Água de Estudo - 2 . 
Turbidez das amostras flotadas e centrifugadas

Água de Estudo 2

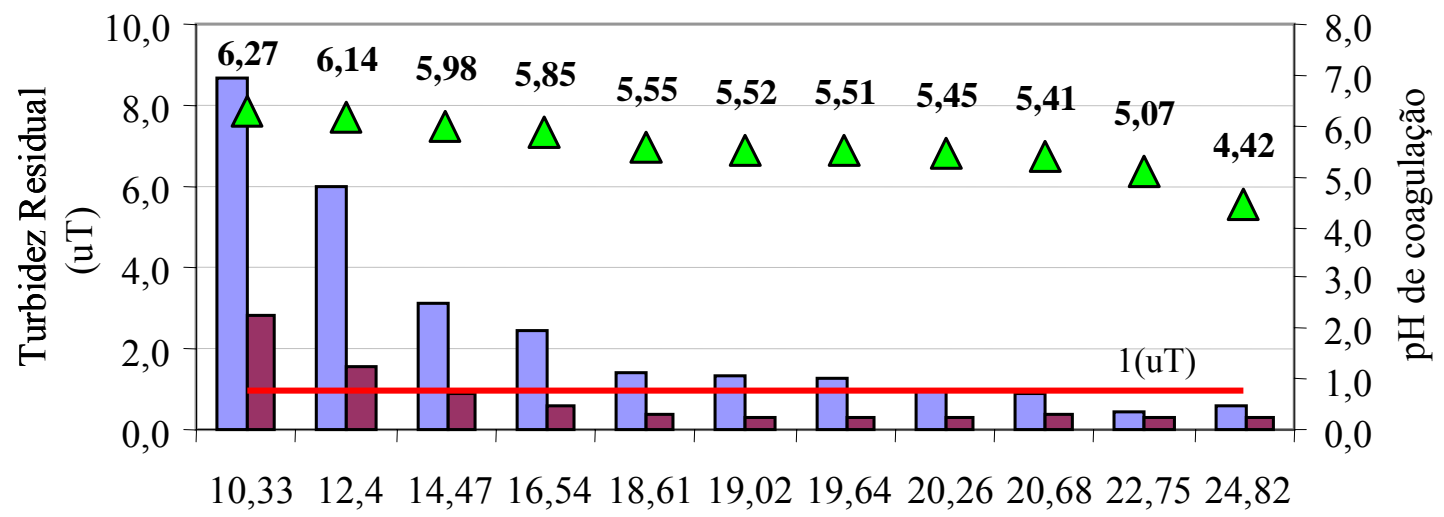

Dosagem de Coagulante $\left(\mathrm{mgFe}^{3+} / \mathrm{L}\right)$

$\square$ Turbidez Flot. $\square$ Turbidez Cent. $\Delta$ pH de Coagulação

Figura 5.71: Turbidez residual das amostras flotadas e centrifugadas e $\mathrm{pH}$ de coagulação.

Água de estudo 2: Turbidez $=42,8 \mathrm{uT} ; \mathrm{MC}=21,40 \mu \mathrm{g} / \mathrm{L}$.

Condições do ensaio: Pré-cloração $(6,0 \mathrm{mgCl} / \mathrm{L})$; Coagulação $\left(\mathrm{Vr}_{\mathrm{MR}}=350 \mathrm{rpm} ; \mathrm{T}_{\mathrm{MR}}=20 \mathrm{~s}\right)$; Aplicação de CAP $(25 \mathrm{mg} / \mathrm{L}) ;$ Floculação $\left(\mathrm{Vr}_{\mathrm{FLO}}=68 \mathrm{rpm} ; \mathrm{T}_{\mathrm{FLO}}=18 \mathrm{~min}\right) ; \mathrm{FAD}\left(\mathrm{p}_{\mathrm{SAT}}=500 \mathrm{kPa} ; \mathrm{R}=8 \% ; \mathrm{V}_{2}=12,0 \mathrm{~cm} / \mathrm{min}\right)$ Centrifugação $\left(\mathrm{f}_{\mathrm{CEN}}=2000 \mathrm{rpm} ; \mathrm{T}_{\mathrm{CEN}}=15 \mathrm{~min}\right)$.

Cor aparente das amostras flotadas e centrifugadas

Água de Estudo 2

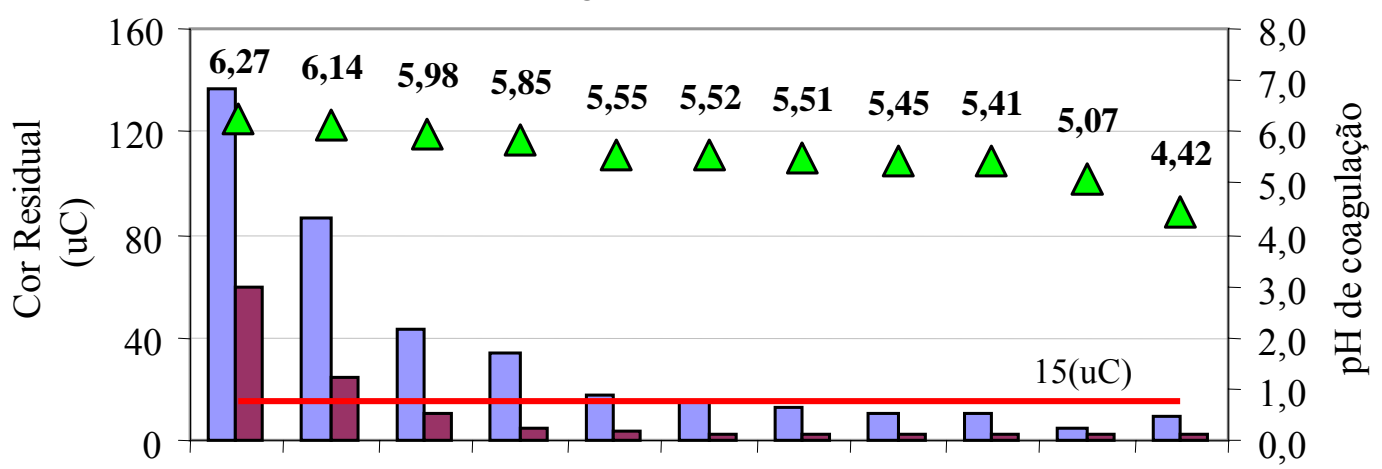

$10,3312,4 \quad 14,4716,5418,6119,0219,6420,2620,6822,7524,82$

Dosagem de Coagulante $\left(\mathrm{mgFe}^{3+} / \mathrm{L}\right)$

$\square$ Cor aparente Flot. $\quad \square$ Cor aparente Cent. $\Delta \mathrm{pH}$ de Coagulação

Figura 5.72: Cor aparente residual das amostras flotadas e centrifugadas e pH de coagulação. Água de estudo 2: Cor aparente $=430 \mathrm{uC} ; \mathrm{MC}=21,40 \mu \mathrm{g} / \mathrm{L}$.

Condições do ensaio: Pré-cloração $(6,0 \mathrm{mgCl} / \mathrm{L}) ;$ Coagulação $\left(\mathrm{Vr}_{\mathrm{MR}}=350 \mathrm{rpm} ; \mathrm{T}_{\mathrm{MR}}=20 \mathrm{~s}\right)$; Aplicação de CAP

$(25 \mathrm{mg} / \mathrm{L})$; Floculação $\left(\mathrm{Vr}_{\mathrm{FLO}}=68 \mathrm{rpm} ; \mathrm{T}_{\mathrm{FLO}}=18 \mathrm{~min}\right) ; \mathrm{FAD}\left(\mathrm{p}_{\mathrm{SAT}}=500 \mathrm{kPa} ; \mathrm{R}=8 \% ; \mathrm{V}_{2}=12,0 \mathrm{~cm} / \mathrm{min}\right)$ Centrifugação $\left(\mathrm{f}_{\mathrm{CEN}}=2000 \mathrm{rpm} ; \mathrm{T}_{\mathrm{CEN}}=15 \mathrm{~min}\right)$. 
Para a Água de Estudo - 2, a dosagem de cloreto férrico escolhida foi a de 20,68 $\mathrm{mgFe}^{3+} / \mathrm{L}$. Conforme as Figuras 5.71 e 5.72, esta dosagem promoveu residuais de turbidez e cor aparente abaixo dos limites de $1 \mathrm{uT}$ para turbidez e $15 \mathrm{uC}$ para a cor aparente, tanto das amostras flotadas quanto para as centrifugadas. Seguramente, esta dosagem resultou maior do que a verificada na etapa anterior devido à aplicação dos $25 \mathrm{mg} / \mathrm{L}$ de CAP, que interfere na turbidez e cor aparente da água, e dos $6,0 \mathrm{mgCl}_{2} / \mathrm{L}$ de oxidante que eleva o valor do $\mathrm{pH}$ de coagulação.

Os resultados observados foram: $0,90 \mathrm{uT}$ e $10 \mathrm{uC}$ para as amostras flotadas e $0,36 \mathrm{uT}$ e $2 \mathrm{uC}$ para as amostras centrifugadas.

\subsubsection{3. Água de Estudo 3 (FASE - A)}

As características da Água de Estudo - 3 são: pH - 7,02; turbidez - 25,3 uT; cor aparente $-301 \mathrm{uC}$.

As Figuras 5.73 e 5.74 mostram, respectivamente, os resultados de turbidez e cor aparente residuais das amostras flotadas e centrifugadas para a Água de Estudo - 3 . 
Turbidez das amostras flotadas e centrifugadas

Água de Estudo 3

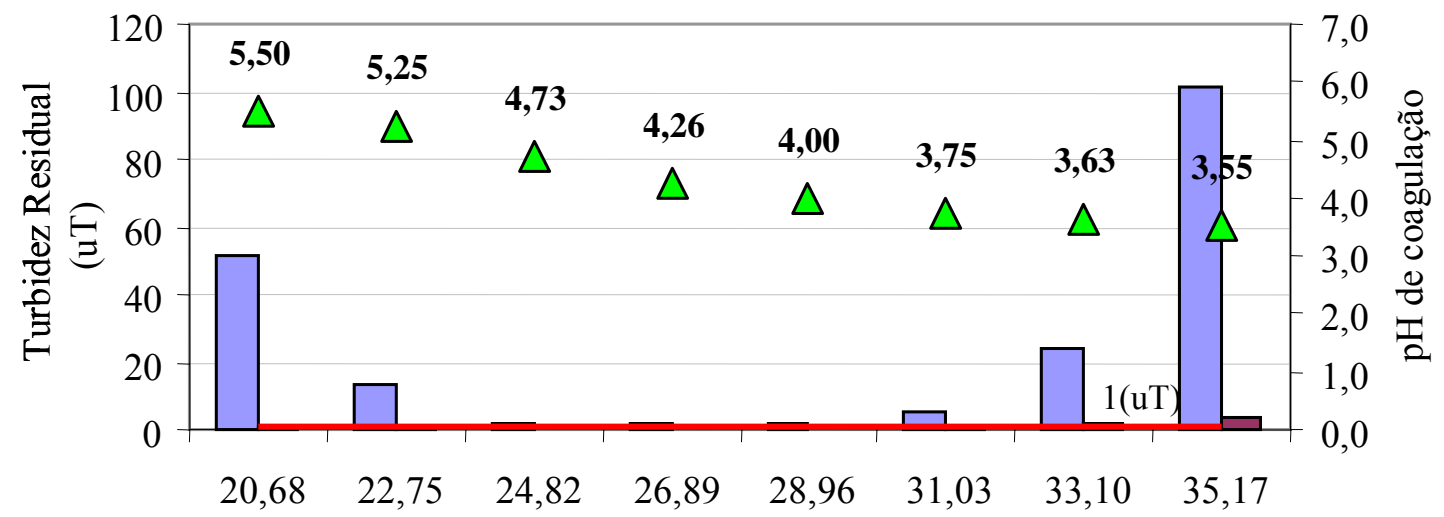

Dosagem de Coagulante $\left(\mathrm{mgFe}^{3+} / \mathrm{L}\right)$

$\square$ Turbidez Flot. $\square$ Turbidez Cent. $\Delta$ pH de Coagulação

Figura 5.73: Turbidez residual das amostras flotadas e centrifugadas e pH de coagulação.

Água de estudo 3: Turbidez $=25,3 \mathrm{uT} ; \mathrm{MC}=86,94 \mu \mathrm{g} / \mathrm{L}$.

Condições do ensaio: Pré-cloração $(6,0 \mathrm{mgCl} / \mathrm{L})$; Coagulação $\left(\mathrm{Vr}_{\mathrm{MR}}=350 \mathrm{rpm} ; \mathrm{T}_{\mathrm{MR}}=20 \mathrm{~s}\right)$; Aplicação de CAP $(100 \mathrm{mg} / \mathrm{L})$; Floculação $\left(\mathrm{Vr}_{\mathrm{FLO}}=68 \mathrm{rpm} ; \mathrm{T}_{\mathrm{FLO}}=18 \mathrm{~min}\right) ; \mathrm{FAD}\left(\mathrm{p}_{\mathrm{SAT}}=500 \mathrm{kPa} ; \mathrm{R}=8 \% ; \mathrm{V}_{2}=12,0 \mathrm{~cm} / \mathrm{min}\right)$

Centrifugação $\left(\mathrm{f}_{\mathrm{CEN}}=2000 \mathrm{rpm} ; \mathrm{T}_{\mathrm{CEN}}=15 \mathrm{~min}\right)$.

Cor aparente das amostras flotadas e centrifugadas

Água de Estudo 3

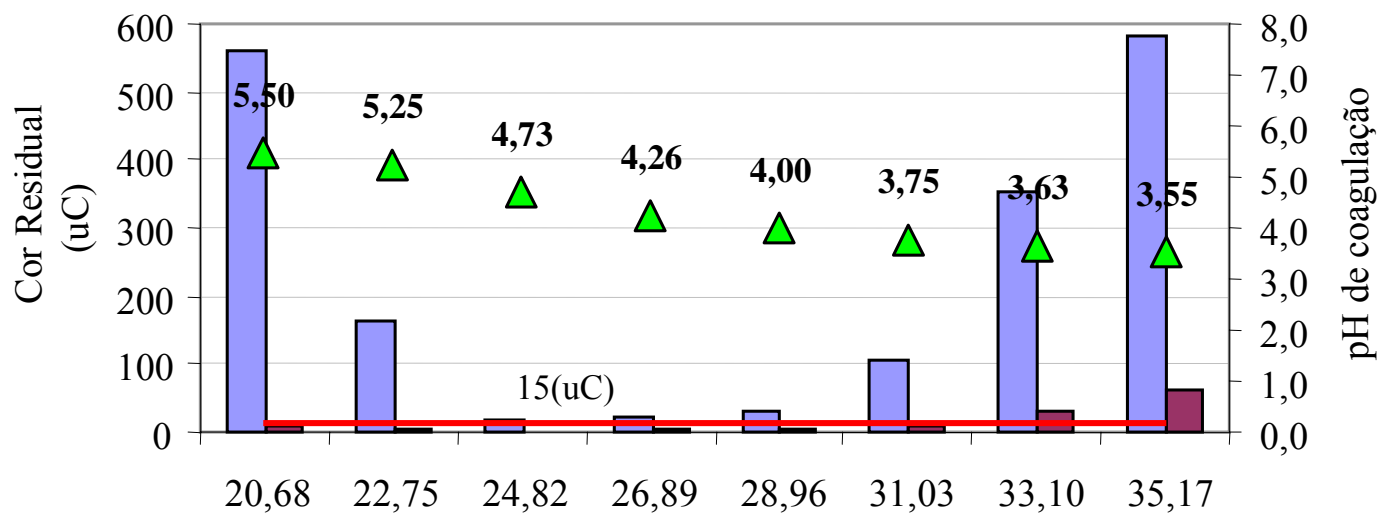

Dosagem de Coagulante $\left(\mathrm{mgFe}^{3+} / \mathrm{L}\right)$

$\square$ Cor aparente Flot. $\quad \square$ Cor aparente Cent. $\quad \Delta \mathrm{pH}$ de Coagulação

Figura 5.74: Cor aparente residual das amostras flotadas e centrifugadas e pH de coagulação.

Água de estudo 3: Cor aparente $=301 \mathrm{uC} ; \mathrm{MC}=86,94 \mu \mathrm{g} / \mathrm{L}$.

Condições do ensaio: Pré-cloração $\left(6,0 \mathrm{mgCl}_{2} / \mathrm{L}\right) ;$ Coagulação $\left(\mathrm{Vr}_{\mathrm{MR}}=350 \mathrm{rpm} ; \mathrm{T}_{\mathrm{MR}}=20 \mathrm{~s}\right)$; Aplicação de CAP $(100 \mathrm{mg} / \mathrm{L})$; Floculação $\left(\mathrm{Vr}_{\mathrm{FLO}}=68 \mathrm{rpm} ; \mathrm{T}_{\mathrm{FLO}}=18 \mathrm{~min}\right) ; \mathrm{FAD}\left(\mathrm{p}_{\mathrm{SAT}}=500 \mathrm{kPa} ; \mathrm{R}=8 \% ; \mathrm{V}_{2}=12,0 \mathrm{~cm} / \mathrm{min}\right)$ Centrifugação $\left(f_{\mathrm{CEN}}=2000 \mathrm{rpm} ; \mathrm{T}_{\mathrm{CEN}}=15 \mathrm{~min}\right)$. 
As figuras mostram que ao aplicar a dosagem de $20,68 \mathrm{mgFe}^{3+} / \mathrm{L}$ de cloreto férrico, os valores de turbidez e cor aparente das amostras flotadas foram maiores que da água bruta, sendo respectivamente iguais a $52 \mathrm{uT}$ e $562 \mathrm{uC}$. Isto ocorreu devido à elevada dosagem de carvão ativado em pó empregada no ensaio. Contudo, ao centrifugar tais amostras estes valores reduziram significativamente para $1,16 \mathrm{uT}$ e $10 \mathrm{uC}$.

A partir da dosagem de $24,82 \mathrm{mgFe}^{3+} / \mathrm{L}$ de coagulante, é possível observar uma tendência no aumento dos valores de cor e turbidez de ambas as amostras flotadas e centrifugadas. Durante os ensaios, foi visível a formação de flocos maiores e mais densos com dosagens a partir de $26,89 \mathrm{mgFe}^{3+} / \mathrm{L}$, sendo claramente observada a sedimentação dos flocos e conseqüente diminuição na eficiência de remoção destes parâmetros pela flotação por ar dissolvido.

Assim, a dosagem ótima de coagulante definida para a Água de Estudo - 3 foi 24,82 $\mathrm{mgFe}^{3+} / \mathrm{L}$, com resultados de 1,49 uT e $16 \mathrm{uC}$ para as amostras flotadas, e 0,27 uT e 2 uC para as amostras centrifugadas.

\subsubsection{Resumo dos resultados da FASE - A / ETAPA - II}

Conforme apresentado, a escolha da dosagem ótima de coagulante foi realizada com a variação de oito dosagens de cloreto férrico para cada água de estudo, sendo que durante os ensaios, foi aplicada a maior das dosagens de oxidante $\left(6,0 \mathrm{mgCl}_{2} / \mathrm{L}\right)$ que foram avaliadas na FASE - B da ETAPA - II, junto com a dosagem de CAP estimada, para cada água de estudo, que resultaria em residual de microcistina abaixo do limite estabelecido pela Portaria 518 / 04 do Ministério da Saúde.

Com isto, a dosagem de coagulante definida para cada água de estudo foi: 
- $\quad$ ÁGUA DE ESTUDO - 1: dosagem de $\mathrm{FeCl}_{3}=14,47 \mathrm{mgFe}^{3+} / \mathrm{L}$;

- $\quad$ ÁGUA DE ESTUDO - 2: dosagem de $\mathrm{FeCl}_{3}=20,68 \mathrm{mgFe}^{3+} / \mathrm{L}$;

- $\quad$ ÁGUA DE ESTUDO - 3: dosagem de $\mathrm{FeCl}_{3}=24,82 \mathrm{mgFe}^{3+} / \mathrm{L}$.

\subsubsection{FASE - B}

Para a FASE - B da ETAPA - II foi repetido o fluxograma, de tratamento em escala de bancada, da FASE - C da ETAPA - I por ter apresentado os melhores resultados de cor aparente , turbidez, absorbância em 254 nm e residual de microcistina. Contudo, para a précloração foram testadas as dosagens de 3,0 e 6,0 $\mathrm{mgCl}_{2} / \mathrm{L}$ de cloro livre a partir da aplicação de hipoclorito de sódio. Para a adsorção em CAP, com aplicação após a mistura rápida, foi avaliada a estimativa da dosagem mínima de carvão necessária para reduzir a concentração final de microcistina (após a flotação seguida da centrifugação em substituição da etapa de clarificação final por filtração) para $1 \mu \mathrm{g} / \mathrm{L}$, conforme limite estabelecido pela Portaria 518 / 04 do Ministério da Saúde, considerando-se que a etapa final de pós-cloração (não aplicada neste trabalho) constituiria barreira adicional final para remoção de microcistina.

A grade de ensaios estabelecida para esta fase possibilitou a simulação completa, em escala de bancada, do tratamento proposto pela técnica de flotação por ar dissolvido. O sistema foi avaliado com as três águas preparadas, e foram realizados com: pré-cloração com hipoclorito de sódio $\left(0 ; 3,0\right.$ e $6,0 \mathrm{mgCl}_{2} / \mathrm{L}$ cloro livre $)$ com tempo de contato de $10 \mathrm{~s} \rightarrow$ coagulação com cloreto férrico (dosagem ótima de coagulante) $\rightarrow$ aplicação de CAP logo após a mistura rápida ( 0 e dosagem estimada de CAP) com tempo de contato de $50 \mathrm{~s} \rightarrow$ floculação $\rightarrow$ flotação por ar dissolvido $\rightarrow$ centrifugação. 
Os ensaios foram monitorados pelos parâmetros: pH de coagulação; cor aparente, turbidez, absorbância em 254 nm (ABS 254), carbono orgânico total (COT) e microcistina (MC) das amostras flotadas; cor aparente, turbidez, ABS 254, DQO, nitrogênio total (NT), cloro residual, COT, MC e trialometanos (THM) das amostras centrifugadas.

\subsubsection{1. Água de Estudo 1 (FASE - B)}

As características da Água de Estudo - 1, conforme os parâmetros avaliados no controle dos ensaios, são: $\mathrm{pH}$ - 7,26; turbidez - 52,8 uT; cor aparente - 502 uC, ABS $254 \mathrm{~nm}$ $-0,290 ; \mathrm{NT}-7,35 \mathrm{mg} / \mathrm{L} ; \mathrm{DQO}-65 \mathrm{mgO}_{2} / \mathrm{L} ; \mathrm{COT}-7,96 \mathrm{mgC} / \mathrm{L}$ e $\mathrm{MC}-5,58 \mu \mathrm{g} / \mathrm{L}$.

A Tabela 5.29 apresenta os resultados das amostras flotadas e centrifugadas da FASE - B para a Água de Estudo - 1 . 
Tabela 5.29: Valores dos resultados da FASE - B da ETAPA - II para Água de Estudo - 1.

\begin{tabular}{|c|c|c|c|c|c|c|}
\hline & \multicolumn{6}{|c|}{ Amostras Flotadas } \\
\hline & $\begin{array}{c}\mathrm{Cl}_{2}=0 \\
\mathrm{CAP}=0\end{array}$ & $\begin{array}{c}\mathrm{Cl}_{2}=3 \\
\mathrm{CAP}=0\end{array}$ & $\begin{array}{c}\mathrm{Cl}_{2}=6 \\
\mathrm{CAP}=0\end{array}$ & $\begin{array}{c}\mathrm{Cl}_{2}=0 \\
\mathrm{CAP}=5\end{array}$ & $\begin{array}{c}\mathrm{Cl}_{2}=3 \\
\mathrm{CAP}=5\end{array}$ & $\begin{array}{c}\mathrm{Cl}_{2}=6 \\
\mathrm{CAP}=5\end{array}$ \\
\hline $\begin{array}{c}\text { Dcoag. } \\
\left(\mathrm{mgFe}^{3+} / \mathrm{L}\right)\end{array}$ & 14,47 & 14,47 & 14,47 & 14,47 & 14,47 & 14,47 \\
\hline pH de Coag. & 5,76 & 5,86 & 6,00 & 5,87 & 5,92 & 5,97 \\
\hline Cor (uC) & 8 & 7 & 7 & 10 & 10 & 9 \\
\hline Turbidez (uT) & 0,54 & 0,66 & 0,46 & 0,70 & 0,82 & 0,66 \\
\hline ABS $254 \mathrm{~nm}$ & 0,064 & 0,066 & 0,089 & 0,060 & 0,062 & 0,064 \\
\hline $\mathrm{COT}(\mathrm{mgC} / \mathrm{L})$ & 4,46 & 3,97 & 4,06 & 3,20 & 3,44 & 3,74 \\
\hline \multirow[t]{3}{*}{$\mathrm{MC}(\mu \mathrm{g} / \mathrm{L})$} & 1,50 & 2,30 & 0,92 & 0,85 & 1,34 & 0,76 \\
\hline & \multicolumn{6}{|c|}{ Amostras Centrifugadas } \\
\hline & $\begin{array}{c}\mathrm{Cl}_{2}=0 \\
\mathrm{CAP}=0\end{array}$ & $\begin{array}{c}\mathrm{Cl}_{2}=3 \\
\mathrm{CAP}=0\end{array}$ & $\begin{array}{c}\mathrm{Cl}_{2}=6 \\
\mathrm{CAP}=0\end{array}$ & $\begin{array}{c}\mathrm{Cl}_{2}=0 \\
\mathrm{CAP}=5\end{array}$ & $\begin{array}{c}\mathrm{Cl}_{2}=3 \\
\mathrm{CAP}=5\end{array}$ & $\begin{array}{c}\mathrm{Cl}_{2}=6 \\
\mathrm{CAP}=5\end{array}$ \\
\hline $\begin{array}{c}\text { Dcoag. } \\
\left(\mathrm{mgFe}^{3+} / \mathrm{L}\right)\end{array}$ & 14,47 & 14,47 & 14,47 & 14,47 & 14,47 & 14,47 \\
\hline pH de Coag. & 5,76 & 5,86 & 6,00 & 5,87 & 5,92 & 5,97 \\
\hline Cor (uC) & 6 & 4 & 4 & 4 & 4 & 4 \\
\hline Turbidez (uT) & 0,33 & 0,33 & 0,31 & 0,32 & 0,31 & 0,33 \\
\hline ABS $254 \mathrm{~nm}$ & 0,059 & 0,060 & 0,075 & 0,054 & 0,055 & 0,057 \\
\hline $\mathrm{DQO}(\mathrm{mgO} / \mathrm{L})$ & 8 & 6 & 6 & 8 & 9 & 7 \\
\hline NT (mg/L) & 4,70 & 4,88 & 4,44 & 4,29 & 4,62 & 4,75 \\
\hline $\mathrm{Cl}_{2}$ Res. $(\mathrm{mg} / \mathrm{L})$ & 0,00 & 0,71 & 3,55 & 0,00 & 0,00 & 1,42 \\
\hline COT (mgC/L) & 3,69 & 4,04 & 4,38 & 3,18 & 3,51 & 3,64 \\
\hline $\mathrm{MC}(\mu \mathrm{g} / \mathrm{L})$ & 1,28 & 1,07 & 0,96 & 0,80 & 1,29 & 0,75 \\
\hline THM (mg/L) & $<0,001$ & 0,143 & 0,107 & $<0,001$ & 0,151 & 0,092 \\
\hline
\end{tabular}

Os resultados da Tabela 5.29 mostram que a dosagem de cloreto férrico de 14,47 $\mathrm{mgFe}^{3+} / \mathrm{L}$ foi capaz de neutralizar o efeito da adição do oxidante no $\mathrm{pH}$ de coagulação, e assim produzir amostras flotadas com turbidez e cor aparente abaixo dos limites de 1 uT e 15 uC. A aplicação do carvão promoveu um pequeno aumento nos valores de turbidez das amostras flotadas, contudo, após a centrifugação, tal aumento se mostrou insignificante conforme os valores de turbidez que ficaram em torno de $0,33 \mathrm{uT}$ e a cor em torno de $4 \mathrm{uC}$. 
A aplicação do CAP proporcionou aumento na remoção de nitrogênio total (NT) quando não foi realizada a pré-cloração. O valor residual de NT, para a mostra centrifugada, foi de 4,29 mg/L que representa remoção de aproximadamente 42 \%.

Ficou claro o consumo de cloro devido à oxidação da matéria orgânica dissolvida, e a adsorção do cloro pelo CAP. Para a dosagem de $3,0 \mathrm{mgCl}_{2} / \mathrm{L}$ de cloro livre sem CAP, o residual foi de $0,71 \mathrm{mg} / \mathrm{L}$, contudo, não houve residual de cloro quando foram aplicados 5 $\mathrm{mg} / \mathrm{L}$ de CAP. Com o aumento da dosagem de cloro livre para $6,0 \mathrm{mgCl}_{2} / \mathrm{L}$, o residual foi de 3,55 $\mathrm{mgCl}_{2} / \mathrm{L}$ sem a aplicação de CAP. Aplicando-se $5 \mathrm{mg} / \mathrm{L}$ de CAP o residual de cloro caiu para $1,42 \mathrm{mgCl}_{2} / \mathrm{L}$.

A determinação do valor de trialometanos consistiu na soma dos seguintes compostos: bromodiclorometano, bromofórmio, clorofórmio e dibromoclorometano. A Figura 5.75 apresenta o gráfico elaborado a partir dos dados da Tabela 5.29.

Trialometanos das amostras centrifugadas

Água de Estudo 1

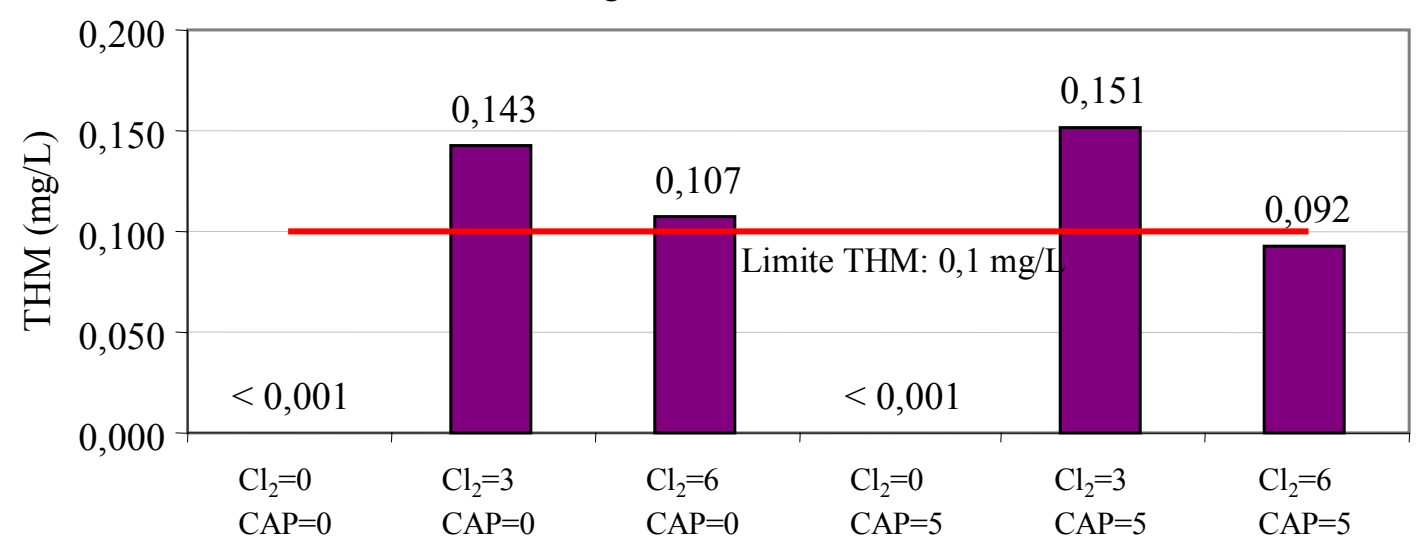

Dosagem de Cloro e CAP (mg/L)

THM (mg/L)

Figura 5.75: Concentração de trialometanos das amostras centrifugadas - Água de Estudo - 1 .

Água de estudo $1: \mathrm{MC}=5,58 \mu \mathrm{g} / \mathrm{L}$.

Condições do ensaio: Pré-cloração $\left(0 ; 3,0 ; 6,0 \mathrm{mgCl} / 2\right.$ ) ; Coagulação $\left(\mathrm{D}_{\mathrm{FeCl} 13}=14,47 \mathrm{mgFe}^{3+} / \mathrm{L} ; \mathrm{Vr}_{\mathrm{MR}}=350 \mathrm{rpm}\right.$; $\left.\mathrm{T}_{\mathrm{MR}}=20 \mathrm{~s}\right) ;$ Aplicação de CAP $(5 \mathrm{mg} / \mathrm{L}) ;$ Floculação $\left(\mathrm{Vr}_{\mathrm{FLO}}=68 \mathrm{rpm} ; \mathrm{T}_{\mathrm{FLO}}=18 \mathrm{~min}\right) ; \mathrm{FAD}\left(\mathrm{p}_{\mathrm{SAT}}=500 \mathrm{kPa} ; \mathrm{R}=\right.$ $8 \% ; \mathrm{V}_{2}=12,0 \mathrm{~cm} / \mathrm{min}$ ) Centrifugação $\left(\mathrm{f}_{\mathrm{CEN}}=2000 \mathrm{rpm} ; \mathrm{T}_{\mathrm{CEN}}=15 \mathrm{~min}\right)$. 
A figura mostra que a aplicação de $3,0 \mathrm{mgCl}_{2} / \mathrm{L}$ de cloro livre, com e sem CAP, produziram os maiores valores de concentração de trialometanos. Inclusive, tais valores se apresentaram acima do limite estabelecido pela legislação que define os parâmetros de água para o consumo humano. A condição de ensaio de pré-cloração com $6,0 \mathrm{mgCl} / \mathrm{L}$ de cloro livre e $5 \mathrm{mg} / \mathrm{L}$ de CAP apresentou concentração de trialometanos ligeiramente abaixo de 100 $\mu \mathrm{g} / \mathrm{L}(92 \mu \mathrm{g} / \mathrm{L})$.

Com relação à matéria orgânica dissolvida, foi determinada a concentração de carbono orgânico total (COT) das amostras flotadas e centrifugadas. A Figura 5.76 mostra os resultados para as determinações de COT.

COT das amostras flotadas e centrifugadas

Água de Estudo 1

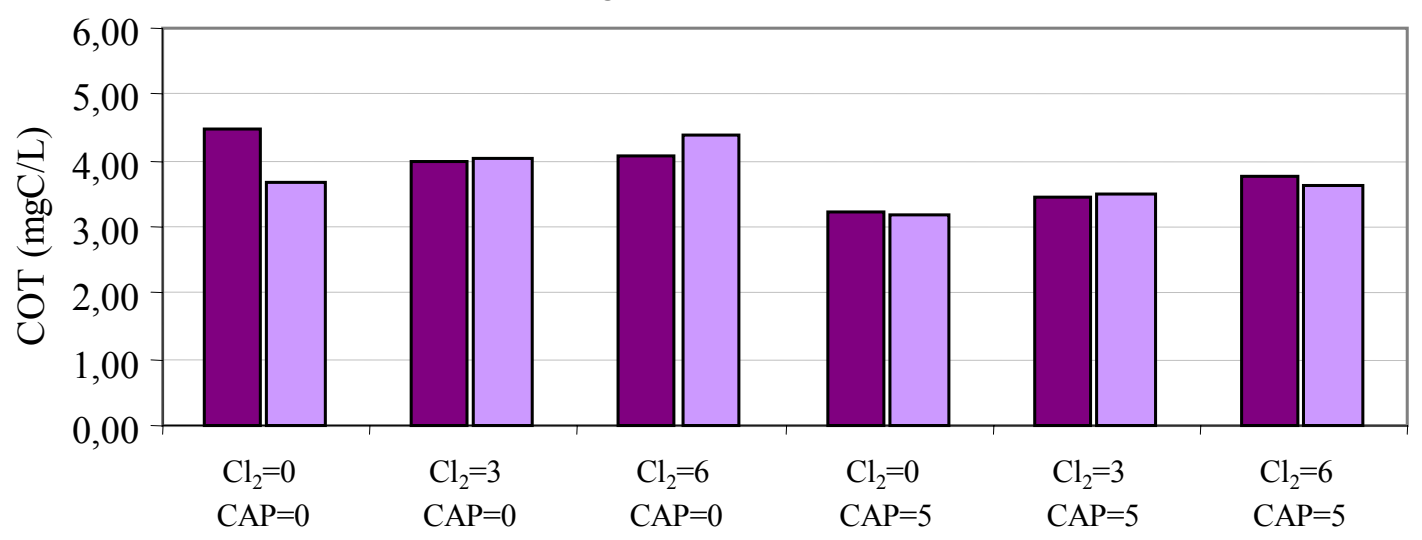

Dosagem de Cloro e CAP (mg/L)

$\square$ COT flotado $\square$ COT centrifugado

Figura 5.76: Carbono orgânico total das amostras flotadas e centrifugadas - Água de Estudo - 1. Água de estudo $1: \mathrm{COT}=7,96 \mathrm{mgC} / \mathrm{L} ; \mathrm{MC}=5,58 \mu \mathrm{g} / \mathrm{L}$.

Condições do ensaio: Pré-cloração $\left(0 ; 3,0 ; 6,0 \mathrm{mgCl}_{2} / \mathrm{L}\right)$; Coagulação $\left(\mathrm{D}_{\mathrm{FeCl}}=14,47 \mathrm{mgFe} \mathrm{ge}^{3+} / \mathrm{L} ; \mathrm{Vr}_{\mathrm{MR}}=350 \mathrm{rpm}\right.$; $\left.\mathrm{T}_{\mathrm{MR}}=20 \mathrm{~s}\right)$; Aplicação de CAP $(5 \mathrm{mg} / \mathrm{L})$; Floculação $\left(\mathrm{Vr}_{\mathrm{FLO}}=68 \mathrm{rpm} ; \mathrm{T}_{\mathrm{FLO}}=18 \mathrm{~min}\right) ; \mathrm{FAD}\left(\mathrm{p}_{\mathrm{SAT}}=500 \mathrm{kPa} ; \mathrm{R}=\right.$ $\left.8 \% ; \mathrm{V}_{2}=12,0 \mathrm{~cm} / \mathrm{min}\right)$ Centrifugação $\left(\mathrm{f}_{\mathrm{CEN}}=2000 \mathrm{rpm} ; \mathrm{T}_{\mathrm{CEN}}=15 \mathrm{~min}\right)$.

A Figura 5.76 mostra que o aumento da dosagem de cloro elevou os residuais de COT. No entanto, a aplicação de carvão ativado promoveu leve redução na concentração das amostras. Os melhores resultados foram das amostras centrifugadas sem a aplicação de cloro. 
Sem CAP o residual foi de 4,46 mgC/L (44 \% de remoção), com a aplicação de $5 \mathrm{mg} / \mathrm{L}$ de CAP a remoção aumentou para $60 \%$ com residual de 3,18 mgC/L.

A absorbância em $254 \mathrm{~nm}$ (ABS $254 \mathrm{~nm}$ ) é outro controle, indireto, da matéria orgânica dissolvida. Assim, conforme a Tabela 5.30, determinou-se a correlação entre a concentração de carbono orgânico total (COT) e a ABS $254 \mathrm{~nm}$ das amostras flotadas e centrifugadas.

Tabela 5.30: Correlação entre ABS 254 nm e COT das amostras flotadas e centrifugadas - Água de estudo 1.

\begin{tabular}{ccc}
\hline \hline \multicolumn{3}{c}{ Amostras flotadas } \\
\hline \hline Ensaio & $\begin{array}{c}\mathrm{ABS} \\
254 \mathrm{~nm}\end{array}$ & $\begin{array}{c}\mathrm{COT} \\
(\mathrm{mgC} / \mathrm{L})\end{array}$ \\
\hline \hline $\mathrm{Cl}_{2}=0$ / CAP $=0$ & 0,064 & 4,46 \\
$\mathrm{Cl}_{2}=3$ / CAP $=0$ & 0,066 & 3,97 \\
$\mathrm{Cl}_{2}=6$ / CAP $=0$ & 0,089 & 4,06 \\
$\mathrm{Cl}_{2}=0$ / CAP $=5$ & 0,060 & 3,20 \\
$\mathrm{Cl}_{2}=3$ / CAP $=5$ & 0,062 & 3,44 \\
$\mathrm{Cl}_{2}=6 / \mathrm{CAP}=5$ & 0,064 & 3,74 \\
\hline
\end{tabular}

\begin{tabular}{ccc}
\hline \hline \multicolumn{3}{c}{ Amostras centrifugadas } \\
\hline \hline Ensaio & $\begin{array}{c}\mathrm{ABS} \\
254 \mathrm{~nm}\end{array}$ & $\begin{array}{c}\mathrm{COT} \\
(\mathrm{mgC} / \mathrm{L})\end{array}$ \\
\hline \hline $\mathrm{Cl}_{2}=0 / \mathrm{CAP}=0$ & 0,059 & 3,69 \\
$\mathrm{Cl}_{2}=3$ / CAP $=0$ & 0,060 & 4,04 \\
$\mathrm{Cl}_{2}=6 / \mathrm{CAP}=0$ & 0,075 & 4,38 \\
$\mathrm{Cl}_{2}=0 / \mathrm{CAP}=5$ & 0,054 & 3,18 \\
$\mathrm{Cl}_{2}=3 / \mathrm{CAP}=5$ & 0,055 & 3,51 \\
$\mathrm{Cl}_{2}=6 / \mathrm{CAP}=5$ & 0,057 & 3,64 \\
\hline
\end{tabular}

$$
\begin{aligned}
\text { Covariância }(\text { ABS }, \text { COT }) & =0,002 \\
\text { Desv. Padrão IAM }= & 0,010 \\
\text { Desv. Padrão MC }= & 0,413 \\
r & =\mathbf{0 , 4 0 3}
\end{aligned}
$$

$$
\begin{aligned}
\text { Covariância }(\text { ABS }, \text { COT }) & =0,002 \\
\text { Desv. Padrão IAM } & =0,007 \\
\text { Desv. Padrão } M C & =0,383 \\
\boldsymbol{r} & =\mathbf{0 , 8 9 6}
\end{aligned}
$$

As Figuras 5.77 e 5.78 mostram o comportamento destas características para as amostras flotadas e centrifugadas, respectivamente. 
ABS $254 \mathrm{~nm}$ e COT das amostras flotadas

Água de Estudo 1

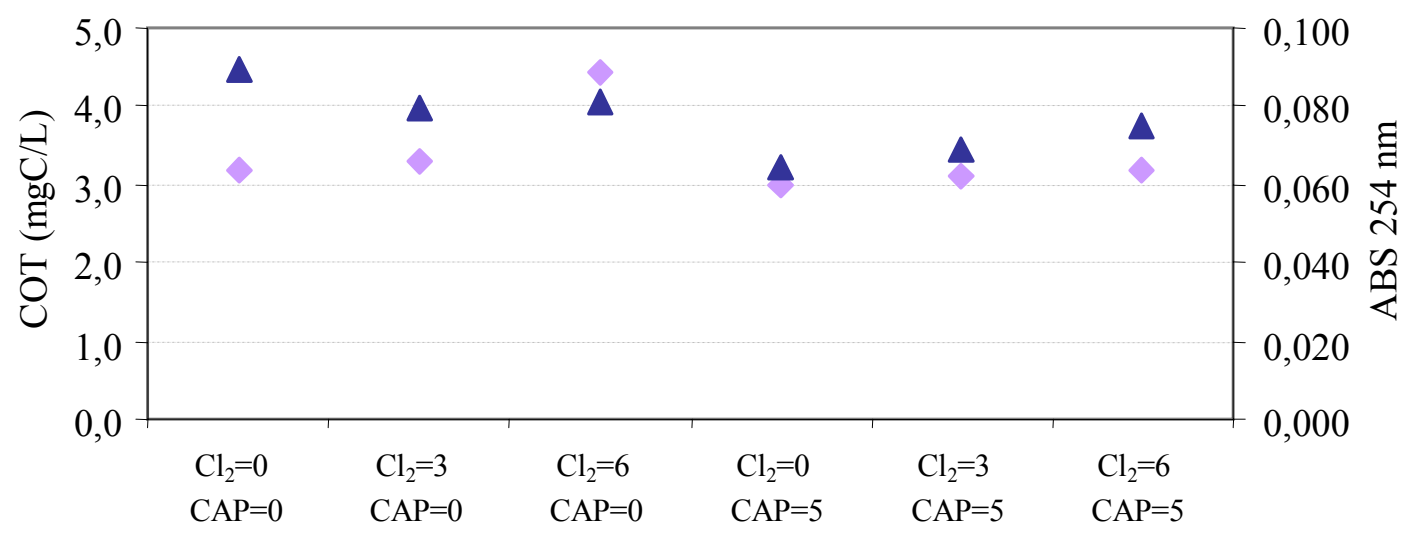

Dosagem de cloro e CAP (mg/L)

ABS 254 Flot. $\triangle$ COT Flot.

Figura 5.77: ABS $254 \mathrm{~nm}$ e COT das amostras flotadas - Água de Estudo - 1. Água de estudo 1: ABS $254 \mathrm{~nm}=0,290 ; \mathrm{COT}=7,96 \mathrm{mgC} / \mathrm{L} ; \mathrm{MC}=5,58 \mu \mathrm{g} / \mathrm{L}$.

Condições do ensaio: Pré-cloração $\left(0 ; 3,0 ; 6,0 \mathrm{mgCl}_{2} / \mathrm{L}\right)$; Coagulação $\left(\mathrm{D}_{\mathrm{FeCl} 13}=14,47 \mathrm{mgFe} \mathrm{ge}^{3+} / \mathrm{L} ; \mathrm{Vr}_{\mathrm{MR}}=350 \mathrm{rpm}\right.$; $\left.\mathrm{T}_{\mathrm{MR}}=20 \mathrm{~s}\right)$; Aplicação de CAP $(5 \mathrm{mg} / \mathrm{L})$; Floculação $\left(\mathrm{Vr}_{\mathrm{FLO}}=68 \mathrm{rpm} ; \mathrm{T}_{\mathrm{FLO}}=18 \mathrm{~min}\right) ; \mathrm{FAD}\left(\mathrm{p}_{\mathrm{SAT}}=500 \mathrm{kPa} ; \mathrm{R}=\right.$ $\left.8 \% ; \mathrm{V}_{2}=12,0 \mathrm{~cm} / \mathrm{min}\right)$ Centrifugação $\left(\mathrm{f}_{\mathrm{CEN}}=2000 \mathrm{rpm} ; \mathrm{T}_{\mathrm{CEN}}=15 \mathrm{~min}\right)$.

ABS $254 \mathrm{~nm}$ e COT das amostras centrifugadas

Água de Estudo 1

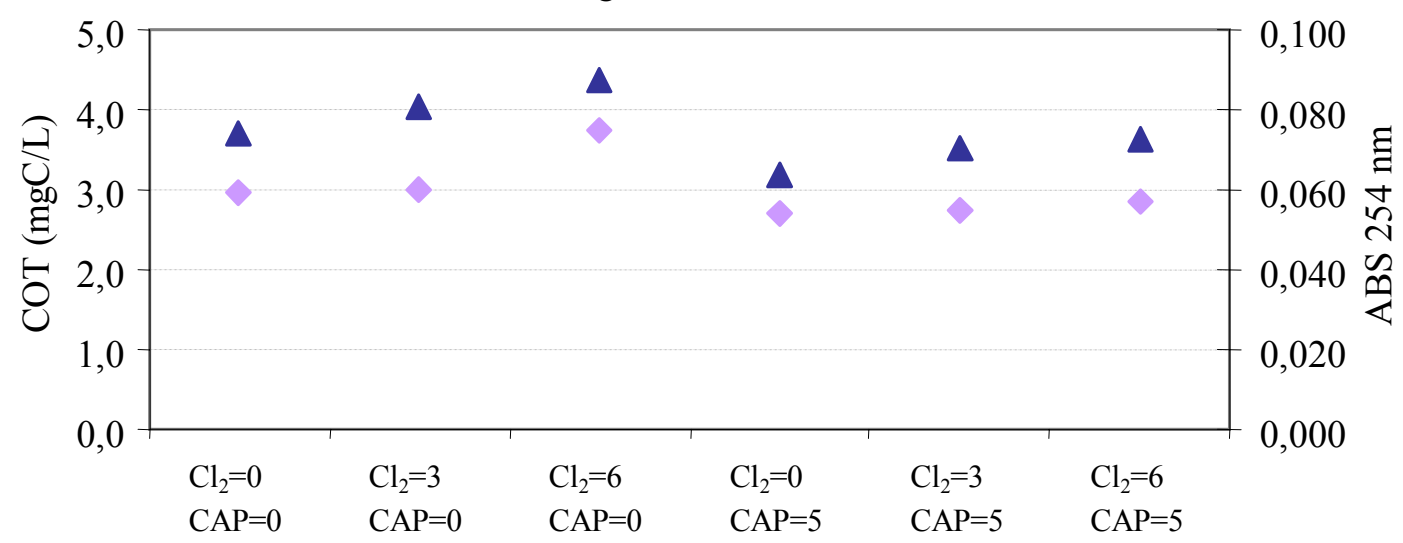

Dosagem de cloro e CAP $(\mathrm{mg} / \mathrm{L})$

$\triangle$ COT Cent. $\diamond$ ABS 254 Cent.

Figura 5.78: ABS $254 \mathrm{~nm}$ e COT das amostras centrifugadas - Água de Estudo - 1.

Água de estudo 1: ABS $254 \mathrm{~nm}=0,290 ;$ COT $=7,96 \mathrm{mgC} / \mathrm{L} ; \mathrm{MC}=5,58 \mu \mathrm{g} / \mathrm{L}$.

Condições do ensaio: Pré-cloração $\left(0 ; 3,0 ; 6,0 \mathrm{mgCl}_{2} / \mathrm{L}\right)$; Coagulação $\left(\mathrm{D}_{\mathrm{FeCl} 13}=14,47 \mathrm{mgFe}^{3+} / \mathrm{L} ; \mathrm{Vr}_{\mathrm{MR}}=350 \mathrm{rpm}\right.$; $\left.\mathrm{T}_{\mathrm{MR}}=20 \mathrm{~s}\right)$; Aplicação de CAP $(5 \mathrm{mg} / \mathrm{L})$; Floculação $\left(\mathrm{Vr}_{\mathrm{FLO}}=68 \mathrm{rpm} ; \mathrm{T}_{\mathrm{FLO}}=18 \mathrm{~min}\right) ; \mathrm{FAD}\left(\mathrm{p}_{\mathrm{SAT}}=500 \mathrm{kPa} ; \mathrm{R}=\right.$ $\left.8 \% ; \mathrm{V}_{2}=12,0 \mathrm{~cm} / \mathrm{min}\right)$ Centrifugação $\left(\mathrm{f}_{\mathrm{CEN}}=2000 \mathrm{rpm} ; \mathrm{T}_{\mathrm{CEN}}=15 \mathrm{~min}\right)$. 
A Figura 5.77 apresenta certa tendência entre a ABS 254 e o COT das amostras flotadas após a adição do carvão ativa em pó. Porém, foram definidos baixos índices de correlação para as amostras flotadas, $r=0,403$. Com a centrifugação das amostras (Figura 5.78), ficou claro o comportamento semelhante de ambas as determinações. Para as amostras centrifugadas, os índices de correlação foram $\mathrm{r}=0,896$, ou seja, a absorbância em $254 \mathrm{~nm}$ apresentou boa correlação com a matéria orgânica dissolvida no líquido.

Com relação à remoção de microcistina pelo sistema de tratamento em bancada, aplicado à Água de Estudo - 1, a Figura 5.79 apresenta o gráfico elaborado com os resultados apresentados na Tabela 5.29.

Concentração de microcistina das amostras flotadas e centrifugadas

Água de Estudo 1

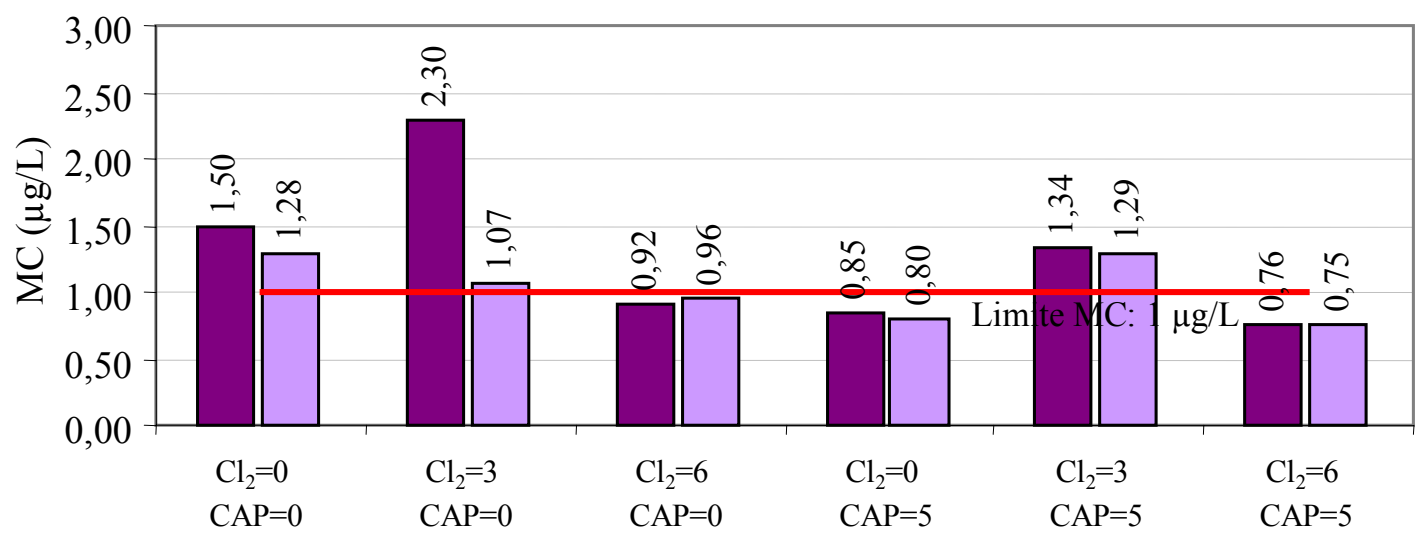

Dosagem de Cloro e CAP (mg/L)

$\square$ MC flotado $\square \mathrm{MC}$ centrifugado

Figura 5.79: Concentração de microcistina (MC) das amostras flotadas e centrifugadas - Água de Estudo - 1. Água de estudo $1: \mathrm{MC}=5,58 \mu \mathrm{g} / \mathrm{L}$.

Condições do ensaio: Pré-cloração $\left(0 ; 3,0 ; 6,0 \mathrm{mgCl} / 2\right.$ ); Coagulação $\left(\mathrm{D}_{\mathrm{FeCl} 13}=14,47 \mathrm{mgFe} \mathrm{ge}^{3+} / \mathrm{L} ; \mathrm{Vr}_{\mathrm{MR}}=350 \mathrm{rpm}\right.$; $\left.\mathrm{T}_{\mathrm{MR}}=20 \mathrm{~s}\right)$; Aplicação de CAP $(5 \mathrm{mg} / \mathrm{L}) ;$ Floculação $\left(\operatorname{Vr}_{\mathrm{FLO}}=68 \mathrm{rpm} ; \mathrm{T}_{\mathrm{FLO}}=18 \mathrm{~min}\right) ; \mathrm{FAD}\left(\mathrm{p}_{\mathrm{SAT}}=500 \mathrm{kPa} ; \mathrm{R}=\right.$ $8 \% ; \mathrm{V}_{2}=12,0 \mathrm{~cm} / \mathrm{min}$ ) Centrifugação ( $\left.\mathrm{f}_{\mathrm{CEN}}=2000 \mathrm{rpm} ; \mathrm{T}_{\mathrm{CEN}}=15 \mathrm{~min}\right)$.

A Figura 5.79 mostra que somente a flotação por ar dissolvido $\left(\mathrm{Cl}_{2}=0\right.$ e $\left.\mathrm{CAP}=0\right)$ não foi capaz de promover residual de toxina abaixo do estabelecido pela legislação. Nesta condição o residual foi de $1,50 \mu \mathrm{g} / \mathrm{L}$. 
Quando foi realizada a pré-cloração com $3,0 \mathrm{mgCl}_{2} / \mathrm{L}$ de cloro livre com e sem CAP, os residuais de microcistina foram os mais elevados. Isto pode estar relacionado com a lise celular pelo oxidante e conseqüente liberação de toxina. Por outro lado, a dosagem de 6,0 $\mathrm{mgCl}_{2} / \mathrm{L}(\mathrm{CAP}=0)$ foi capaz de produzir situação tal que, apesar da provável liberação de toxina por lise celular, a concentração de cloro livre aplicada foi suficiente para oxidar a maior parte da toxina liberada e pré-existente no meio, resultando em residual final de 0,96 $\mu \mathrm{g} / \mathrm{L}$ de microcistina.

A estimativa da dosagem mínima de carvão ativado em pó teve sucesso na redução da concentração de microcistina. Visto que, esta estimativa visava residual menor que $1 \mu \mathrm{g} / \mathrm{L}$, a aplicação de $5 \mathrm{mg} / \mathrm{L}$ de CAP promoveu remoção de 84,8 \% que representa um residual de $0,85 \mu \mathrm{g} / \mathrm{L}$ de microcistina.

A combinação da pré-cloração com $6,0 \mathrm{mgCl}_{2} / \mathrm{L}$ de cloro com 5,0 mg/L de CAP resultou na menor concentração de microcistina para a Água de Estudo - 1, sendo igual a 0,76 $\mu \mathrm{g} / \mathrm{L}$. Por outro lado, constatou-se que não houve ganho significativo na remoção da toxina quando comparado com a aplicação da dosagem de CAP estimada.

\subsubsection{2. Água de Estudo 2 (FASE - B)}

As características da Água de Estudo - 2, conforme os parâmetros avaliados no controle dos ensaios, são: $\mathrm{pH}$ - 7,15; turbidez - 42,8 uT; cor aparente - 430 uC, ABS 254 nm - 0,278; NT - 7,40 mg/L; DQO - $50 \mathrm{mgO}_{2} / \mathrm{L} ; \mathrm{COT}-8,76 \mathrm{mgC} / \mathrm{L}$ e $\mathrm{MC}-21,40 \mu \mathrm{g} / \mathrm{L}$.

A Tabela 5.31 apresenta os resultados das amostras flotadas e centrifugadas da FASE - B para a Água de Estudo - 2. 
Tabela 5.31: Valores dos resultados da FASE - B da ETAPA - II para Água de Estudo - 2.

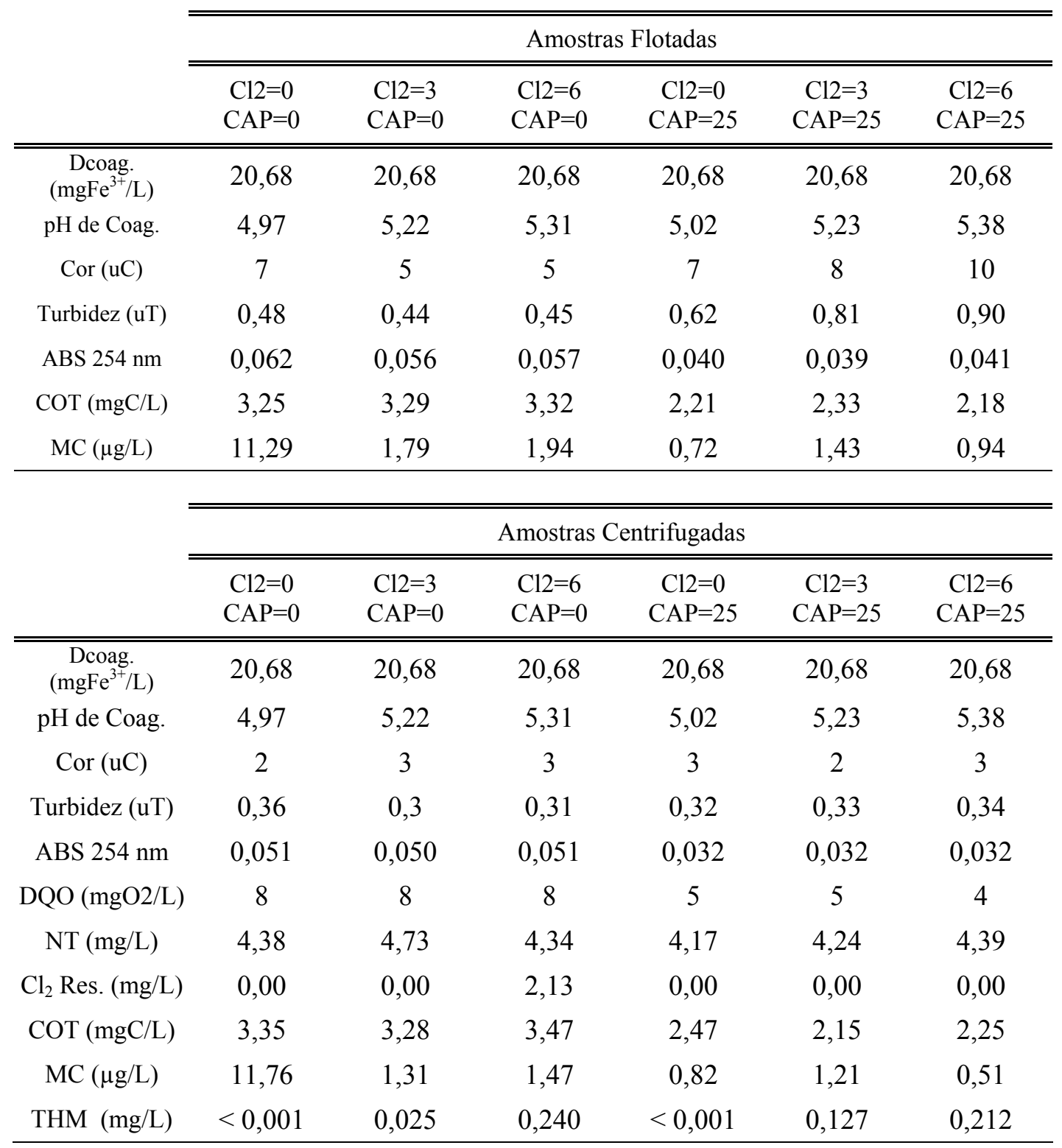

Os valores de pH de coagulação apresentados na Tabela 5.31 mostram a influência do hipoclorito de sódio neste parâmetro. $\mathrm{O}$ pH aumentou conforme a adição de maiores dosagens de hipoclorito, entretanto, a dosagem de $100 \mathrm{mg} / \mathrm{L}$ de cloreto férrico garantiu condições para a coagulação das partículas conforme os valores de turbidez e cor aparente residual. Para todas as condições testadas, as amostras flotadas apresentaram residuais de turbidez abaixo de $1 \mathrm{uT}$ e residuais de cor aparente abaixo de $15 \mathrm{uC}$. O pior resultado das amostras flotadas, em termos de turbidez, foi com a aplicação de $6,0 \mathrm{mg} / \mathrm{L}$ de cloro e $25 \mathrm{mg} / \mathrm{L}$ de CAP $(0,90 \mathrm{uT}$ e 10 uC). Contudo, estes valores foram os mesmos observados durante a escolha da dosagem de 
coagulante para a Água de Estudo - 2, o que mostra a reprodutibilidade dos resultados após a correção das falhas cometidas durante a ETAPA - I desta pesquisa.

A remoção de DQO, nas condições sem adsorção em CAP, variou entre 84,3 - 84,9 \%. A aplicação de $25 \mathrm{mg} / \mathrm{L}$ de CAP promoveu um aumento na remoção, esta variou entre 90,5 92,2 \%. Com relação ao NT residual das amostras, não houve diferença significativa com a aplicação do carvão ativado. A remoção de NT ficou entre $36,1-43,6$ \%, considerando o maior e menor valor verificado nas condições avaliadas.

Foi observado cloro residual somente com a aplicação de $6,0 \mathrm{mgCl}_{2} / \mathrm{L}$ de cloro livre sem CAP, sendo igual a $2,13 \mathrm{mgCl}_{2} / \mathrm{L}$ de cloro livre. Isto mostra um maior consumo do oxidante na oxidação da matéria orgânica presente na Água de Estudo - 2, sendo este fato uma justificativa plausível pelas características desta água que apresentou concentração de COT igual a $8,76 \mathrm{mgC} / \mathrm{L}$ e concentração de microcistina de $21,40 \mu \mathrm{g} / \mathrm{L}$.

A Figura 5.80 apresenta os residuais de COT, das amostras flotadas e centrifugadas, determinados para todas as condições de tratamento avaliadas.

COT das amostras flotadas e centrifugadas

Água de Estudo 2

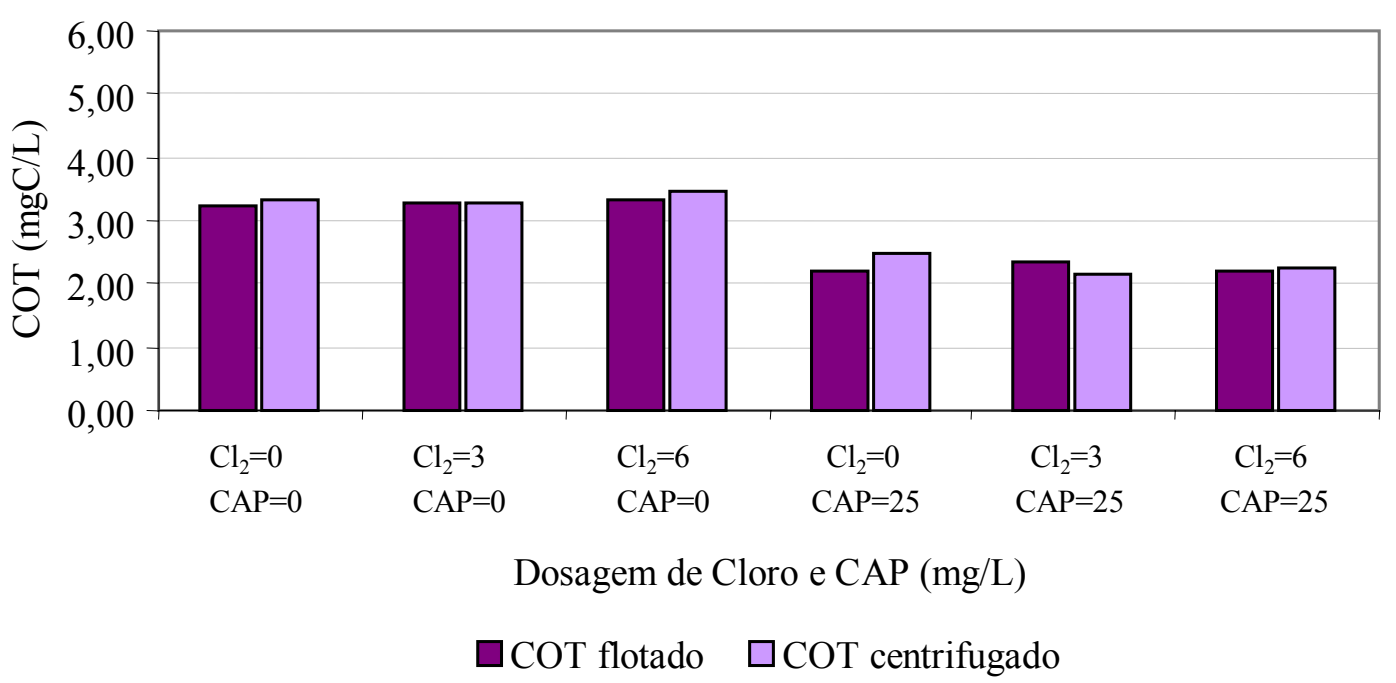

Figura 5.80: Carbono orgânico total das amostras flotadas e centrifugadas - Água de Estudo - 2 . Água de estudo 2: $\mathrm{COT}=8,76 \mathrm{mgC} / \mathrm{L} ; \mathrm{MC}=21,40 \mu \mathrm{g} / \mathrm{L}$. Condições do ensaio: Pré-cloração $\left(0 ; 3,0 ; 6,0 \mathrm{mgCl}_{2} / \mathrm{L}\right)$; Coagulação $\left(\mathrm{D}_{\mathrm{FeCl}}=14,47 \mathrm{mgFe} \mathrm{ge}^{3+} / \mathrm{L} ; \mathrm{Vr}_{\mathrm{MR}}=350 \mathrm{rpm}\right.$; $\left.\mathrm{T}_{\mathrm{MR}}=20 \mathrm{~s}\right) ;$ Aplicação de CAP $(25 \mathrm{mg} / \mathrm{L}) ;$ Floculação $\left(\mathrm{Vr}_{\mathrm{FLO}}=68 \mathrm{rpm} ; \mathrm{T}_{\mathrm{FLO}}=18 \mathrm{~min}\right) ; \mathrm{FAD}\left(\mathrm{p}_{\mathrm{SAT}}=500 \mathrm{kPa} ; \mathrm{R}\right.$ $\left.=8 \% ; \mathrm{V}_{2}=12,0 \mathrm{~cm} / \mathrm{min}\right)$ Centrifugação $\left(\mathrm{f}_{\mathrm{CEN}}=2000 \mathrm{rpm} ; \mathrm{T}_{\mathrm{CEN}}=15 \mathrm{~min}\right)$. 
Conforme a Figura 5.80, a pré-cloração, sem CAP, apresentou um leve incremento nos residuais de COT com o aumento da dosagem de cloro. Contudo, associando-se a précloração com a adsorção em CAP, as amostras apresentaram menores concentrações de COT. Isto indica a adsorção da matéria orgânica presente na água pelo carvão ativado em pó.

Foi determinada a correlação entre a ABS 254 nm e o COT para a Água de Estudo - 2 conforme a Tabela 5.32 .

Tabela 5.32: Correlação entre ABS $254 \mathrm{~nm}$ e COT das amostras flotadas e centrifugadas - Água de estudo 2.

\begin{tabular}{ccc}
\hline \hline \multicolumn{3}{c}{ Amostras flotadas } \\
\hline \hline Ensaio & $\begin{array}{c}\mathrm{ABS} \\
254 \mathrm{~nm}\end{array}$ & $\begin{array}{c}\mathrm{COT} \\
(\mathrm{mgC} / \mathrm{L})\end{array}$ \\
\hline \hline $\mathrm{Cl} 2=0$ / CAP $=0$ & 0,062 & 3,25 \\
$\mathrm{Cl} 2=3$ / CAP $=0$ & 0,056 & 3,29 \\
$\mathrm{Cl} 2=6$ / $\mathrm{CAP}=0$ & 0,057 & 3,32 \\
$\mathrm{Cl} 2=0$ / $\mathrm{CAP}=5$ & 0,040 & 2,21 \\
$\mathrm{Cl} 2=3$ / $\mathrm{CAP}=5$ & 0,039 & 2,33 \\
$\mathrm{Cl} 2=6$ / CAP $=5$ & 0,041 & 2,18 \\
\hline
\end{tabular}

Covariância $(A B S, C O T)=0,005$ Desv. Padrão IAM = 0,009 Desv. Padrão $M C=0,524$ $r=0,962$

\begin{tabular}{ccc}
\hline \hline \multicolumn{3}{c}{ Amostras centrifugadas } \\
\hline \hline Ensaio & $\begin{array}{c}\mathrm{ABS} \\
254 \mathrm{~nm}\end{array}$ & $\begin{array}{c}\mathrm{COT} \\
(\mathrm{mgC} / \mathrm{L})\end{array}$ \\
\hline \hline $\mathrm{Cl} 2=0$ / CAP $=0$ & 0,051 & 3,35 \\
$\mathrm{Cl} 2=3$ / CAP $=0$ & 0,050 & 3,28 \\
$\mathrm{Cl} 2=6$ / $\mathrm{CAP}=0$ & 0,051 & 3,47 \\
$\mathrm{Cl} 2=0$ / $\mathrm{CAP}=5$ & 0,032 & 2,47 \\
$\mathrm{Cl} 2=3$ / $\mathrm{CAP}=5$ & 0,032 & 2,15 \\
$\mathrm{Cl} 2=6$ / $\mathrm{CAP}=5$ & 0,032 & 2,25 \\
\hline
\end{tabular}

Covariância $(A B S, C O T)=0,005$ Desv. Padrão IAM = 0,009 Desv. Padrão $M C=0,549$

$r=0,982$

As Figuras 5.81 e 5.82 demonstram o comportamento de tais parâmetros durante os ensaios para as amostras flotadas e centrifugadas, respectivamente. 
ABS 254 nm e COT das amostras flotadas

Água de Estudo 2

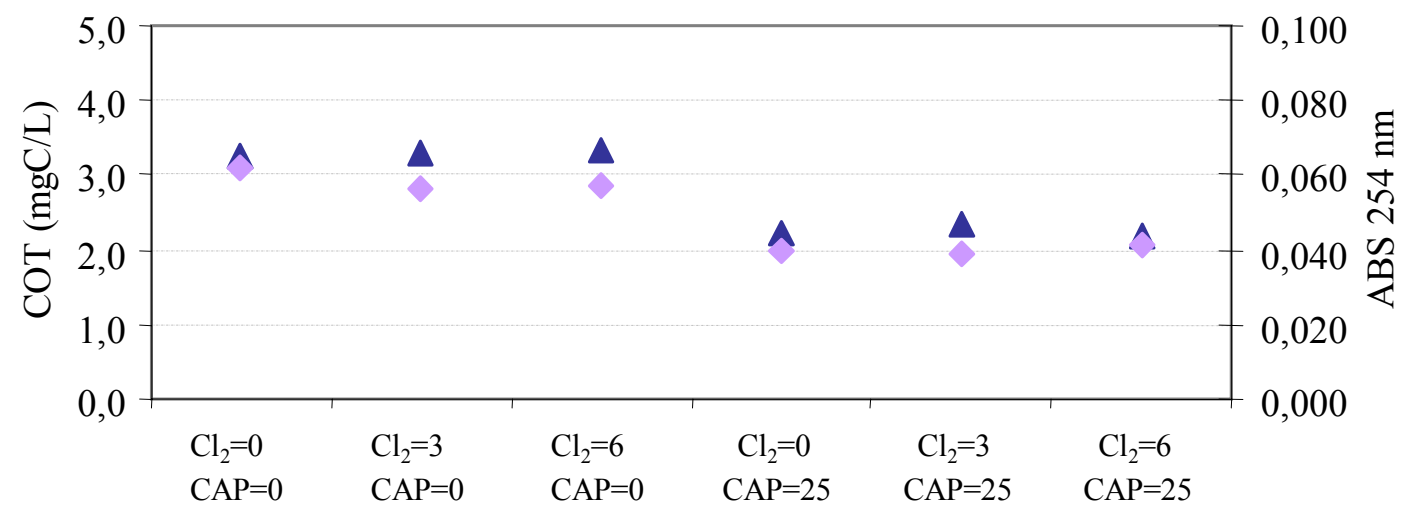

Dosagem de cloro e CAP $(\mathrm{mg} / \mathrm{L})$

$\Delta$ COT Flot. $\diamond$ ABS 254 Flot.

Figura 5.81: ABS $254 \mathrm{~nm}$ e COT das amostras flotadas - Água de Estudo - 2. Água de estudo 2: ABS $254 \mathrm{~nm}=0,278 ; \mathrm{COT}=8,76 \mathrm{mgC} / \mathrm{L} ; \mathrm{MC}=21,40 \mu \mathrm{g} / \mathrm{L}$.

Condições do ensaio: Pré-cloração $\left(0 ; 3,0 ; 6,0 \mathrm{mgCl}_{2} / \mathrm{L}\right)$; Coagulação $\left(\mathrm{D}_{\mathrm{FeCl}}=14,47 \mathrm{mgFe} \mathrm{ge}^{3+} / \mathrm{L} ; \mathrm{Vr}_{\mathrm{MR}}=350 \mathrm{rpm}\right.$; $\left.\mathrm{T}_{\mathrm{MR}}=20 \mathrm{~s}\right) ;$ Aplicação de CAP $(25 \mathrm{mg} / \mathrm{L}) ;$ Floculação $\left(\mathrm{Vr}_{\mathrm{FLO}}=68 \mathrm{rpm} ; \mathrm{T}_{\mathrm{FLO}}=18 \mathrm{~min}\right) ; \mathrm{FAD}\left(\mathrm{p}_{\mathrm{SAT}}=500 \mathrm{kPa} ; \mathrm{R}\right.$ $\left.=8 \% ; \mathrm{V}_{2}=12,0 \mathrm{~cm} / \mathrm{min}\right)$ Centrifugação $\left(\mathrm{f}_{\mathrm{CEN}}=2000 \mathrm{rpm} ; \mathrm{T}_{\mathrm{CEN}}=15 \mathrm{~min}\right)$.

ABS $254 \mathrm{~nm}$ e COT das amostras centrifugadas

Água de Estudo 2

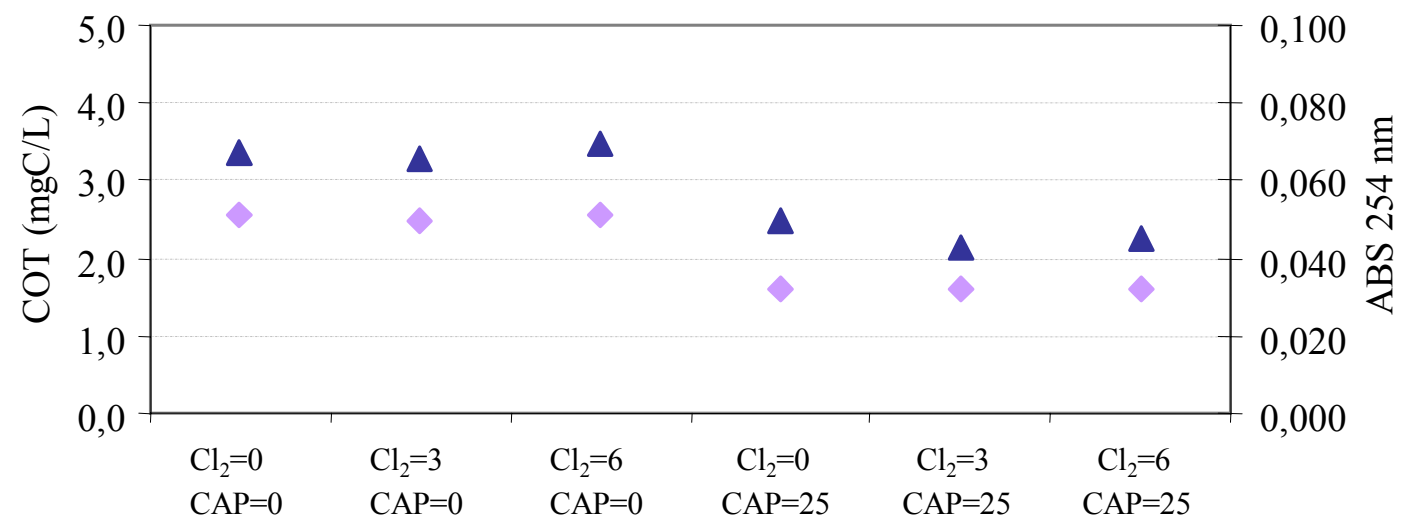

Dosagem de cloro e CAP (mg/L)

$\Delta$ COT Cent. $\diamond$ ABS 254 Cent.

Figura 5.82: ABS $254 \mathrm{~nm}$ e COT das amostras centrifugadas - Água de Estudo - 2.

Água de estudo 2: $\mathrm{COT}=8,76 \mathrm{mgC} / \mathrm{L} ; \mathrm{MC}=21,40 \mu \mathrm{g} / \mathrm{L}$.

Condições do ensaio: Pré-cloração $\left(0 ; 3,0 ; 6,0 \mathrm{mgCl}_{2} / \mathrm{L}\right)$; Coagulação $\left(\mathrm{D}_{\mathrm{FeCl}}=14,47 \mathrm{mgFe} \mathrm{ge}^{3+} / \mathrm{L} ; \mathrm{Vr}_{\mathrm{MR}}=350 \mathrm{rpm}\right.$;

$\left.\mathrm{T}_{\mathrm{MR}}=20 \mathrm{~s}\right) ;$ Aplicação de CAP $(25 \mathrm{mg} / \mathrm{L}) ;$ Floculação $\left(\mathrm{Vr}_{\mathrm{FLO}}=68 \mathrm{rpm} ; \mathrm{T}_{\mathrm{FLO}}=18 \mathrm{~min}\right) ; \mathrm{FAD}\left(\mathrm{p}_{\mathrm{SAT}}=500 \mathrm{kPa} ; \mathrm{R}\right.$ $\left.=8 \% ; \mathrm{V}_{2}=12,0 \mathrm{~cm} / \mathrm{min}\right)$ Centrifugação $\left(\mathrm{f}_{\mathrm{CEN}}=2000 \mathrm{rpm} ; \mathrm{T}_{\mathrm{CEN}}=15 \mathrm{~min}\right)$. 
As Figuras 5.81 e 5.82 mostram que os valores de COT e ABS $254 \mathrm{~nm}$ apresentam respostas semelhantes em cada condição de tratamento simulada. O índice de correlação para as amostras flotadas foram $r=0,962$. Já com a centrifugação das amostras, a correlação entre os parâmetros aumentou para $r=0,982$, o que pode ser verificado pela Figura 5.82.

Os resultados de concentração de trialometanos estão apresentados na Figura 5.83.

Trialometanos das amostras centrifugadas

Água de Estudo 2

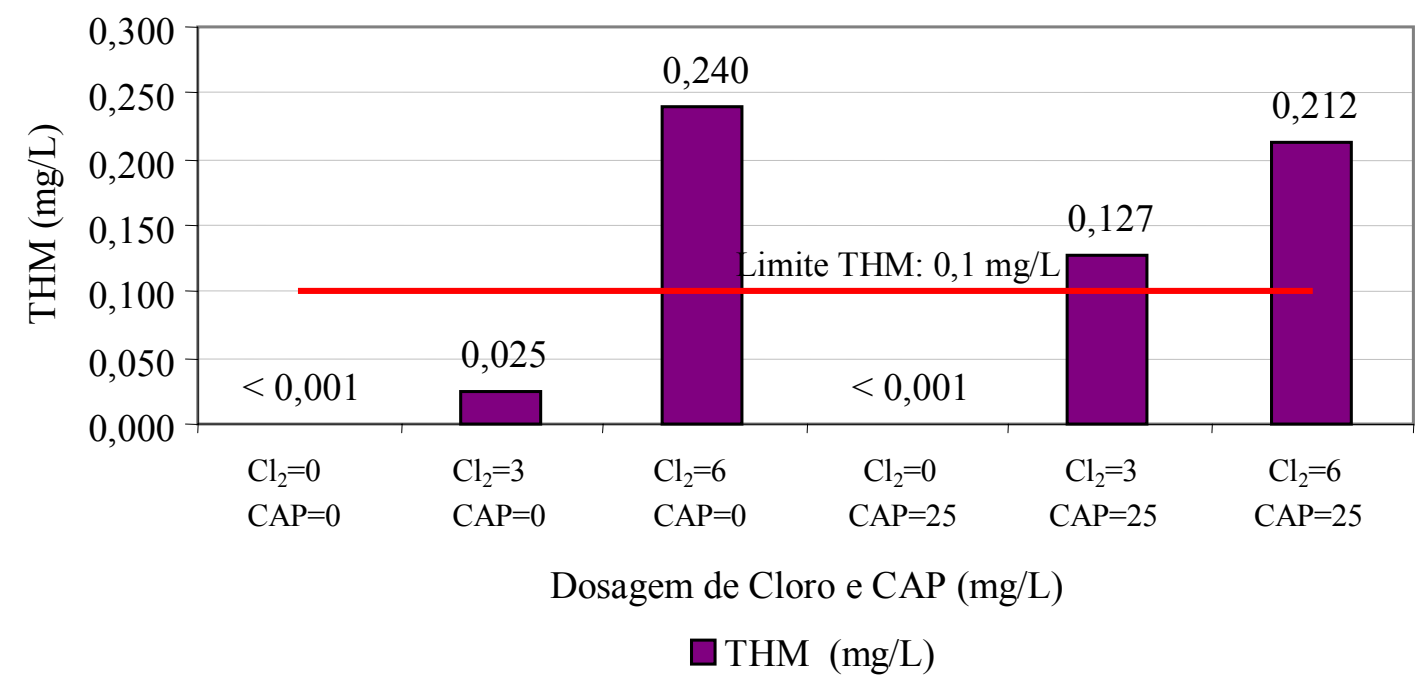

Figura 5.83: Concentração de trialometanos das amostras centrifugadas - Água de Estudo - 2 . Água de estudo 2: $\mathrm{MC}=21,40 \mu \mathrm{g} / \mathrm{L}$.

Condições do ensaio: Pré-cloração $\left(0 ; 3,0 ; 6,0 \mathrm{mgCl} / 2\right.$ ) ; Coagulação $\left(\mathrm{D}_{\mathrm{FeCl} 13}=14,47 \mathrm{mgFe}^{3+} / \mathrm{L} ; \mathrm{Vr}_{\mathrm{MR}}=350 \mathrm{rpm}\right.$; $\left.\mathrm{T}_{\mathrm{MR}}=20 \mathrm{~s}\right)$; Aplicação de CAP $(25 \mathrm{mg} / \mathrm{L}) ;$ Floculação $\left(\mathrm{Vr}_{\mathrm{FLO}}=68 \mathrm{rpm} ; \mathrm{T}_{\mathrm{FLO}}=18 \mathrm{~min}\right) ; \mathrm{FAD}\left(\mathrm{p}_{\mathrm{SAT}}=500 \mathrm{kPa} ; \mathrm{R}\right.$ $\left.=8 \% ; \mathrm{V}_{2}=12,0 \mathrm{~cm} / \mathrm{min}\right)$ Centrifugação $\left(\mathrm{f}_{\mathrm{CEN}}=2000 \mathrm{rpm} ; \mathrm{T}_{\mathrm{CEN}}=15 \mathrm{~min}\right)$.

É interessante observar que a pré-cloração com 3,0 $\mathrm{mgCl}_{2} / \mathrm{L}$ de cloro livre, sem CAP, produziu valor de trialometanos abaixo do limite estabelecido, ao contrário do observado na Água de Estudo - 1, o que pode estar relacionado com a maior demanda do oxidante pela matéria orgânica presente na Água de Estudo - 2. Já a pré-cloração com $6,0 \mathrm{mgCl} 2 / \mathrm{L}$ de cloro livre apresentou concentração de trialometanos acima de $0,1 \mathrm{mg} / \mathrm{L}$. A adsorção em CAP não promoveu redução dos valores em níveis satisfatórios, sendo que o aumento da dosagem de cloro promoveu um incremento nos valores observados para as amostras centrifugadas, (ver Figura 5.83). 
Com relação à remoção de microcistina pelo sistema de tratamento empregado, a Figura 5.84 apresenta os resultados para as amostras flotadas e centrifugadas conforme os dados apresentados na Tabela 5.31.

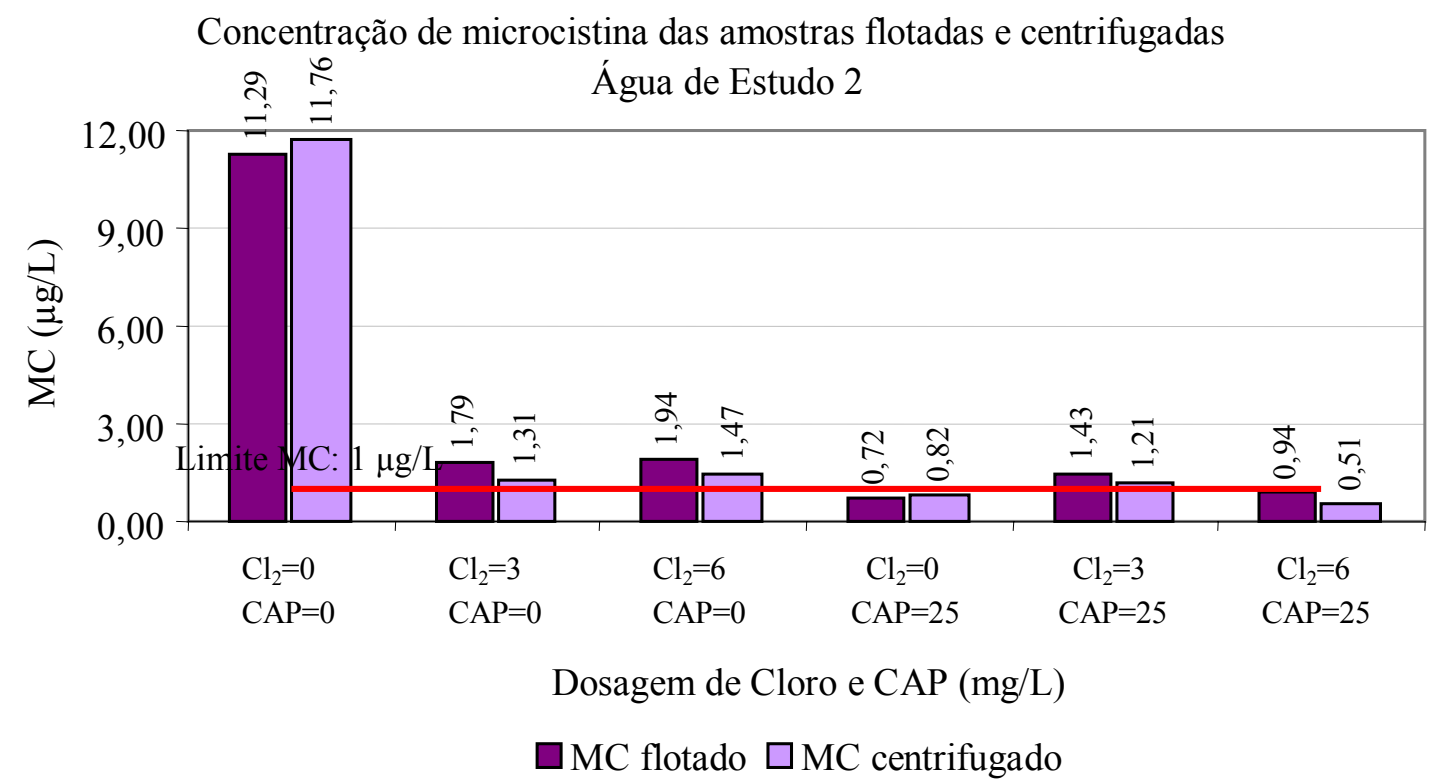

Figura 5.84: Concentração de microcistina (MC) das amostras flotadas e centrifugadas - Água de Estudo - 2. Água de estudo 2: $\mathrm{MC}=21,40 \mu \mathrm{g} / \mathrm{L}$.

Condições do ensaio: Pré-cloração $\left(0 ; 3,0 ; 6,0 \mathrm{mgCl}_{2} / \mathrm{L}\right)$; Coagulação ( $\mathrm{D}_{\mathrm{FeCl}}=14,47 \mathrm{mgFe} \mathrm{ge}^{3+} / \mathrm{L} ; \mathrm{Vr}_{\mathrm{MR}}=350 \mathrm{rpm}$; $\left.\mathrm{T}_{\mathrm{MR}}=20 \mathrm{~s}\right)$; Aplicação de CAP $(25 \mathrm{mg} / \mathrm{L})$; Floculação $\left(\mathrm{Vr}_{\mathrm{FLO}}=68 \mathrm{rpm} ; \mathrm{T}_{\mathrm{FLO}}=18 \mathrm{~min}\right) ; \mathrm{FAD}\left(\mathrm{p}_{\mathrm{SAT}}=500 \mathrm{kPa} ; \mathrm{R}\right.$ $\left.=8 \% ; \mathrm{V}_{2}=12,0 \mathrm{~cm} / \mathrm{min}\right)$ Centrifugação $\left(\mathrm{f}_{\mathrm{CEN}}=2000 \mathrm{rpm} ; \mathrm{T}_{\mathrm{CEN}}=15 \mathrm{~min}\right)$.

A Figura 5.84 mostra que a flotação por ar dissolvido não foi eficiente na remoção de microcistina dissolvida presente na água, a concentração observada nesta condição foi de $11,29 \mu \mathrm{g} / \mathrm{L}$ (cerca de $48 \%$ de redução). Somente a pré-cloração não foi capaz de reduzir a concentração da toxina para menos de $1 \mu \mathrm{g} / \mathrm{L}$, tornando-se necessária a associação da adsorção em CAP. Com isto, aplicando-se $6,0 \mathrm{mgCl}_{2} / \mathrm{L}$ de cloro livre combinado com 25 $\mathrm{mg} / \mathrm{L}$ de CAP, obteve-se o residual de microcistina do tratamento simulado igual a $0,94 \mu \mathrm{g} / \mathrm{L}$.

Também foi verificado o sucesso na estimativa da dosagem de CAP, para a Água de Estudo - 2, visando residuais de toxina abaixo do limite estabelecido para águas de consumo humano. Obteve-se concentração de $0,72 \mu \mathrm{g} / \mathrm{L}$ de microcistina com a aplicação de $25 \mathrm{mg} / \mathrm{L}$ 
de CAP, remoção de aproximadamente $96,6 \%$ da concentração inicial de $21,4 \mu \mathrm{g} / \mathrm{L}$ de microcistina.

\subsubsection{3. Á́gua de Estudo 3 (FASE - B)}

As características da Água de Estudo - 3, conforme os parâmetros avaliados no controle dos ensaios, são: $\mathrm{pH}$ - 7,02; turbidez - 25,3 uT; cor aparente - 301 uC, ABS 254 nm - 0,268; NT - 7,57 mg/L; DQO - 35,98 $\mathrm{mgO}_{2} / \mathrm{L} ; \mathrm{COT}-10,15 \mathrm{mgC} / \mathrm{L}$ e MC - 86,94 $\mu \mathrm{g} / \mathrm{L}$.

A Tabela 5.33 apresenta os resultados das amostras flotadas e centrifugadas da FASE - B para a Água de Estudo - 3. 
Tabela 5.33: Valores dos resultados da FASE - B da ETAPA - II para Água de Estudo - 3.

\begin{tabular}{|c|c|c|c|c|c|c|}
\hline & \multicolumn{6}{|c|}{ Amostras Flotadas } \\
\hline & $\begin{array}{l}\mathrm{Cl} 2=0 \\
\mathrm{CAP}=0\end{array}$ & $\begin{array}{l}\mathrm{Cl} 2=3 \\
\mathrm{CAP}=0\end{array}$ & $\begin{aligned} \mathrm{C} 12 & =6 \\
\mathrm{CAP} & =0\end{aligned}$ & $\begin{array}{c}\mathrm{C} 2=0 \\
\mathrm{CAP}=100\end{array}$ & $\begin{array}{c}\mathrm{Cl} 2=3 \\
\mathrm{CAP}=100\end{array}$ & $\begin{array}{c}\mathrm{Cl} 2=6 \\
\mathrm{CAP}=100\end{array}$ \\
\hline $\begin{array}{c}\text { Dcoag. } \\
\left(\mathrm{mgFe}^{3+} / \mathrm{L}\right)\end{array}$ & 24,82 & 24,82 & 24,82 & 24,82 & 24,82 & 24,82 \\
\hline pH de Coag. & 4,03 & 4,22 & 4,38 & 4,50 & 4,71 & 4,68 \\
\hline Cor (uC) & 25 & 16 & 11 & 11 & 13 & 13 \\
\hline Turbidez (uT) & 1,35 & 0,95 & 0,75 & 1,04 & 1,09 & 1,21 \\
\hline ABS $254 \mathrm{~nm}$ & 0,114 & 0,084 & 0,073 & 0,035 & 0,032 & 0,035 \\
\hline $\mathrm{COT}(\mathrm{mgC} / \mathrm{L})$ & 4,15 & 3,64 & 3,74 & 2,21 & 2,77 & 2,09 \\
\hline \multirow[t]{3}{*}{$\mathrm{MC}(\mu \mathrm{g} / \mathrm{L})$} & 41,12 & 2,90 & 2,65 & 0,15 & 1,21 & 1,25 \\
\hline & \multicolumn{6}{|c|}{ Amostras Centrifugadas } \\
\hline & $\begin{array}{l}\mathrm{Cl} 2=0 \\
\mathrm{CAP}=0\end{array}$ & $\begin{array}{l}\mathrm{Cl} 2=3 \\
\mathrm{CAP}=0\end{array}$ & $\begin{array}{l}\mathrm{Cl} 2=6 \\
\mathrm{CAP}=0\end{array}$ & $\begin{array}{c}\mathrm{Cl} 2=0 \\
\mathrm{CAP}=100\end{array}$ & $\begin{array}{c}\mathrm{Cl} 2=3 \\
\mathrm{CAP}=100\end{array}$ & $\begin{array}{c}\mathrm{Cl} 2=6 \\
\mathrm{CAP}=100\end{array}$ \\
\hline $\begin{array}{c}\text { Dcoag. } \\
\left(\mathrm{mgFe}^{3+} / \mathrm{L}\right)\end{array}$ & 120 & 120 & 120 & 120 & 120 & 120 \\
\hline pH de Coag. & 4,03 & 4,22 & 4,38 & 4,50 & 4,71 & 4,68 \\
\hline Cor $(\mathrm{uC})$ & 7 & 6 & 5 & 3 & 3 & 3 \\
\hline Turbidez (uT) & 0,52 & 0,49 & 0,52 & 0,54 & 0,37 & 0,41 \\
\hline ABS $254 \mathrm{~nm}$ & 0,065 & 0,056 & 0,055 & 0,023 & 0,020 & 0,025 \\
\hline $\mathrm{DQO}(\mathrm{mgO} / \mathrm{L})$ & 9,86 & 6,75 & 7,03 & 4,21 & 2,80 & 3,36 \\
\hline $\mathrm{NT}(\mathrm{mg} / \mathrm{L})$ & 4,39 & 5,37 & 4,19 & 4,43 & 5,03 & 5,01 \\
\hline $\mathrm{Cl}_{2}$ Res. $(\mathrm{mg} / \mathrm{L})$ & 0,00 & 0,00 & 0,00 & 0,00 & 0,00 & 0,00 \\
\hline $\mathrm{COT}(\mathrm{mgC} / \mathrm{L})$ & 4,87 & 4,62 & 4,86 & 2,36 & 2,46 & 1,95 \\
\hline $\mathrm{MC}(\mu \mathrm{g} / \mathrm{L})$ & 42,18 & 3,11 & 2,56 & 0,23 & 0,88 & 0,89 \\
\hline THM (mg/L) & $<0,001$ & 0,152 & 0,200 & $<0,001$ & 0,163 & 0,140 \\
\hline
\end{tabular}

Conforme os dados da Tabela 5.33, a turbidez e cor aparente das amostras flotadas foram satisfatórias quanto aos limites de potabilidade. Exceto para a condição sem précloração e sem a aplicação do CAP, que pode estar relacionado com valor de $\mathrm{pH}$ muito baixo devido à dosagem excessiva de coagulante que foi escolhida com a aplicação de $6,0 \mathrm{mgCl} / \mathrm{L}$ de cloro livre e $100 \mathrm{mg} / \mathrm{L}$ de CAP. Contudo, após a centrifugação das amostras, os valores de turbidez e cor aparente foram reduzidos e apresentaram valores que atenderam os limites de 1 uT e $15 \mathrm{uC}$. 
A aplicação de CAP promoveu redução nos valores de DQO determinados para as amostras centrifugadas. Sem a aplicação de CAP a remoção de DQO ficou entre 72,6 e 81,23\%. Aplicando-se 100 mg/L de carvão ativado tais índices de remoção se elevaram para faixa de $88,3-92,2 \%$.

Não foi observado nenhum residual de cloro para a Água de Estudo - 3. Seguramente houve elevada demanda do oxidante diante das características da água preparada. A concentração de carbono orgânico total para esta água foi $\mathrm{COT}=10,15 \mathrm{mgC} / \mathrm{L}$ e de microcistina $\mathrm{MC}=86,94 \mu \mathrm{g} / \mathrm{L}$, o que comprova a hipótese de demanda de cloro pela matéria orgânica presente na água de estudo.

A Figura 5.85 apresenta os valores de COT para as amostras flotadas e centrifugadas da Água de Estudo - 3.

COT das amostras flotadas e centrifugadas

Água de Estudo 3

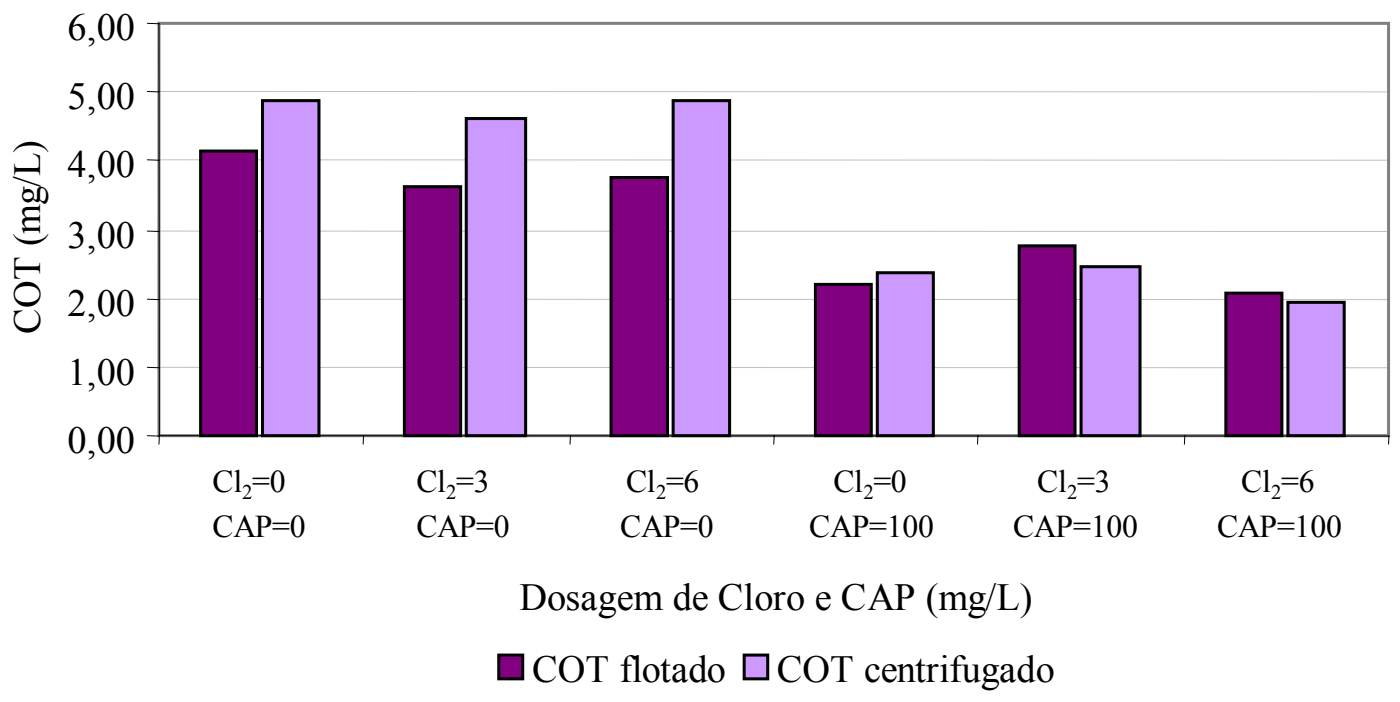

Figura 5.85: Carbono orgânico total das amostras flotadas e centrifugadas - Água de Estudo - 3 . Água de estudo 3: $\mathrm{COT}=10,15 \mathrm{mgC} / \mathrm{L} ; \mathrm{MC}=86,94 \mu \mathrm{g} / \mathrm{L}$.

Condições do ensaio: Pré-cloração $(0 ; 3,0 ; 6,0 \mathrm{mgCl} / \mathrm{L})$; Coagulação $\left(\mathrm{D}_{\mathrm{FeCl}}=14,47 \mathrm{mgFe}^{3+} / \mathrm{L} ; \mathrm{Vr}_{\mathrm{MR}}=350 \mathrm{rpm}\right.$; $\left.\mathrm{T}_{\mathrm{MR}}=20 \mathrm{~s}\right)$; Aplicação de CAP $(100 \mathrm{mg} / \mathrm{L}) ;$ Floculação $\left(\mathrm{Vr}_{\mathrm{FLO}}=68 \mathrm{rpm} ; \mathrm{T}_{\mathrm{FLO}}=18 \mathrm{~min}\right) ; \mathrm{FAD}\left(\mathrm{p}_{\mathrm{SAT}}=500 \mathrm{kPa} ; \mathrm{R}\right.$ $\left.=8 \% ; \mathrm{V}_{2}=12,0 \mathrm{~cm} / \mathrm{min}\right)$ Centrifugação $\left(\mathrm{f}_{\mathrm{CEN}}=2000 \mathrm{rpm} ; \mathrm{T}_{\mathrm{CEN}}=15 \mathrm{~min}\right)$.

A Figura 5.85 mostra que a aplicação de $100 \mathrm{mg} / \mathrm{L}$ de carvão ativado promoveu a adsorção da matéria orgânica presente na Água de Estudo - 3. O menor valor observado, nas 
amostras centrifugadas, foi medido no ensaio em que se combinou a pré-cloração com 6,0 $\mathrm{mgCl}_{2} / \mathrm{L}$ de cloro livre e $100 \mathrm{mg} / \mathrm{L}$ de CAP. Nesta condição, a concentração de COT foi de $1,95 \mathrm{mgC} / \mathrm{L}$.

A correlação entre ABS $254 \mathrm{~nm}$ e COT foi determinada para as amostras flotadas e centrifugadas conforme apresentado na Tabela 5.34 .

Tabela 5.34: Correlação entre ABS $254 \mathrm{~nm}$ e COT das amostras flotadas e centrifugadas - Água de estudo 3.

\begin{tabular}{ccc}
\hline \hline \multicolumn{3}{c}{ Amostras flotadas } \\
\hline \hline Ensaio & $\begin{array}{c}\mathrm{ABS} \\
254 \mathrm{~nm}\end{array}$ & $\begin{array}{c}\mathrm{COT} \\
(\mathrm{mgC} / \mathrm{L})\end{array}$ \\
\hline \hline $\mathrm{Cl} 2=0 / \mathrm{CAP}=0$ & 0,114 & 4,15 \\
$\mathrm{Cl} 2=3$ / $\mathrm{CAP}=0$ & 0,084 & 3,64 \\
$\mathrm{Cl} 2=6$ / $\mathrm{CAP}=0$ & 0,073 & 3,74 \\
$\mathrm{Cl} 2=0 / \mathrm{CAP}=5$ & 0,035 & 2,21 \\
$\mathrm{Cl} 2=3 / \mathrm{CAP}=5$ & 0,032 & 2,77 \\
$\mathrm{Cl} 2=6 / \mathrm{CAP}=5$ & 0,035 & 2,09 \\
\hline
\end{tabular}

\begin{tabular}{ccc}
\hline \hline \multicolumn{3}{c}{ Amostras centrifugadas } \\
\hline \hline Ensaio & $\begin{array}{c}\mathrm{ABS} \\
254 \mathrm{~nm}\end{array}$ & $\begin{array}{c}\mathrm{COT} \\
(\mathrm{mgC} / \mathrm{L})\end{array}$ \\
\hline \hline $\mathrm{C} 12=0 / \mathrm{CAP}=0$ & 0,065 & 4,87 \\
$\mathrm{Cl} 2=3 / \mathrm{CAP}=0$ & 0,056 & 4,62 \\
$\mathrm{C} 2=6$ / CAP $=0$ & 0,055 & 4,86 \\
$\mathrm{Cl} 2=0 / \mathrm{CAP}=5$ & 0,023 & 2,36 \\
$\mathrm{C} 2=3 / \mathrm{CAP}=5$ & 0,020 & 2,46 \\
$\mathrm{Cl} 2=6 / \mathrm{CAP}=5$ & 0,025 & 1,95 \\
\hline
\end{tabular}

Covariância $(A B S, C O T)=0,022$

Desv. Padrão $I A M=0,031$

Desv. Padrão $M C=0,787$

$r=0,926$
Covariância $(A B S, C O T)=0,023$
Desv. Padrão IAM $=0,018$
Desv. Padrão $M C=1,273$
$r=0,968$

O comportamento da ABS 254 nm e a concentração de COT, para as amostras flotadas e centrifugadas, está ilustrado pelas Figuras 5.86 e 5.87, respectivamente. 
ABS $254 \mathrm{~nm}$ e COT das amostras flotadas

Água de Estudo 3

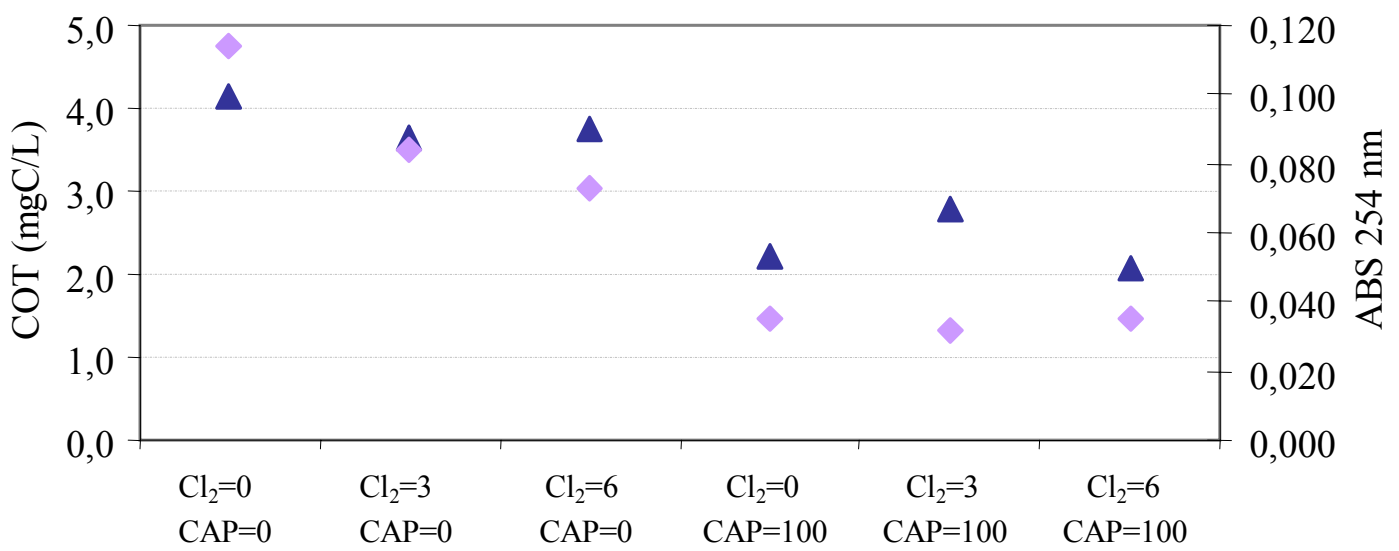

Dosagem de cloro e CAP (mg/L)

$\triangle$ COT Flot. $\diamond$ ABS 254 Flot.

Figura 5.86: ABS $254 \mathrm{~nm}$ e COT das amostras flotadas - Água de Estudo - 3. Água de estudo 3: ABS $254 \mathrm{~nm}=0,268 ; \mathrm{COT}=10,15 \mathrm{mgC} / \mathrm{L} ; \mathrm{MC}=86,94 \mu \mathrm{g} / \mathrm{L}$.

Condições do ensaio: Pré-cloração $\left(0 ; 3,0 ; 6,0 \mathrm{mgCl}_{2} / \mathrm{L}\right)$; Coagulação $\left(\mathrm{D}_{\mathrm{FeCl}}=14,47 \mathrm{mgFe}{ }^{3+} / \mathrm{L} ; \mathrm{Vr}_{\mathrm{MR}}=350 \mathrm{rpm}\right.$; $\left.\mathrm{T}_{\mathrm{MR}}=20 \mathrm{~s}\right)$; Aplicação de CAP $(100 \mathrm{mg} / \mathrm{L}) ;$ Floculação $\left(\mathrm{Vr}_{\mathrm{FLO}}=68 \mathrm{rpm} ; \mathrm{T}_{\mathrm{FLO}}=18 \mathrm{~min}\right) ; \mathrm{FAD}\left(\mathrm{p}_{\mathrm{SAT}}=500 \mathrm{kPa} ; \mathrm{R}\right.$ $\left.=8 \% ; \mathrm{V}_{2}=12,0 \mathrm{~cm} / \mathrm{min}\right)$ Centrifugação $\left(\mathrm{f}_{\mathrm{CEN}}=2000 \mathrm{rpm} ; \mathrm{T}_{\mathrm{CEN}}=15 \mathrm{~min}\right)$.

ABS $254 \mathrm{~nm}$ e COT das amostras centrifugadas

Água de Estudo 3

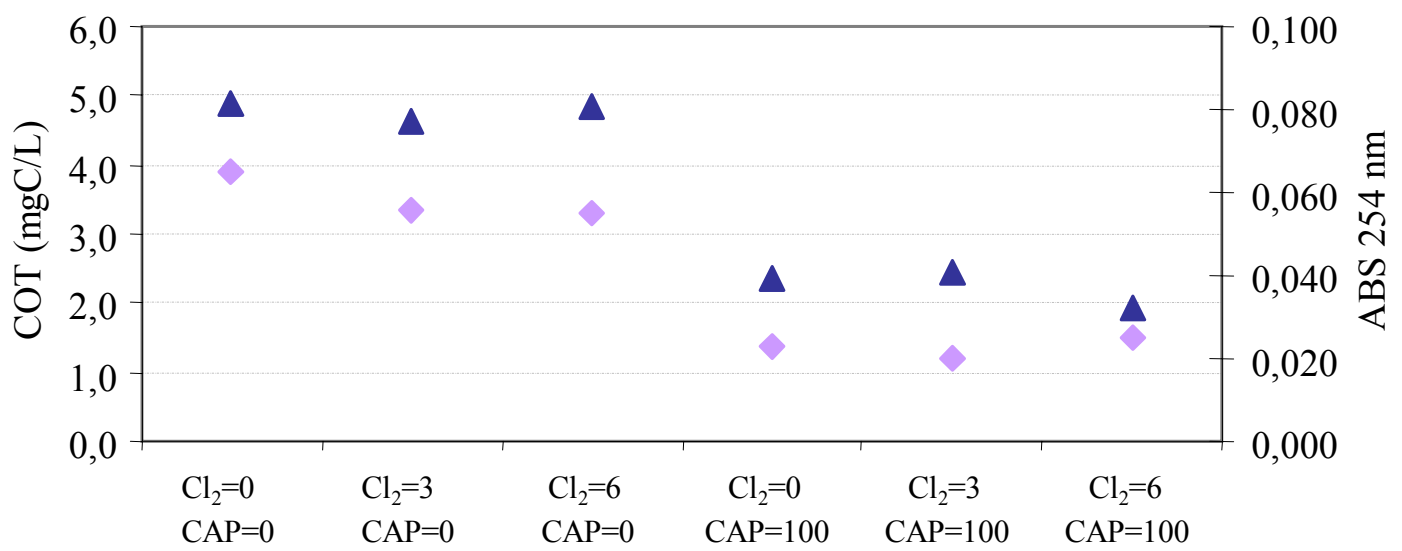

Dosagem de cloro e CAP $(\mathrm{mg} / \mathrm{L})$

$\triangle$ COT Cent. $\diamond$ ABS 254 Cent.

Figura 5.87: ABS $254 \mathrm{~nm}$ e COT das amostras centrifugadas - Água de Estudo - 3.

Água de estudo 3: ABS $254 \mathrm{~nm}=0,268 ; \mathrm{COT}=10,15 \mathrm{mgC} / \mathrm{L} ; \mathrm{MC}=86,94 \mu \mathrm{g} / \mathrm{L}$.

Condições do ensaio: Pré-cloração $(0 ; 3,0 ; 6,0 \mathrm{mgCl} / 2)$; Coagulação $\left(\mathrm{D}_{\mathrm{FeCl}}=14,47 \mathrm{mgFe}^{3+} / \mathrm{L} ; \mathrm{Vr}_{\mathrm{MR}}=350 \mathrm{rpm}\right.$; $\left.\mathrm{T}_{\mathrm{MR}}=20 \mathrm{~s}\right)$; Aplicação de CAP $(100 \mathrm{mg} / \mathrm{L}) ;$ Floculação $\left(\mathrm{Vr}_{\mathrm{FLO}}=68 \mathrm{rpm} ; \mathrm{T}_{\mathrm{FLO}}=18 \mathrm{~min}\right) ; \mathrm{FAD}\left(\mathrm{p}_{\mathrm{SAT}}=500 \mathrm{kPa} ; \mathrm{R}\right.$ $\left.=8 \% ; \mathrm{V}_{2}=12,0 \mathrm{~cm} / \mathrm{min}\right)$ Centrifugação $\left(\mathrm{f}_{\mathrm{CEN}}=2000 \mathrm{rpm} ; \mathrm{T}_{\mathrm{CEN}}=15 \mathrm{~min}\right)$. 
As leituras de ABS $254 \mathrm{~nm}$ e a determinação das concentrações de COT das amostras flotadas (Figura 5.86) apresentaram boa correlação $(r=0,926)$. Contudo, com a centrifugação das amostras, o comportamento de ambas as análises é semelhante conforme mostra a Figura 5.87. Para estas amostras o índice de correlação entre os resultados foi $r=0,968$.

A concentração de trialometanos determinada após a realização dos ensaios de précloração e adsorção em CAP são representadas no gráfico da Figura 5.88.

Trialometanos das amostras centrifugadas

Água de Estudo 3

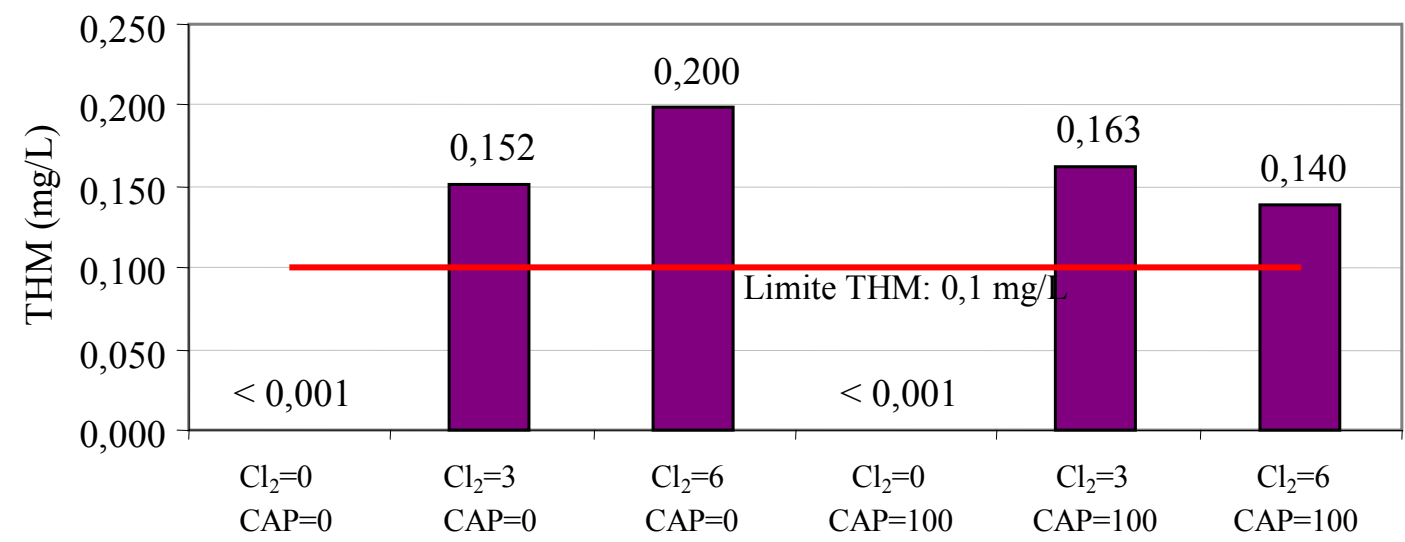

Dosagem de Cloro e CAP (mg/L)

$\square$ THM (mg/L)

Figura 5.88: Concentração de trialometanos das amostras centrifugadas - Água de Estudo - 3. Água de estudo 3: $\mathrm{MC}=86,94 \mu \mathrm{g} / \mathrm{L}$.

Condições do ensaio: Pré-cloração $\left(0 ; 3,0 ; 6,0 \mathrm{mgCl}_{2} / \mathrm{L}\right)$; Coagulação ( $\mathrm{D}_{\mathrm{FeCl} 13}=14,47 \mathrm{mgFe} \mathrm{er}^{3+} / \mathrm{L} ; \mathrm{Vr}_{\mathrm{MR}}=350 \mathrm{rpm}$; $\left.\mathrm{T}_{\mathrm{MR}}=20 \mathrm{~s}\right) ;$ Aplicação de CAP $(100 \mathrm{mg} / \mathrm{L}) ;$ Floculação $\left(\mathrm{Vr}_{\mathrm{FLO}}=68 \mathrm{rpm} ; \mathrm{T}_{\mathrm{FLO}}=18 \mathrm{~min}\right) ; \mathrm{FAD}\left(\mathrm{p}_{\mathrm{SAT}}=500 \mathrm{kPa} ; \mathrm{R}\right.$ $\left.=8 \% ; \mathrm{V}_{2}=12,0 \mathrm{~cm} / \mathrm{min}\right)$ Centrifugação $\left(\mathrm{f}_{\mathrm{CEN}}=2000 \mathrm{rpm} ; \mathrm{T}_{\mathrm{CEN}}=15 \mathrm{~min}\right)$.

O aumento da dosagem de cloro, sem aplicação de carvão, produziu maiores concentrações de trialometanos para a Água de Estudo - 3. Mesmo a elevada dosagem de carvão ativado em pó, não foi capaz de reduzir a concentração de THM, conforme o limite máximo de $0,1 \mathrm{mg} / \mathrm{L}$, durante o processo de tratamento simulado. $\mathrm{O}$ melhor resultado obtido foi combinando a pré-cloração com $6,0 \mathrm{mgCl}_{2} / \mathrm{L}$ de cloro livre com $100 \mathrm{mg} / \mathrm{L}$ de CAP, sendo que a concentração de trialometano ficou igual a $0,140 \mathrm{mg} / \mathrm{L}$. 
No que se refere à remoção de microcistina, a Figura 5.89 apresenta os valores de concentração de microcistina determinadas, para as amostras flotadas e centrifugadas, em todas as condições de tratamento avaliadas com a Água de Estudo - 3.

Concentração de microcistina das amostras flotadas e centrifugadas

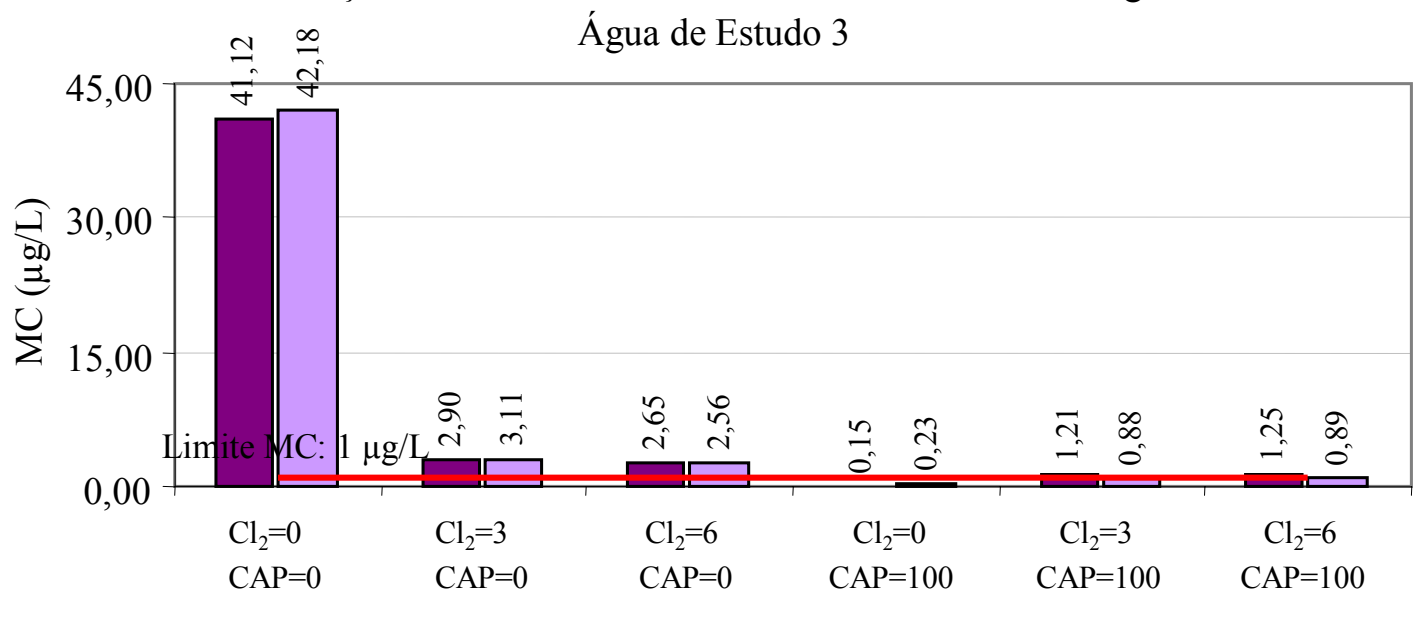

Dosagem de Cloro e CAP (mg/L)

MC flotado $\square \mathrm{MC}$ centrifugado

Figura 5.89: Concentração de microcistina (MC) das amostras flotadas e centrifugadas - Água de Estudo - 3. Água de estudo 3: $\mathrm{MC}=86,94 \mu \mathrm{g} / \mathrm{L}$.

Condições do ensaio: Pré-cloração $\left(0 ; 3,0 ; 6,0 \mathrm{mgCl}_{2} / \mathrm{L}\right)$; Coagulação $\left(\mathrm{D}_{\mathrm{FeCl}}=14,47 \mathrm{mgFe}^{3+} / \mathrm{L} ; \mathrm{Vr}_{\mathrm{MR}}=350 \mathrm{rpm}\right.$; $\left.\mathrm{T}_{\mathrm{MR}}=20 \mathrm{~s}\right)$; Aplicação de CAP $(100 \mathrm{mg} / \mathrm{L}) ;$ Floculação $\left(\mathrm{Vr}_{\mathrm{FLO}}=68 \mathrm{rpm} ; \mathrm{T}_{\mathrm{FLO}}=18 \mathrm{~min}\right) ; \mathrm{FAD}\left(\mathrm{p}_{\mathrm{SAT}}=500 \mathrm{kPa} ; \mathrm{R}\right.$ $\left.=8 \% ; \mathrm{V}_{2}=12,0 \mathrm{~cm} / \mathrm{min}\right)$ Centrifugação ( $\left.\mathrm{f}_{\mathrm{CEN}}=2000 \mathrm{rpm} ; \mathrm{T}_{\mathrm{CEN}}=15 \mathrm{~min}\right)$.

O gráfico de resultados mostra que a pré-cloração não foi suficiente para reduzir a concentração de microcistina para menos de $1 \mu \mathrm{g} / \mathrm{L}$. Com isto, se prova a necessidade de combinar a adsorção diante de uma eventual pré-oxidação com cloro. A flotação por ar dissolvido também não reduziu a toxina presente na água a níveis aceitáveis para o consumo humano, visto que o residual de microcistina foi igual a $41,12 \mu \mathrm{g} / \mathrm{L}$.

A dosagem de CAP aplicada na Água de Estudo - 3 promoveu a redução da microcistina inicial de $86,94 \mu \mathrm{g} / \mathrm{L}$ para uma concentração residual de $0,23 \mu \mathrm{g} / \mathrm{L}$, conforme hipótese adotada, na estimativa da dosagem de carvão ativado, para que a água tratada com adsorção em CAP atendesse a condição estabelecida pela Portaria 518 / 04 do Ministério da Saúde. A pré-cloração conjunta à aplicação de CAP não interferiu na adsorção da 
microcistina, tendo-se valores iguais das concentrações observadas com a aplicação de 3,0 e $6,0 \mathrm{mgCl}_{2} / \mathrm{L}$ de cloro livre. Para a primeira dosagem de cloro, o residual de microcistina foi de $0,88 \mu \mathrm{g} / \mathrm{L}$, e para a segunda dosagem, a concentração de microcistina foi igual a $0,89 \mu \mathrm{g} / \mathrm{L}$.

\subsubsection{Resumo dos resultados da FASE - B / ETAPA - II}

Os valores de turbidez e cor aparente, determinados para cada água de estudo ensaiada (valores médios amostras flotadas: Água de estudo 1 - 0,64 uT e 9 uC; Água de estudo 2 0,62 uT e 7 uC; Água de estudo 3 - 1,07 uT e 15 uC)(valores médios amostras centrifugadas: Água de estudo 1 - 0,32 uT e 4 uC; Água de estudo 2 - 0,33 uT e 3 uC; Água de estudo 3 0,48 uT e $5 \mathrm{uC}$ ), resultaram abaixo dos limites ( $1 \mathrm{uT}$ e $15 \mathrm{uC}$ ) determinados para estes parâmetros. Isto se deve à maneira que foi realizada a escolha da dosagem de cloreto férrico durante os ensaios de flotação por ar dissolvido. Ou seja, aplicando-se a maior dosagem de cloro especificada para os ensaios, e a dosagem de carvão ativado estimada para cada água de estudo. Desta forma, as dosagens de coagulante puderam compensar a interferência do oxidante no pH de coagulação, e a influência do CAP na turbidez e cor aparente das amostras de água ensaiadas.

O consumo de cloro na oxidação da matéria orgânica ficou claro conforme as características das águas preparadas. $\mathrm{O}$ aumento da concentração de microcistina foi acompanhado por maiores concentrações de carbono orgânico total, e conseqüentemente pela diminuição do cloro residual das amostras.

Foi determinada a correlação entre a absorbância em 254 nm e o carbono orgânico total das amostras submetidas ao tratamento. Matilainen et al. (2002) monitoraram a remoção da matéria orgânica natural em diferentes estágios do tratamento de água para consumo 
humano. A remoção foi avaliada com medições de COT, ABS $254 \mathrm{~nm}$ e $\mathrm{KMnO}_{4}$. Ao comparar os resultados entre o COT e ABS $254 \mathrm{~nm}$, os autores verificaram a correlação entre os parâmetros com índice $r=0,965$. Westphal et al. (2004) avaliaram as variações de COT e ABS $254 \mathrm{~nm}$ de um reservatório usado para abastecimento público, os autores verificaram um índice de correlação $\mathrm{r}=0,91$ entre o histórico de dados.

A aplicação de cloro como oxidante resultou na formação de trialometanos (Figuras $5.75,5.83$ e 5.88). Para as três águas avaliadas houve a formação destes produtos durante o tratamento, inclusive, foi possível verificar a dificuldade de remoção dos trialometanos mesmo com a aplicação de elevadas dosagens de carvão ativado em pó, que pode estar relacionado com a competição por sítios de adsorção com outros compostos, como, por exemplo, a matéria orgânica dissolvida na água.

A influência da concentração de microcistina foi clara no tratamento simulado, pois com o aumento da concentração de tal toxina, as dosagens de oxidante não foram capazes de reduzir o residual de microcistina para menos de $1 \mu \mathrm{g} / \mathrm{L}$ (Água de estudo $3 \mathrm{MC}$ inicial = $86,94 \mu \mathrm{g} / \mathrm{L}$ - aplicação 3,0 $\mathrm{mgCl}_{2} / \mathrm{L}$ resultou no residual de $\mathrm{MC}=3,11 \mu \mathrm{g} / \mathrm{L}$; aplicação 6,0 $\mathrm{mgCl}_{2} / \mathrm{L}$ resultou no residual de $\left.\mathrm{MC}=2,56 \mu \mathrm{g} / \mathrm{L}\right)$. Com isto, foi necessária a combinação da adsorção para o sucesso do tratamento simulado em termos de microcistina. Também foi clara a necessidade do aumento das dosagens de CAP conforme se elevava a concentração de microcistina (Água de estudo $3 \mathrm{MC}$ inicial $=86,94 \mu \mathrm{g} / \mathrm{L}-$ aplicação 3,0 $\mathrm{mgCl} / 2$ combinada com $100 \mathrm{mg} / \mathrm{L}$ de CAP resultou no residual de $\mathrm{MC}=0,88 \mu \mathrm{g} / \mathrm{L}$; aplicação $6,0 \mathrm{mgCl} / 2 / \mathrm{L}$ combinada com $100 \mathrm{mg} / \mathrm{L}$ de CAP resultou no residual de $\mathrm{MC}=0,89 \mu \mathrm{g} / \mathrm{L}$ ). 


\section{CONCLUSÕES}

a) O carvão ativado em pó (CAP - 4) produzido a partir de casca de coco apresentou o melhor desempenho nos parâmetros de avaliados (NI = 830,24 mg/g; IAM = 230,65 mg/g; MC = 26,67 $\mu \mathrm{g} / \mathrm{mg}$ ). Foi determinada a correlação entre o índice de azul de metileno (IAM) e a adsorção máxima de microcistina (MC) resultando em $r=0,830$, assim, o IAM pode ser usado na avaliação de carvões ativados para adsorção de microcistina.

b) O fluxograma em que o carvão ativado em pó foi aplicado logo após a mistura rápida (FASE - C da ETAPA - I) apresentou os melhores resultados para residual de microcistina: Água de estudo 1 com concentração inicial de 6,76 $\mu \mathrm{g} / \mathrm{L}$ de microcistina (10 mg/L de CAP resultou em 0,96 $\mu \mathrm{g} / \mathrm{L}$ de microcistina); Água de estudo 2 com concentração inicial de 25,84 $\mu \mathrm{g} / \mathrm{L}$ microcistina (20 mg/L de CAP resultou em 0,79 $\mu \mathrm{g} / \mathrm{L}$ de microcistina). Quando foi combinada a pré-cloração com $3 \mathrm{mgCl}_{2} / \mathrm{L}$ de cloro livre houve um aumento na remoção de microcistina: Água de estudo 1 (10 mg/L de CAP e 3 $\mathrm{mgCl}_{2} / \mathrm{L}$ resultou em 0,12 $\mu \mathrm{g} / \mathrm{L}$ de microcistina); Água de estudo 2 (20mg/L de CAP e 3 $\mathrm{mgCl}_{2} / \mathrm{L}$ resultou em $0,26 \mu \mathrm{g} / \mathrm{L}$ de microcistina). Já para a Água de estudo 3, com concentração inicial de 104,92 $\mu \mathrm{g} / \mathrm{L}$ de microcistina, nenhuma das configurações de 
tratamento simuladas reduziu a concentração de microcistina residual para menos de 1 $\mu \mathrm{g} / \mathrm{L}$.

c) A estimativa da dosagem mínima de carvão proporcionou a redução da concentração inicial de microcistina para menos de $1 \mu \mathrm{g} / \mathrm{L}$ para as três águas preparadas na ETAPA II: Água de estudo 1 concentração inicial de 5,58 (dosagem estimada de 5 mg/L de CAP com residual de 0,85 $\mu \mathrm{g} / \mathrm{L}$ ); Água de estudo 2 concentração inicial de 21,40 $\mu \mathrm{g} / \mathrm{L}$ (dosagem estimada de $25 \mathrm{mg} / \mathrm{L}$ de CAP com residual de 0,72 $\mu \mathrm{g} / \mathrm{L}$ ); Água de estudo 3 concentração inicial de 86,94 $\mu \mathrm{g} / \mathrm{L}$ (dosagem estimada de 100 mg/L de CAP com residual de $0,15 \mu \mathrm{g} / \mathrm{L})$.

d) Os ensaios com pré-cloração resultaram em residuais de trialometanos superiores ao limite estabelecido pala Portaria 518/04 do Ministério da Saúde, sobretudo, quando associada à adsorção com carvão ativado em pó, foi notória a dificuldade de remoção destes compostos diante dos resultados obtidos.

\section{RECOMENDAÇÕES}

- Determinar a correlação entre os índices de caracterização de carvão ativado e outras toxinas produzidas por algas que sejam prejudiciais ao consumo humano.

- Avaliar a ação de outros oxidantes em relação à microcistina, avaliando-se também a geração de subprodutos da oxidação. 
- Realizar estudos em escala piloto com a pré-cloração, coagulação, aplicação de CAP, floculação e flotação por ar dissolvido para avaliar o impacto do aumento da concentração de microcistina no custo do tratamento da água. 


\section{REFERÊNCIAS BIBLIOGRÁFICAS}

ACERO, J. L.; RODRIGUEZ, E.; MERILUOTO, J. (2005). Kinetics of Reactions Between Chlorine and the Cyanobacterial Toxins Microcystins. Water Research, v.39, n.8, p 1628 -1638 .

AWWA (1991). Standard for Granular Activated Carbon. 6666 West Avenue, Denver, Colorado.

AWWA (1995). Cyanobacterial (Bleu-Green Algal) Toxins: A Reource Guide. American Water Works Association - Research Foundation, U.S.A.

BAÇAOUI, A.; YAACOUBI, A.; DAHBI, A.; BENNOUNA, C.; PHAN TAN LUU, R.; MALDONADO - HODAR, F. J.; RIVERA - UTRILLA, J.; MORENO - CASTILLA, C. (2001). Optimization of conditions or the preparation of activated carbons olie-waste cakes. Carbon, v. 39, p. $425-432$.

BANSAL et al. (1988). Activated Carbon. Ed Marcel Dekker.

BARTON, S. S. (1987). The adsorption of methylene blue by activated carbon. Carbon, v. 25, n. 3 , p. $343-350$.

BLACK, J. G. (2002). Microbiologia: fundamentos e perspectiva. $4^{\mathrm{a}}$ ed. Editora Guanabara Koogan S.A. 829p. 
BUENO, F. B. A. (2005). Tratamento de Água para Abastecimento Contendo cianobactérias e Microcistina em Sistema Constituído por Etapas de Pré-cloração, Coagulação/Floculação, Flotação e Adsorção em Carvão Ativado. Dissertação (mestrado), Universidade de São Paulo - Escola de Engenharia de São Carlos Departamento de Hidráulica e Saneamento, 123p.

CALIJURI, M. C. (1999). A Comunidade Fitoplanctônica em um Reservatório tropical (Barra Bonita - SP). Tese (Livre docência em Hidráulica e Saneamento), Escola de Engenharia de São Carlos, Universidade de São Paulo, 211 p.

CHARMICHAEL, W. W. (1992). A Status Reporto on Planktonic Cyanobacteria (blue-green algae) and their toxins. EPA / 600 / R-92 / 079.

CHORUS, I \& BARTRAM, J. (1999). Toxic Cyanobacteria in Water. E \& FN Spon, Londres, 416p.

CHOW, C. W. K., HOUSE, J., VELZEBOER, R. M. A., DRIKAS, M., BURCH, M. D. \& STEFFENSEN, D. A. (1998). The Effect of Ferric Chloride Flocculation on Cyanobacterial Cells. Water Research, v.32, n.3, p 808 - 814.

CHOW, C. W. K., DRIKAS, M., HOUSE, J., BURCH, D., \& VELZEBOER, R. M. A. (1999). The Impact of Conventional Water Treatment Processes on Cells of the Cyanobacterium Microcystis Aeruginosa. Water Research, v.33, n.15, p 3253 - 3262.

DANIEL, L. A. - coordenador - (2001). Processos de Desinfecção e Desinfetantes Alternativos na Produção de Água Potável. Rio de Janeiro, RiMa, ABES.

DI BERNARDO , L.; DANTAS, A. D. B. (2005). Métodos e Técnicas de Tratamento de Água - Volumes I e II, Ed. RiMa, São Carlos, Brasil.

DONATI, C.; DRIKAS, M.; HAYES, R.; NEWCOMBE, G. (1994). Microcystin - LR adsorption by powdered carbon. Water Research, v.28, n. 8, p. 1735 - 1742. 
EDZWALD. J. K. (1995). Principles na Applications of Dissolved Air Flotation. In: IVES, K. \& BERNHART, H. J. (eds.). Flotation Processes in Water and Sludge Treatment. Water Science \& Technology, Gret Britain, v. 31, n. 3 - 4, p. 1 - 23.

EPA (1999). Alternative Disinfectants and Oxidants Guidance Manual. United States Environmental Protection Agency. 346p.

FALCONER, I. R., RUNNEGAR, M. T. C., BUCKLEY, T., HUYN, V. L. \& BRADSHAW, P. (1989). Using Activated Carbon to Remove Toxicity from Drinking Water Containing Cyanobacterial Blooms. Journal of the American Water Works Association, U.S.A. p $102-105$.

FERREIRA, L. P. H. (2004). Remoção da Biomassa Algal e Determinação da Concentração de Microcistina em Ensaios de Coagulação, Sedimentação, Filtração e Adsorção com Emprego do Método ELISA. Dissertação (mestrado), Universidade de São Paulo Escola de Engenharia de São Carlos - Departamento de Hidráulica e Saneamento, 109p.

HUANG, W. J., CHENG, B. L. \& CHENG, Y. L. (2006). Adsorption of Microcystin-LR by Three Types of Activated Carbon. Journal of Hazardous Materials, disponível online em 04/07/2006.

JAPANESE INDUSTRIAL STANDARD - JIS K 1474. Test Methods for Activated Carbon. Japanese Standard Association, Tokyo. 1991.

KURODA, E. K.; ALBUQUERQUE JR, E. C.; DI BERNARDO, L.; TROFINO, J. C (2005). Caracterização e escolha do tipo de carvão ativado a ser empregado no tratamento de águas contendo microcistinas I - 072. In: XXIII Congresso Brasileiro de Engenharia Sanitária e Ambiental, Campo Grande - MS, set.

LAMBERT, T. W., HOLMES, C. F. B. \& HRUDEY, S. E. (1996). Adsorption of Microcystin-LR by Activated Carbon and Removal in Full Scale Water Treatment. Water Research, v.30, n.6, p 1411 - 1422. 
MATILAINEN, A.; LINDQVIST, N.; KORHONEN, S.; TUHKANEN, T. (2002). Removal of NOM in the different stages of the water treatment process. Environment International, v. 28, p. 457 - 465.

MATTHHIENSEN, A. (1996). Ocorrência, Distribuição e Toxicidade de Cianobactérias no Estuário da Lagoa dos Patos - RS. Revista Brasileira de Biologia, v. 59, p. 2204 - 2209.

MARSH, H.; HEINZ, E. A. \& RODRÍGUEZ REINOSO, F. (1997) Introduction to Carbon Technology. University of Alicante, Spain.

PENDLETON, P.; SCHUMANN, R.; WONG, S. H. (2001). Microcystin - LR adsorption by activated carbon. Journal of Colloid and Interface Science, v. 240, p. 1 - 8.

REALI, M. A. P. (1991). Concepção e Avaliação de um Sistema Compacto para Tratamento de Águas de Abastecimento Utilizando o Processo de Flotação por Ar Dissolvido e Filtração com Taxa Declinante. Tese (Doutorado). Escola de Engenharia de São Carlos Universidade de São Paulo.

REYNOLDS, T. D. \& RICHARDS, P. A. (1995). Unit Operations and Processes in Environmenta Engineering. $2^{\text {a }}$ ed. Editora PWS Publishing Company. 798p.

SILVA, A. L. V. (2005). Remoção de Microcistina de Águas para Abastecimento em Sistema que Associa Unidades de Adsorção por Carvão Ativado em Pó e Flotação por Ar Dissolvido em Escala de Laboratório. Dissertação (mestrado), Universidade de São Paulo - Escola de Engenharia de São Carlos - Departamento de Hidráulica e Saneamento, 96p.

SILVA, A. S.; BRANDÃO, C. C. S.; PIRES JR., O. R. (2007) Remoção de saxitoxinas por diferentes tipos de carvão ativado em pó produzidos no Brasil I - 140. In: XXIV Congresso Brasileiro de Engenharia Sanitária e Ambiental, Belo Horizonte - MG, set.

TEIXEIRA, M. R. \& ROSA, M. J. (2006 a). Comparing Dissolved Air Flotation and Conventional Sedimentation to Remove Cyanobacterial Cells of Microcystis aeruginosa 
Part I: The Key Operating Conditions. Separation and Purification Technology, v.52, n.1, p $84-94$.

TEIXEIRA, M. R. \& ROSA, M. J. (2006 b). Comparing Dissolved Air Flotation and Conventional Sedimentation to Remove Cyanobacterial Cells of Microcystis aeruginosa Part II: The Effect of Water Background Organics. Separation and Purification Technology, disponível online em 05/09/2006.

WARHURST, A. M.; McCONNACHIE, G. L.; POLLARD, S. J. T. (1997). Characterization and applications of activated carbon produced from moringa oleifera seed husks by single-step steam pyrolysis. Water Research, v. 31, n. 4, p. 759 - 766.

WATER ENVIRONMENT FEDERATION (1996). Wastewater Desinfection: Manual of Practice FD - 10. Alexandria VA, USA, 29 p.

WESTPHAL, K. S.; CHAPRA, S. C.; SUNG, W. (2004). Modeling TOC and UV - 254 absorbance for reservoir planning and operation. Journal of the American Water Resources Association, v. 40, n. 3, p. 795 - 809.

WHO (2006). Guidelines for Drinking-water Quality [electronic resourse]: incorporating first addendum. Vol. 1, recommendations. - $3^{\text {rd }}$ edition, 595 p.

XAGORARAKI, I., ZULligER, K., HARRINGTON, G. W., ZEIER, B., KRICK, W. \& KARNER, D. A. (2006). Ct Values Required for Degradation of Microcystin-LR by Free Chlorine. Journal of Water Supply, v.55, n.4, p 233 - 245.

YENISOY - KARAKAS, S.; AYGÜN, A.; GÜNES, M.; TAHTASAKAL, E. (2004). Physical and chemical characteristics of polymer-based spherical activated carbon and its ability to adsorb organics. Carbon, v. 42, p. $477-484$. 


\section{ANEXO A}

Tabelas com os resultados da FASE - A da ETAPA I, para as três águas preparadas, na qual foi realizada a escolha da dosagem ótima de coagulante que foi aplicada nas Fases B e C que compuseram esta etapa.

\section{Água de Estudo 1:}

\begin{tabular}{|c|c|c|c|c|c|c|c|c|c|c|}
\hline \multirow[b]{2}{*}{$\begin{array}{c}\text { Dosagem } \\
\mathrm{FeCl} 3^{*} 6 \mathrm{H} 20 \\
(\mathrm{mg} / \mathrm{L})\end{array}$} & \multirow[b]{2}{*}{$\begin{array}{c}\text { Dosagem } \\
\mathrm{Fe} 3+(\mathrm{mg} / \mathrm{L})\end{array}$} & \multirow[b]{2}{*}{$\begin{array}{c}\mathrm{pH} \\
\text { Coagulação }\end{array}$} & \multicolumn{4}{|c|}{ FLOTADO } & \multicolumn{4}{|c|}{ CENTRIFUGADO } \\
\hline & & & $\begin{array}{c}\text { Turbidez } \\
\text { V1 }\end{array}$ & $\begin{array}{c}\text { Turbidez } \\
\text { V2 }\end{array}$ & $\begin{array}{c}\text { Cor } \\
\text { Aparente } \\
\text { V1 } \\
\end{array}$ & $\begin{array}{c}\text { Cor } \\
\text { Aparente } \\
\text { V2 } \\
\end{array}$ & $\begin{array}{c}\text { Turbidez } \\
\text { V1 }\end{array}$ & $\begin{array}{c}\text { Turbidez } \\
\text { V2 }\end{array}$ & $\begin{array}{c}\text { Cor } \\
\text { Aparente } \\
\text { V1 } \\
\end{array}$ & $\begin{array}{c}\text { Cor } \\
\text { Aparente } \\
\text { V2 } \\
\end{array}$ \\
\hline 30 & 6,20 & 6,33 & 29 & 295 & 278 & 280 & 0,63 & 1,03 & 13 & 13 \\
\hline 40 & 8,26 & 6,18 & 5.91 & 5.18 & 80 & 76 & 0.58 & 0.54 & 15 & 12 \\
\hline 50 & 10,33 & 598 & 199 & 162 & 39 & 36 & 065 & 062 & 14 & 12 \\
\hline 60 & 12,40 & 5,88 & 1,9 & 0,96 & 24 & 16 & 0,38 & 0,37 & 7 & 6 \\
\hline 62 & 12,81 & 5,83 & 0.77 & 0,58 & 13 & 10 & 0.46 & 0,45 & 6 & 6 \\
\hline 65 & 1343 & 571 & 062 & 0.53 & 14 & 10 & 0.44 & 0,45 & 6 & 5 \\
\hline 68 & 14,05 & 5,62 & 0,61 & 0,57 & 11 & 8 & 0.48 & 0.53 & 5 & 5 \\
\hline 70 & 1447 & 5.72 & 066 & 0.57 & 9 & 9 & 0,30 & 0,34 & 6 & 5 \\
\hline 80 & 1654 & 547 & 0,8 & 046 & 10 & 8 & 0.28 & 0,33 & 4 & 5 \\
\hline 90 & 1861 & 5,32 & 0,98 & 0,51 & 11 & 7 & 0,30 & 0,34 & 5 & 8 \\
\hline 100 & 20,68 & - & & - & & - & - & - & - & - \\
\hline & & & & & & & & & & \\
\hline
\end{tabular}

\section{Água de Estudo 2:}

\begin{tabular}{|c|c|c|c|c|c|c|c|c|c|c|}
\hline & & & \multicolumn{4}{|c|}{ FLOTADO } & \multicolumn{4}{|c|}{ CENTRIFUGADO } \\
\hline $\begin{array}{c}\text { Dosagem } \\
\mathrm{FeCl}^{\star} 6 \mathrm{H} 20 \\
(\mathrm{mg} / \mathrm{L})\end{array}$ & $\begin{array}{c}\text { Dosagem } \\
\text { Fe3+ (mg/L) }\end{array}$ & $\begin{array}{c}\mathrm{pH} \\
\text { Coagulação }\end{array}$ & $\begin{array}{c}\text { Turbidez } \\
\text { V1 }\end{array}$ & $\begin{array}{c}\text { Turbidez } \\
\text { V2 }\end{array}$ & $\begin{array}{c}\text { Cor } \\
\text { Aparente } \\
\text { V1 } \\
\end{array}$ & $\begin{array}{c}\text { Cor } \\
\text { Aparente } \\
\text { V2 } \\
\end{array}$ & $\begin{array}{c}\text { Turbidez } \\
\text { V1 }\end{array}$ & $\begin{array}{c}\text { Turbidez } \\
\text { V2 }\end{array}$ & $\begin{array}{c}\text { Cor } \\
\text { Aparente } \\
\text { V1 } \\
\end{array}$ & $\begin{array}{c}\text { Cor } \\
\text { Aparente } \\
\text { V2 } \\
\end{array}$ \\
\hline 30 & 6,20 & 7,33 & 25,9 & 25,3 & 277 & 266 & 2,86 & 2,61 & 74 & 67 \\
\hline 40 & 8,26 & 7,09 & 7,61 & 707 & 113 & 108 & 1.43 & 1.07 & 41 & 28 \\
\hline 50 & 10,33 & 6.95 & 2,18 & 1.89 & 53 & 50 & 1,15 & 1,27 & 28 & 31 \\
\hline 60 & 12,40 & 623 & 1,38 & 109 & 29 & 25 & 0.71 & 0,7 & 17 & 16 \\
\hline 62 & 12,81 & 6,18 & 1,51 & 1,06 & 31 & 25 & 0,86 & 0,85 & 19 & 19 \\
\hline 65 & 13,43 & 6,11 & 1,01 & 0,84 & 19 & 18 & 0.57 & 0,56 & 12 & 12 \\
\hline 68 & 14,05 & 6,15 & 0.9 & 0,65 & 17 & 15 & 0.45 & 0.45 & 9 & 9 \\
\hline 70 & 14,47 & 6,10 & $.0,75$ & 0.54 & 13 & 11 & 0,29 & 0,31 & 7 & 6 \\
\hline 80 & 16,54 & 5,73 & 0,55 & 0.42 & 10 & 8 & 0,22 & 0,23 & 4 & 4 \\
\hline 90 & 18,61 & 5,47 & 0.44 & 0,36 & 8 & 6 & 0,24 & 0,22 & 4 & 4 \\
\hline 100 & 20,68 & 5,04 & 0,91 & 0,45 & 10 & 6 & 0.23 & 0.22 & 3 & 3 \\
\hline
\end{tabular}




\section{Água de Estudo 3:}

\begin{tabular}{|c|c|c|c|c|c|c|c|c|c|c|}
\hline \multirow[b]{2}{*}{$\begin{array}{c}\text { Dosagem } \\
\mathrm{FeCl} 3^{*} 6 \mathrm{H} 20 \\
(\mathrm{mg} / \mathrm{L})\end{array}$} & \multirow[b]{2}{*}{$\begin{array}{c}\text { Dosagem } \\
\text { Fe3+ (mg/L) }\end{array}$} & \multirow[b]{2}{*}{$\begin{array}{c}\mathrm{pH} \\
\text { Coagulação }\end{array}$} & \multicolumn{4}{|c|}{ FLOTADO } & \multicolumn{4}{|c|}{ CENTRIFUGADO } \\
\hline & & & $\begin{array}{c}\text { Turbidez } \\
\text { V1 }\end{array}$ & $\begin{array}{c}\text { Turbidez } \\
\text { V2 }\end{array}$ & $\begin{array}{c}\text { Cor } \\
\text { Aparente } \\
\text { V1 } \\
\end{array}$ & $\begin{array}{c}\text { Cor } \\
\text { Aparente } \\
\text { V2 } \\
\end{array}$ & $\begin{array}{c}\text { Turbidez } \\
\text { V1 }\end{array}$ & $\begin{array}{c}\text { Turbidez } \\
\text { V2 }\end{array}$ & $\begin{array}{c}\text { Cor } \\
\text { Aparente } \\
\text { V1 } \\
\end{array}$ & $\begin{array}{c}\text { Cor } \\
\text { Aparente } \\
\text { V2 } \\
\end{array}$ \\
\hline 30 & 6,20 & 7,18 & 19 & 18,2 & 271 & 264 & 6,63 & 66 & 135 & 135 \\
\hline 40 & 8,26 & 6.91 & 10,9 & 10,2 & 181 & 177 & 5,16 & 4,97 & 113 & 105 \\
\hline 50 & 10,33 & 670 & 659 & 64 & 126 & 125 & 3,99 & 3,93 & 86 & 84 \\
\hline 60 & 12,40 & 6,38 & 4,26 & 3,81 & 89 & 83 & 2,93 & 2,79 & 62 & 58 \\
\hline 70 & 1447 & 6,33 & 2,54 & 2,55 & 60 & 60 & 1,85 & 1,82 & 35 & 36 \\
\hline 80 & 1654 & 6,07 & 1,25 & 1,26 & 27 & 27 & 0,64 & 0,64 & 13 & 12 \\
\hline 82 & 16,95 & 6,19 & 1,09 & 1,17 & 28 & 27 & 0,92 & 0,96 & 22 & 22 \\
\hline 85 & 17,57 & 6,06 & 0,88 & 0,89 & 21 & 20 & 0,69 & 0,66 & 16 & 14 \\
\hline 88 & 18,19 & 5,98 & 0,84 & 0.78 & 19 & 18 & 0,70 & 0,68 & 14 & 14 \\
\hline 90 & 18,61 & 588 & 0.57 & 0,45 & 9 & 8 & 0,33 & 0,29 & 5 & 5 \\
\hline 100 & 20,68 & 5,68 & 0,61 & 0,48 & 7 & 5 & 0.27 & 0,25 & 4 & 4 \\
\hline
\end{tabular}




\section{ANEXO B}

Tabelas com os resultados da FASE - A da ETAPA II, para as três águas preparadas, na qual foi realizada a escolha da dosagem ótima de coagulante que foi aplicada na Fase B desta mesma etapa.

\section{Água de Estudo 1:}

\begin{tabular}{|c|c|c|c|c|c|c|c|c|c|c|c|}
\hline & & & & & & & & \multicolumn{2}{|c|}{ FLOTADO } & \multicolumn{2}{|c|}{ CENTRIFUGADO } \\
\hline $\begin{array}{c}\text { Dosagem } \\
\mathrm{FeCl}^{*} 6 \mathrm{H} 2 \mathrm{O} \\
(\mathrm{mg} / \mathrm{L}) \\
\end{array}$ & \begin{tabular}{|c|} 
Dosagem \\
$\mathrm{Fe} 3+$ \\
$(\mathrm{mg} / \mathrm{L})$ \\
\end{tabular} & \begin{tabular}{|l|} 
Volume \\
C.F. (mL)
\end{tabular} & \begin{tabular}{|c|} 
Dosagem \\
Cloro \\
(mg/L) \\
\end{tabular} & $\begin{array}{c}\text { Volume } \\
\text { Cloro } \\
\text { (mL) } \\
\end{array}$ & \begin{tabular}{|c|} 
Dosagem \\
CAP \\
(mg/L) \\
\end{tabular} & $\begin{array}{l}\text { Volume } \\
\text { CAP (mL) }\end{array}$ & $\begin{array}{c}\mathrm{pH} \mathrm{de} \\
\text { Coagulação }\end{array}$ & $\begin{array}{l}\text { Turbidez } \\
\text { Flot. }\end{array}$ & $\begin{array}{c}\text { Cor } \\
\text { aparente } \\
\text { Flot. } \\
\end{array}$ & $\begin{array}{c}\text { Turbidez } \\
\text { Cent. }\end{array}$ & $\begin{array}{c}\text { Cor } \\
\text { aparente } \\
\text { Cent. } \\
\end{array}$ \\
\hline 50 & 10,33 & 5,0 & 6.0 & 0,260 & 5,0 & 0,500 & 6,50 & 2,24 & 42 & 1,08 & 23 \\
\hline 60 & 12,40 & 6,0 & - & - & - & - & 6,44 & 1,47 & 21 & 0,88 & 9 \\
\hline 62 & 12,81 & 6,2 & 6,0 & 0,260 & 5,0 & 0,500 & 6,06 & 0,88 & 13 & 0,38 & 4 \\
\hline 65 & 13,43 & 6,5 & - & - & - & - & 6,15 & 0,86 & 14 & 0,36 & 3 \\
\hline 68 & 14,05 & 6,8 & - & - & - & - & 5,90 & 0,63 & 9 & 0,33 & 3 \\
\hline $70^{\circ}$ & 14,47 & 7,0 & $\cdots$ & $\begin{array}{c}\cdots \\
-\cdots\end{array}$ & - & - & 6,15 & 0,89 & 11 & 0,41 & 5 \\
\hline $80^{\circ}$ & 16,54 & 8,0 & - & - & - & - & 6,00 & 0,86 & 9 & 0,36 & 3 \\
\hline 90 & 18,61 & 9,0 & - & - & - & - & 5,45 & 0,49 & 6 & 0,21 & 2 \\
\hline 100 & 20,68 & 10,0 & - & - & - & - & 5,27 & 0,43 & 4 & 0,28 & 2 \\
\hline 110 & 22,75 & 11,0 & - & - & - & - & 4,85 & 0,37 & 4 & 0,26 & 2 \\
\hline 120 & 24,82 & 12,0 & - & - & - & - & 4,25 & 0,53 & 8 & 0,31 & 2 \\
\hline
\end{tabular}

\section{Água de Estudo 2:}

\begin{tabular}{|c|c|c|c|c|c|c|c|c|c|c|c|}
\hline & & & & & & & & \multicolumn{2}{|c|}{ FLOTADO } & \multicolumn{2}{|c|}{ CENTRIFUGADO } \\
\hline $\begin{array}{c}\text { Dosagem } \\
\mathrm{FeCl}^{*} 6 \mathrm{H} 2 \mathrm{O} \\
(\mathrm{mg} / \mathrm{L}) \\
\end{array}$ & \begin{tabular}{|c|} 
Dosagem \\
$\mathrm{Fe} 3+$ \\
$(\mathrm{mg} / \mathrm{L})$ \\
\end{tabular} & $\begin{array}{l}\text { Volume } \\
\text { C.F. (mL) }\end{array}$ & \begin{tabular}{c|} 
Dosagem \\
Cloro \\
$(\mathrm{mg} / \mathrm{L})$ \\
\end{tabular} & $\begin{array}{c}\text { Volume } \\
\text { Cloro } \\
(\mathrm{mL}) \\
\end{array}$ & \begin{tabular}{|c|} 
Dosagem \\
CAP \\
(mg/L) \\
\end{tabular} & $\begin{array}{c}\text { Volume } \\
\text { CAP }(\mathrm{mL})\end{array}$ & $\begin{array}{c}\mathrm{pH} \text { de } \\
\text { Coagulação }\end{array}$ & $\begin{array}{c}\text { Turbidez } \\
\text { Flot. }\end{array}$ & $\begin{array}{c}\text { Cor } \\
\text { aparente } \\
\text { Flot. } \\
\end{array}$ & $\begin{array}{c}\text { Turbidez } \\
\text { Cent. }\end{array}$ & $\begin{array}{c}\text { Cor } \\
\text { aparente } \\
\text { Cent. } \\
\end{array}$ \\
\hline 50 & 10,33 & 5,0 & 6,0 & 0,260 & 25,0 & 2,500 & 6,27 & 8,64 & 137 & 2,79 & 59 \\
\hline 60 & 124 & 6,0 &.- & $-\ldots$ & $-\ldots$ & -1 & 6,14 & 6,00 & 87 & 1.59 & 24 \\
\hline $70^{\circ}$ & 14,47 & 7,0 & - & - & - & - & 5,98 & 3,08 & 43 & $0,90^{\circ}$ & $10^{\circ}$ \\
\hline $80^{\circ}$ & 16.54 & 8,0 & - & - & - & - & 5,85 & 2,45 & 34 & 0,59 & 5 \\
\hline 90 & 18,61 & 9,0 & - & - & - & - & 5,55 & 1,38 & 17 & $0,40^{\circ}$ & 3 \\
\hline 92 & 19,02 & 9,2 & 6,0 & 0,260 & 25,0 & 2,500 & 5,52 & 1,30 & 15 & 0,31 & 2 \\
\hline 95 & 1964 & 9,5 & - & $-\ldots$ & $-\ldots$ & - & 5,51 & 1,23 & 13 & 0,30 & 2 \\
\hline 98 & 20,26 & 9,8 & - & - & - & - & 5,45 & 0,93 & 11 & 0,29 & 2 \\
\hline $100^{\circ}$ & 20,68 & 10,0 & - & - & - & - & 5,41 & 0,90 & 10 & 0,36 & 2 \\
\hline $110^{\circ}$ & 22,75 & 11,0 & - & - & - & - & 5,07 & 0,46 & 5 & 0,29 & 2 \\
\hline 120 & 24,82 & 12,0 & - & - & - & - & 4,42 & 0,59 & 9 & 0,30 & 2 \\
\hline
\end{tabular}




\section{Água de Estudo 3:}

\begin{tabular}{|c|c|c|c|c|c|c|c|c|c|c|c|}
\hline \multirow[b]{2}{*}{$\begin{array}{c}\text { Dosagem } \\
\mathrm{FeCl} 3^{*} 6 \mathrm{H} 2 \mathrm{O} \\
(\mathrm{mg} / \mathrm{L})\end{array}$} & \multirow[b]{2}{*}{\begin{tabular}{|c|} 
Dosagem \\
Fe3+ \\
$(\mathrm{mg} / \mathrm{L})$ \\
\end{tabular}} & \multirow[b]{2}{*}{$\begin{array}{l}\text { Volume } \\
\text { C.F. (mL) }\end{array}$} & \multirow[b]{2}{*}{\begin{tabular}{|c|}
$\begin{array}{c}\text { Dosagem } \\
\text { Cloro } \\
(\mathrm{mg} / \mathrm{L})\end{array}$ \\
\end{tabular}} & \multirow[b]{2}{*}{$\begin{array}{c}\text { Volume } \\
\text { Cloro } \\
\text { (mL) }\end{array}$} & \multirow[b]{2}{*}{$\begin{array}{c}\text { Dosagem } \\
\text { CAP } \\
(\mathrm{mg} / \mathrm{L}) \\
\end{array}$} & \multirow[b]{2}{*}{$\begin{array}{c}\text { Volume } \\
\text { CAP }(\mathrm{mL})\end{array}$} & \multirow[b]{2}{*}{$\begin{array}{c}\text { pH de } \\
\text { Coagulação }\end{array}$} & \multicolumn{2}{|c|}{ FLOTADO } & \multicolumn{2}{|c|}{ CENTRIFUGADO } \\
\hline & & & & & & & & $\begin{array}{c}\text { Turbidez } \\
\text { Flot. }\end{array}$ & $\begin{array}{c}\text { Cor } \\
\text { aparente } \\
\text { Flot. } \\
\end{array}$ & $\begin{array}{c}\text { Turbidez } \\
\text { Cent. }\end{array}$ & $\begin{array}{c}\text { Cor } \\
\text { aparente } \\
\text { Cent. } \\
\end{array}$ \\
\hline 100 & 20,68 & 10,0 & 6,0 & 0,260 & 100,0 & 10,000 & 5,50 & 52,00 & 562 & 1,16 & 10 \\
\hline 110 & 22,75 & 11,0 & - & - & - & - & 5,25 & 13,20 & 163 & 0,50 & 4 \\
\hline 120 & 24,82 & 12,0 & - & - & - & - & 4,73 & 1,49 & 16 & 0,27 & 2 \\
\hline 130 & 26.89 & 130 & $\begin{array}{c}- \\
-\cdots\end{array}$ & $\begin{array}{c}\cdots \\
-\cdots\end{array}$ & - & - & 4,26 & 1,75 & 23 & 0,34 & 3 \\
\hline 140 & 28,96 & 14,0 & - & - & - & - & 4,00 & 1,91 & 31 & 0,40 & 4 \\
\hline 150 & 31,03 & 15,0 & - & - & - & - & 3,75 & 5,68 & 104 & 0,58 & 9 \\
\hline 160 & 33,10 & 16,0 & - & - & - & - & 3,63 & 24,20 & 353 & 1,43 & 29 \\
\hline 170 & 35,17 & 17,0 & -... & - & -... & - & 3,55 & 101,00 & 584 & 3,12 & 61 \\
\hline
\end{tabular}

